Florida International University FIU Digital Commons

$11-10-2011$

\title{
Evaluation of Wind-Induced Internal Pressure In Low-Rise Buildings: A Multi Scale Experimental and Numerical Approach
}

Amanuel Sebhatu Tecle

Florida International University, amanseb2007@hotmail.com

DOI: $10.25148 /$ etd.FI11120905

Follow this and additional works at: https://digitalcommons.fiu.edu/etd

\section{Recommended Citation}

Tecle, Amanuel Sebhatu, "Evaluation of Wind-Induced Internal Pressure In Low-Rise Buildings: A Multi Scale Experimental and Numerical Approach" (2011). FIU Electronic Theses and Dissertations. 529.

https://digitalcommons.fiu.edu/etd/529 


\section{FLORIDA INTERNATIONAL UNIVERSITY}

Miami, Florida

EVALUATION OF WIND-INDUCED INTERNAL PRESSURE IN LOW-RISE

BUILDINGS: A MULTI SCALE EXPERIMENTAL AND NUMERICAL APPROACH

A dissertation submitted in partial fulfillment of the

requirements for the degree of

DOCTOR OF PHILOSOPHY

in

CIVIL ENGINEERING

by

Amanuel Sebhatu Tecle

2011 
To: Dean Amir Mirmiran

College of Engineering and Computing

This dissertation, written by Amanuel Sebhatu Tecle, and entitled Evaluation of WindInduced Internal Pressure in Low-Rise Buildings: A Multi Scale Experimental and Numerical Approach, having been approved in respect to style and intellectual content, is referred to you for judgment.

We have read this dissertation and recommend that it be approved.

Arindam Gan Chowdhury

Caesar Abi Shdid

Ibrahim Nur Tansel

Girma Tsegaye Bitsuamlak, Major Professor

Date of Defense: November 10, 2011

The dissertation of Amanuel Sebhatu Tecle is approved.

$\begin{array}{r}\text { Dean Amir Mirmiran } \\ \text { College of Engineering and Computing } \\ \hline \begin{array}{r}\text { Dean Lakshmi N. Reddi } \\ \text { University Graduate School }\end{array}\end{array}$

Florida International University, 2011 
(C) Copyright 2011 by Amanuel Sebhatu Tecle

All rights reserved. 


\section{DEDICATION}

I dedicate this dissertation to my mother, Letekidan Kifle, who taught me the meaning of hard work, persistence, honesty and courage in the face of adversity since the day I came to this world. Mom, you gave up everything in life, you went all the way down and paid the price to mold and make me become the person that I am today, you struggled against all odds alone and eventually you won. I can't thank you enough for all the spiritual support and love you have poured on me. I never would have made it here without you. You deserve all the best in life.

I also dedicate this work to my siblings Ghenet, Temesghen and Biniam who have been very supportive and compassionate. 


\section{ACKNOWLEDGMENTS}

Firstly, I acknowledge God, who has been the lighthouse of my life, guiding me the direction so that I follow the right path.

I am grateful to my advisor Dr. Girma T. Bitsuamlak who accepted me as his Ph.D. student without hesitation. It is an honor for me to work under his leadership as I have gained more even outside the Ph.D. work. I acknowledge his resilience, relentless support and encouragement. Without him this thesis would not have been possible.

It is my pleasure to thank Dr. Arindam G. Chowdhury for his critical comments and guidance, Dr. Caesar A. Shdid and Dr. Ibrahim N. Tansel for all the encouragement and constructive advice they nourished me during my career at the University. I also wish to extend my sincere gratitude to James Erwin, Walter Conklin, Roy Liu-Marques, Thomas Baheru, Edward Ledesma, Robert Erwin, Brandon Mintz, Pedram Zohrevand, Daniel Abdi, Workamaw Warsido, Agerneh Dagnew, all former and present WoW crew for their technical support and profound cooperation.

I owe my deepest gratitude to my friends Asmerom Hagos, Kahsay Tsega, Feruz Tewelde, Jemal Shekay, Zebib Tecklegiorgis, and Yergalem Habtesilase for all their close intimate care, love, motivation and spiritual encouragement.

The financial supports from Florida Department of Emergency Management, Center of Excellence, and National Science Foundation CAREER project are also acknowledged. My sincere gratitude and appreciation also goes to Florida International University Civil Engineering department for providing me facilities and supplies during my career. 


\begin{abstract}
OF THE DISSERTATION
EVALUATION OF WIND INDUCED INTERNAL PRESSURE IN LOW RISE

BUILDINGS: A MULTI SCALE EXPERIMENTAL AND NUMERICAL APPROACH

by
\end{abstract}

Amanuel Sebhatu Tecle

Florida International University, 2011

Miami, Florida

\title{
Professor Girma T. Bitsuamlak, Major Professor
}

Hurricane is one of the most destructive and costly natural hazard to the built environment and its impact on low-rise buildings, particularity, is beyond acceptable. The major objective of this research was to perform a parametric evaluation of internal pressure (IP) for wind-resistant design of low-rise buildings and wind-driven natural ventilation applications. For this purpose, a multi-scale experimental, i.e. full-scale at Wall of Wind (WoW) and small-scale at Boundary Layer Wind Tunnel (BLWT), and a Computational Fluid Dynamics (CFD) approach was adopted. This provided new capability to assess wind pressures realistically on internal volumes ranging from small spaces formed between roof tiles and its deck to attic to room partitions. Effects of sudden breaching, existing dominant openings on building envelopes as well as compartmentalization of building interior on the IP were systematically investigated.

Results of this research indicated: (i) for sudden breaching of dominant openings, the transient overshooting response was lower than the subsequent steady state peak IP and internal volume correction for low-wind-speed testing facilities was necessary. For example a building without volume correction experienced a response four times faster 
and exhibited $30-40 \%$ lower mean and peak IP; (ii) for existing openings, vent openings uniformly distributed along the roof alleviated, whereas one sided openings aggravated the IP; (iii) larger dominant openings exhibited a higher IP on the building envelope, and an off-center opening on the wall exhibited (30-40\%) higher IP than center located openings; (iv) compartmentalization amplified the intensity of IP and; (v) significant underneath pressure was measured for field tiles, warranting its consideration during net pressure evaluations. The study aimed at wind driven natural ventilation indicated: (i) the IP due to cross ventilation was 1.5 to 2.5 times higher for $A_{\text {inlet }} / A_{\text {outlet }}>1$ compared to cases where $A_{\text {inlet }} / A_{\text {outlet }}<1$, this in effect reduced the mixing of air inside the building and hence the ventilation effectiveness; (ii) the presence of multi-room partitioning increased the pressure differential and consequently the air exchange rate. Overall good agreement was found between the observed large-scale, small-scale and CFD based IP responses. Comparisons with ASCE 7-10 consistently demonstrated that the code underestimated peak positive and suction IP. 


\section{TABLE OF CONTENTS}

CHAPTER

PAGE

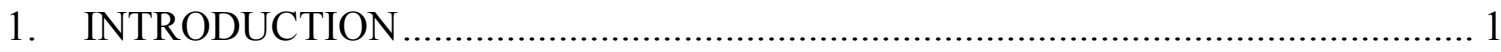

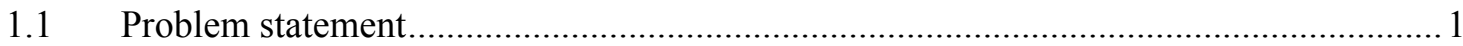

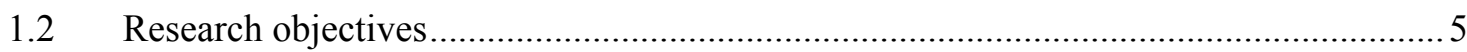

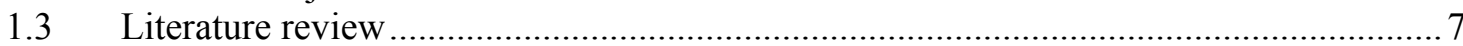

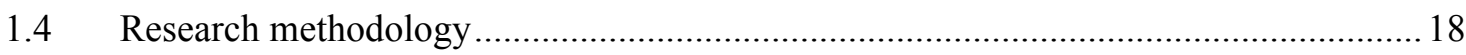

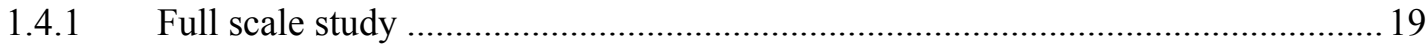

1.4.2 Boundary layer wind tunnel study (BLWT) ………………………………..... 19

1.4.3 CFD computation of internal pressure …………………………………...2

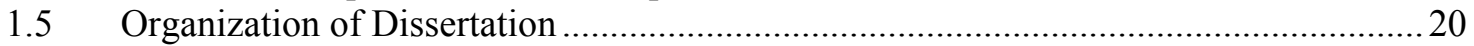

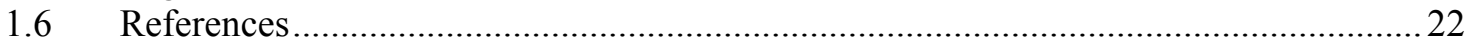

\section{OPENING AND COMPARTMENTALIZATION EFFECTS ON INTERNAL} PRESSURE IN LOW-RISE BUILDINGS WITH GABLE AND HIP ROOFS ............... 25

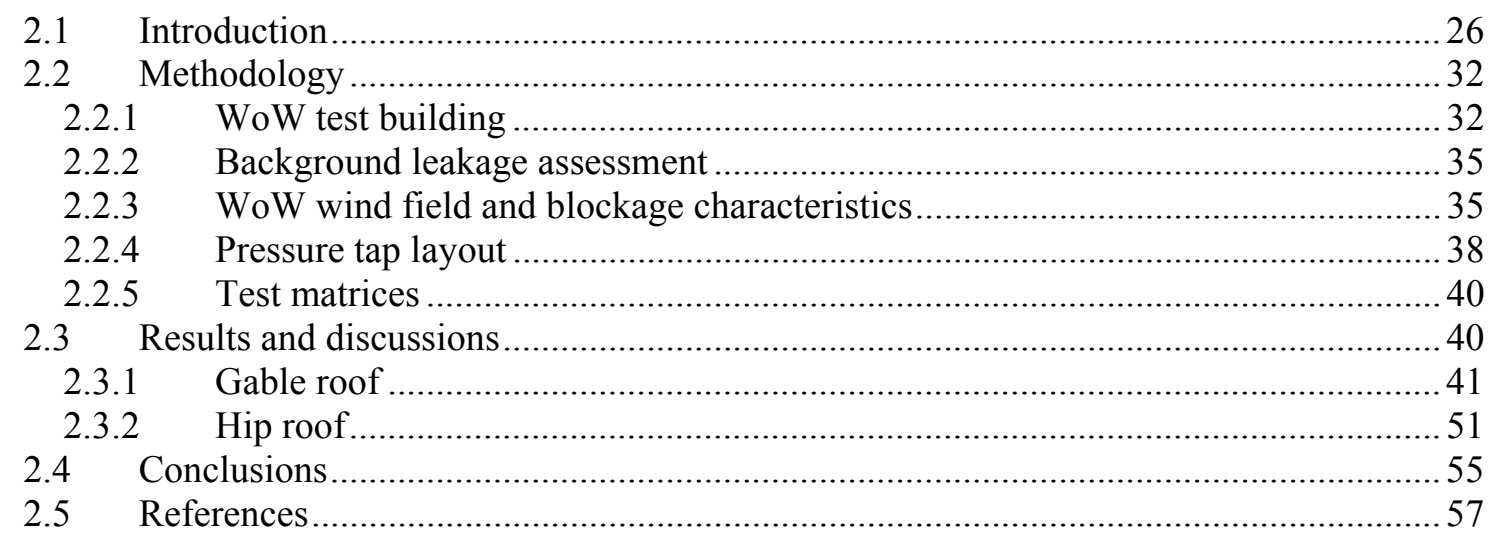

\section{INTERNAL PRESSURE FOR A LOW-RISE BUILDING WITH EXISTING}

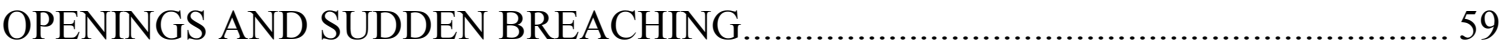

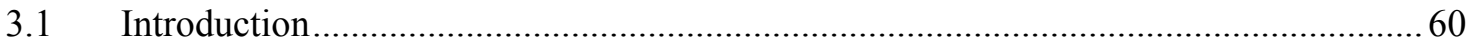

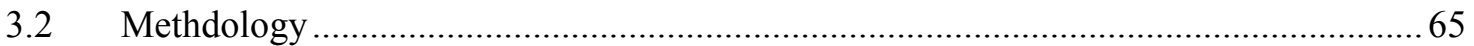

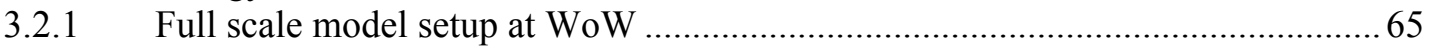

3.2.2 Boundary Layer Wind Tunnel (BLWT) setup .......................................................67

3.2.3 Wind tunnel model internal volume scaling .............................................................. 68

3.2.4 Sudden door or window opening test setup ………………………………...... 71

3.2.5 Building porosity arrangement........................................................................ 72

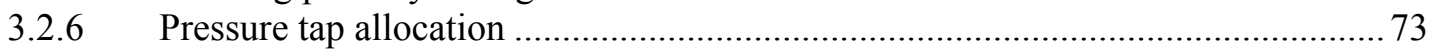

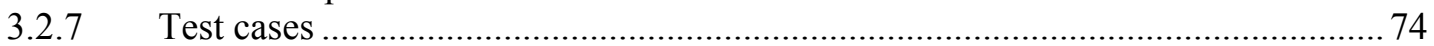

3.2.8 Internal and external pressure distribution..........................................................76

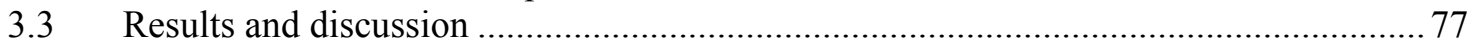

3.3.1 Internal pressure variation with respect to dominant openings................................77

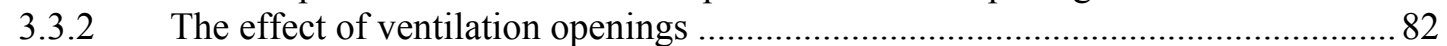

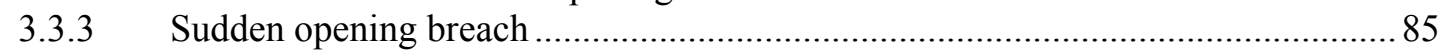

3.3.4 Full scale to wind tunnel internal pressure comparison ......................................... 94

3.3.5 Comparison of internal pressure experimental vs ASCE 7-10 ………………......96

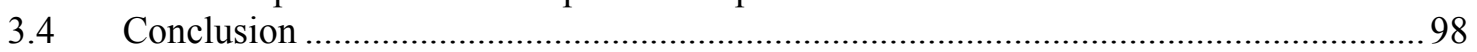




\section{WIND-INDUCED INTERNAL PRESSURE IN HIP ROOF LOW-RISE} BUILDING: A BOUNDARY LAYER WIND TUNNEL STUDY ........................... 102

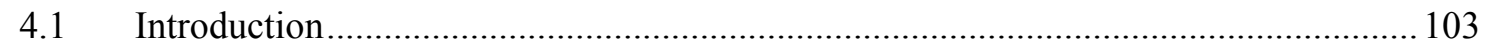

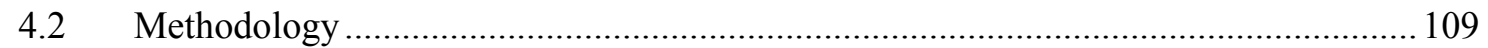

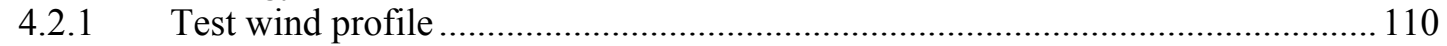

4.2.2 Full scale to wind tunnel length and velocity ratio scaling ................................ 111

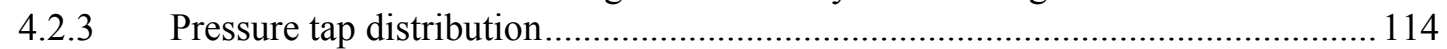

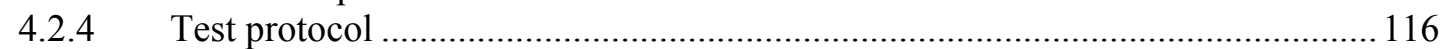

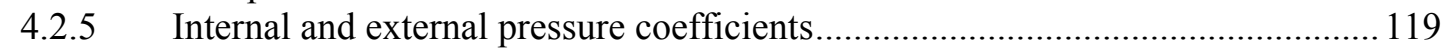

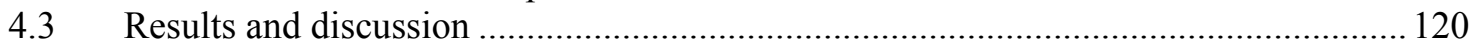

4.3.1 Internal pressure variation with and without volume correction............................ 120

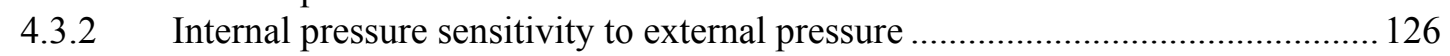

4.3.3 Influence of envelope opening on internal pressure ....................................... 128

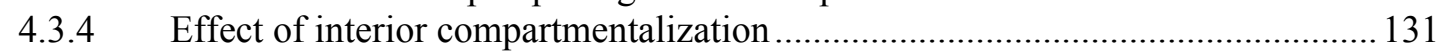

4.3.5 Effect of Ventilation openings on internal pressure ............................................. 135

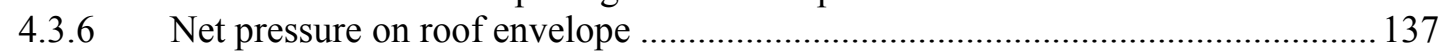

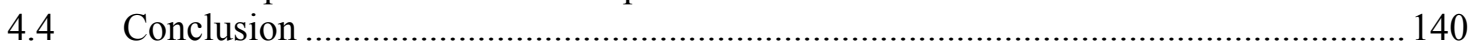

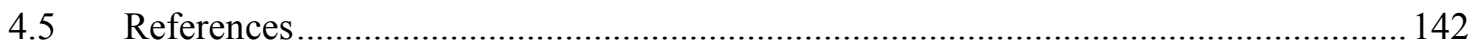

\section{WIND-DRIVEN NATURAL VENTILATION IN HIP ROOF LOW RISE}

BUILDING: A BOUNDARY LAYER WIND TUNNEL STUDY ............................ 144

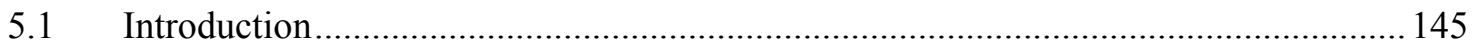

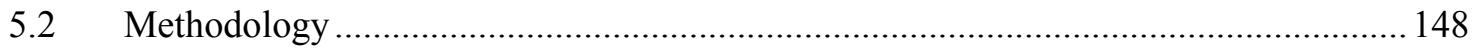

5.2.1 Test building, porosity and pressure tap layout ................................................ 148

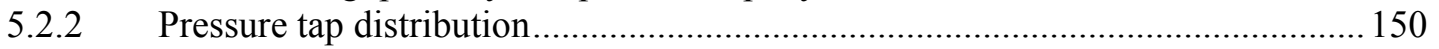

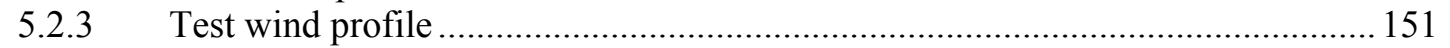

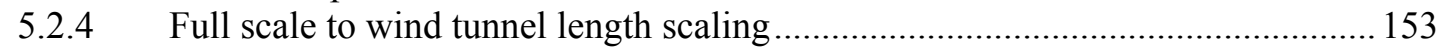

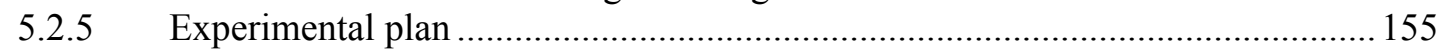

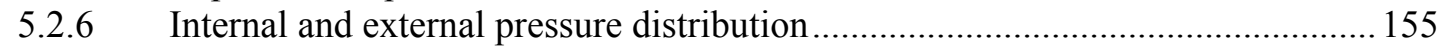

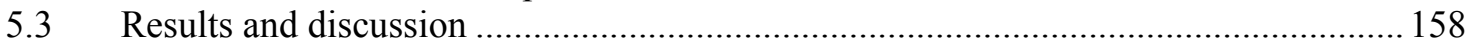

5.3.1 Effect of volume distortion on mean and rms internal pressure coefficients ....... 158

5.3.2 The effects of relative opening size: Dominant openings porosity ….................... 163

5.3.3 The effects of relative opening size: Inlet-outlet area ratio.................................... 166

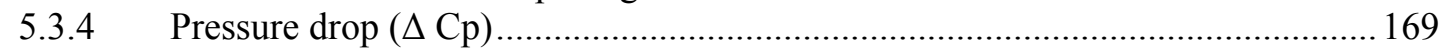

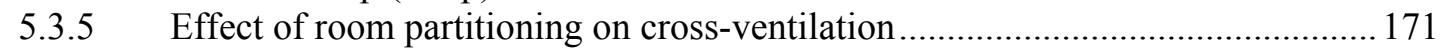

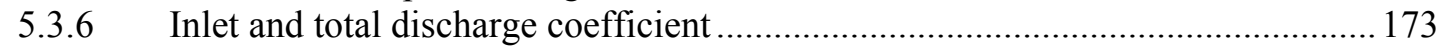

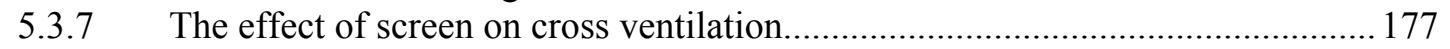

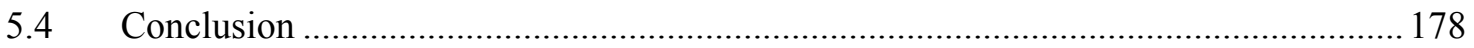

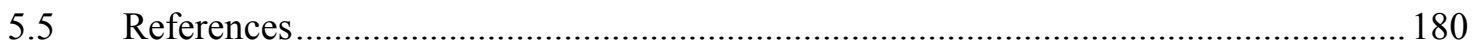

6. RIDGE AND FIELD TILE AERODYNAMICS FOR A LOW-RISE BUILDING: A

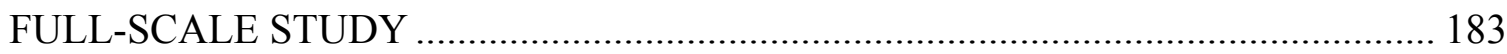

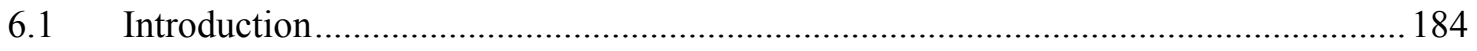

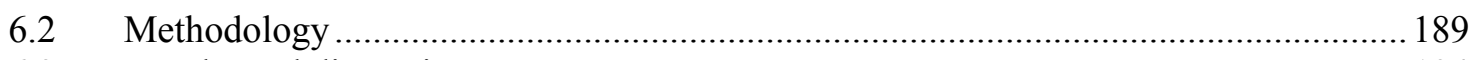

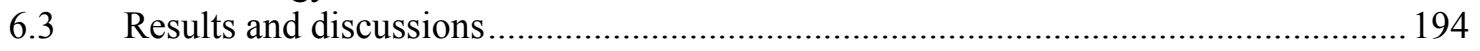

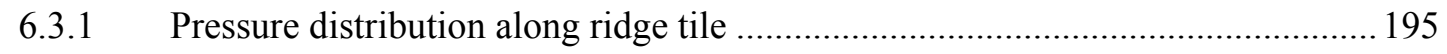

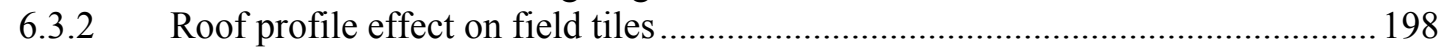




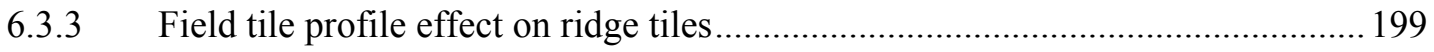

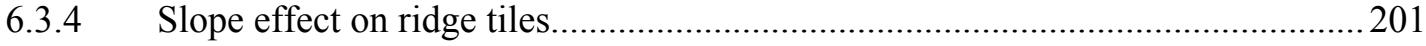

6.3.5 Comparison of edge field tiles vs edge ridge tiles .............................................202

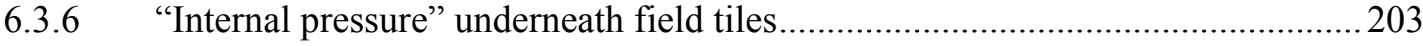

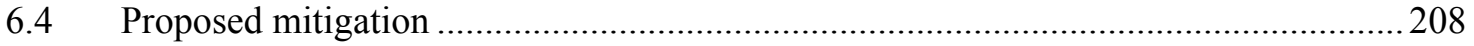

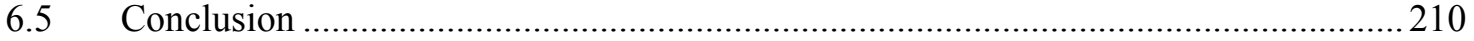

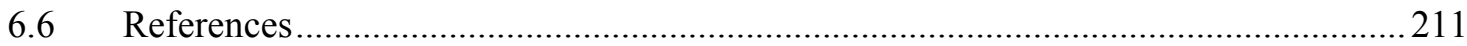

\section{COMPUTATIONAL EVALUATION AND VALIDATION OF INTERNAL AND}

EXTERNAL PRESSURE FOR LOW-RISE BUILDING ........................................ 214

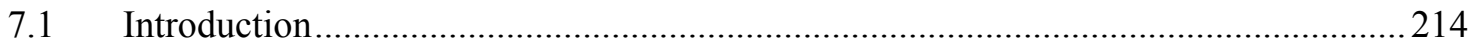

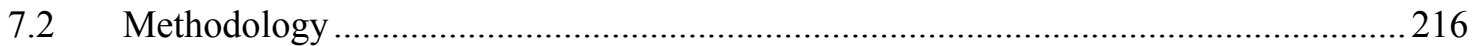

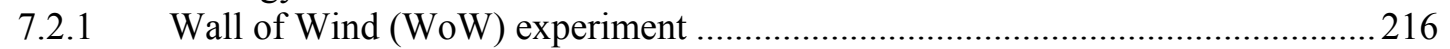

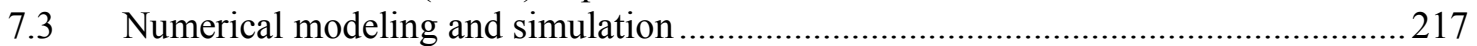

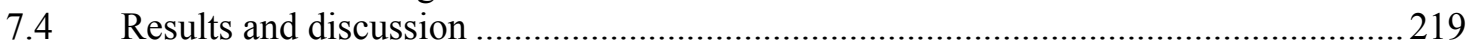

7.4.1 3.1. Experimental study of internal and external pressure using WOW ..............219

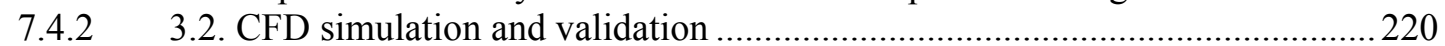

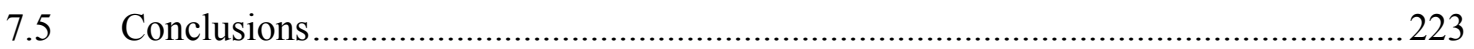

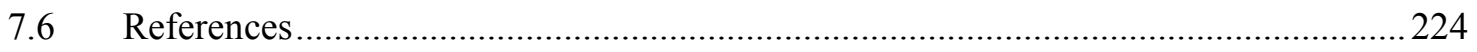

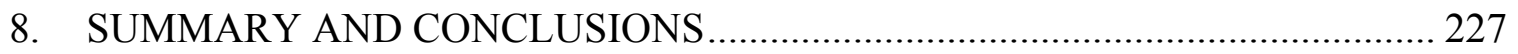

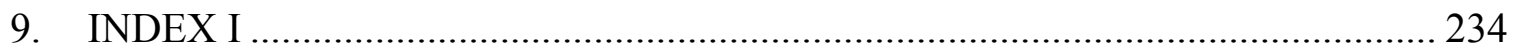




\section{LIST OF FIGURES}

FIGURE

PAGE

Figure 1.1: Wind induced damage: a) Roof deck failure due to uplift force; b) interior damage due to wind driven rain; c) windows damage by windborne debris; d) internal pressure damage due to failure of external door causing the partition wall to tilt. (Hurricane Charley in Florida, FEMA, 2006)

Figure 1.2: Variation of internal pressure with windward dominant opening (block lines showing critical loading); a) floor plan; b) elevation

Figure 1.3: Variation of internal pressure with leeward dominant opening (block line showing critical loading); a) floor plan and b) elevation....

Figure 1.4: Mean internal pressure distribution for dominant opening sizes of $(1 \%, 4 \%, 9 \%, 16 \%$ $\& 25 \%$ ): a) Central openings at $30^{\circ} \&$ b) corner openings at $45^{\circ}$

Figure 1.5: Advantages of full scale (top), small scale (middle) and computational (bottom)...... 17

Figure 1.6: Three-tier communication among the simulation techniques.................................. 17

Figure 2.1: Low-rise building with gable and hip roof in front of $W o W$ in a testing position....... 29

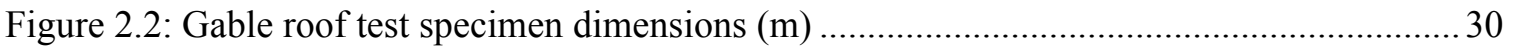

Figure 2.3: Gable ( $a, b$ and $c$ ) and Hip roof (d, e and f) shingle and underlayment nailing patterns

Figure 2.4: Air leakage test using fan pressurization technique: a) model 3 fan with rings; b) test setup; c) DG-700 pressure gauge. 33

Figure 2.5: Full-scale 6-fan $W o W(a)$, non-dimensional mean velocity profiles at y $=1.22 \mathrm{~m} \mathrm{-}-4$ $\mathrm{ft}-\mathrm{b}$ (b), at $\mathrm{y}=3.66 \mathrm{~m}-12 \mathrm{ft}--(\mathrm{c})$, at $\mathrm{y}=4.27 \mathrm{~m} \mathrm{--} 14 \mathrm{ft}--(\mathrm{d})$, and longitudinal (e) and vertical turbulence profile (f) at $\mathrm{y}=3.66 \mathrm{~m}(12 \mathrm{ft})$. 34

Figure 2.6: Comparison between full scale $W o W$ tests for $5 \mathrm{ft}, 7 \mathrm{ft}$ and $9 \mathrm{ft}$ cubes with data from SILSOE.

Figure 2.7: Exploded plan view of gable roof external pressure (left) and internal pressure (right) tap layout.

Figure 2.8: Exploded view of hip roof external pressure (left) and internal pressure (right) tap layout

Figure 2.9: Ventilation openings pressure tap layout: gable (left) and hip (right)...... .38

Figure 2.10: Internal pressure inside living room: (a) Maximum, (b) rms, (c) Mean and (d) Minimum $C p$ values for test cases 1-5 
Figure 2.11: Correlation of internal pressure coefficients with area averaged external pressure coefficients

Figure 2.12: Internal pressure inside attic floor: (a) Maximum, (b) rms, (c) Mean and (d)

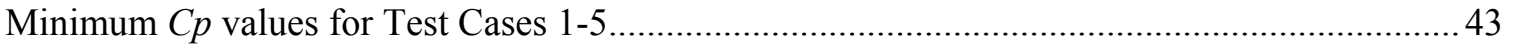

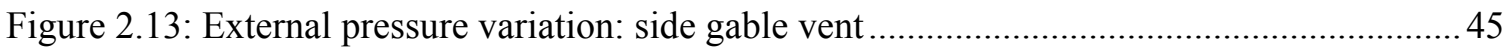

Figure 2.14: External pressure variation for: front soffit vents................................................ 45

Figure 2.15: External pressure coefficient at the openings of the living room (area averaged) .... 46

Figure 2.16: Power Spectra of Internal pressure for door opening (left) and window opening

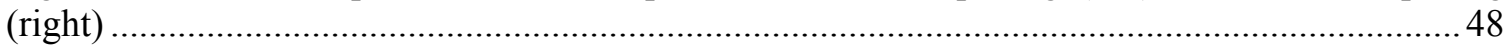

Figure 2.17: Hip roof living room coefficient of internal pressure: a) Mean, b) RMS, c)

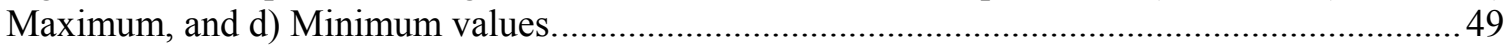

Figure 2.18: Maximum internal and external pressure distribution for test cases 2 and $3 \ldots \ldots \ldots \ldots . . .50$

Figure 2.19: Attic floor coefficient of internal pressure: a) Maximum, b) rms, c) Mean, and d)

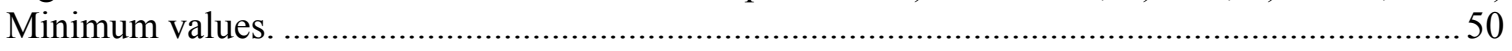

Figure 2.20: External pressure contribution of soffits: a) soffit No.1 \& b) soffit No.4 …............52

Figure 2.21: Attic internal pressure with vent (Test_3) and without ventilation (test_8) opening 52

Figure 2.22: Pressure distributions at ceiling partition: a) Peak suction $\mathrm{C}_{\mathrm{pi}}$, and b) Peak positive

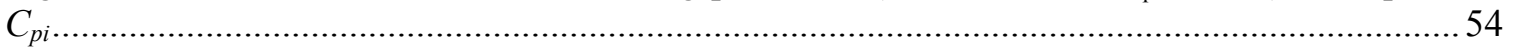

Figure 2.23: Gable and hip roof net pressure loading comparison. ...........................................5

Figure 3.1: Low-rise building with gable roof, full scale in front of $W o W$ testing position (a\&b); small scale $B L W T(\mathrm{c})$......

Figure 3.2: Exploded view of building model with external and internal pressure taps layout and location of dominant openings. Hip roof building has the same pattern of tap arrangement. (Dimensions given are full scale) ..... 66

Figure 3.3: Normalized: a) wind velocity profile; b) Turbulence intensity profile; c) spectra 67

Figure 3.4: $B L W T$ model setup (1:9 scale): a) Volume correction chamber before final placement under the $B L W T$ floor, final test setup placement for gable (b) and hip (c).

Figure 3.5: Sudden failure simulation technique: a) digital servo motor Hitec HSG-5084MG (Courtesy of ServoCity ${ }_{\mathrm{TM}}$ ), b) window Assembly and Servo in open position. .71

Figure 3.6: Internal pressure comparison between background leakage (blg), 5\% porosity door and $4 \%$ porosity window 78 
Figure 3.7: Correlation of $r m s$ external pressure at dominant opening periphery and internal pressure.

Figure 3.8: Living room internal pressure (mean, rms, $\max$ and $\min$ ) distribution due to various dominant openings. 81

Figure 3.9: Comparison of internal pressure inside attic when vent is opened and closed. .83

Figure 3.10: Comparison of internal pressure inside living room when vent is opened and closed. . .84

Figure 3.11: Time history of internal pressure coefficient for sudden breach of $7.5 \%$ door (a) and $9 \%$ window (b), external pressure coefficient on the periphery of $7.5 \%$ door (c) and $9 \%$ window (d). 87

Figure 3.12: Internal pressure fluctuation at the moment of sudden door opening. .88

Figure 3.13: internal pressure response comparison due to sudden opening given in a block of $6 \mathrm{~s}$.

Figure 3.14: internal pressure response for off-center window in a block of $6 \mathrm{~s}$ .91

Figure 3.15: Internal pressure response for various wind $A o A\left(45^{\circ}, 75^{\circ}\right.$ and $\left.90^{\circ}\right)$. 92

Figure 3.16: Uniformity of internal pressure distribution at various wind $A o A\left(45^{\circ}, 75^{\circ}\right.$ and $\left.90^{\circ}\right)$. .. 94

Figure 3.17: Full scale to small scale (BLWT) comparison of internal pressure. .95

Figure 4.1: Exploded view of building model with external pressure taps layout and location of dominant openings. (Dimensions given are full scale)..... 108

Figure 4.2: Open terrain profiles: a) wind velocity, b) Turbulence intensity, and c) spectra of wind velocity at mid roof height 109

Figure 4.3: Model setup: a) Hip roof tube leakage inspection, b) Hip roof with volume chamber, c) Volume chamber set up underneath turntable, and d) Hip roof building model inside the wind tunnel. 113

Figure 4.4: Room compartmentalization: a) Partitioning with tap layout for Case 8A; b) Case 8B; c) Case $9 \mathrm{~A} \&$ d) Case $9 \mathrm{~B}$ 119

Figure 4.5: Case 2A: a) model setup with door, soffit openings and ceiling partition; b) internal pressure response, rms, for building with volume chamber $(V)$ and no volume chamber (NoV) 121

Figure 4.6: Case 3A: a) model setup with door, windows, soffit openings and ceiling partition; b) internal pressure response, $r m s$, for building with volume chamber $(V)$ and no volume chamber $(\mathrm{NoV})$. 121 
Figure 4.7: Case 5A: a) model setup with door, soffit openings and no ceiling partition; b) internal pressure response, rms, for building with volume chamber $(V)$ and no volume chamber (NoV) 122

Figure 4.8: Case 6A: a) model setup with window, soffit opening and no ceiling partition; b) internal pressure response, rms, for building with volume chamber $(V)$ and no volume chamber $(\mathrm{NoV})$ 122

Figure 4.9: Mean and peak internal pressure coefficient for test cases 2A and 5A: With and without volume chamber.

Figure 4.10: Power spectra of internal pressure Spi(f) in $\mathrm{Pa}^{2} \mathrm{~s}$ for test Case 5A for $270^{\circ}$ wind angle of attack. 125

Figure 4.11: Internal to external pressure coefficient comparison. 127

Figure 4.12: Effect of variable openings on internal pressure with respect to wind AoA. 129

Figure 4.13: Internal pressure coefficient, closed vs opened hatch for test Case 2: a\&b) Attic space, c\&d) Living room space 130

Figure 4.14: Internal pressure distribution for multi-room partitioning: a\&b) Case 8; c\&d) Case 9 131

Figure 4.15: Peak internal and external pressure distribution for: a) Case 9A; b) Case 9B ........ 133

Figure 4.16: Internal pressure comparison in the presence of horizontal and vertical partitioning 135

Figure 4.17: Internal pressure coefficient, closed versus opened soffit for: a) test Case $5 \&$ b) test Case 7 ....... 136

Figure 4.18: Schematics showing the interaction of wind and building (hip/gable) and net pressure direction. . 137

Figure 4.19: Mean and suction net pressure for test: a) Case 5B and b) Case 7B 139

Figure 5.1: Exploded view of building model with external and internal pressure taps layout and location of dominant openings. (Dimensions given are full scale)...... 148

Figure 5.2: Normalized open terrain: a) wind velocity, b) turbulence intensity profiles, and c) spectra.

Figure 5.3: 1:20 scale model setup: a) model with volume chamber, and b) model inside wind tunnel in a final testing position. 154

Figure 5.4: Cross ventilation with adjacent openings: a) Case 1a, $E=10 \%$ and $S=6 \%$; b) Case $1 \mathrm{~b}$, $\mathrm{E}=22 \%$ and $\mathrm{S}=18 \%$. 159

Figure 5.5: Case 2 cross ventilation with opposite side openings: a) Case 2a, $E=10 \%$ and $\mathrm{W}=14 \%$; b) Case $2 \mathrm{~b}, \mathrm{E}=22 \%$ and $\mathrm{W}=14 \%$, c) Case $2 \mathrm{~d}, \mathrm{~S}=18 \%$ and $\mathrm{N}=17 \%$. 160 
Figure 5.6: Maximum and minimum internal pressure characteristics for the building with only East opening: a) Case $3 \mathrm{~A}$ having ceiling (10\% porosity), b) Case $3 \mathrm{~A}$ with no ceiling (22\% porosity)

Figure 5.7: Maximum and minimum internal pressure characteristics for the building with only East opening $=0.0051 \mathrm{~m}^{2}\left(7.85 \mathrm{in}^{2}\right)(10 \%)$; a) Case 3A having ceiling, b) Case $3 \mathrm{~A}$ with no ceiling 162

Figure 5.8: Effect of dominant opening porosity on internal pressure. 163

Figure 5.9: Internal pressure due to cross-ventilation for opposite direction dominant openingalong length. 164

Figure 5.10: Internal pressure due to cross-ventilation for opposite direction dominant openingalong width. 164

Figure 5.11: Internal pressure due to cross-ventilation in opposite direction vs inlet to outlet ratio and windward porosity: a \& b) along the width of building, c \& d) along the length of building. 166

Figure 5.12: Internal pressure due to cross-ventilation in adjacent side vs inlet to outlet ratio and windward porosity.

Figure 5.13: Pressure drop inside building as a function of: a) inlet to outlet opening ratio, b) windward wall porosity. 168

Figure 5.14: Internal pressure distribution comparison: a) single dominant opening $(10 \%)$, b) cross-ventilation with multi-room partitioning.

Figure 5.15: Internal pressure distribution comparison: a \& b) cross-ventilation for $10 \%$ porosity without (Case 2A) and with room partitioning, respectively; c \& d) cross-ventilation for $22 \%$ porosity without (Case $2 \mathrm{~B}$ ) and with room partitioning, respectively.

Figure 5.16: Inlet, total discharge coefficient and ventilation rate with respect to: a) inlet to out let ratio, b) velocity ratio. 176

Figure 5.17: Internal pressure variation with and without screen on dominant openings. 177

Figure 6.1: Damage to roof hip and ridge tiles: a) Hurricane Charley (FEMA 2005); b \& c) Hurricane Ike (IHBS 2009) 184

Figure 6.2: Test specimen in front of Wall of Wind at $0^{\circ} \mathrm{AoA}$ 187

Figure 6.3: Field and ridge tile combinations a) High profile field with barrel ridge tiles; b) Medium profile field with barrel ridge tiles; c) Low profile field with three sided ridge tiles .... 188

Figure 6.4: Full-scale 6-fan $W o W(a)$, non-dimensional mean velocity profiles at y $=1.22 \mathrm{~m}--4$ $\mathrm{ft}-$ (b), at $\mathrm{y}=3.66 \mathrm{~m}--12 \mathrm{ft}--(\mathrm{c})$, at $\mathrm{y}=4.27 \mathrm{~m} \mathrm{--} 14 \mathrm{ft}--(\mathrm{d})$, and longitudinal (e) and vertical turbulence profile (f) at $\mathrm{y}=3.66 \mathrm{~m}(12 \mathrm{ft})$... 190 
Figure 6.5: Pressure tap distribution on the field tiles (plan view): a) tap layout; b) tap placement 191

Figure 6.6 Ridge tile Pressure tap distributions: Pressure tap layout along ridge line. 193

Figure 6.7: Pressure distribution along the crest of the ridge tiles 196

Figure 6.8: Field tile profile effect on wind pressure coefficients.

Figure 6.9: WB Profile effect on ridge tile pressure distribution with roof slope of 7:12.

Figure 6.10: Profile effect on 7:12 slope barrel ridge tile

Figure 6.11: Slope effect on ridge tiles for the case with weather block and medium profile field tile. 201

Figure 6.12: Edge ridge crest (tap\#4) versus corner edge field tile (tap\#1) pressure coefficient comparison. 202

Figure 6.13: $C_{p i}$ underneath field tile: a) $90^{\circ} A o A N W B \_$max; b) $90^{\circ} A o A W B \_$max; c) $90^{\circ} A o A$ $N W B \_$mean; d) $90^{\circ} A o A$ WB_mean . 204

Figure 6.14: Max $C_{p i}$ versus wind angle of attack 206

Figure 6.15: Comparison net mean roof pressure between weather blocked and non-weather blocked roof tiles 206

Figure 6.16: Comparison between weather blocked and non-weather blocked roof tiles: mean $C_{p e}$ (a \&b); mean $C_{p i}(\mathrm{c} \& \mathrm{~d})$ 207

Figure 6.17: Metal angle and FRP mitigation techniques. 209

Figure 7.1: Low-rise building with gable roof in testing position, and CFD model. 217

Figure 7.2: Building model from conceptual design to construction, fabrication and door blower test for porosity. 218

Figure 7.3: a) Roof external pressure tap location, b) maximum internal and external Cp correlation 218

Figure 7.4: WoW vs literature data comparison of roof external pressure coefficient: a) mean $90^{\circ}$,

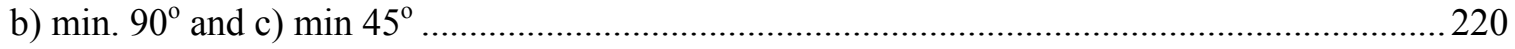

Figure 7.5: Experimental roof internal pressure coefficient at $45^{\circ}$ and $90^{\circ}$ angles of attack ....... 221

Figure 7.6: Experimental roof external pressure coefficient at $45^{\circ}$ and $90^{\circ}$ angles of attack.......221

Figure 7.7: Velocity flow field vertical plane at mid-section and horizontal plane at $1 \mathrm{~m}$ high for $90^{\circ}$ angle of attack. 222 
Figure 7.8: Velocity flow field vertical plane at mid-section and horizontal plane at $1 \mathrm{~m}$ height for $45^{\circ}$ angle of attack.

Figure 7.9: Mean roof external pressure coefficient for $90^{\circ}$ and $45^{\circ}$ angle of attack ..................222

Figure 7.10: Experimental versus CFD roof centerline internal pressure comparison ................ 223

Figure 7.11: Experimental versus $C F D$ roof centerline external pressure coefficients comparison 


\section{LIST OF TABLES}

TABLE

PAGE

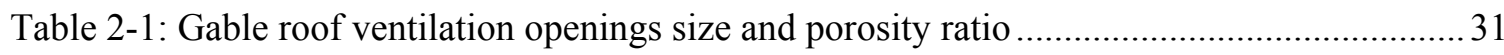

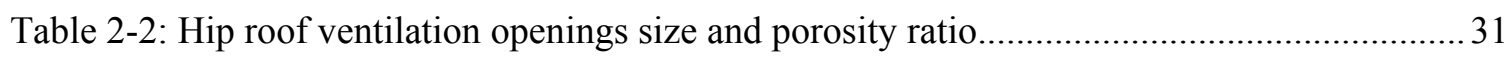

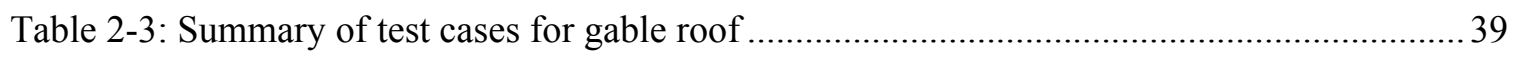

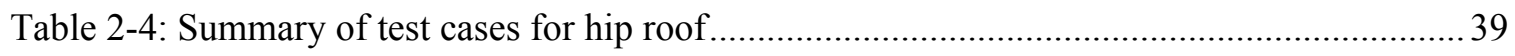

Table 3-1: Dominant openings and background leakage distribution in model scale dimensions. 73

Table 3-2: Summary of test cases for low-rise building with gable and hip roof......................... 75

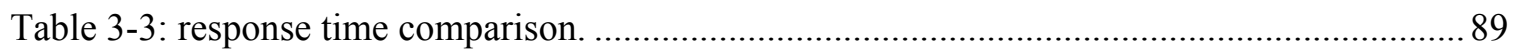

Table 3-4: Peak internal pressure coefficients $\left(G C_{p i}\right)$ in $A S C E$ 7-10 versus equivalent values

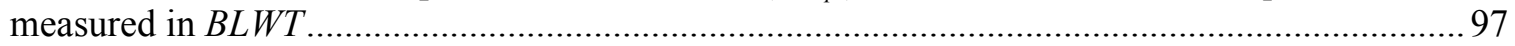

Table 4-1: Dominant openings and background leakage distribution in model scale dimensions. 116

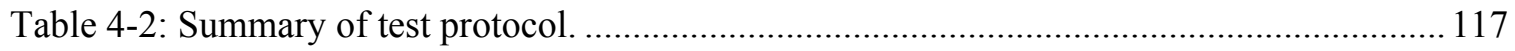

Table 4-3: Statistical variation of internal pressure coefficient: NoV vs V ................................ 125

Table 4-4: Test Case 5B: mean, peak and suction pressure coefficients. ................................... 138

Table 4-5: Test Case 7B: mean, peak and suction pressure coefficients. ................................ 138

Table 5-1: Dominant openings and background leakage distribution in model scale dimensions. 150

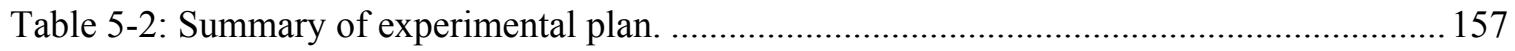

Table 5-3: Total discharge coefficient and equivalent area. ................................................. 158

Table 5-4: Mean internal and external pressure distribution with respect to wind AoA. ............ 168

Table 5-5: velocity ratio $\left(\mathrm{u} / \mathrm{V}_{\mathrm{r}}\right)$ for present and previous studies........................................... 174

Table 5-6: Porosity ratio, discharge coefficients and ventilation rate ....................................... 175 


\section{INTRODUCTION}

\subsection{Problem statement}

Hurricanes are one of the most destructive and costliest natural disasters. Population growth and increased development in the coastal regions have exacerbated the damages caused by hurricanes. Over the past 50 years, America's coastal regions have experienced significant growth in population and infrastructure development, making these areas more vulnerable to hurricane-induced losses. Hurricane-induced economic and social impact on communities has been massive. The losses have increased from $\$ 1.3 \mathrm{~B} / \mathrm{yr}$ pre 1990 to $\$ 36 \mathrm{~B} / \mathrm{yr}$ post-2000 (Rappaport 2000) with more than 1400 fatalities in 2004-05(Cutter, Johnson et al. 2007). The more recent hurricanes (Katrina, Rita and Wilma) in 2005 together accounted for a total estimated loss of \$160 billion (FEMA 549:2006). These losses are either from direct wind or wind driven rain induced damages.

Low-rise buildings make the majority of the infrastructure stock and represent the bulk of residential, commercial and industrial buildings. In most cases, low-rise buildings are either non-engineered or poorly designed to resist hurricane winds and the subsequent impacts from wind borne debris, wind driven rain, and interior pressurization. Low risebuildings, relative to tall buildings, are also immersed within the lower aerodynamic boundary layer on the earth's surface where the turbulence intensities are high (Holmes 2001). Post hurricane investigations have shown that low-rise buildings being exposed to majority of the damages. Investigations of major wind events have revealed that major damage to low-rise buildings is initiated due to failure of external building envelopes. The common damages often observed are to the roof components, windows, doors and 
roof vents (Minor and Mehta 1979; Stathopoulos, Surry et al. 1979; Kopp, Oh et al. 2008). The direct damage effects to these building components subsequently transfer to the internal part of the building leading to over pressurization and the intrusion of wind driven rain.

The overall interaction of building and hurricane wind forces is complex in its nature and is influenced by a number of aerodynamic and micro environment factors.

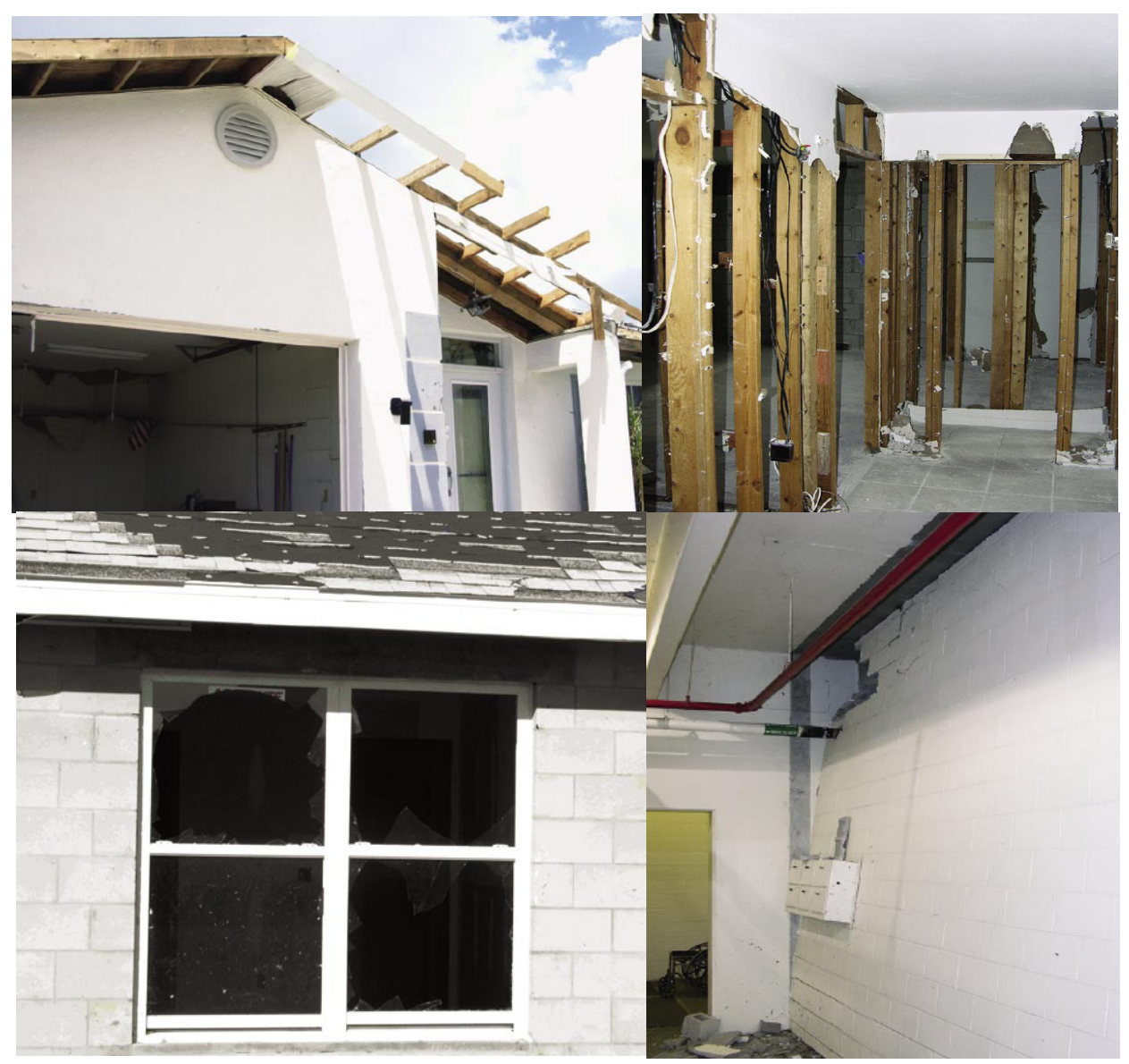

Figure 1.1: Wind induced damage: a) Roof deck failure due to uplift force; b) interior damage due to wind driven rain; c) windows damage by windborne debris; d) internal pressure damage due to failure of external door causing the partition wall to tilt. (Hurricane Charley in Florida, FEMA, 2006) 
Some of these factors are the shape of the building and its envelope components, roof slope, envelope openings (such as doors and windows, ventilation outlets), geometry, terrain, wind speed and the aerodynamic performance of the impacted building in transferring loads between components of the envelope (Holmes 1979; Liu and Saathoff 1982).

Wind induces both external and internal pressure on building envelopes and components. While the external pressure develops as a result of wind-building surface interactions, the internal pressure develops due to infiltration/exfiltration of air thorough building envelope openings and components. The common types of openings include breached door and windows, ventilation openings such as soffit, ridge and gable vents and background leakages that result from defects in construction and utility ducts.

The combined effect of external and internal pressures, at critical condition, causes the formation of extreme forces on building envelope which undermines the building envelope systems and components. Common examples of failures include roof sheathing, shingle and tiles as shown in Figure 1.1. A common observation during hurricane landfall is the increase in wind speed and turbulence, which picks up windborne debris from neighboring structures and loose attachments. The debris often is projectiled into buildings and punch holes on the envelope. This, in return, causes the rushing in of forced air through the openings created by the projectile missile. A drastic buildup of internal pressure as a result of forced air inflow could lead to the discontinuity of building load path. This often causes the failure of the structure. Observations made by Mitigation Assessment Team deployed by FEMA (2006) have shown that structural 
damage in some buildings is due to the internal pressure excitation following breach of envelope. Commonly, hurricane winds are accompanied by strong wind driven rain that can infiltrate through leaky building envelopes and roof vents. This eventually causes damage to interior parts of the buildings and health of the people living in it (Figure $1.1 \mathrm{~b} \& \mathrm{~d})$. Post hurricane damage assessment have revealed that the majority of severe wind-related property damages were caused by failure of roofing system and the subsequent damage to building interiors by wind and rain (McDonald and Smith 1990; FEMA 240:2005). Studies have shown that the provisions of ASCE 7 wind loading code under predicts peak internal pressure and case studies performed have also recorded a 23$60 \%$ higher net uplift pressure coefficient as compared to that of provisions of $A S C E 7$ (Sharma and Richards 2003; Sharma and Richards 2005; Kopp, Oh et al. 2008).

The difference in pressure between the exterior and interior of a building governs envelope net wind load and the subsequent wind-driven rain infiltration. Even though the contribution of internal pressure to the total design wind load on building envelope is significant, there are very few studies performed as compared to that of external pressure. Most internal and external pressure related studies were conducted in Boundary Layer Wind Tunnels $(B L W T)$. Unlike the external pressure, internal pressure is highly influenced by the size and location of dominant openings and the internal volume of the building. In retrospect, these factors are governed by Strouhal and Reynolds number which cannot be represented accurately in small scale wind tunnel studies.

For wind load application, minimization of the internal pressure to reduce the net design pressure might be an effective target. This can be achieved by sealing and 
blocking any opening on the building envelope. Active system can opt for a different combination (e.g. increasing the suction inside a building to reduce uplift, etc). Similarly higher differential pressure (external versus internal) can lead to movement of moisture (or wind driven rain) through a building envelope. From energy efficiency point of view, however, vent openings are necessary to help control temperature of the interior building and minimize energy cost. This, generally, underscores the necessity of a parametric evaluation of internal and external pressures on low-rise buildings to address the effective design wind loads under the constraints of natural ventilation for energy efficiency.

\section{$1.2 \quad$ Research objectives}

As specified in the literature, most previous researches on internal pressure were conducted using small-scale boundary layer wind tunnel. The strategies and techniques involved often needed volume modifications and aerodynamic assumptions in order to approximate the real life wind-building interactions. Few of the available full scale studies also rely on natural wind and have to wait long enough till the roof height mean wind speed exceeds the pre-set value. This often takes months and sometimes years to capture all intended data at the required wind angle of attack $(A o A)$. Also, most of these studies focus on the internal pressure characteristics due to a single dominant opening. It is known that single dominant openings lead to peak internal pressure at certain wind angle of attack. However, the assessment of internal pressure that replicates the real life scenario at the time of wind-building interaction needs to encompass factors such as nominal leakages and partitions with realistic dominant openings. An experiment with all-inclusive governing factors is essential in obtaining more rational wind load values for the application of load standards and optimum natural ventilation. 
The major objective of this research was to perform a parametric evaluation of internal pressure in low-rise buildings, useful both for wind-resistant design and winddriven natural ventilation applications. To achieve the intended goal, several specific objectives were pursued as given below:

- Perform a multi-scale experimental parametric evaluation of wind-induced internal pressure by using both a full scale building at $\mathrm{WoW}$ and model scale at Boundary Layer Wind Tunnel (BLWT) from design of wind-resistant low-rise building and natural-ventilation application perspectives,

- Assessment of internal pressure excitation due to variable location and size of dominant openings, vents and background leakage for low rise buildings with different roof shapes,

- Perform parametric assessment of the significance of internal volume scaling corrections on the statistical characteristics of internal pressure while conducting a low wind speed $B L W T$ investigations,

- Investigate peak internal pressure loading due to sudden breach of dominant openings (transient condition) and its comparison with existing dominant opening conditions (steady state condition) to determine the governing design conditions,

- Analysis of internal pressure and wind-driven cross-ventilation having realistic multi-room partitioning representing an "actual" low-rise building and with and without screens on the dominant openings,

- Aerodynamic performance investigation of underneath pressure for various types of roof tiles (both ridge and field tiles) and design of effective low cost mitigations, 
- Computational evaluation of internal pressure for low-rise buildings as well as its validation in comparison with experimental internal pressure data obtained both from full-scale $W o W$ and model-scale $B L W T$.

\subsection{Literature review}

Major contribution has been done in boundary layer wind tunnels to realize the wind-building envelope interaction and subsequently evaluate the external and internal pressure distribution that govern the impact scale of interaction. However, compared to external pressure studies performed on buildings, very limited works are available on assessment of internal pressure (Holmes 1979; Stathopoulos , Surry et al. 1979; Liu and Saathoff 1983; Davenport and Surry 1984; Irwin and Sifton 1998; Sharma and Richards 2003; Oh, Kopp et al. 2007). As described by numerous researchers, internal pressure can contribute a significant portion to the total design wind load. The intensity and distribution of the load depends on the severity of the dominant aerodynamic factors involved. Sometimes, internal pressure can account for more than $50 \%$ of the wind load. Wind-induced internal pressure on low rise buildings with dominant openings can form a higher proportion of the total design wind load (Holmes 2001).

Post hurricane assessments have shown that variation of internal pressure often led to roof and wall failures (FEMA 240:2005; FEMA 549:2006). 

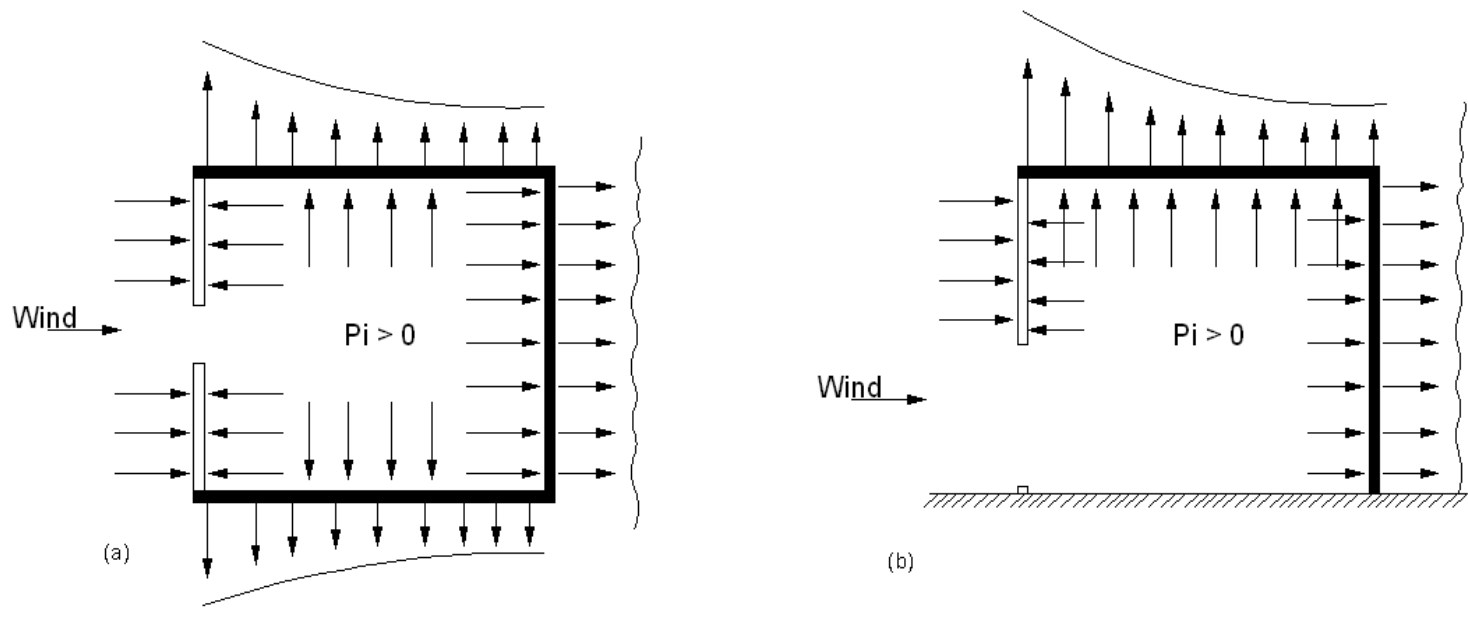

(b)

Figure 1.2: Variation of internal pressure with windward dominant opening (block lines showing critical loading); a) floor plan; b) elevation
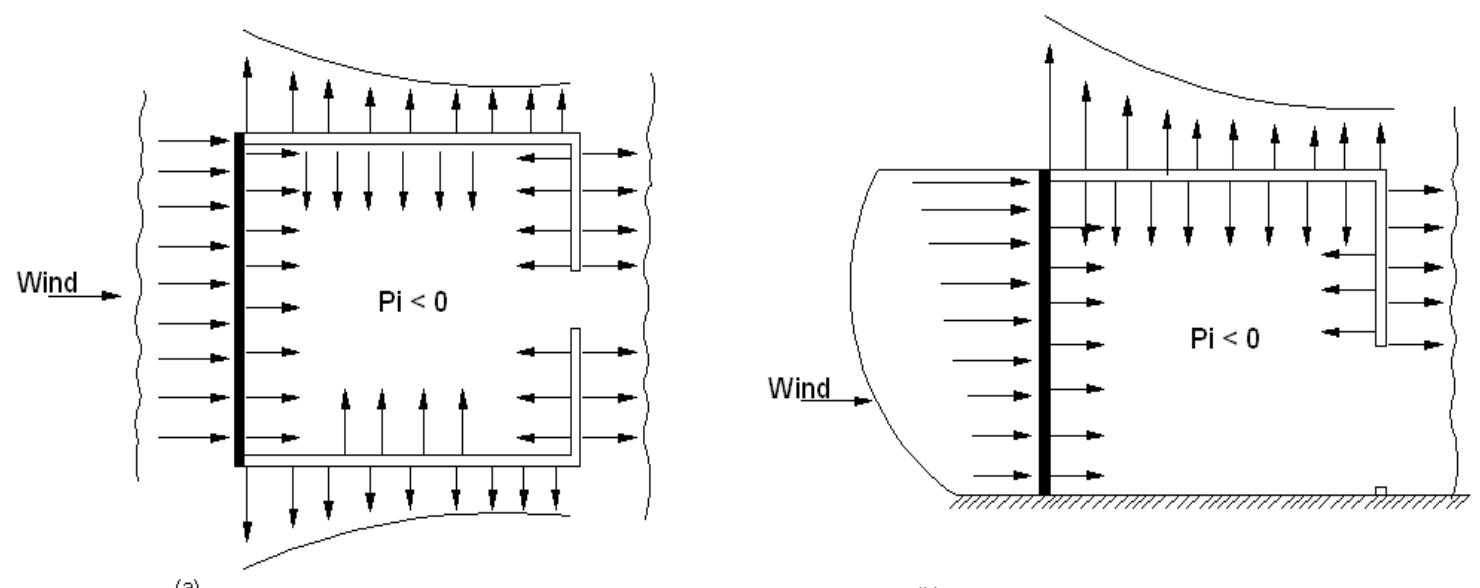

(a)

(b)

Figure 1.3: Variation of internal pressure with leeward dominant opening (block line showing critical loading); a) floor plan and b) elevation

In addition to aerodynamic factors that affect external pressure (such as shape, upstream terrain, oncoming wind characteristics etc.), internal pressure is affected in a complex manner by opening size and location, compartmentalization, background leakage, flexibility of envelope, internal volume, external pressure distribution at the opening, wind direction (Holmes 1979; Liu and Saathoff 1982; Sharma and Richards 2003; Kopp, Oh et al. 2008). Thus, understanding the physics of internal pressure, how it is affected by the complex dynamics of wind and building interaction, is essential to 
properly design building envelopes and components from the perspective of wind resistance, water intrusion and energy performance. Unless properly assessed and investigated, the interaction of wind and building causes the variation of pressure in excess of the resistance capacity of the building envelope that could lead to progressive failure of the building components.

The presence of dominant cladding openings (such as door and window) play significant role on the magnitude of the internal pressure that develops inside the building. Since the intensity of the internal pressure is inversely proportional to the ratio of interior volume to area of dominant opening, the size of door or window has a significant impact and thus need proper attention. For a given volume, an increase in the size of dominant opening causes an increase in the resonance frequency and decrease in damping. Moreover, the position of the dominant opening (i.e., windward or leeward, center or edge) has a significant impact on the intensity of internal pressure that develop as a result. Commonly, doors and windows located in the windward side cause an increase in the density of the air inside and hence inflation of the building as wind induced air rushes in. This, of course, result in the build-up of positive internal pressure (Figure 1.2). Doors and windows located in the leeward side, however, cause deflation of the building`s volume leading to the development of suction pressure (Figure 1.3). Keeping other aerodynamic factors constant, these two specific scenarios have different impact on the net wind load that develops on the building envelope, particularly the roof components (since it is mostly non-structural highly vulnerable to failure). The former scenario causes critical loading on the windward roof envelope due to the coupling effect 
of the positive internal pressure with the suction external pressure leading to formation of extreme uplift force.

Since the interaction of wind and building creates a region of separation and reattachment of flows depending on the size of the building and angle of attack, the location of dominant openings at specific part of the envelope lead to the development of significant internal pressure variation. It becomes essential, thus, to study the impact of dominant opening in exciting internal pressure during sudden opening.

Most of the internal pressure experimental studies performed previously involve a single dominant opening (either door or window) to characterize the pressure distribution inside the building and identify the role that the internal pressure plays in generating critical loading. Some of these studies include: Holmes (1979) conducted a study on the internal pressure fluctuation of a building model using boundary layer wind tunnel at James Cook University. The study was a pioneer in the investigation of the relationship between internal pressure and Helmholtz resonance. The study revealed that the internal pressure in buildings with dominant opening responds quickly to external pressure fluctuations. The building behaves like a Helmholtz resonator. The study showed that Air 'slug' moves in and out of a building in response to external pressures and the internal pressure fluctuations are due to the compressibility effects of the air. Experimental studies on wind tunnel models with variable single dominant openings have also shown that excitation of peak internal pressure occurs close to the undamped Helmholtz frequency (Liu and Saathoff 1981). 
A boundary layer study at University of Western Ontario investigated the behavior of transient wind-induced internal pressure and compared the phenomenon of overshooting vs peak values of steady-state internal pressure fluctuations (Stathopoulos and Luchian 1989). The experimental observation showed that the steady-state peak fluctuations being higher than that of the transient response overshooting. The study, however, didn't account for the influence of background porosity and flexibility of the building. Even though the effect of inherent porosity and flexibility is to dampen the transient peaks, it would be appropriate to compare the real variation between steadystate and transient overshooting by considering such factors that play a role. A study was also performed to investigate the transient behavior of the internal pressure following a sudden breach of dominant opening envelope under smooth and turbulent flow (Vickery 1994). The experimental boundary layer wind tunnel study, which was supported by unsteady discharge equations, attempted to demonstrate the buildup of a large differential pressure across ceilings as a result of the failure of large dominant wall openings. The study due to sudden smooth flow demonstrated that pressure abruptly rises to a peak value in an overshoot far in excess of the new local mean and consequently undergo decaying oscillation till the pressure stabilizes close to the mean value (Figure 1.4). In the case of the turbulence flow, however, the experiment showed that the internal pressure doesn't decay with time. 


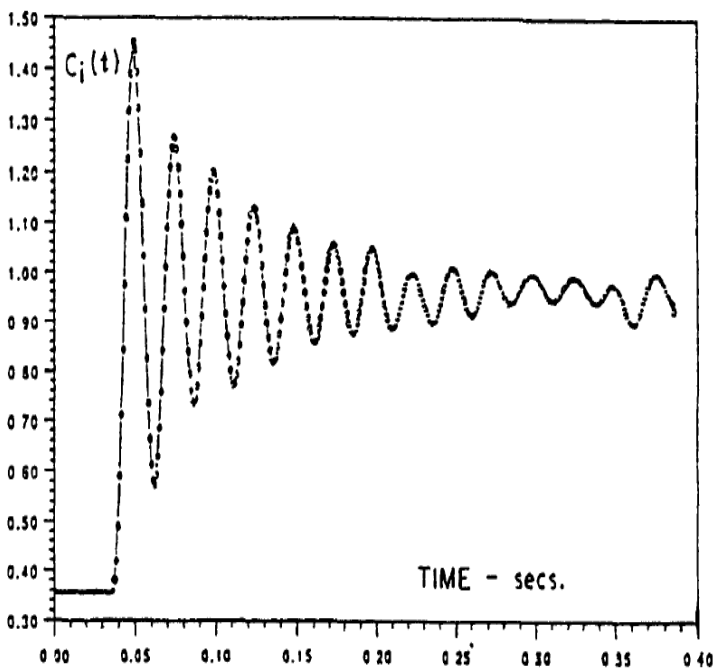

(a)

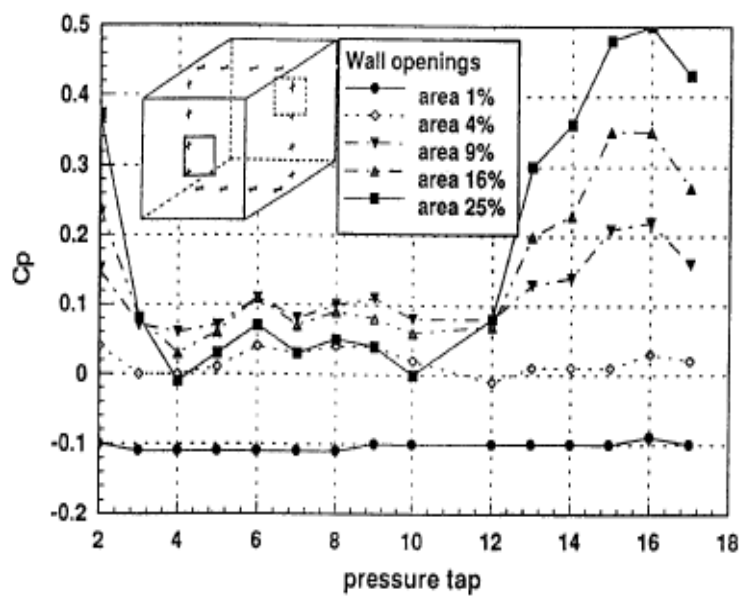

(c)

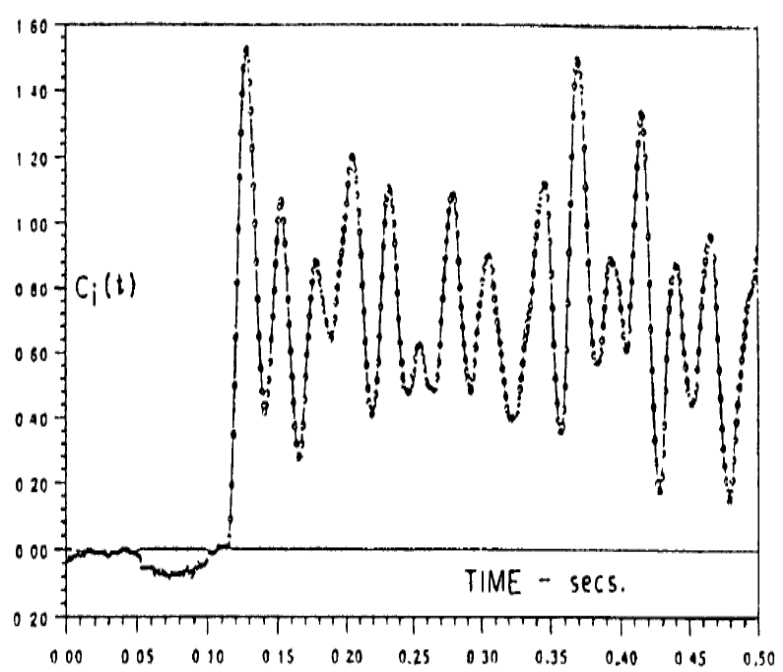

(b)

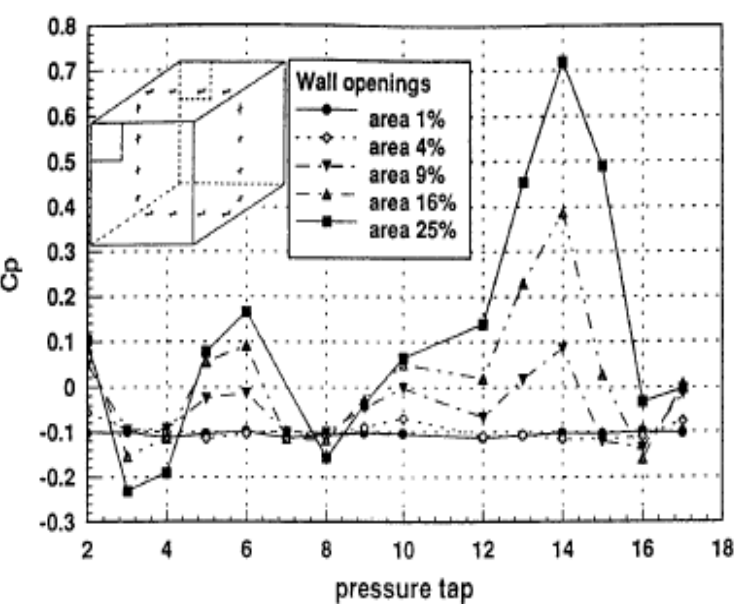

(d)

Figure 1.4: Mean internal pressure distribution for dominant opening sizes of $(1 \%, 4 \%, 9 \%, 16 \%$ $\& 25 \%$ ): a) Central openings at $30^{\circ} \&$ b) corner openings at $45^{\circ}$

The fluctuation of the internal pressure was equivalent to that of the external pressure.

Moreover, it was found that the expected peak load values of internal pressure using only Helmholtz resonance principle and overshoot ratio is often conservative. The correlation of the internal pressure fluctuations with that of external pressure provided a higher peak load than that of the overshoot at Helmholtz resonance frequency. Similar results were obtained in other experiments as well (Vickery and Bloxham 1992; Yeatts and Mehta 1992) which illustrated the sustained dynamic action of turbulent wind over a dominant 
opening being more vital in imposing damage to the building than the short duration of the "overshoot". On the other hand, a numerical study performed has raised concern on the viability of the synchrony of formation of sudden overshoot characteristics between wind tunnel and full scale studies (Sharma, Mason et al. 2010). The result of the modeling showed the significance of sudden overshoot over the steady state peak internal pressure.

The effect of dominant openings and inherent porosity on internal pressures was examined to evaluate its influence on the internal pressure (Woods and Blackmore 1995). The study employed a parametric boundary layer wind tunnel simulation which was executed using various sizes of dominant openings ranging from $1 \%$ to $25 \%$ of the wall area. The test also introduced uniform leakage in order to evaluate the impact of background leakage. Results of the experiment showed that steady-state theory agrees quite well with experimental measurements of internal pressure for the case of a single dominant opening. The internal pressure distribution was found to be uniform for smaller size dominant openings. Beyond $9 \%$ opening size, however, the uniformity begins to cease and the variation in internal pressure increases as shown in Figure 1.5. Sharma and Richards (2003) investigated the influence of Helmholtz resonance on internal pressure in a low-rise building under oblique wind flow. In their study, a 1:50 scale model of Texas Tech University (TTU) test building was used with a number of wall openings being incorporated on its windward surface. A single central pressure tap was provided to capture internal pressure data, while a point pressure tap next to each of the openings were set up to measure external pressure at the opening. The result of the experiment 
showed that the effect of resonance at oblique flow being significant causing large fluctuation in internal pressure. Another observation of the experiment was the dependence of oblique flow Helmholtz resonance upon Reynolds number, specifically the Strouhal number (i.e. $\left.f_{H} \omega_{o} / \bar{U}_{o}\right)$. It was also observed that the distance from the upstream wall corner to the dominant opening substantially influenced the magnitude of response in the oblique flow mode of Helmholtz resonance. It was obtained that the RMS of the internal pressure for the dominant opening at a distance of $109.3 \mathrm{~mm}$ from the upstream wall corner (i.e., when the wind angle is $-55^{\circ}$ ) was greater than that at a distance of $56.7 \mathrm{~mm}$ (i.e., when the wind angle is $+55^{\circ}$ ). One observation on this experiment is the application of point external pressure tap at the door instead of allocating multiple taps that should have represented the area-average variation of external pressure at the opening. This issue need attention since the proper representation of external pressure influences the accuracy of internal pressure response. Moreover, similar to the previously discussed experimental researches, the contribution of inherent background porosity was undermined. Since the phenomenon of oblique flow is essential for proper internal pressure analysis, the response in internal pressure fluctuations due to the impact of Helmholtz resonance under oblique flow need to be studied by making use of full scale analysis that engages the crucial parameters left out in the previously done model experiments. A full scale experimental research performed by Ginger et al. (1997) examined the interaction of internal pressure and Helmholtz frequency. The work demonstrated the influence of Helmholtz frequency in exciting internal pressure fluctuations. Similar to the research carried out by Sharma \& Richards (2003), the analysis of internal pressure for a $2 \%$ single windward wall opening showed an increase 
in internal pressure energy close to the Helmholtz frequency, $f_{H}=1.58 \mathrm{~Hz}$. Furthermore, the increase in size of the opening from $2 \%$ to $5 \%$ increased the energy spectrum reaching peak value at $1.80 \mathrm{~Hz}$. Thus, as the area of dominant opening increases, the tendency for resonance also increases significantly. This is in agreement with the observations made from the works of (Holmes 1979; Liu and Saathoff 1983; Vickery and Bloxham 1991; Sharma and Richards 2003).

A wind tunnel test on low-rise buildings was carried out to investigate the windinduced internal pressure with dominant opening and leakage scenarios (Oh, Kopp et al. 2007). The study introduced internal volume correction by multiplying the nominal volume (obtained from geometric length scaling) by the ratio of the square of the full to model scale velocity in order to maintain model to full scale dynamic similarity. The experimental study showed that the internal pressure fluctuation for nominally sealed buildings (having background leakage only) were significantly attenuated by the damping effect of the flow through the small holes (representing background leakages). It showed that, for single door opening near center of the wall, peak internal pressures occur for wind direction normal to the wall having the dominant opening. Moreover, it was obtained that peak internal pressure coefficient exceed codal values recommended by design standards such as $A S C E 7$.

Kopp et al. (2008) performed an internal volume-scaled wind tunnel experimental study to examine the effects of ten different opening configurations on the internal pressures of low-rise buildings. Results of the experiment have shown that the peak internal pressure strongly correlates in time with the external pressure. The internal 
pressure coefficients were substantially large when there was a dominant opening in the windward side of the building. The internal pressure also gained considerable Helmholtz resonance amplification for open area ratios greater than 3\%. Furthermore, peak values of pressure coefficients were observed at wind angle of attack close to $90^{\circ}$. However, other studies, performed in a similar procedure have shown that peak pressure coefficients can occur at an oblique flow condition (De Metz and Farabee 1977; Panton.R.L. 1988; Sharma 2007). Comparing the simulation cases of wind flow having dominant opening with background leakage versus one with dominant opening but no background leakage, it was shown that the wall leakage acts to ease the internal pressure fluctuation. This could basically be due to the leakage of air through the leeward and side walls (left, right and rear) that contribute to deflate the building interior.

From the literature review gathered, it can be deduced that significant work has been accomplished in understanding the principles of internal pressure and its importance towards the contribution of net wind loading and wind-induced natural ventilations. Equivalently, it is apparent that there is misunderstanding on the major factors that determine the internal pressure intensity and distribution. Few of these include: the importance of internal volume correction in wind tunnel study for low-rise building model, the significance of transient overshooting over its subsequent steady state peak internal pressure response during sudden breach of dominant openings, background leakages due to faulty construction and utility ducts and the closing/opening of mechanical roof vents. 

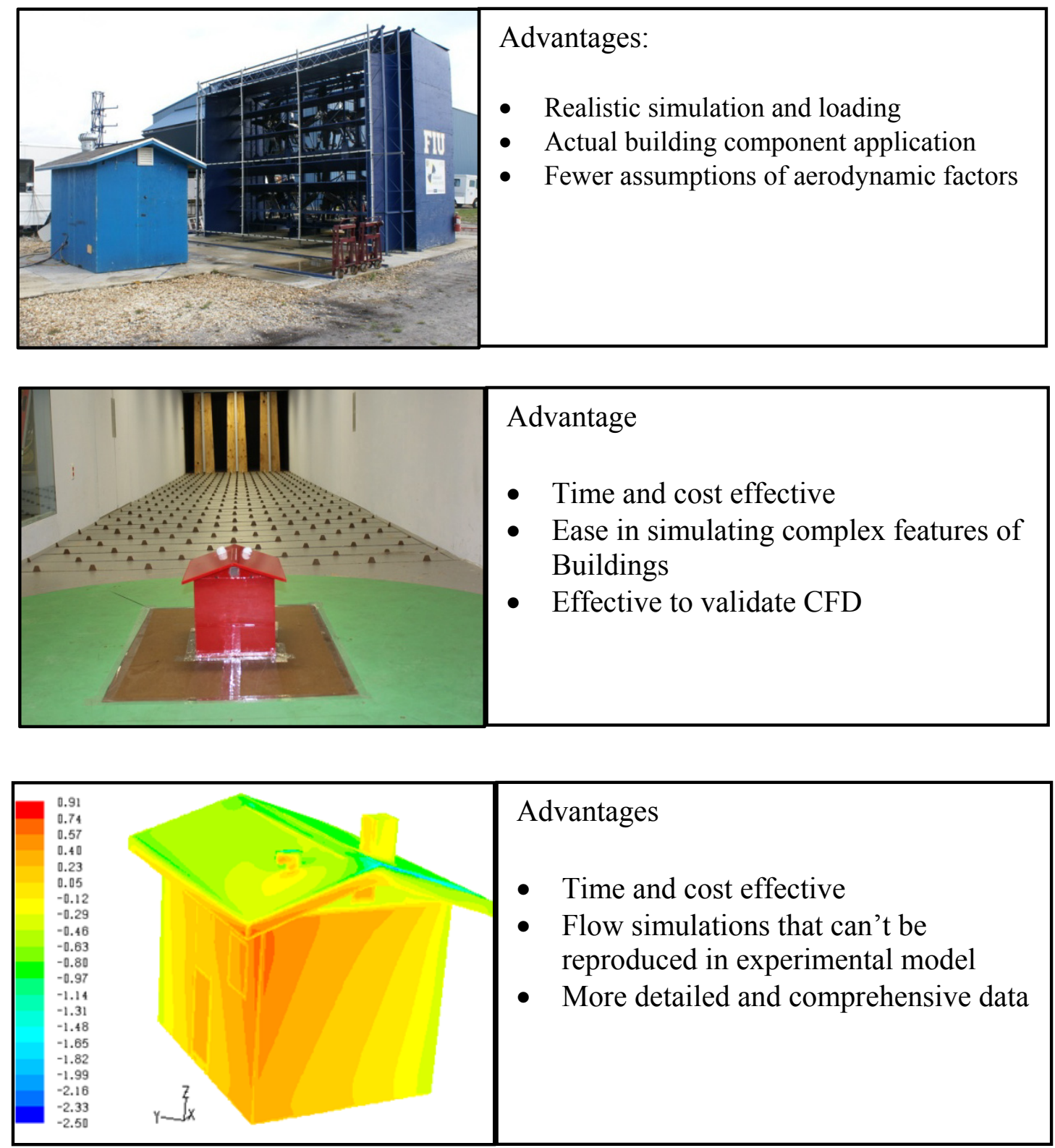

Figure 1.5: Advantages of full scale (top), small scale (middle) and computational (bottom)
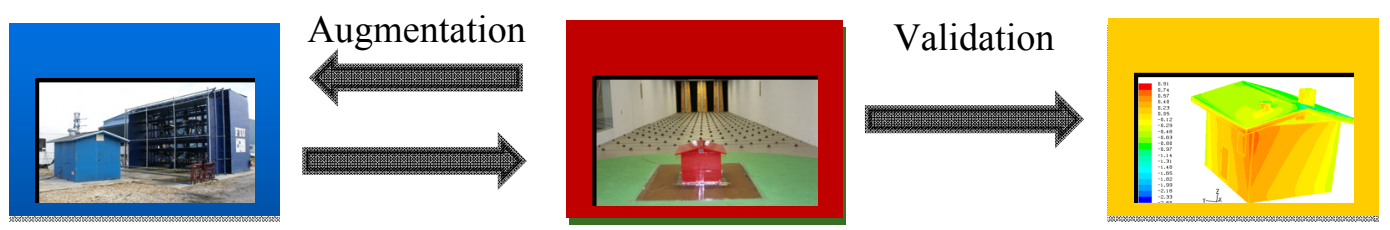

Figure 1.6: Three-tier communication among the simulation techniques 
Some researchers have described these factors as major and urged the need to incorporate them in the design processes while some other researchers argue that these factors are less significant. The present research is aimed at undertaking a comprehensive, realistic investigation intended to address the above stated issues by implementing a multi-scale approach.

\section{$1.4 \quad$ Research methodology}

The research embraced a multi-scale approach (Full scale-WoW, Small scale$B L W T$ and computational-CFD) to cover a wide array of internal pressure problems. The full scale approach was applied in the investigation of the effect of realistic construction materials and building envelopes (to satisfy Reynolds and Strouhal numbers), background and dominant openings on the internal pressure without the need to worry about the provision of internal volume correction as in the case of wind tunnel studies. The small scale wind tunnel study, on the other hand, provided the capability to examine wide variability of dominant openings, wind directions, building compartmentalization with the advantage of augmenting the full scale study for the benefit of saving time and minimizing costs. With the rapid improvement of numerical schemes, fairly accurate predictions are obtained in computerized simulations. In this research, an attempt was also made to foresee the future by making use of computational fluid dynamics $(C F D)$ to simulate and validate the internal pressure experiments performed in the full scale and wind tunnel technique. The three tier-scheme is shown in Figure 1.6 \&1.7. 


\subsubsection{Full scale study}

The full scale study of internal pressure was carried out at Wall of Wind (WoW), a full-scale testing facility at the IHRC of Florida International University. A gable and hip roof building having a roof slope of 4:12 were constructed following Florida Building Code. It has a $2.74 \mathrm{~m}(9 \mathrm{ft})$ wide $\times 2.13 \mathrm{~m}(7 \mathrm{ft})$ long x $2.13 \mathrm{~m}(7 \mathrm{ft})$ dimension. The building has ventilation openings such as soffit, goose neck and turbine vents (gable end vents for gable roof case) provided in accordance with the minimum requirement for passive ventilation, two interchangeable shingle roofing, gable and hip as shown in Figure 1.1. Dominant openings with porosity size 7.5\% (door) and 3.75\% (window) were incorporated to evaluate the variation of internal pressure. For the aerodynamic performance evaluation of gable ridge and field roof tiles, three different slopes were adopted (i.e.7:12, 5:12, and 2:12) interchangeably on a single base. Three different field tile profiles (i.e. high, medium and low) and two types of ridge tiles (barrel and three sided) were tested at different wind angle of attack. Besides, each experiment was carried out under weather block $(W B)$ and no weather block $(N W B)$ conditions.

\subsubsection{Boundary layer wind tunnel study (BLWT)}

The model scale study of the gable and hip roof low-rise building was carried out at a standard commercial boundary layer wind tunnel: Rowan Williams Davies \&Irwin Inc. $(R W D I)$. The models studied were a replica of the full scale buildings with 4:12 roof slope constructed at a model scale of 1:9. The models were constructed using acrylic sheet made from a Plexiglas that has similar wall thickness as the 1:9 scale of the full scale building. All the claddings, ventilation systems, thickness of dominant openings 
were mirrored from the full scale building. An open country exposure was selected for the upstream terrain.

\subsubsection{CFD computation of internal pressure}

The numerical computation of the $4: 12$ roof slope gable roof building internal pressure was executed using commercial software $A N S Y S^{\circledR}$. Unsteady RANS (Reynolds Averaged Navier-Stokes) together with the Renormalization Group $(R N G) \mathrm{k}-\varepsilon$ turbulence

model were adopted as the governing equation of the flowfield. The computational domain $(C D)$ was delineated using the Height $(H)$ of the model building as a reference. The $C D$ was extended vertically $5 H$ above the roof of the model building, and laterally $5 H$ from the walls. In the flow direction, the $C D$ was extended $5 H$ from front wall to the inflow boundary and $15 H$ from the back wall to the outflow boundary. The latter allows the flow re-development behind the wake region.

\subsection{Organization of Dissertation}

The dissertation is organized following a journal paper format. It was divided into 8 chapters including introduction as the $1^{\text {st }}$ chapter and conclusion as the $8^{\text {th }}$ chapter. Chapters 2 through 7 present technical papers under review for publication, produced over the course of the present study to meet the objectives. Chapter 2 covers the full-scale $(W o W)$ study of internal pressure characteristics of a "simplified" low-rise building in the presence of variable size of dominant openings and compartmentalization built with actual construction material using a prevailing construction practices in the state of Florida. Chapter 3 presents a cost-effective small-scale boundary layer wind tunnel study of internal pressure on a model building similar to the "simplified" low-rise building used 
for a full-scale study at $W o W$ in Chapter 2. It focuses on the characterization of transient and steady state (due to sudden breaching) and steady state (due to existing opening) internal pressure responses at various wind angles of attack. It also covers more configurations of dominant openings, partitioning and wind angle of attacks. Chapter 4 presents a boundary layer wind tunnel investigation of internal pressure on an "actual" 5:12 slope hip roof low-rise building with multi-room partitioning and ventilation openings. The building represents a typical low cost housing in Miami. Chapter 5 presents a boundary wind tunnel investigation of wind-driven natural ventilation with and without internal volume distortion, multi-room partitioning, with dominant openings on adjacent side and opposite sides of an "actual" low-rise building used in Chapter 5. Chapter 6 presents a full scale investigation at the Wall of Wind on the aerodynamic performance of roof tiles (both ridge and field tiles) installed on a "simplified" low-rise building. The building has three interchangeable gable roofs with different roof slopes (i.e., 2:12, 5:12 and 7:12) and different tile profiles to investigate underneath pressure that develops between the tiles and roof deck. Chapter 7 covers a computational evaluation and validation of internal pressure for the "simplified" building used at the Wall of Wind. Chapter 8 provides summary and conclusions of the present work and recommendations for future research. 


\subsection{References}

FEMA 240:2005., Summary Report on Building Performance: 2004 Hurricane Season.

FEMA 549:2006., Hurricane Katrina in the Gulf Coast: Building Performance Observations, Recommendations and Technical Guidance.

Cutter, S.L., Johnson, L.A., Finch, C. and Berry, M. (2007), "The US Hurricane Coasts: Increasingly Vulnerable?", Environment. 47(7).

Davenport, A.G. and Surry, D. (1984). "The estimation of internal pressures due to wind with application to cladding pressures and infiltration". Proc., Wind pressure workshop, Brussels, Belgium.

De Metz, F.C. and Farabee, T.M. (1977). "Laminar and Turbulent Shear Flow Induced Cavity Resonances", American Institute of Aeronautics and Astronautics Journal. 77 1293.

Holmes, J.D. (1979). "Mean and fluctuating internal pressures induced by wind". Proc. 5th Int. Conf. on wind engineering, Colorado, USA.

Holmes, J.D. (2001). Wind Loading of Structures, Spon Press.

Irwin, P.A. and Sifton, V.L. (1998). "Risk Considerations for Internal Pressures", J. Wind Engineering and Industrial Aerodynamics. 77 \& 78 715-723.

Kopp, G.A., Oh, J.H. and R.Inculet, D. (2008). "Wind-induced Internal Pressures in Houses", Journal of Structural Engineering. 134(7), 1129-1138.

Liu, H. and Saathoff, P.J. (1981). "Internal pressure and building safety", Proceedings, J.Struct. Div., ASCE,. 108.

Liu, H. and Saathoff, P.J. (1982). "Internal pressure and building safety", J.Struct. Div., ASCE. 108(10), 2223-2234.

Liu, H. and Saathoff, P.J. (1983). "Internal pressure of multi-room buildings", $J$. Engineering Mechanics Division. 109(EM3), 908-919.

McDonald, J.R. and Smith, T.L. (1990). Performance of Roofing Systems in the Hurricane Hugo, Institute for Disaster Research, Texas Tech University, Lubbock, Texas.

Minor, J.E. and Mehta, K.C. (1979). "Wind Damage Observations and Implications", Journal of the Structural Division ASCE. 11 2279-2291. 
Oh, J.H., Kopp, G.A. and Inculet, D.R. (2007). "The UWO contribution to the NIST aerodynamic database for wind loads on low buildings. 3: Internal pressures", Journal of Wind Engineering and Industrial Aerodynamics. 95(8), 755-779.

Panton.R.L. (1988). "Effect of orifice geometry on Helmholtz resonator excitation by grazing flow", American Institute of Aeronautics and Astronautics Journal. 28(1), 60-65.

Rappaport, E.N. (2000). "Loss of Life in the United States Associated with Recent Tropical Cyclones", Bulletin of the American Meteorological Society. 81(9), 2065-2074.

Sharma, R.N. (2007). "Internal and net envelope pressures in a building having quasistatic flexibility and a dominant opening", Journal of Wind Engineering and Industrial Aerodynamics. 91 807-828.

Sharma, R.N., Mason, S. and Driver, P. (2010). "Scaling methods for wind tunnel modeling of building internal pressures induced through openings", wind and structures. 13(4), 363-374.

Sharma, R.N. and Richards, P.J. (2003). "The influence of Helmholtz resonance on internal pressures in a low-rise building", Journal of Wind Engineering Industrial Aerodynamics. 91 807-828.

Sharma, R.N. and Richards, P.J. (2005). "Net pressure on the roof of a low-rise building with wall openings", Journal of Wind Engineering and Industrial Aerodynamics. 93 267291.

Stathopoulos, T. and Luchian, H.D. (1989). "Transient Wind-Induced Internal Pressures", Journal of Engineering Mechanics, ASCE. 115(7), 1501-1514.

Stathopoulos, T., Surry, D. and Davenport, A.G. (1979). "Internal pressure characteristics of low-rise buildings due to wind action". In: Proc. 5th Int. Conf. on Wind Engineering, Fort Collins, Colorado.

Stathopoulos , T., Surry, D. and Davenport, A.G. (1979). "Internal pressure characteristics of low-rise buildings due to wind action". In: Proc. 5th Int. Conf. on Wind Engineering, Fort Collins, Colorado.

Vickery, B.J. (1994). "Internal pressures and interactions with the building envelope", Journal of Wind Engineering and Industrial Aerodynamics. 53 125-144.

Vickery, B.J. and Bloxham, C. (1991). "Internal Pressure Dynamics with a Dominant Opening”, London, Ontario, Canada.

Woods, A.R. and Blackmore, P.A. (1995). "The effect of dominant openings and porosity on internal pressures", Journal of Wind Engineering and Industrial Aerodynamics. 57(23), 167-177. 
Yeatts, B.B. and Mehta, K.C. (1992). "Field experiments for building aerodynamics". Proceedings of the Second International Colloquium on Bluff Body Aerodynamics and Applications, Melbourne, Australia, December. 


\title{
2. OPENING AND COMPARTMENTALIZATION EFFECTS ON INTERNAL PRESSURE IN LOW-RISE BUILDINGS WITH GABLE AND HIP ROOFS
}

\author{
Amanuel S. Tecle ${ }^{\mathrm{a}}$, Girma T. Bitsuamlak ${ }^{\mathrm{b}}$, Arindam Gan Chowdhury ${ }^{\mathrm{c}}$ \\ Accepted for publication in Journal of Architectural Engineering
}

\begin{abstract}
Wind-induced internal and external pressures in typical low-rise building models were investigated by using a full-scale wind testing facility, generically named Wall of Wind $\left(W_{o} W\right)$. The test building had optimal size with dimensions $2.74 \mathrm{~m}(9 \mathrm{ft})$ long, $2.13 \mathrm{~m}(7 \mathrm{ft})$ wide, and $2.13 \mathrm{~m}$ (7ft). It had also interchangeable gable and hip roofs, multiple dominant openings (doors with secondary openings and windows), ventilation openings (soffit, gooseneck, turbine and soffits) and inherent background leakages, vertical and horizontal (due to ceiling and internal wall) compartments. These details coupled with high Reynolds number $\left(\sim 10^{6}\right)$ flow test enabled the realistic assessment of: the effects of: (i) internal and external pressure, (ii) background leakages, dominant openings, location and (iii) compartmentalization on internal pressure. For the study case, the opening of the hatch in the ceiling increased the coefficient of internal pressure from 0.05 to 0.69 for the dominant door opened case and from 0.08 to 0.98 for the dominant window opened case compared with the closed hatch case indicating the importance of compartmentalization. The peak attic internal pressure for the gable roof was higher than the hip roof (by more than $190 \%$ ). Furthermore, the worst net pressure coefficient at eave of gable roof was found to be significantly higher compared to that at the hip roof.
\end{abstract}


Key words: Full-scale testing, internal pressure, vents, compartmentalization, Wall of Wind.

\subsection{Introduction}

Design wind loads on building envelope are due to a net combination of external and internal pressures. Internal pressure can contribute a significant portion to the total design wind load depending upon the dominant opening size and location, shape of the building, surrounding conditions and other aerodynamic factors (Simiu and Scanlan 1996; Irwin and Sifton 1998). Internal and external pressure measurements are also essential for assessing infiltration/exfiltration of air, moisture movement and thermal variations through building envelope and have significant influence on both the internal environment and the energy needs of buildings (Lidament 1986; Karava, Stathopoulos et al. 2007). Accurate assessment of internal pressures is, therefore, essential both from resiliency (e.g. wind loads) and sustainability (e.g. energy efficiency of buildings) aspects. However, measures taken to enhance the resiliency of buildings at times could be in conflict with the sustainability requirements. For example, the use of typical energy efficient roof vents to naturally ventilate attic spaces provide comfort, prevent accumulation of moisture, formation of molds and other health hazards, and improve the durability of the structural members. However, these openings can lead to high wind load on the building envelop due to internal pressure development and facilitate the intrusion of wind-driven rain. Thus, sustainability measures need to be reviewed under the constraints of wind performance. 
Significant research on external building aerodynamics using Boundary Layer Wind Tunnels $(B L W T)$ is reported in literature compared to that of internal aerodynamics. Unlike tall buildings, low rise-buildings are fully immersed within the layer of aerodynamic roughness where the turbulence intensities are high (Holmes 2001). The complexities in aerodynamic conditions that characterize low rise-buildings often lead to extreme wind pressure fluctuations that develop within the lower portion of the atmospheric boundary layer. Internal pressure develops inside a building owing to the action of wind and the presence of openings in the building envelope. The change in internal pressure is due to the infiltration or exfiltration of air from the interior of a building through the openings. These could include dominant openings (e.g., windows and doors) or background leakage (due to poor air tightness of walls, door- and windowwall interfaces, soffits, utility ducts and vents); or a sudden wind-borne breach of a building envelope. In addition to common aerodynamic factors that affect external pressure (such as shape of building, surrounding, upcoming wind characteristics and its direction, etc), the magnitude of internal pressure is influenced by the size and location of dominant openings as well as the background porosity, internal volume and compartmentalization, and flexibility of the structure (Holmes 1979; Stathopoulos, Surry et al. 1979; Liu and Saathoff 1981; Liu and Saathoff 1983; Vickery 1986; Vickery and Bloxham 1992; Oh, Kopp et al. 2007). Compared to external pressure measurements, internal pressure measurements are more complex (Liu 1990).

A detailed review of internal pressures was given by Oh et al. (2007). Earlier internal pressure studies focused mainly on cladding and structural design applications. Previous studies reported that the contribution of internal pressure to the total load to be very 
significant (Holmes 1979; Stathopoulos, Surry et al. 1979; Davenport and Surry 1984; Irwin and Sifton 1998; Sharma and Richards 2003; Sharma and Richards 2005). Holmes (1979) performed BLWT studies on the transient responses of internal pressure fluctuations in a non-porous low rise building models with a single dominant opening. The study revealed that such buildings behave like a Helmholtz resonator, and introduced the method of volume adjustment by applying internal volume scaling to obtain the correct model-scale natural frequency. Stathopoulos and Luchian (1989) investigated the behavior of transient wind-induced internal pressure and compared the phenomenon of overshooting with the peak values of steady-state internal pressure fluctuations. Bloxham and Vickery (1989) investigated the effect of background porosity on internal pressure. Vickery (1994) studied internal pressure for a building envelope with a dominant opening and ceiling/roof partitions following a sudden breach of envelope under smooth and turbulent flow. Woods and Blackmore (1995) examined the effect of dominant openings and porosity on internal pressures. Saathoff and Liu (1983) performed a numerical study of the transient response of internal pressure of buildings with multi-rooms during breach of dominant openings. Vickery (1994) also showed ceiling/roof partition effect on the internal pressure. Sharma and Richards (2003) investigated the sensitivity of internal pressure to compartmentalization and observed an increase in the internal pressures when the internal volume was reduced through partitioning. In majority of the studies performed, however, the impacts of inherent leakages were not included. More recently, Kopp et al (2008) studied the effect of different opening configurations and compartmentalization including background leakage on internal pressure. It was reported that decreasing the ratio of the internal volume to the opening area increased the peak 
internal pressures and Helmholtz resonance, particularly for wind directions normal to the opening.

Most previous internal pressure studies were based on small-scale studies where some inherent approximations associated with the small scale models required further investigation. These include internal volume adjustment in order to obtain the real natural frequency of Helmholtz resonance, Reynolds number mismatch problems apparent in low wind speed $B L W T$ studies and significant external pressure attenuation due to entrance and friction losses in long thin holes. Experimental modeling of background leakage is another factor that requires due attention.

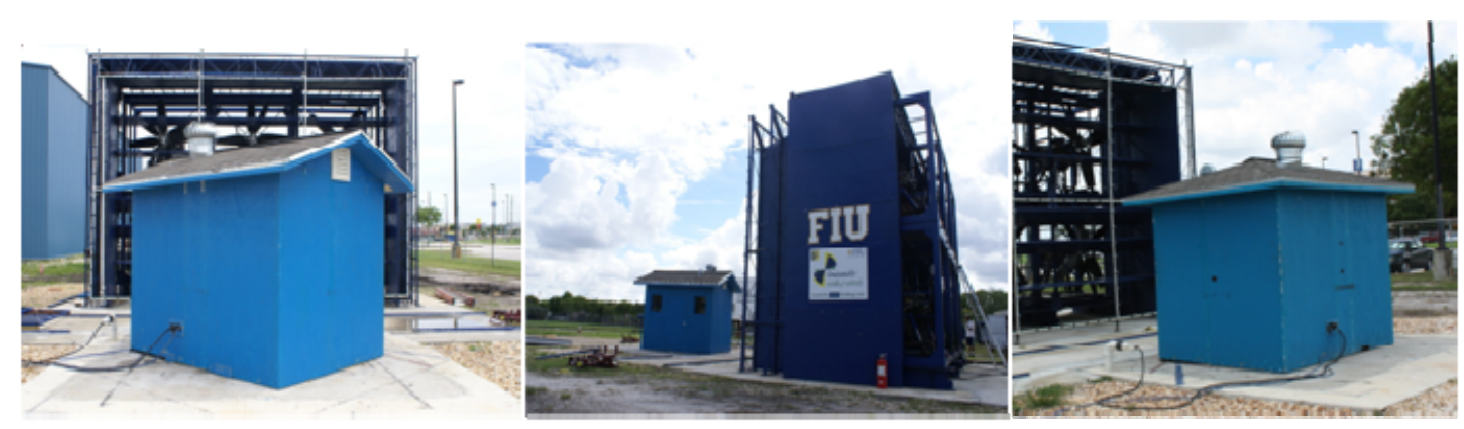

Figure 2.1: Low-rise building with gable and hip roof in front of $\mathrm{WoW}$ in a testing position 


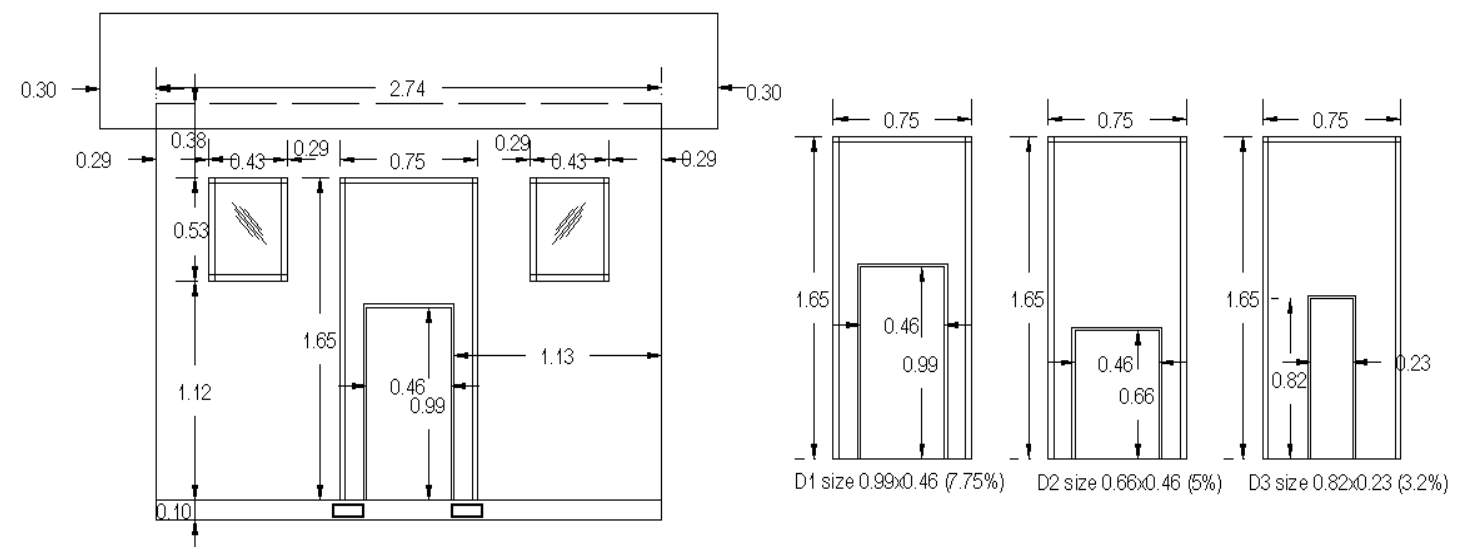

Figure 2.2: Gable roof test specimen dimensions (m).

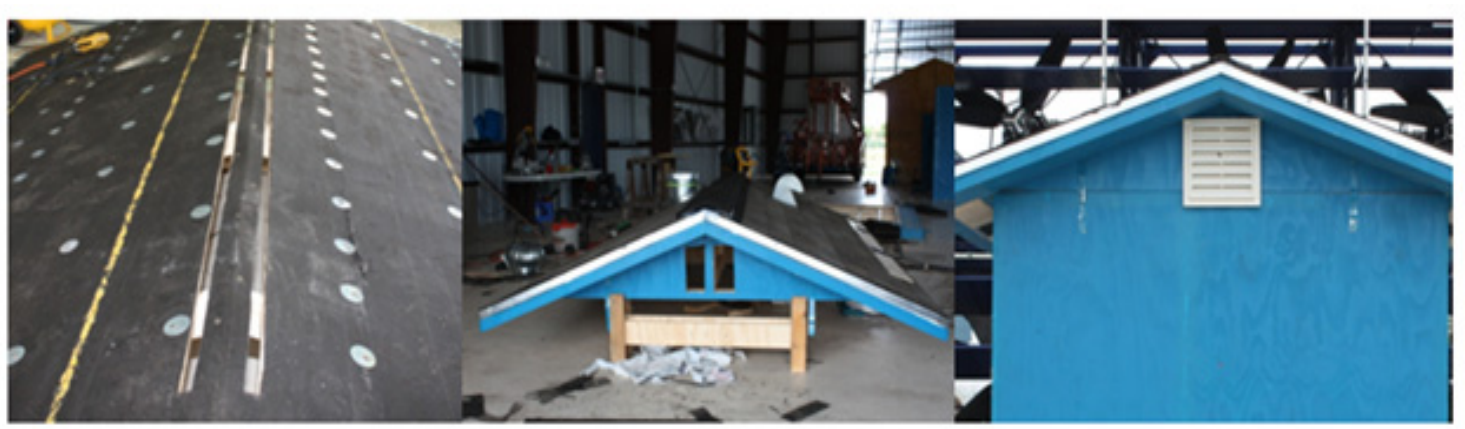

(a)

(b)

(c)

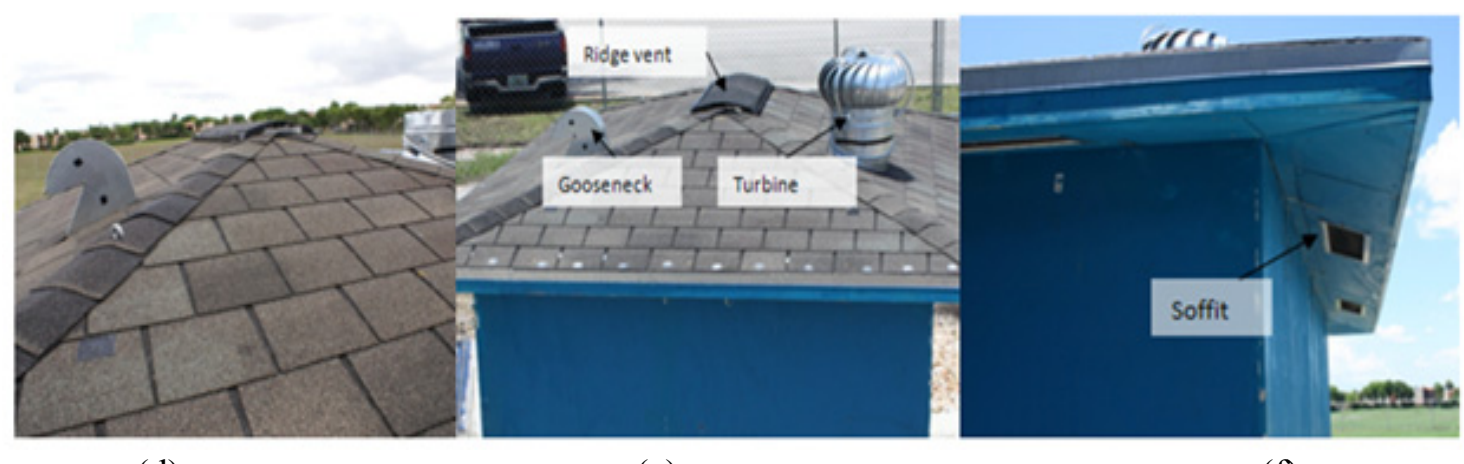

(d)

(e)

(f)

Figure 2.3: Gable (a, b and c) and hip roof (d, e and f) shingle and underlayment nailing patterns. The present study attempted to deal with scale issue related to the internal volume, as well as those related with the Reynold's number $(R e)$ and background leakage by testing 
a large building model constructed in accordance with prevailing code of practice and construction materials at high wind speed. The study was carried out at Wall of Wind $(W o W)$, a full-scale testing facility at the International Hurricane Research Center (IHRC) of Florida International University.

Table 2-1: Gable roof ventilation openings size and porosity ratio.

\begin{tabular}{|c|c|c|c|}
\hline S.N & Description & area $\left[\mathrm{m}^{2}\right]$ & $\begin{array}{l}\text { Vent opening to attic } \\
\text { floor ratio [\%] }\end{array}$ \\
\hline 1 & Attic area $(2.74 \mathrm{~m} \times 3.35 \mathrm{~m})$ & 9.20 & \\
\hline 2 & Soffit opening ( $4 \mathrm{pcs}, 0.11 \mathrm{~m} \times 0.36 \mathrm{~m})$ & 0.16 & 1.76 \\
\hline 3 & Gable end opening $(4 \mathrm{pcs}, 0.23 \mathrm{~m} \times 0.13 \mathrm{~m})$ & 0.12 & 1.26 \\
\hline 4 & Goose neck opening ( $0.1 \mathrm{~m} \mathrm{x} 0.24 \mathrm{~m})$ & 0.02 & 0.27 \\
\hline 5 & Turbine opening (Dia. $0.26 \mathrm{~m}$ ) & 0.06 & 0.61 \\
\hline \multirow[t]{4}{*}{6} & Ridge opening ( $\left.2 \mathrm{pcs}, 1.8 \mathrm{~m}^{2}\right)$ & 0.09 & 1.01 \\
\hline & Total vent opening area $\left(\mathrm{m}^{2}\right)$ & \multicolumn{2}{|r|}{0.45} \\
\hline & Ceiling area to be ventilated $\left(\mathrm{m}^{2}\right)$ & \multicolumn{2}{|r|}{9.20} \\
\hline & Ratio of free vent opening to ceiling floor & 0.0491 & \\
\hline
\end{tabular}

Table 2-2: Hip roof ventilation openings size and porosity ratio.

\begin{tabular}{|c|c|c|c|}
\hline S.N & Description & area $\left[\mathrm{in}^{2}\right]$ & $\begin{array}{l}\text { Vent opening to attic } \\
\text { floor ratio }[\%]\end{array}$ \\
\hline 1 & Attic area $(2.74 \mathrm{~m} \times 3.35 \mathrm{~m})$ & 9.20 & \\
\hline 2 & Soffit opening ( $8 \mathrm{pcs}, 0.11 \mathrm{~m} \times 0.36 \mathrm{~m})$ & 0.32 & 3.53 \\
\hline 3 & Goose neck opening ( $0.1 \mathrm{~m} \times 0.24 \mathrm{~m})$ & 0.02 & 0.27 \\
\hline 4 & Turbine opening (Dia. $0.26 \mathrm{~m}$ ) & 0.06 & 0.61 \\
\hline \multirow[t]{4}{*}{5} & Ridge opening ( 2 pcs, 1 x 14 in) & 0.02 & 0.20 \\
\hline & Total vent opening area $\left(\mathrm{m}^{2}\right)$ & \multicolumn{2}{|r|}{0.42} \\
\hline & Ceiling area to be ventilated $\left(\mathrm{m}^{2}\right)$ & \multicolumn{2}{|r|}{9.20} \\
\hline & Ratio of free vent opening to ceiling floor & 0.0460 & \\
\hline
\end{tabular}




\subsection{Methodology}

\subsubsection{WoW test building}

The test building was designed and constructed in accordance with locally prevailing construction methods in Miami, $F L$ to replicate realistic construction details. It had a 2.74 m (9 ft) wide x $2.13 \mathrm{~m}(7 \mathrm{ft})$ long x $2.13 \mathrm{~m}(7 \mathrm{ft})$ dimension, soffit, goose neck and turbine vents (gable end vents for gable roof case), two interchangeable shingle roofing, gable and hip with 1:4 roof slope, as shown in Figure 2.1 to 2.3. For a dominant opening study case, a door size $0.96 \mathrm{~m}$ by $0.46 \mathrm{~m}(3.15 \mathrm{ft}$ by $1.50 \mathrm{ft})$ and a window size $(0.53 \mathrm{~m}$ by $0.43 \mathrm{~m})(1.76 \mathrm{ft}$ by $1.43 \mathrm{ft})$ was considered that provided a porosity of $7.5 \%$ and $3.75 \%$ (area ratio of the opening to that of the wall where the opening is located), respectively. In addition, the door had three interchangeable openings as illustrated in Figure 2.2.

Ventilation openings for the attic floor were another type of openings that were considered in the present study. Building performance guides such as Florida Building Code $(F B C)$, American Society of Heating, Refrigerating, Air-Conditioning Engineers (ASHRAE), Canadian Mortgage and Housing Corporation (CMHC) require the provision of openings on the surface of roofing envelopes so as to effectively cross-ventilate attic space between ceiling joists and roof rafters. $F B C$ R4409.13.3.2, for instance, recommends for approved mechanical ventilation systems having a total opening area of at least $1 / 150^{\text {th }}$ of that of the attic floor. To satisfy this requirement, the study model was equipped with different type of vents. The type, size and porosity ratio of each ventilation 
openings is given in Tables 2.1 and 2.2. Commercially available and Miami Dade County approved Goose neck, Turbine and ridge vents were installed as shown in Figure 2.3. For the soffit openings, a bird/insect screens with mesh sizes of $6.35 \mathrm{~mm}(1 / 4 \mathrm{inch})$ were installed two at each side of the eave of the wooden building. The test building was compartmentalized horizontally by a ceiling at $2.13 \mathrm{~m}$ (7ft) from the ground and vertically with a folding-wall along the wider length of the building.

A rectangular ceiling hatch opening, common in low-rise residential buildings, with a $0.46 \mathrm{~m}$ (1.5ft) by $0.47 \mathrm{~m}(1.54 \mathrm{ft})$ dimension was also provided. The test building model was constructed to represent a house with tight connections. For example, rubber pads were provided to all door and window jambs in order to reduce the leakage of air through the door/window and wall interface.

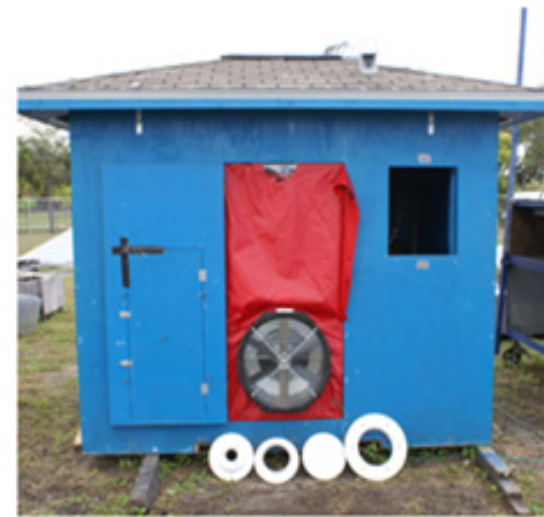

(a)

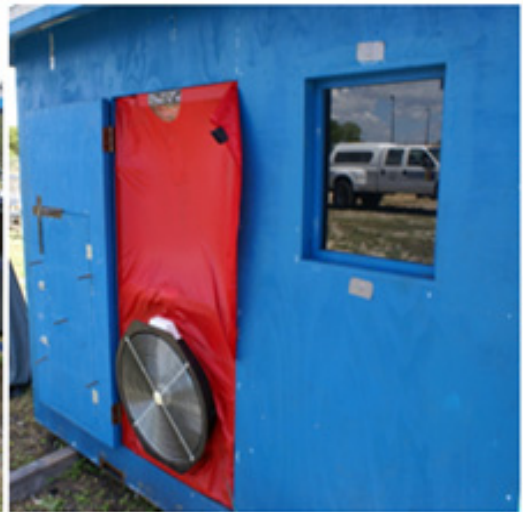

(b)

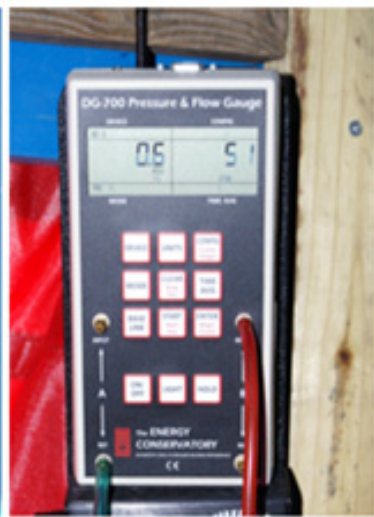

(c)

Figure 2.4: Air leakage test using fan pressurization technique: a) model 3 fan with rings; b) test setup; c) DG-700 pressure gauge. 


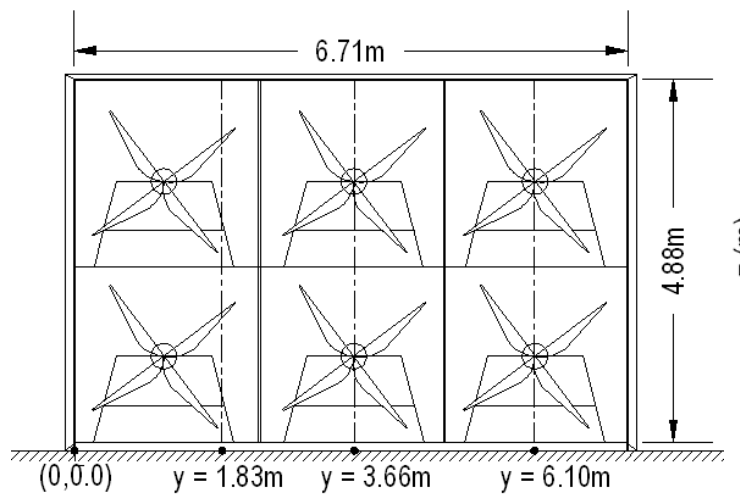

(a)

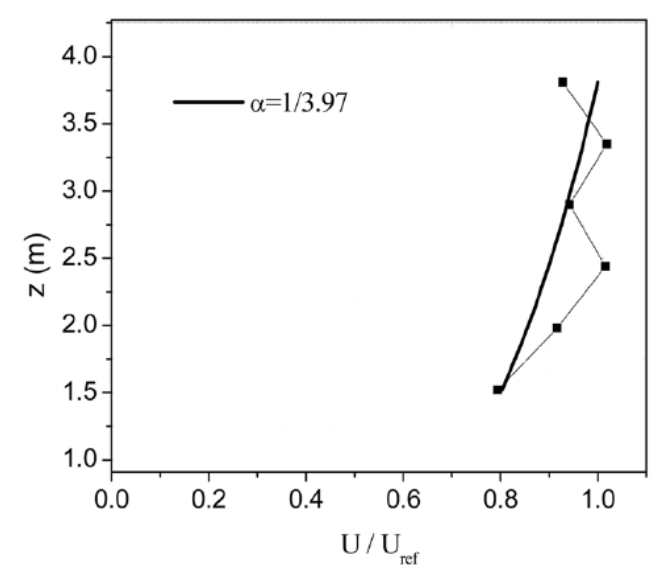

(c)

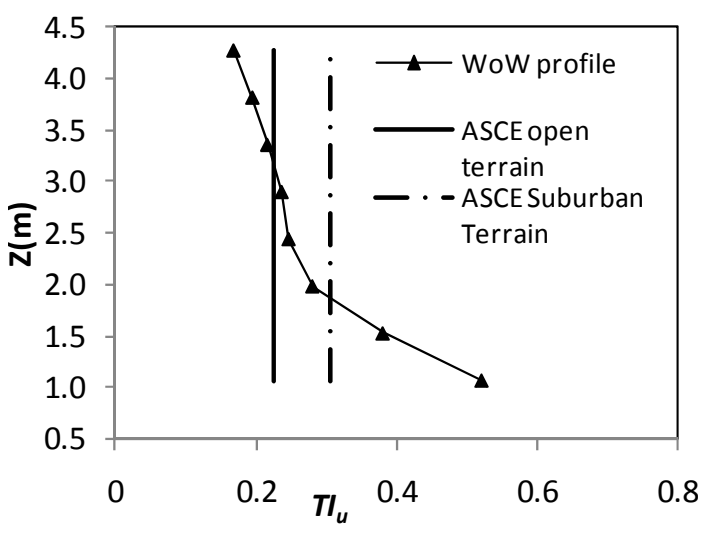

(e)

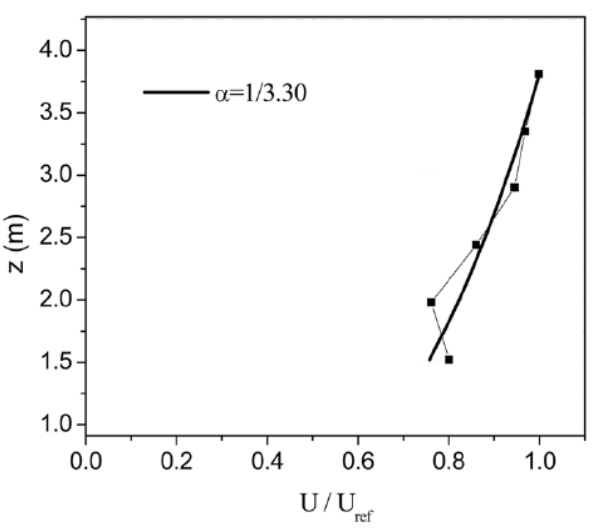

(b)

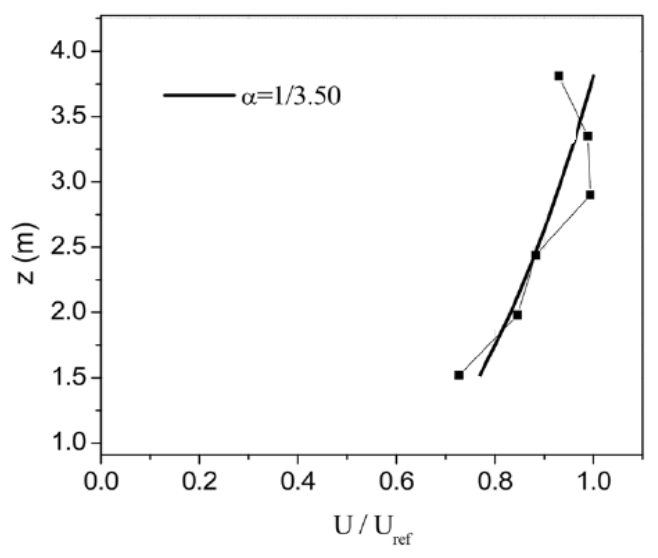

(d)

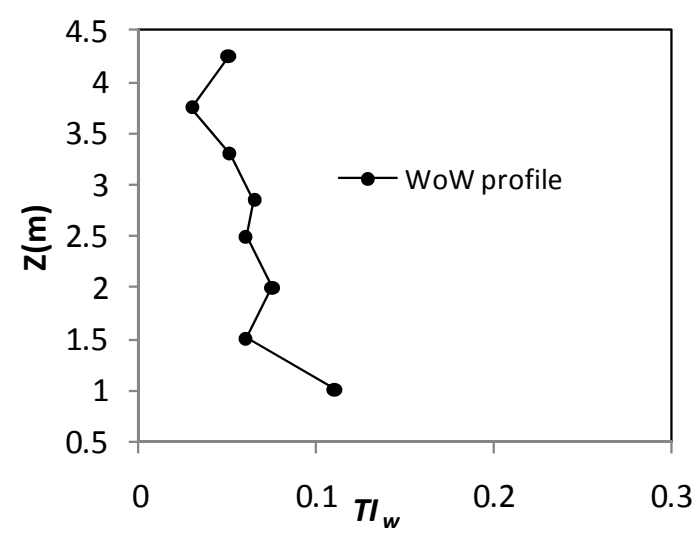

(f)

Figure 2.5: Full-scale 6-fan $W o W(\mathrm{a})$, non-dimensional mean velocity profiles at $\mathrm{y}=1.22 \mathrm{~m}--4$ $\mathrm{ft}-\mathrm{(b})$, at $\mathrm{y}=3.66 \mathrm{~m} \mathrm{--} 12 \mathrm{ft}--(\mathrm{c})$, at $\mathrm{y}=4.27 \mathrm{~m} \mathrm{--} 14 \mathrm{ft}--(\mathrm{d})$, and longitudinal (e) and vertical turbulence profile $(\mathrm{f})$ at $\mathrm{y}=3.66 \mathrm{~m}(12 \mathrm{ft})(\alpha=$ power law exponent). 


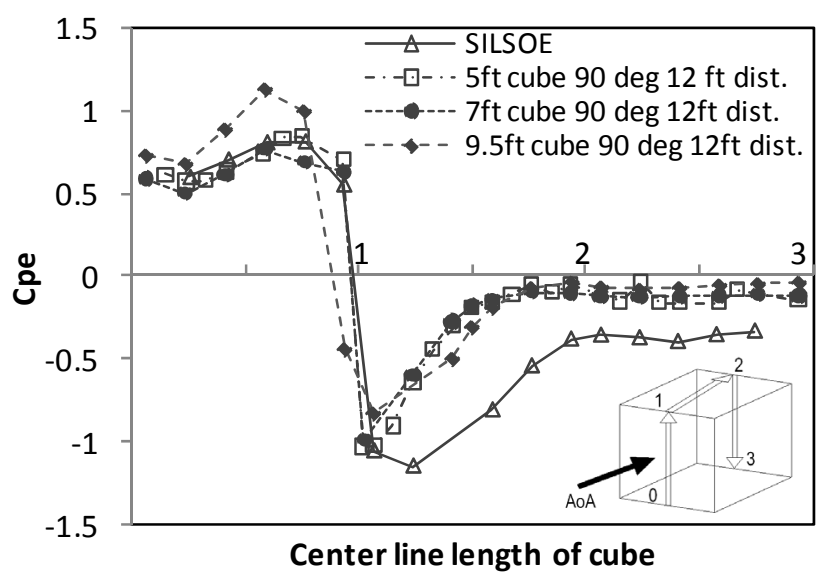

Figure 2.6: Comparison between full scale $W o W$ tests for $5 \mathrm{ft}, 7 \mathrm{ft}$ and $9.5 \mathrm{ft}$ cubes with data from Silsoe.

\subsubsection{Background leakage assessment}

Unlike the flow of air through doors and windows, background leakages can't be easily measured. A fan pressurization technique using Blower Door (Figure 2.4), commonly used for energy loss assessment studies was used in the present study. Blower Door measures the air tightness of a building envelope by either pressurization or depressurization technique. A series of fun pressurization tests were carried out for each specimen (i.e., gable and hip) to assess the air tightness of the building model and evaluate its influence on the internal pressure. In the present cases, the background leakage ratio was determined to be $2.76 \times 10^{-4}$.

\subsubsection{WoW wind field and blockage characteristics}

The building models were tested (Figures 2.1 and 2.5a) at mean wind speed $20.4 \mathrm{~m} / \mathrm{s}$ (45.6 mph) and turbulence intensity of $25 \%$ measured at $3.7 \mathrm{~m}(12 \mathrm{ft})$ distance from the fans and at eave height of the building i.e. at $2.18 \mathrm{~m}(7.16 \mathrm{ft})$ from the ground. The mean wind and turbulence intensity profiles are shown in Figures $2.5 \mathrm{~b}$ to $2.5 \mathrm{f}$. For more details on the wind flow generation methods refer (Huang, Mirmiran et al. 2009). 
Testing larger specimens within the finite $\mathrm{WoW}$ wind field, either to achieve Re similarity or to assess the performance of full-scale building components under wind, wind-driven rain, and debris impact resistance, may entail blockage issues. The major concern with the blockage effect was the size of the test specimen in relation to the finite size of the wind field generated by the $W o W$ at the inlet. The initial model size of the test building specimen was obtained through a computational blockage and proximity assessment simulation performed at the Wall of Wind (Bitsuamlak, Dagnew et al. 2009). Following this initial recommendation, an experimental blockage and proximity assessment tests were carried out in the $\mathrm{WoW}$ for the following three cube sizes: $1.52 \mathrm{~m}$ $(5 \mathrm{ft}), 2.31 \mathrm{~m}(7 \mathrm{ft})$, and $2.89 \mathrm{~m}(9.5 \mathrm{ft})$. Optimal size of the model was selected by comparing the results with Silsoe cube test (Richards, Hoxey et al. 2007). While the 1.52 $\mathrm{m}(5 \mathrm{ft})$ and $2.31 \mathrm{~m}(7 \mathrm{ft})$ cubes produced similar pressure distribution with the Silsoe cube for $90^{\circ} \mathrm{AoA}$, the $9.5 \mathrm{ft}$ cube results deviated both from the other cubes as well as the Silsoe cube as shown in Figure. 2.6. Particularly, the external pressure on the windward wall and the peak roof pressure for the $1.52 \mathrm{~m}(5 \mathrm{ft})$ and $2.31 \mathrm{~m}(7 \mathrm{ft})$ cubes were in good agreement with the Silsoe cube data while the results for the $9.5 \mathrm{ft}$ cube deviated. On the roof, however, the mean external pressures for all cases drop quickly when compared with Silsoe values which showed longer separation zone. This difference could be attributed to the relatively higher turbulence and higher wind speed used in the present study compared to the Silsoe model which is located in open field. It was also observed that Silsoe measurements produced higher pressure coefficient $(C p)$ values on the leeward walls when compared to literature values such as those observed from Texas Tech full-scale measurements (Levitan and Mehta 1991). 

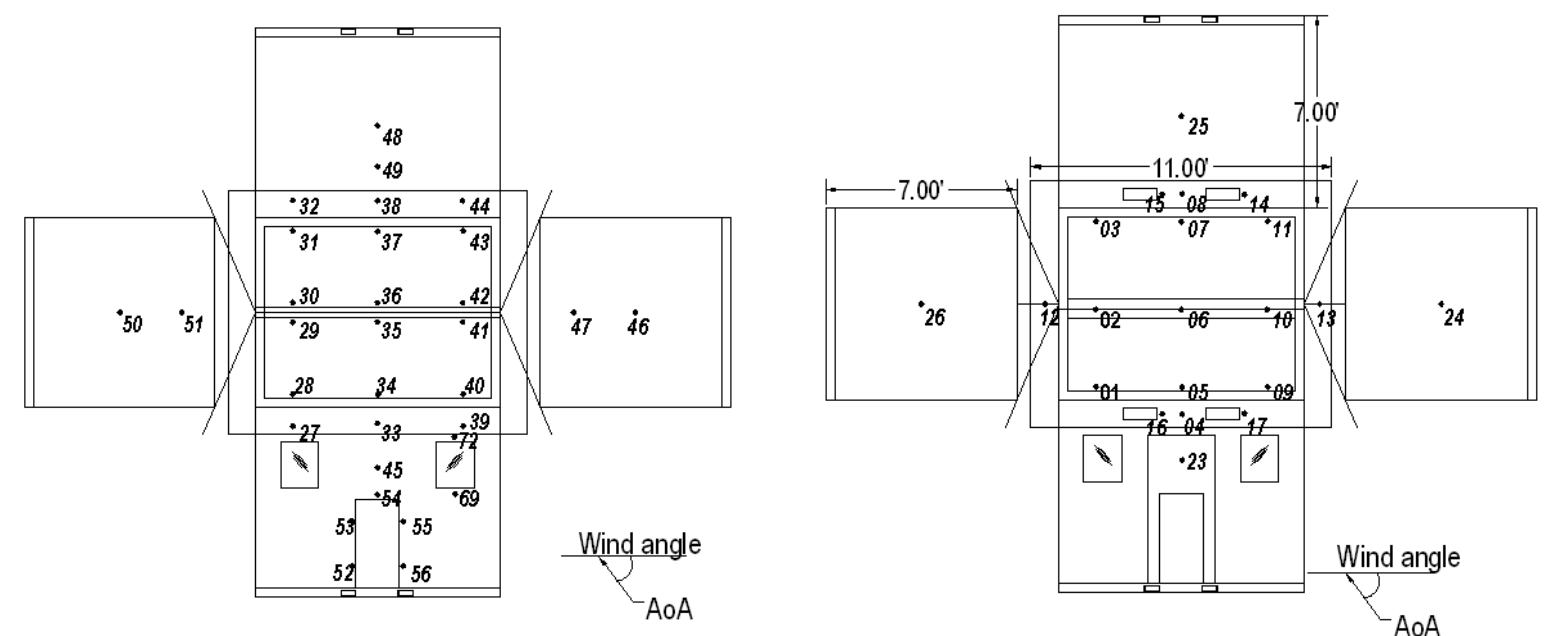

Figure 2.7: Exploded plan view of gable roof external pressure (left) and internal pressure (right) tap layout.
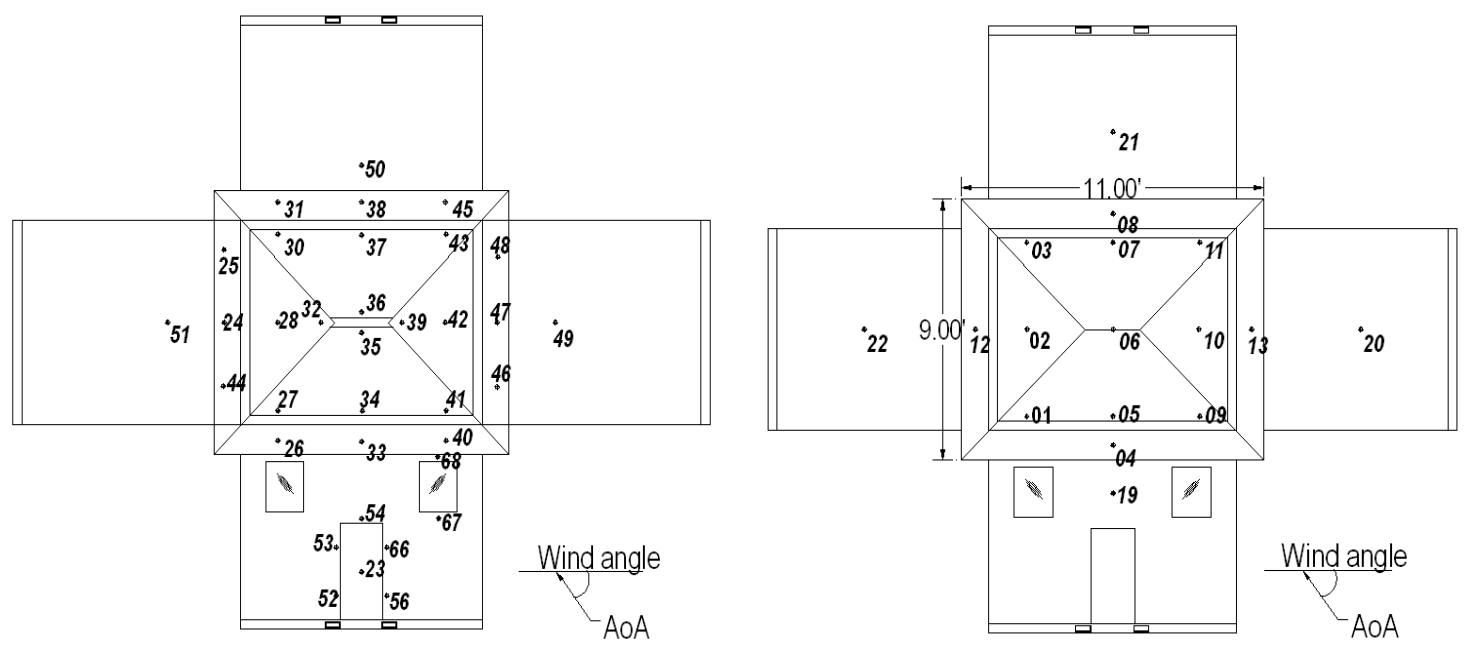

Figure 2.8: Exploded view of hip roof external pressure (left) and internal pressure (right) tap layout. 

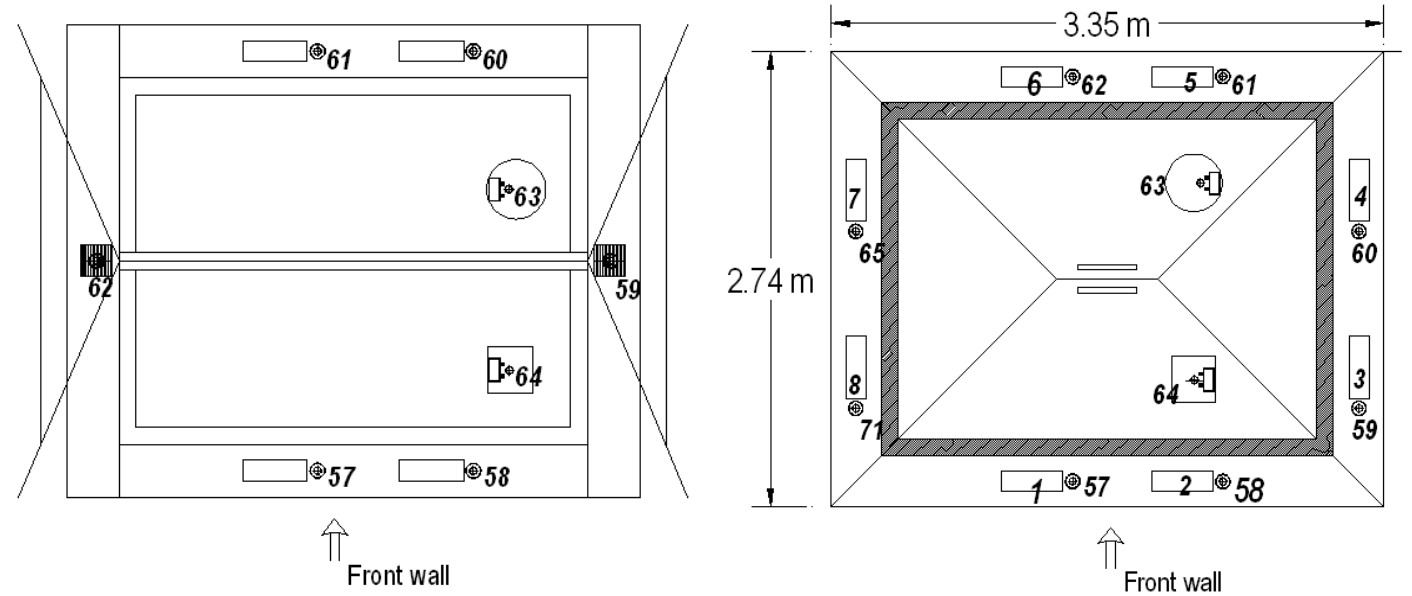

Figure 2.9: Ventilation openings pressure tap layout: gable (left) and hip (right).

\subsubsection{Pressure tap layout}

In order to capture external and internal pressure variation on the test building with gable roof, a total of 68 differential SETRA transducers were distributed as shown in Figure 2.7. A total of 34 pressure transducers were installed along the longitudinal and transverse center line of the building envelope to capture external pressure distribution. Similar tap layout was used on the hip roofs. Additional pressure taps were placed at the periphery and center of each dominant opening (a middle door and an upstream edge window) to obtain a reasonable estimate of external pressures at these locations. To measure the internal pressure, a total of 31 pressure transducers were uniformly installed in the living room and the attic (Figure 2.7). As shown in Figure 2.9, the internal and external pressures around the ventilation system were also recorded. Similarly, the distribution of external and internal pressure tap layout for the hip roof model is illustrated in Figures $2.8 \& 2.9$. The pressure signals from all taps were sampled at a rate of $100 \mathrm{~Hz}$ for 180 seconds. 
Table 2-3: Summary of test cases for gable roof.

\begin{tabular}{|c|c|c|c|c|c|c|c|}
\hline AoA & & $\begin{array}{c}\text { Dominant } \\
\text { opening }\end{array}$ & $\begin{array}{l}\text { Background } \\
\text { leakage }\end{array}$ & $\begin{array}{l}\text { Ceiling } \\
\text { hatch }\end{array}$ & Partition & $\begin{array}{l}\text { Vents: } \\
\text { ridge/soffit }\end{array}$ & Remark \\
\hline \multirow{5}{*}{$\begin{array}{l}0^{\circ}, 15^{\circ}, 45^{\circ}, \\
75^{\circ} \& 90^{\circ}\end{array}$} & Test 1 & - & $\checkmark$ & - & - & $\sqrt{ }$ & \multirow{3}{*}{$\begin{array}{c}\text { Envelope opening } \\
\text { combination }\end{array}$} \\
\hline & Test 2 & D1 & $\checkmark$ & - & - & $\checkmark$ & \\
\hline & Test 3 & W1 & $\checkmark$ & - & - & $\checkmark$ & \\
\hline & Test 4 & D1 & $\checkmark$ & $\checkmark$ & - & $\checkmark$ & \multirow{2}{*}{$\begin{array}{l}\text { Dominant opening \& } \\
\text { ceiling compartment }\end{array}$} \\
\hline & Test 5 & W1 & $\checkmark$ & $\checkmark$ & - & $\checkmark$ & \\
\hline
\end{tabular}

Note: Tests 1,3 and 5 were performed for additional $\mathrm{AoA}=105^{\circ}$ and $120^{\circ}$

Table 2-4: Summary of test cases for hip roof.

\begin{tabular}{|c|c|c|c|c|c|c|c|}
\hline AoA & & $\begin{array}{c}\text { Dominant } \\
\text { opening }\end{array}$ & $\begin{array}{c}\text { Background } \\
\text { leakage }\end{array}$ & $\begin{array}{l}\text { Ceiling } \\
\text { hatch }\end{array}$ & Partition & $\begin{array}{c}\text { Vents: } \\
\text { ridge/soffit }\end{array}$ & Remark \\
\hline \multirow{7}{*}{$\begin{array}{c}0^{\circ}, 15^{\circ}, 45^{\circ} \\
75^{\circ} \& 90^{\circ}\end{array}$} & Test 1 & - & $\checkmark$ & - & - & $\checkmark$ & \multirow{3}{*}{$\begin{array}{c}\text { Envelope opening } \\
\text { combination }\end{array}$} \\
\hline & Test 2 & D1 & $\checkmark$ & - & - & $\checkmark$ & \\
\hline & Test 3 & W1 & $\checkmark$ & - & - & $\checkmark$ & \\
\hline & Test 4 & D1 & $\checkmark$ & $\checkmark$ & - & $\checkmark$ & \multirow{4}{*}{$\begin{array}{c}\text { Dominant opening } \\
\text { \& ceiling } \\
\text { compartment }\end{array}$} \\
\hline & Test 5 & W1 & $\checkmark$ & $\checkmark$ & - & $\checkmark$ & \\
\hline & Test 6 & W1 & $\checkmark$ & - & - & - & \\
\hline & Test 7 & W1 & $\checkmark$ & $\checkmark$ & $\checkmark$ & $\checkmark$ & \\
\hline
\end{tabular}

Note: Tests 2 and 3 were performed for additional $\mathrm{AoA}=105^{\circ}, 120^{\circ}, 150^{\circ}$ and $180^{\circ}$ 


\subsubsection{Test matrices}

Five test configurations were carried out for the gable roof as summarized in Table 2.3. For test case 1, all of the openings were closed except for the background leakage. Test case 2 represented a dominant opening scenario with door $\left(D_{1}\right)$ opened. Test case 3 represented another dominant opening scenario due to open window $\left(\mathrm{W}_{1}\right)$. $\mathrm{W}_{1}$ 's center line is at $(2 / 3) h$ from the ground (approximately coinciding with the stagnation point). Test case 4 was a combination of windward door $\left(D_{1}\right)$ and hatch opening scenario. Similarly, test case 5 was a combination of windward window $\left(\mathrm{W}_{1}\right)$ and hatch at the ceiling. The wind direction $90^{\circ}$ corresponds to the test case when the wind is normal to the wall containing the dominant openings.

For the hip roof building, seven test configurations were carried out as summarized in Table 2.4. The first five were similar to that of gable roof. Test case 6 was similar to that of test case 3 except that the vents were closed. Test case 7 was also similar to that of test case 5 except that wall partitioning was provided inside the building.

\subsection{Results and discussions}

The non-dimensional internal $\left(C_{p i}\right)$ and external pressure $\left(C_{p e}\right)$ coefficients at each pressure tap location were calculated by referencing measured pressures to the mean free stream dynamic pressure as:

$C_{p i j}=\frac{P_{i j}-P_{r j}}{\frac{1}{2} \rho \bar{U}^{2}}, \quad C_{p e j}=\frac{P_{e j}-P_{r j}}{\frac{1}{2} \rho \bar{U}^{2}}$ 
Where: $P_{i}$ and $P_{e}$ are the measured internal and external differential pressures, respectively at the $j^{\text {th }}$ tap; $P_{r j}$ is the mean ambient pressure before and after test; $\rho$ is air density taken as $1.225 \mathrm{Kg} / \mathrm{m}^{3} ; V$ is the mean wind speed measured at eave height of the building. The mean pressure coefficient for each tap was obtained by taking the average of the 3 minute recorded differential pressure:

$$
C_{p_{\text {mean }}}=\frac{1}{n} \sum_{i=1}^{n} C_{p i}
$$

Similarly, the peak positive and suction pressure coefficients were obtained from the time history data as shown in Eqn.3. The mean root square value of the pressure coefficient wa obtained by making use of the standard deviation of the pressure coefficient (Eqn.4):

$$
\begin{gathered}
\hat{C}_{p i}=\frac{\hat{P}_{i}-P_{r i}}{\frac{1}{2} \rho \bar{U}^{2}} \\
\widetilde{C}_{p i}=\sqrt{\frac{1}{2} \sum_{i=1}^{n}\left(C_{p i}-C_{p_{-} \text {mean }}\right)^{2}}
\end{gathered}
$$

\subsubsection{Gable roof}

A total of five test cases were performed for angles of attack of $0^{\circ}, 15^{\circ}, 45^{\circ}, 75^{\circ}$, and $90^{\circ}$. As shown in Figure 2.10(a) the internal pressure coefficient $\left(C_{p i}\right)$ reachs peak value for $75^{\circ} A o A$, for all test cases with dominant openings. The internal pressure coefficients for test case 1 (background leakage) were relatively uniform compared to all other cases studied. This implied that the impact of the background leakage alone on internal pressures was not that significant except for energy conservation purposes. Since the nominal background leakages were mostly due to window/door-wall interfaces, suction 
develop when a wall containing those openings is parallel with the wind direction. Peak positive internal pressure was observed as the building was rotated to $75^{\circ}$. The maximum internal pressure for the open door case were about 15 times higher compared to the closed case (i.e., $C_{p i}=0.139$ with only background leakage and $C_{p i}=2.2$ with open door). With window opening, the peak value became 20 times higher compared to the closed case. This attested the most common hurricane advisory, that of covering of doors and windows with shutters (or other means) during storms.
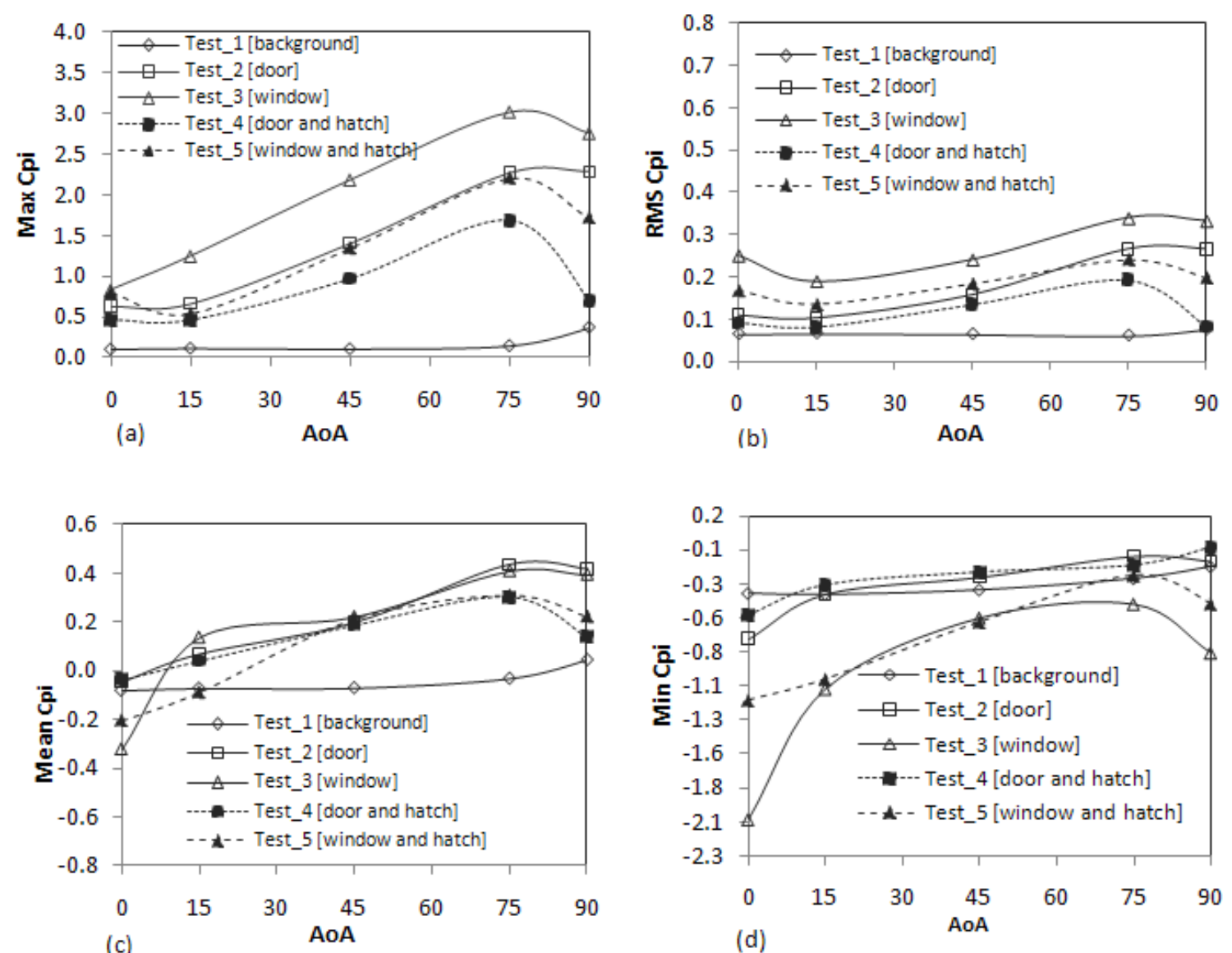

Figure 2.10: Internal pressure inside living room: (a) Maximum, (b) rms, (c) Mean and (d) Minimum $C p$ values for test cases 1-5. 


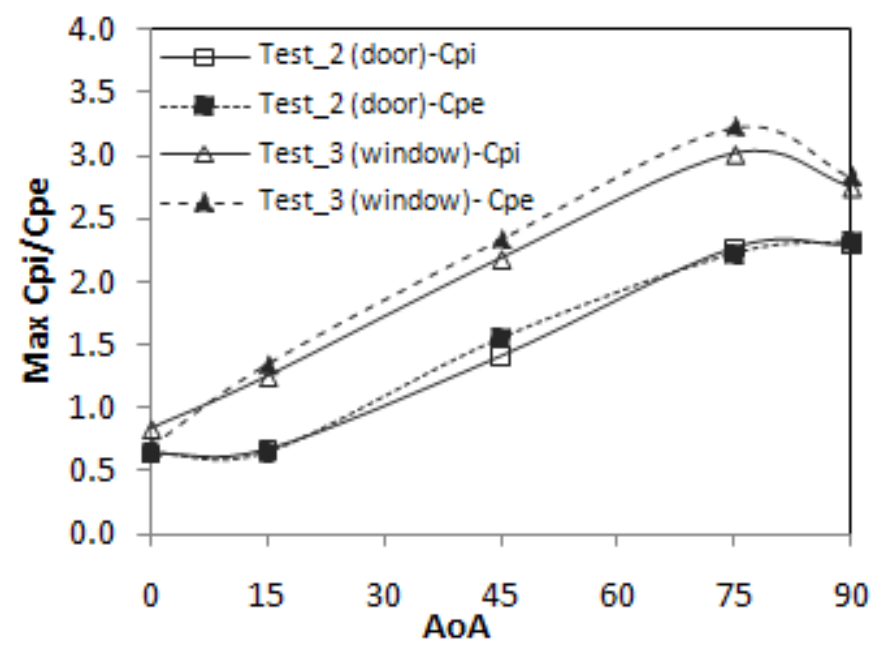

Figure 2.11: Correlation of internal pressure coefficients with area averaged external pressure coefficients.
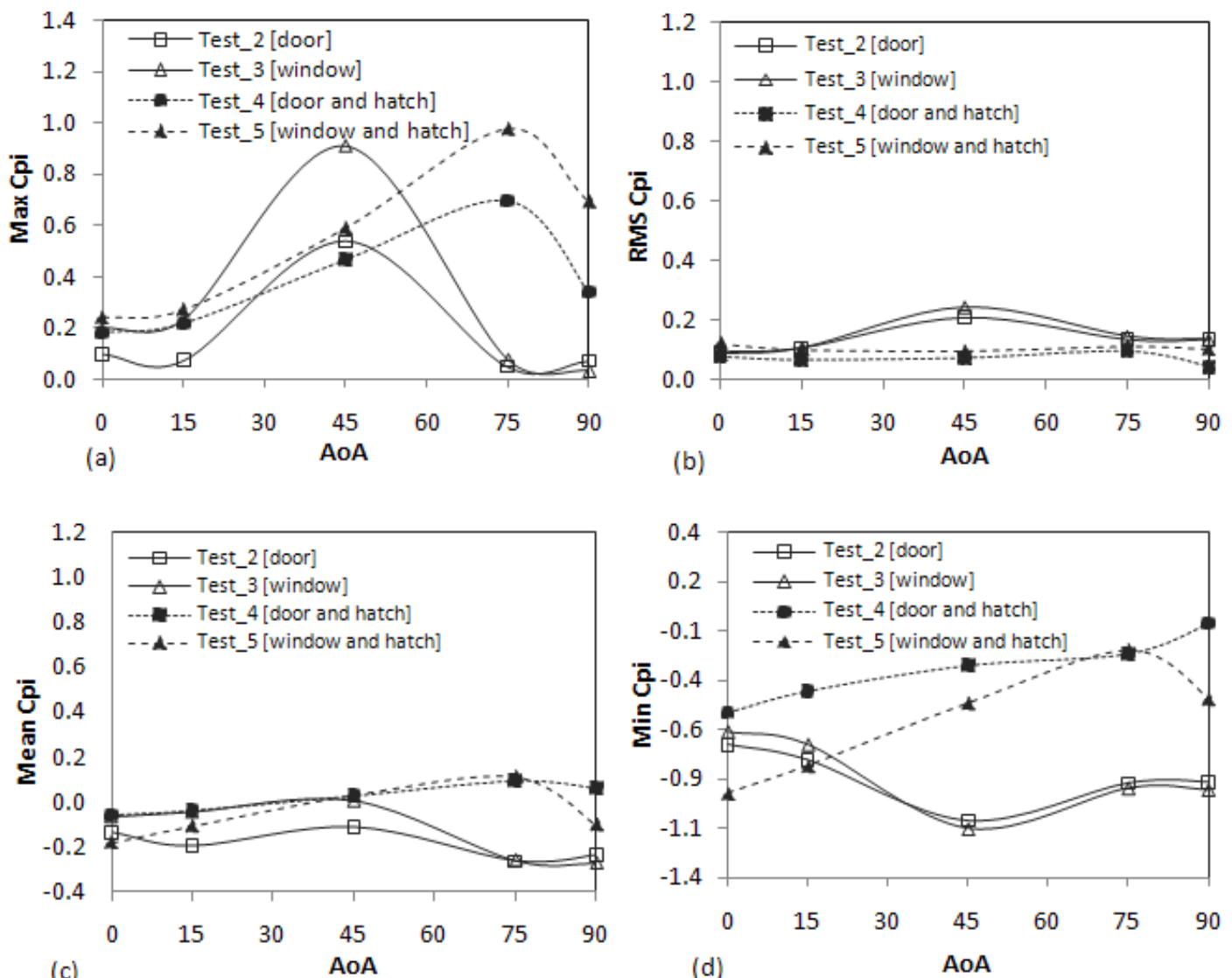

Figure 2.12: Internal pressure inside attic floor: (a) maximum, (b) $r m s$, (c) mean and (d) minimum $C p$ values for Test Cases 1-5. 
Compared to other test scenarios, test case 3 (i.e. window, W1, open case with $3.5 \%$ porosity) produced the highest positive and negative internal pressure coefficients as shown in Figure 2.10(a) and (d), respectively. Even though the porosity of the window was smaller compared to the door, the experiment result showed that the internal $C p$ value was comparatively higher. This may be attributed to: i) location of the window is at a higher elevation from the ground compared to the door, where the window coincided with the stagnation point where the maximum external pressure developed; ii) the relative distance of the two dominant openings from the upstream wall corner. The open window was closer to the upstream edge of the windward wall $(0.29 \mathrm{~m}(0.95 \mathrm{ft})$ from upstream wall corner. The upstream edge experienced high separation flow and it was in a higher

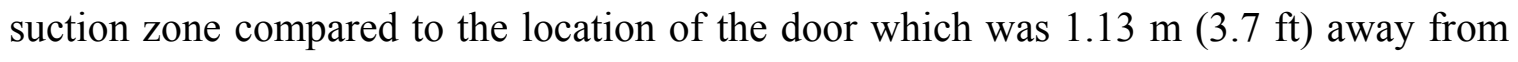
the edge. This was also inferred from the examination of the coefficient of external pressure that was measured along the periphery of the window and the door, as shown in Figure 2.11.

The effect of compartmentalization for different types of openings was shown in Figure $2.12(\mathrm{a}-\mathrm{d})$. When the hatch (connecting the living room with the attic) was closed, the volume of the gable living room was $V_{l}=12.7 \mathrm{~m}^{3}\left(609127 \mathrm{in}^{3}\right)$, while the attic floor accounts for an approximate volume of $V_{a}=1.54 \mathrm{~m}^{3}\left(95992 \mathrm{in}^{3}\right)$. This represents a $13.6 \%$ volume increase to the living room when the ceiling hatch was opened. The hatch opening resulted in a surge in the attic internal pressure and a damping effect inside the living room compared to the closed hatch case. Thus, the internal pressure inside the living room decreased for open hatch case along with the open door (Test_4) as well as 
with the open window (Test_5) cases. The peak internal pressure coefficient in the living room for an open door case with closed hatch was higher compared to open hatch by $25 \%$. An open window case with closed hatch produced peak value, that is $27 \%$ higher compared to that of an open hatch.

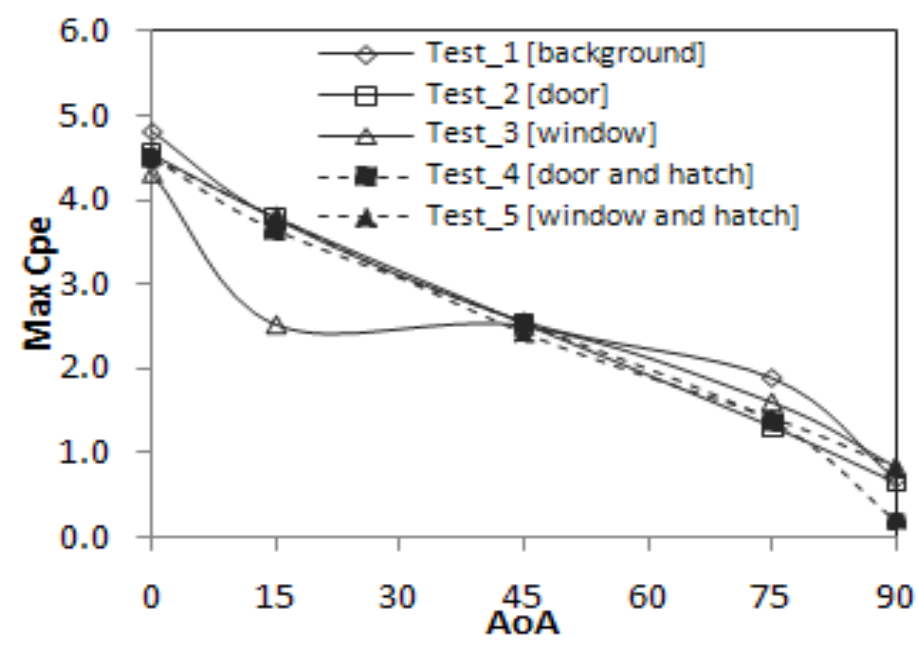

Figure 2.13: External pressure variation: side gable vent.

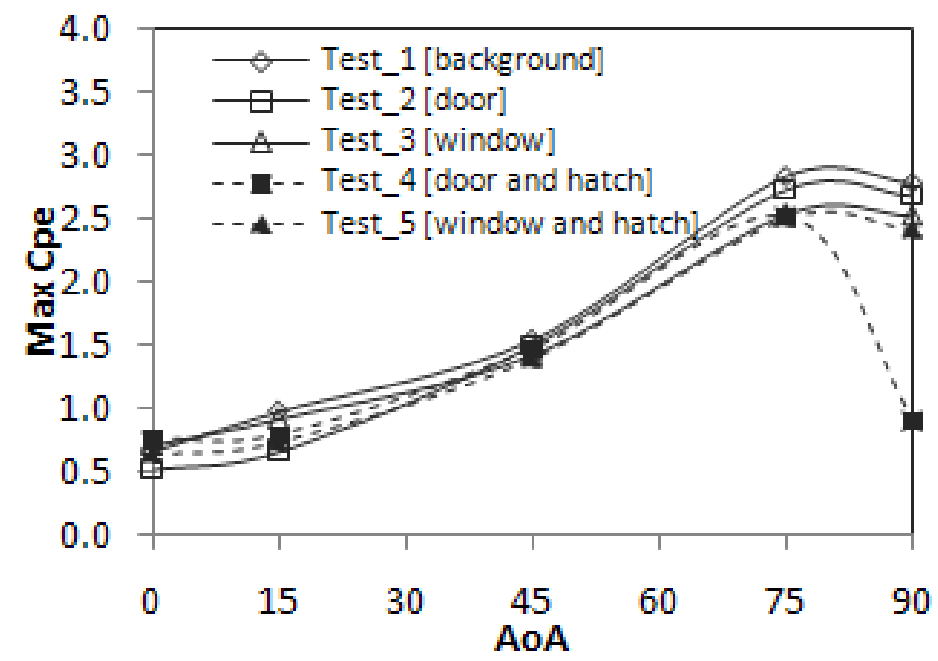

Figure 2.14: External pressure variation for: front soffit vents. 


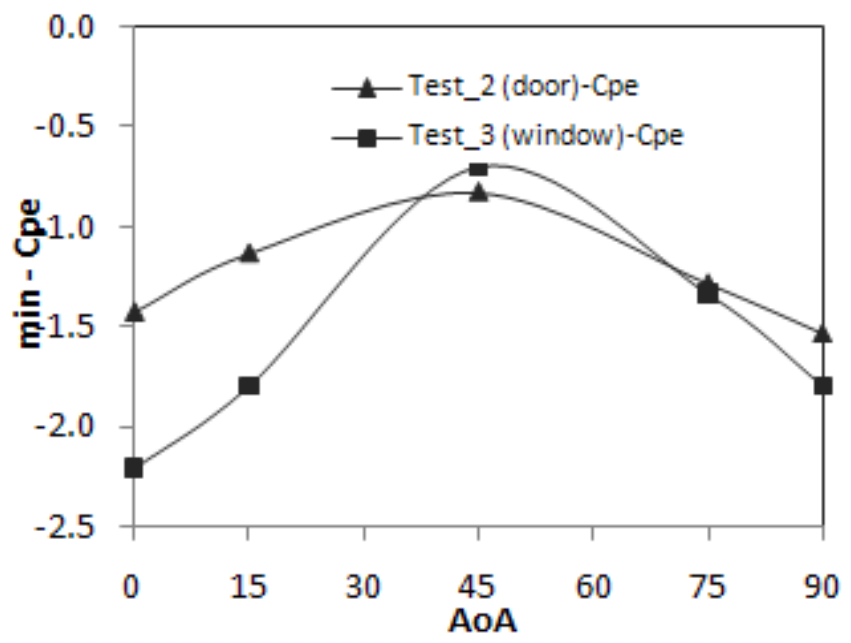

Figure 2.15: External pressure coefficient at the openings of the living room (area averaged).

Unlike the internal pressure fluctuations inside the living room, the pressure distribution inside the attic exhibited two peak points. As shown in Figure 2.12 (a-d), the peak positive internal pressure coefficient occured at about $45^{\circ} \mathrm{AoA}$ when only door or window was opened (i.e., test cases $2 \& 3$ ). The peak value shifted to $75^{\circ} A o A$ when either the door or window with ceiling hatch was opened at the same time (i.e., test cases 4 and 5, respectively). This demonstrated the effect of horizontal compartmentalization. The attic internal pressure was also affected by ventilation openings (such as gable end, turbine, goose neck and soffit vents). The attic internal pressure was governed mostly by the infiltration of air through the front and rear soffit, left and right side gable-end ventilation system. The contribution of gable-end vent was significant when the building model was at $0^{\circ} A o A$ (i.e., wind perpendicular to the gable-end vent). The gable-end vent was located at higher elevation and this contributed for the formation of higher positive pressure. The louver frames of the gable-end vent also helped the wind to cascade directly into the attic. However, as the wind changed to oblique direction, its impact reduced gradually as shown in Figure 2.13. At the same time, the contribution of the front 
soffit began to build up as the model was rotated (Figure 2.14) in which case the wall containing the dominant openings and the front soffit vent faced the $W o W$. The suction external pressure coefficient at the door or window was significantly higher at $0^{\circ} A o A$ with $C_{p e}=-1.5$ for test case 2 (open door) and $C_{p e}=-2.2$ for test case 3 (open window). A decrease to $C_{p e}=-0.75$ occurred when the building was rotated to $45^{\circ}$. Beyond $45^{\circ}$, the suction increased again forming a bell shaped curve as shown in Figure 2.15. For test cases 4 (open door and hatch) and 5 (open window and hatch), the trend of attic internal pressures differed from that of test cases 2 (open door only) and 3 (open window only). At critical wind $A o A$ (i.e., $75^{\circ}$ ), the hatch opening caused the propagation of the pressure from the living room to the attic, resulting in a higher internal pressure in the attic while dampening the internal pressure in the living room. There was an increase in $C_{p i}$ from 0.08 (Test_2) to 0.7 (Test_4) and from 0.08 (Test_3) to 1.0 (Test_5), as depicted in Figure 2.14. This showed how much surge in positive internal pressure resulted on roof sheathing due to opening links such as ceiling hatch. Since the peak external pressure at the windward wall occurred at about $75^{\circ} \mathrm{AoA}$, the attic internal pressure also followed the same trend and reached its peak value at the same wind $A o A$. The peak positive internal pressure inside the attic was comparatively less when the hatch was closed. In this case the internal pressure development was mainly due to the ventilation openings (gable end, goose neck, turbine, soffit vents) combined.

From the point of view of cladding net wind load (i.e. combined external and internal pressure), the magnitude of the internal pressure that developed inside the attic roof was more important as it leads to an increased peak wind load on the roof sheathing. Thus, it 
is preferable to seal ceiling hatch during storms. For example, test 5 (open window with open ceiling hatch) lead to $45 \%$ increase on the net wind load on the windward side of the gable roof compared to test 3 (open window but with closed hatch). This reinforced the need to keep doors, windows and hatches secured with shutters during strong hurricanes. This also indicated the importance of compartmentalization and volume matching during internal pressure tests that usually is missing from small-scale testing. The other importance of proper volume scaling is explained through Helmholtz resonance. Holmes (1979) represented the dynamics of internal pressure by a time dependent non-linear oscillation equation (5). The non-linear numerical equation was used to compute the Helmholtz resonance as given in eqn. (6):

$$
\begin{aligned}
& \frac{\rho_{e} V_{o}}{\gamma A P_{o}} \ddot{C}_{p i}+\frac{\rho V_{o}^{2} U_{H}}{2 k^{2} \gamma^{2} A^{2} P_{o}^{2}} \dot{C}_{p i}\left|\dot{C}_{p i}\right|+C_{p i}=C_{p e} \\
& f_{h h}=\frac{1}{2 \pi} \sqrt{\frac{n A P_{o}}{\rho l_{e} V_{o}}}
\end{aligned}
$$
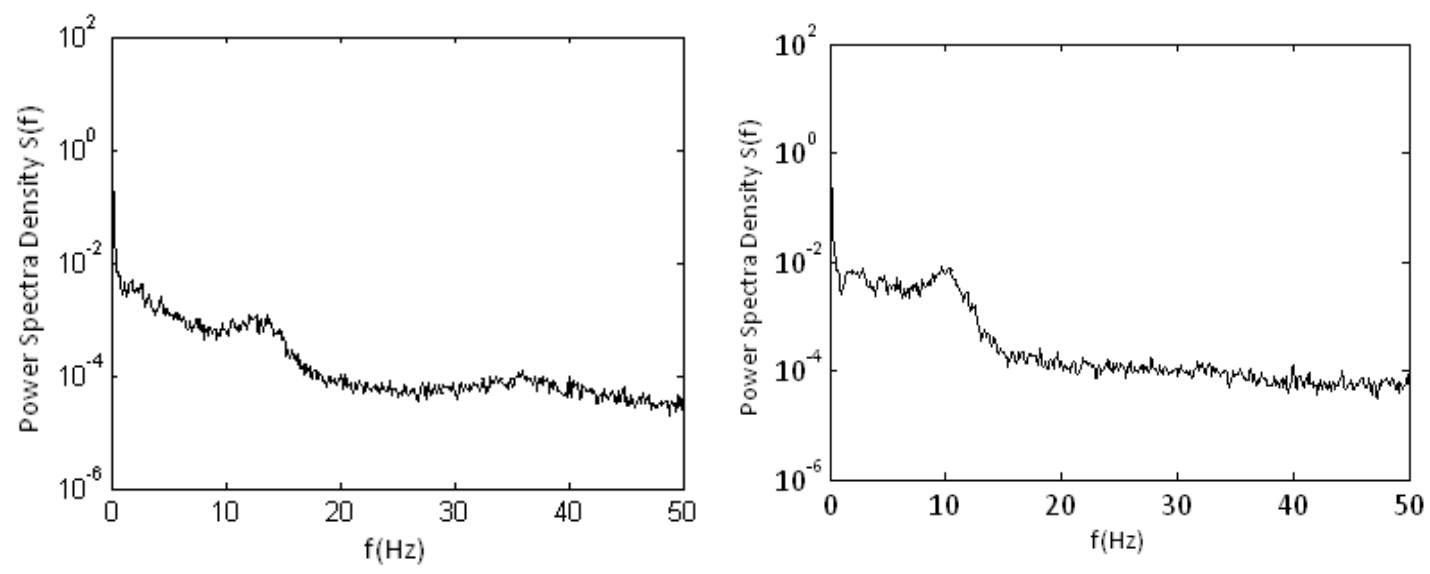

Figure 2.16: Power Spectra of Internal pressure for door opening (left) and window opening (right). 

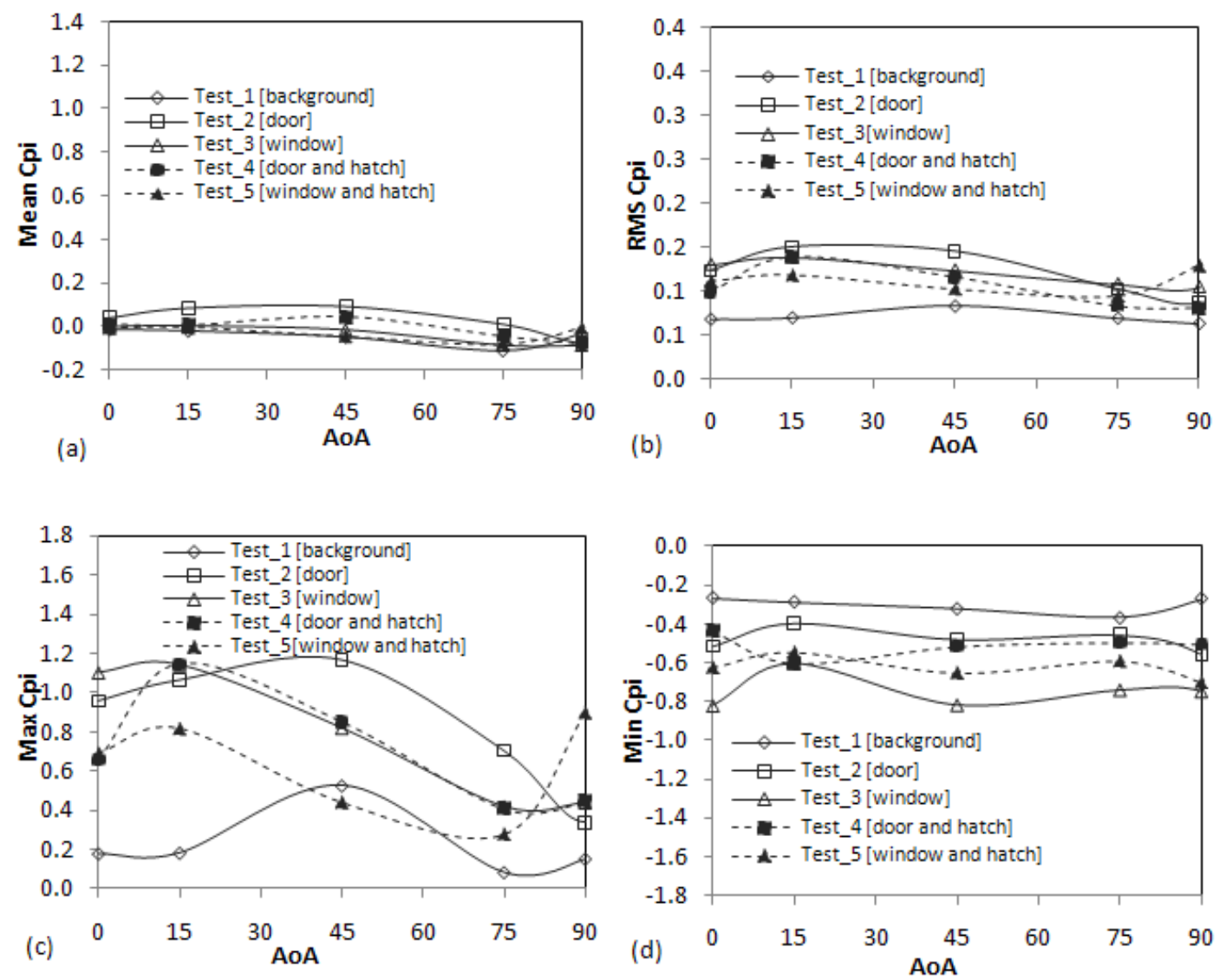

Figure 2.17: Hip roof living room coefficient of internal pressure: a) Mean, b) RMS, c) Maximum, and d) Minimum values.

The values of the parameters for the gable roof low-rise building considered in this section were as follows: $\gamma=1.4$ (ratio of specific heat for air; adiabatic condition is considered); $A=0.439 \mathrm{~m}^{2}$ for door and $0.219 \mathrm{~m}^{2}$ for window; $P_{o}=101284.6 \mathrm{~Pa}$ in Miami area; $\rho=1.25 \mathrm{Kg} / \mathrm{m} 3$, air density; $L_{e}=L_{o}+0.89 \sqrt{A}=0.6913 \mathrm{~m}$ (door) and $0.5181 \mathrm{~m}$ (window); $V_{i e}=9.982 \mathrm{~m}^{3}$ (living room only). Therefore, the measured Helmholtz frequency for dominant opening door case (i.e. $A=0.439 \mathrm{~m}^{2}$ and $L e=0.6913 \mathrm{~m}$ ) was $14.29 \mathrm{~Hz}$ and dominant opening window case $\left(A=0.219 \mathrm{~m}^{2}\right.$ and $\left.L e=0.5181 \mathrm{~m}\right)$ was $11.03 \mathrm{~Hz}$. 


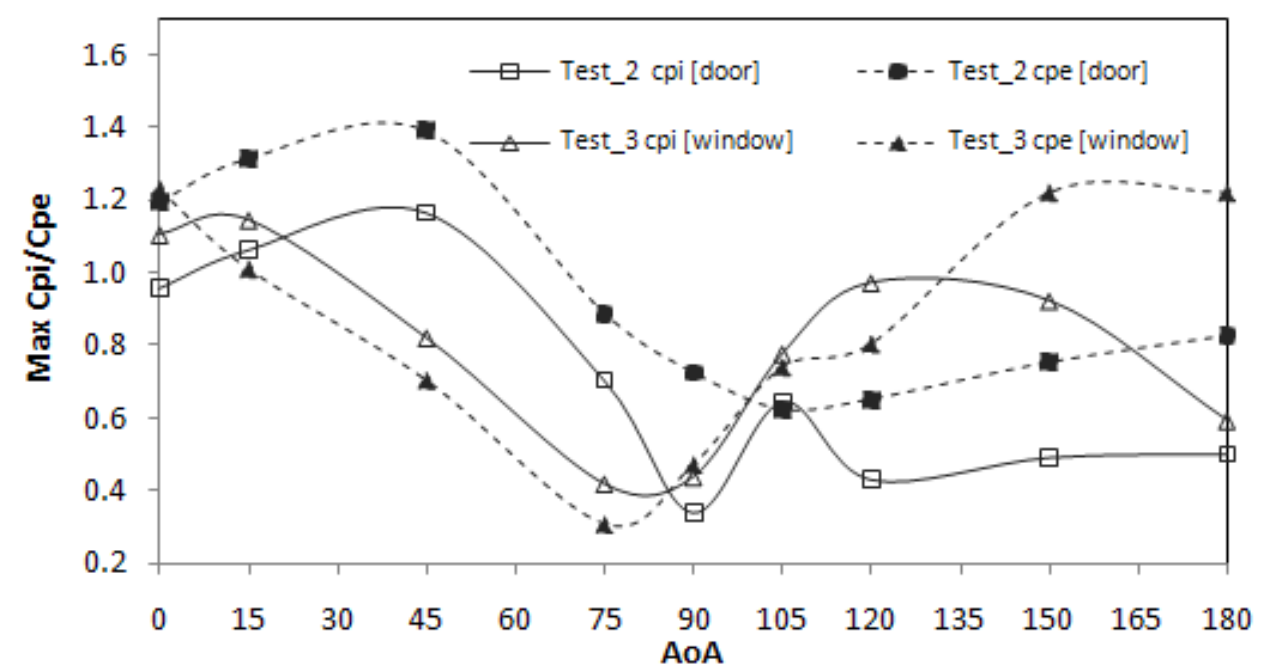

Figure 2.18: Maximum internal and external pressure distribution for test cases 2 and 3.

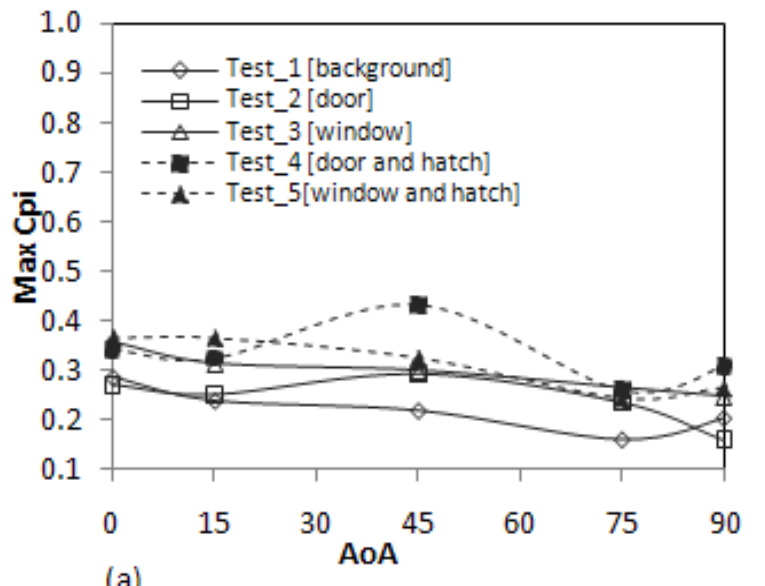

(a)

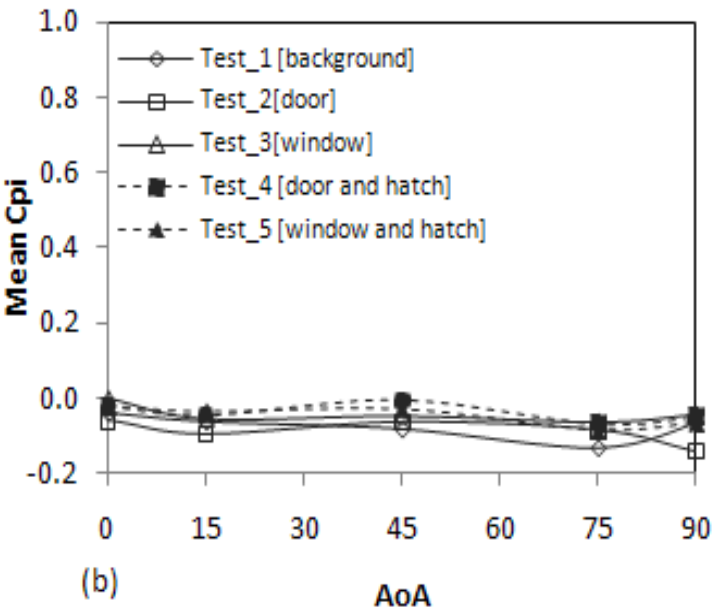

(b)

AoA

Figure 2.19: Attic floor coefficient of internal pressure: a) maximum, b) mean values.

As shown in Figure 2.16, the measured frequency for both the door and window opening cases were in good agreement with these analytically predicted values using Eqn. (6). The significance of Helmholtz resonance on internal pressure excitation was determined by considering the ratio of the rms values of the coefficients of internal and external pressure. When the ratio of the rms value exceeded unity, the Helmholtz resonance was said to be significant (Holmes 1993, Liu 1983 and Sharma 2007, Kopp et al 2008). In this 
project, the peak ratio was 1.05 for a window opening case at $90^{\circ} \mathrm{AoA}$. For the above specified living and attic volume and the area of the dominant openings, it is believed that the rms values of the internal pressure were mainly due to the external pressure variations since the peak ratio was close to 1 .

\subsubsection{Hip roof}

As shown in Table 2.4, a total of 7 test cases were performed for hip roof case. Figure 2.17 depicted the mean, rms, max. and min. of internal pressure coefficients $\left(C_{p i}\right)$ for the five test cases performed (i.e., background leakage only, $7.5 \%$ door opening, 3.75\% window opening, door and hatch, window and hatch). The values given represented only for the living room volume. The rms of the internal pressure was higher when the door or window with ceiling hatch was opened. Comparatively, the $C_{p i}$ was higher when only the door or window was opened similar to that of gable roof. This was because the ratio of the volume to the dominant opening area (i.e., V/a) increases as the ceiling hatch was opened. As the ratio increased, the rms value inside the living room decreased. The same trend was observed for the max. and min. $C_{p i}$ values as shown in Figure $2.17 \mathrm{c} \& \mathrm{~d}$. Unlike gable roof, the internal pressure inside the living room was higher for the open door case compared to the open window case for angles of attack ranging between $0^{\circ}$ and $90^{\circ}$. Beyond the $90^{\circ} \mathrm{AoA}$ (i.e., wind flowing at oblique angle, the living room $C_{p i}$ for the open window case was larger (Figure 2.18). This was believed to be due to high turbulence and suctions closer to the leading edge of the wall, where the windows were located. Another observation was that the peak positive internal pressures tend to occur at about $45^{\circ}$ and $105^{\circ} \mathrm{AoA}$ for the door opened case, and at about $15^{\circ}$ and $135^{\circ} \mathrm{AoA}$ for the 
window opened case (Figure 2.18). Similar to the gable roof, the hip roof building was compartmentalized by separating the living room from the attic using a ceiling partition. A ceiling hatch of the same size as that of the gable building was used. The open hatch test case led to internal pressure propagation from the living room to the attic floor, resulting in high internal pressure inside the attic and reduced internal pressure inside the living room.
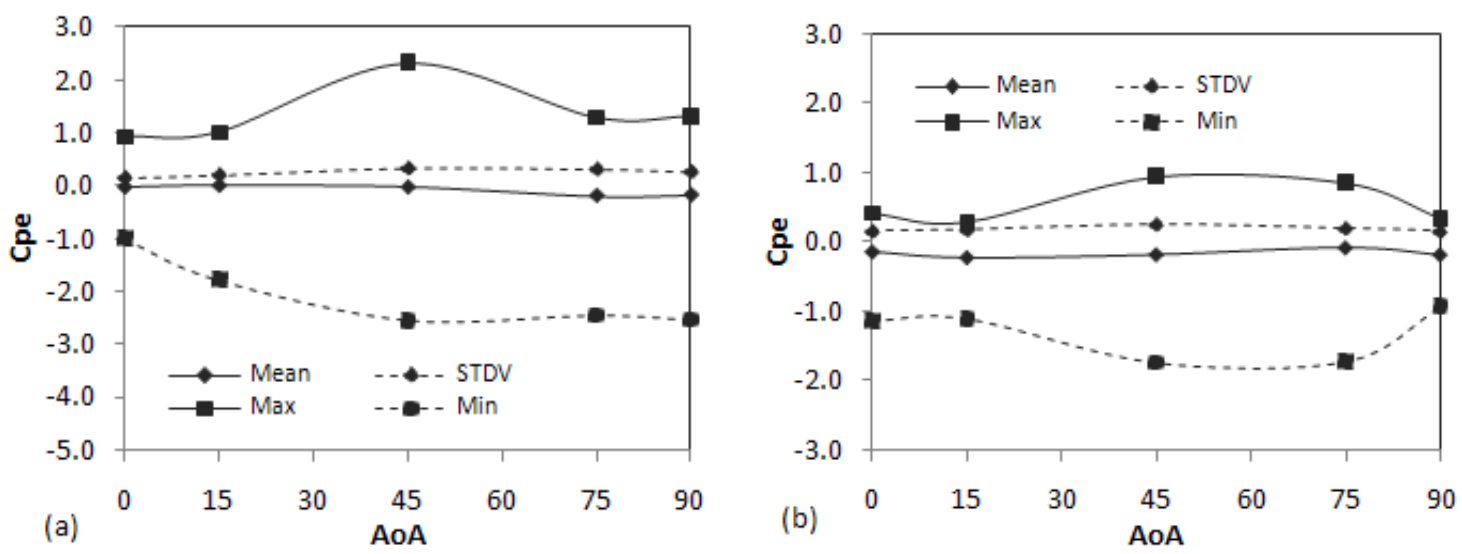

Figure 2.20: External pressure contribution of soffits: a) soffit No.1 \& b) soffit No.4.

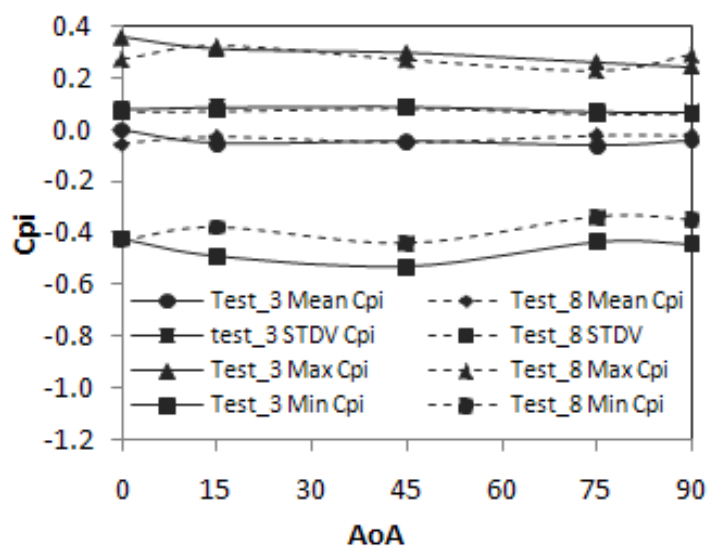

Figure 2.21: Attic internal pressure with vent (Test_3) and without ventilation (test_8) opening.

The decrease was due to the dampening effect of the increased volume created by the opening of the ceiling hatch (living room volume + attic volume) as discussed for the gable roof case. 
Attic floor internal pressure distribution analysis was performed by taking the average pressure obtained from the three center line transducers located underneath the roof sheathing along the length of the building (i.e., taps number 02,06 , and 10 as shown in Figure 2.8). As described previously, the attic floor contains vents (i.e., soffit, ridge, turbine, and goose neck vents). The presence of these vents had significant influence on the internal pressure inside the attic floor depending on the location of the vents and the direction of the wind. As depicted in Figure 2.18, it was observed that a $45^{\circ} \mathrm{AoA}$ caused peak positive coefficient of internal pressure $\left(C_{p i}=0.43\right)$ for door opened case with ceiling hatch. The mean internal pressure inside the attic floor was below zero for all of the wind angles of attack (between 0 and -0.13). For test case 2 (open door only) and case 3(open window only), the peak positive internal pressure fluctuation ranged between 0.25 and 0.35 as shown in Figure 2.19a. The reason for the peak attic internal pressure measured at a $45^{\circ} \mathrm{AoA}$ was attributed to: (i) the wide hip roof building surface area on which the wind acted and (ii) the positive pressure channeled by the four soffit vents (No.1, 2, 3, and 4), as shown in Figures 2.9 and 2.20. The same pattern was observed when the building was positioned at about $135^{\circ}$, wherein which the soffit vents (No. 1, 2, 7, and 8) played a significant role in generating positive pressure inside the attic floor. The effect of the ventilation openings on the attic internal pressure was studied by performing two separate tests on the hip roof building model: one test while the ventilation system (ridge vent, soffit, turbine and goose neck) left to operate and the other by blocking these vent openings completely. As shown in Tables 2.1 and 2.2, the soffit porosity ratio was larger than the other vents on the roof surface. Two rectangular openings with size $0.11 \mathrm{~m} \times 0.365 \mathrm{~m}$ (4.375 in by $14.375 \mathrm{in})$ were used in each overhang 
(the total number of openings being eight), as depicted in Figure 2.9. The presence of the ventilation openings slightly increased the positive internal pressure that developed inside the attic floor and significantly increased the negative pressure (Figure 2.21). Due to the location of the vents, which was mostly on the part of the buildings that experience significant negative external pressures, the vents strengthened the negative internal pressure more than the positive internal pressures.

The relationship between the peak internal and external pressures in buildings was necessary for the assessment of design wind loads.
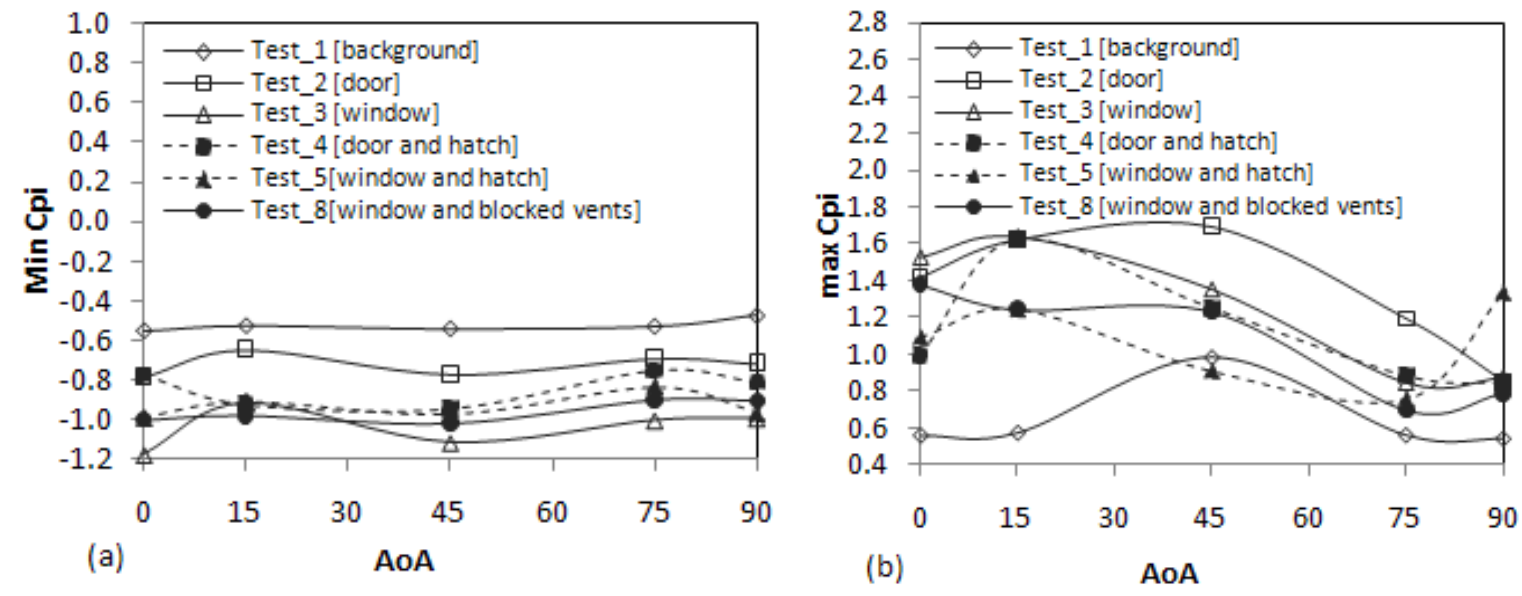

Figure 2.22: Pressure distributions at ceiling partition: a) Peak suction $\mathrm{C}_{\mathrm{p} i}$, and b) Peak positive $C_{p i \text {. }}$

The net effect of the external and internal wind pressure acting simultaneously in the same direction often cause overloading of the envelopes and hence could initiate failure under strong storms. For example, the external pressures that build up over the roof envelope coupled with the positive internal pressures that acted in the same direction 
generated a worst net pressure. Figure 2.22a-b depicted the results of the net internal pressure computation for each test case simulated with its respective wind $A o A$.

Figure 2.22(a) depicted the net suction internal pressure over the ceiling partition. It was observed that the peak suction pressure for test case 8 (window opening with all roof vents blocked) was critical at $0^{\circ} \mathrm{AoA}$.

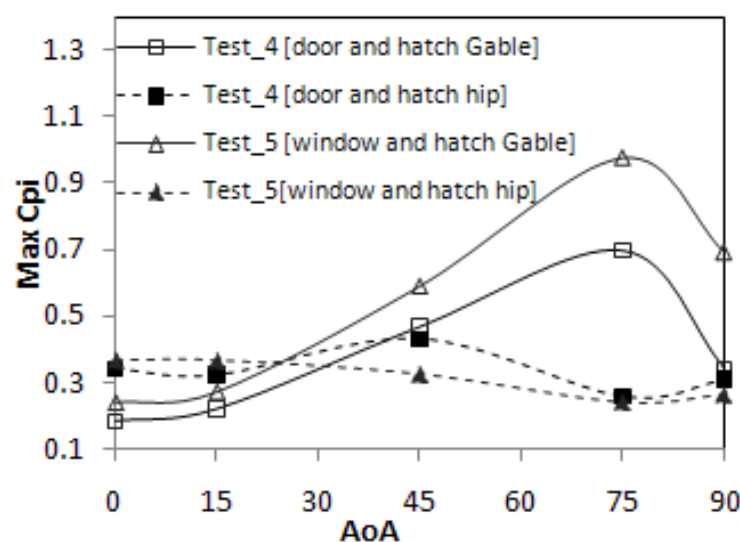

(a)

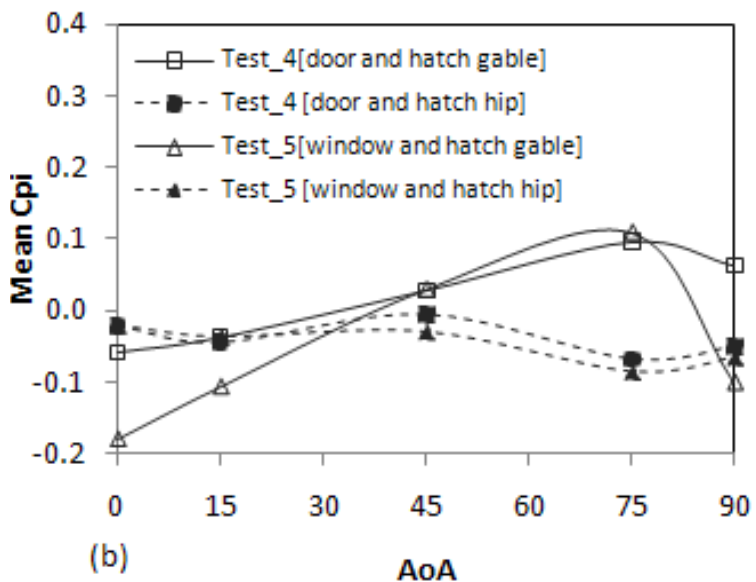

(b)

Figure 2.23: Gable and hip roof net pressure loading comparison.

Gable and hip roof experienced different net roof pressure which was attributed to shape and geometry variation. The net peak pressure that result from the net suction external and positive internal attic pressure was found to be $210 \%$ higher for gable roof compared to hip roof for door and hatch opened cases. The gable peak suction surged to $310 \%$ when window and hatch opened case was considered (Figure 2.23 a \& b).

\subsection{Conclusions}

Assessment of internal pressure of a building using a new-state of the art full-scale testing facility, the Wall of Wind ( $W o W$ ), was performed at the IHRC. The present study dealt with the inherent scale issue related to the internal volume, as well as those related with the Re and background leakage by testing a large building model constructed in 
accordance with prevailing construction practice and construction materials. The following observations were made as a result:

Similar to observations in literature, the intensity of the internal pressure is directly related to the size of dominant openings and their location with respect to the angle of attack. Peak positive internal pressures occurred when a dominant opening of the building faced the oncoming wind flow. Peak negative internal pressures occurred when a dominant opening of the building was parallel to the oncoming wind flow.

The intensity of internal pressure was highly dependent on compartmentalization and the presence of openings in the partitioning wall. For example, the opening of the window together with a ceiling hatch led to $45 \%$ increased net wind load on the windward side of the gable roof and a $20 \%$ increase for hip roofs. This reinforced the need to keep not only doors and windows covered with shutters during strong storms but also to secure hatch opening properly. The peak internal pressure for the gable attic was also higher than the hip attic for the study cases (by more than 190\%). Further, the worst net pressure coefficient at eave of gable roof was found out to be significantly higher compared to the hip roof.

Relative increases both in the negative and positive pressures have been observed due to the presence of vents (gable end, ridge, turbine, goose neck and soffits).

\section{Acknowledgments}

Support through IHRC's Florida Center of Excellence grant and Florida Department of Emergency Management are greatly acknowledged. Help received from our graduate and 
undergraduate research assistants was greatly appreciated. Support received from our Wall of Wind Research Scientists Walter Conklin, Roy Liu and James Erwin is greatly appreciated as well.

\section{$2.5 \quad$ References}

Bitsuamlak, G.T., Dagnew, A. and Chowdhury, A. (2009), "Computational assessment of blockage and wind simulator proximity effects for a new full-scale testing facility", Wind and structures. In press.

Cochran, L.S. and English, E.C. (1997), "Reduction of Roof Wind Loads by Architectural Features", Architectural Science Review. 40 79-87.

Davenport, A.G. and Surry, D. (1984). "The estimation of internal pressures due to wind with application to cladding pressures and infiltration". Proc., Wind pressure workshop, Brussels, Belgium.

Holmes, J.D. (1979). "Mean and fluctuating internal pressures induced by wind". Proc. 5th Int. Conf. on wind engineering, Colorado, USA.

Holmes, J.D. (2001), Wind Loading of Structures, Spon Press

Huang, P., Mirmiran, A., Chowdhury, A.G., Abishdid, C. and Wang, T. (2009), "Performance of Roof Tiles under Simulated Hurricane Impact", Journal of Architectural Engineering, ASCE. Vol. 15(1), 26-34.

Irwin, P.A. and Sifton, V.L. (1998), "Risk Considerations for Internal Pressures", J. Wind Engineering and Industrial Aerodynamics. 77 \& 78 715-723.

Karava, P., Stathopoulos, T. and Athienitis, A.K. (2007), "Wind-driven natural ventilation analysis", International Journal of the Solar Energy Society. 81 21-30. Levitan, M.L. and Mehta, K.C. (1991), Texas tech Field Experiments for Wind Loads Part II: Building and Pressure Measuring System, London, Ontario, Canada.

Lidament, M.W. (1986), Air infiltration calculation techniques - An applications guide. AIVC Document: AIC-AG-1-86.

Liu, H. (1990), Wind Engineering: A Handbook for Structural Engineers, Prentice Hall, USA

Liu, H. and Saathoff, P.J. (1981), "Internal pressure and building safety", Proceedings, J.Struct. Div., ASCE, 108. 
Liu, H. and Saathoff, P.J. (1983), "Internal pressure of multi-room buildings", $J$. Engineering Mechanics Division. 109(EM3), 908-919.

Oh, J.H., Kopp, G.A. and Inculet, D.R. (2007), "The UWO contribution to the NIST aerodynamic database for wind loads on low buildings. 3: Internal pressures", J. Wind Eng. Ind. Aerodyn., 95(8), 755-779.

Richards, P.J., Hoxey, R.P., Connell, B.D. and Lander, D.P. (2007), "Wind-tunnel modelling of the Silsoe Cube", Jnl. of Wind Eng. Ind. Aerod., 95 1384-1399.

Sharma, R.N. and Richards, P.J. (2003), "The influence of Helmholtz resonance on internal pressures in a low-rise building", Journal of Wind Engineering Industrial Aerodynamics. 91 807-828.

Sharma, R.N. and Richards, P.J. (2005), "Net pressure on the roof of a low-rise building with wall openings", J. Wind Eng. Ind. Aerodyn. . 93 267-291.

Simiu, E. and Scanlan, R.H. (1996), Wind Effects On Structures, John Wiley and Sons Stathopoulos , T., Surry, D. and Davenport, A.G. (1979). "Internal pressure characteristics of low-rise buildings due to wind action". In: Proc. 5th Int. Conf. on Wind Engineering, Fort Collins, Colorado.

Vickery, B.J. (1986), "Gust factors for internal pressures in a low rise buildings", Journal of Wind Engineering and Industrial Aerodynamics. 23 259-271.

Vickery, B.J. and Bloxham, C. (1992), Internal Pressure Dynamics with a Dominant Opening, London, Ontario, Canada. 


\title{
3. INTERNAL PRESSURE FOR A LOW-RISE BUILDING WITH EXISTING OPENINGS AND SUDDEN BREACHING
}

\author{
Amanuel S Tecle ${ }^{1}$, Girma T. Bitsuamlak ${ }^{2}$ \\ Submitted to Wind \& Structures Journal
}

\begin{abstract}
This paper deals with an investigation of the effect of variable porosity of dominant openings at different wind direction on both the steady state as well as the transient response (i.e., sudden breach) of wind induced internal pressure in low-rise building in a Boundary Layer Wind Tunnel $(B L W T)$. Peak pressure fluctuations in a transient overshoot during sudden door or window breach were studied along with the subsequent steady state internal pressure responses. A comparison of the $B L W T$ data with its respective full scale data from Wall of Wind $(\mathrm{WoW})$ and current $A S C E 7$ building code was carried out. The conclusions of this study can be summarized as follows: 1) In the presence of dominant openings and all round vent openings, leaving vents open during extreme wind events alleviate the load due to positive internal pressure. Closing ventilation openings, on the other hand, contributes to the buildup of positive internal pressure coefficient $\left(C_{p i}\right)$ underneath roof sheathing which on average $40-140 \%$ bigger than when it is opened depending on the porosity size of the dominant openings; 2) An opening located off-center exhibits higher peak positive and suction $C_{p i}$ than its equivalent dominant opening located at the center of the wall; 3) For critical loading, the location of the dominant opening with respect to upstream wind direction is highly significant compared to the porosity size effects for the study case; 4) The transient overshooting response was found to be lower than the subsequent steady state peak $C_{p i}$
\end{abstract}


consistently for all wind directions and porosity sizes examined; 5) during sudden breaching, correct internal volume scaling in $B L W T$ is necessary as cases without internal volume correction experiences a response 4 times faster and 30-40\% lower peak and mean $\left.C_{p i} ; 6\right)$. The comparison between the $B L W T$ and full scale $(W o W)$ internal pressure responses shows good agreement in both the peak and mean values; 7) The ASCE 7-10 significantly underestimates the peak positive internal pressure in all the configurations and building types considered.

Key words: Internal and external pressure, dominant openings, sudden breach, vents, compartmentalization, Helmholtz resonance, gable roof, hip roof, volume correction, Boundary Layer Wind Tunnel.

\subsection{Introduction}

The impact of wind storms on buildings and infrastructure have been escalating from time to time. Even though regulations and design provisions have been modified for their applications on buildings and infrastructure, the impact on economy and loss of life as a result of wind storms and the subsequent wind driven rain is still significantly high. Post hurricane investigations have shown that wind and wind driven rain caused extensive damage to building components and its premises (FEMA, $2003 \&$ 2005). This is attributed to the large suction external pressure that develops on the building roof envelope due to sharp separation of wind flows. Besides, internal pressure plays a significant contribution to the uplift force when door or window is left open due to either extreme pressure or wind borne debris (Holmes 1979; Simiu and Scanlan 1996; Irwin and Sifton 1998). For low-rise buildings, wind induced internal pressure can contribute a high proportion of the total design wind load, particularly in the presence of dominant 
openings (Holmes 1979; Stathopoulos et al. 1979; Holmes 2001). Thus, in the presence of dominant openings, the algebraic sum of the external and internal pressures are used assess the design wind loads on building envelope components such as walls, roofs, roof tiles, windows and doors. Even though the contribution of internal pressure to design wind load is significant, only few studies are available that explore the complex windbuilding interaction and sudden breakage characteristics (Holmes 1979; Stathopoulos et al. 1979; Liu and Saathoff 1981; Liu and Saathoff 1983; Vickery 1986). Unlike tall buildings, low rise-buildings are fully immersed within the layer of aerodynamic roughness where the turbulence intensities are high (Holmes 2001). Some of the governing factors that significantly influence the internal pressure responses are the shape of the building, the spatial variation of external pressure at the dominant opening, the geometries of the dominant openings, the size (i.e., porosity) and location of dominant openings (i.e., with respect to the incoming wind flow direction, acute vs obtuse angle) as well as the background porosity, ventilation opening sizes, internal volume and compartmentalization (both vertical and horizontal), wind direction, upstream flow turbulence intensities and flexibility of the building envelope (Holmes 1979; Stathopoulos et al. 1979; Liu and Saathoff 1981; Liu and Saathoff 1983; Vickery 1986).

For buildings with single dominant opening, often a time, the magnitude of the internal pressure response closely correlates to the external pressure fluctuations that develop over the area of the dominant opening (Kopp et al. 2008). However, the fulfillment of certain conditions of opening porosity and internal volume become a reason for the formation of enough turbulence energy at the opening that consequently causes the internal pressure to exceed the external pressure fluctuation. This phenomena 
eventually leads to excitation inside the building, called Helmholtz resonance (Holmes 1979; Oh et al. 2007; Kopp et al. 2008) wherein which the undamped Helmholtz resonant frequency of the flow dynamics matches with the natural frequency of the building.

Most internal pressure studies are carried out in Boundary Layer Wind Tunnel $(B L W T)$ at small scale. In $B L W T$ studies, the full scale building geometric length is scaled down by a certain ratio and the wind velocities and turbulence intensities are also developed accordingly. With respect to internal pressure analysis, the realistic assessment can be achieved only if one maintains the similarity of internal pressure dynamic response between the full scale and model scale experiments (Holmes 1979). A nondimensional analysis performed by Homes (1979) show that the dynamic similarity can be ensured if the internal volume of the building is scaled correctly. The correct internal volume scaling is attained by multiplying the nominal volume by the square of velocity scale ratio in cases where the full and wind tunnel velocities are other than unity (Holmes 1979).

According to Holmes (1979), the effect of applying incorrect volume in the study of internal pressure fluctuations for low-rise building such as residential and small industrial buildings with full scale internal volume less than $10000 \mathrm{~m}^{3}$ is less significant.

Recently, a wind tunnel study that incorporated various size of dominant openings and uniform background leakage was carried out (Oh et al. 2007). The study introduced internal volume scaling to maintain model to full scale dynamic similarity. It was shown that the background leakage worked to attenuate the external pressure fluctuations as it passes through the openings. For building with leakage and single dominant opening, 
however, Helmholtz resonance occurred and peak internal pressures measured for wind direction normal to the wall having dominant opening.

A study by Kopp et al. (2008) examined the effects of dominant opening location and sizes, background leakage, compartmentalization of attic space from living space, roof and vents. The experiment showed that peak external roof pressures were highly correlated in time with the internal pressures. It was also obtained that decreasing the ratio of the internal volume to the opening area increased the peak internal pressures and Helmholtz resonance, particularly for wind directions normal to the opening.

Low-rise buildings, as explained above, are prone to damage due to failure of dominant openings. A single dominant opening poses critical failure to a building and this scenario is often used for wind load design purposes. During the passage of storms, the two concerning scenarios for a dominant openings are: case1- a door or window might be left open unknowingly and internal pressure develops inside the building with time; case 2- a closed door or window breach can be instigated by wind borne debris to cause a transient response. With respect to internal pressure, the first scenario causes the formation of steady state condition while the second case leads to an immediate internal pressure overshoot response that later transform to steady state condition. The major concern with these two scenarios is whether the sudden overshoot due to the transient response is higher than the ensuing peak values of steady state internal pressure response.

A BLWT study was carried out to test the transient response of wind induced internal pressure in a building when a sudden opening occurs (Stathopoulos and Luchian 1989). The study found that the magnitude of transient response overshooting of internal pressure as being lower than the subsequent steady state peak fluctuations. The 
experiment was carried out using a cubic box of $0.152 \mathrm{~m}$ length having no background leakage (i.e., inherent porosity). The internal volume was also not corrected for velocity ratio, which both could have the effect of damping and hence reduction of the transient response. Similar results were obtained in other experiments verifying the transient internal pressure overshoot response wouldn't be larger than the steady state resonant response (Vickery and Bloxham 1992; Yeatts and Mehta 1992). The sensitivity of sudden overshoot to dominant opening size and internal volume was also experimented in a multi-room building (Liu and Saathoff 1983). The experiment concluded that the peak $C_{p i}$ resulting from sudden breach of dominant opening increases as the porosity increases, and as the effective internal volume decreases. On the other hand, other researchers (Sharma et al. 2000) have raised their concern over the conclusions reached above. The major concern raised was the possibility of synchrony between the creation of sudden opening in wind tunnel and full scale tests. Based on their modeling, it was shown that the sudden overshoot response could be significant than the subsequent steady state response. This indicates the need for an extensive study on the sudden breach of buildings. This is important to evaluate whether the transient overshoot or the subsequent peak steady state condition dominates the peak internal pressure values.

A comparison of wind tunnel test on low-rise building with $A S C E 7$ provisions was carried out by researchers at $U W O$ as a contribution to the National Institute of Standards and Technology (NIST) (St.Pierre et al. 2005). It was observed that generally, the ASCE 7 standard code provision underestimates the response coefficients significantly. The major factors that govern the interaction such as geometry, orientation, proximity of adjacent buildings are not realistically and comprehensively accounted in 
the standard provisions (Simiu and Stathopoulos 1997; Whalen et al. 1998; Sharma and Richards 2003; Oh et al. 2007). A study also found out that the non-conservative provisions for internal pressure plays a considerable contribution to the non-conservative values in current codes (Sharma and Richards 2003; 2005).

The present study focuses on characterization of internal pressure due to sudden door or window breaching, effects of volume correction, various dominant opening porosity sizes and their location with respect to the incoming (upstream) wind direction. It also compares aerodynamic data obtained from experiments carried at small-scale $(B L W T)$ and large-scale $(W o W)$. The study also examines the peak internal pressure loading and compares with existing wind load provisions, ASCE 7-10.

\subsection{Methdology}

\subsubsection{Full scale model setup at WoW}

The full scale test building was designed and constructed in accordance with locally prevailing construction methods in Miami, $F L$ to replicate realistic construction details.

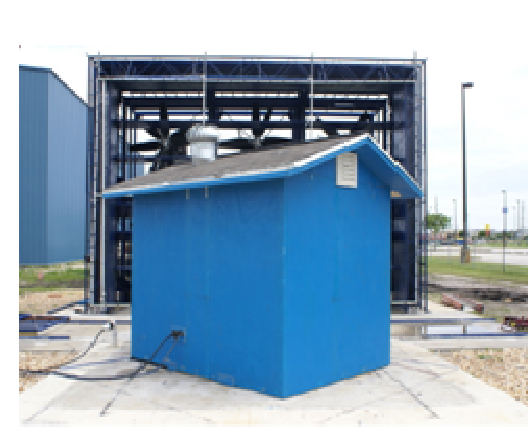

(a)

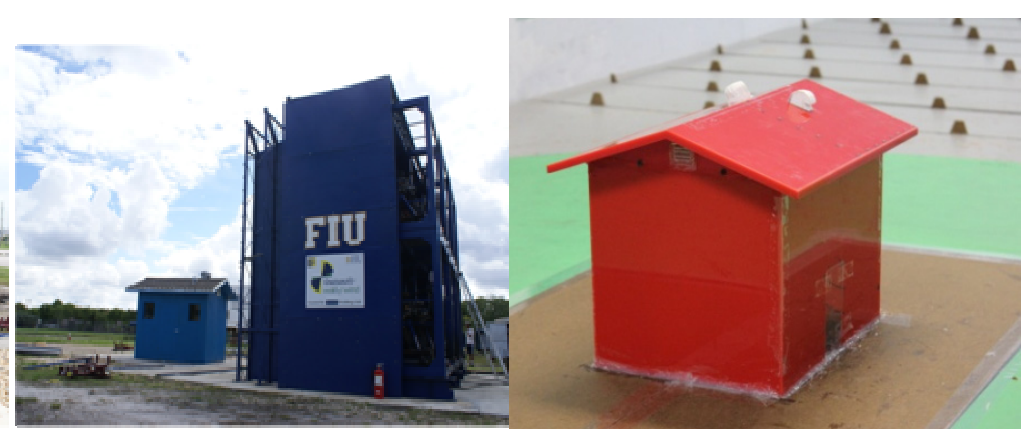

(b) (c)

Figure 3.1: Low-rise building with gable roof, full scale in front of $W o W$ testing position (a\&b); small scale $B L W T(\mathrm{c})$. 


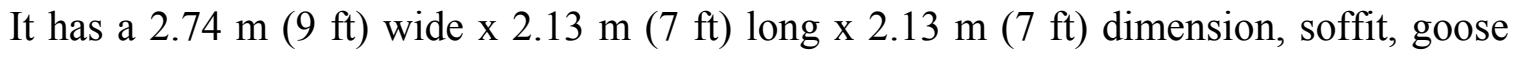
neck and turbine vents (additional gable end vents for gable roof case), two interchangeable shingle roofing, gable and hip with 1:4 slope, as shown in Figure 3.1. For dominant opening study case, a door size $0.96 \mathrm{~m}$ by $0.46 \mathrm{~m}(3.15 \mathrm{ft}$ by $1.50 \mathrm{ft})$ and a window size $(0.53 \mathrm{~m}$ by $0.43 \mathrm{~m})(1.76 \mathrm{ft}$ by $1.43 \mathrm{ft})$ was incorporated that provided a porosity of $7.5 \%$ and $3.75 \%$ (area ratio of the opening to that of the wall where the opening is located), respectively. In addition, the door had three interchangeable openings.

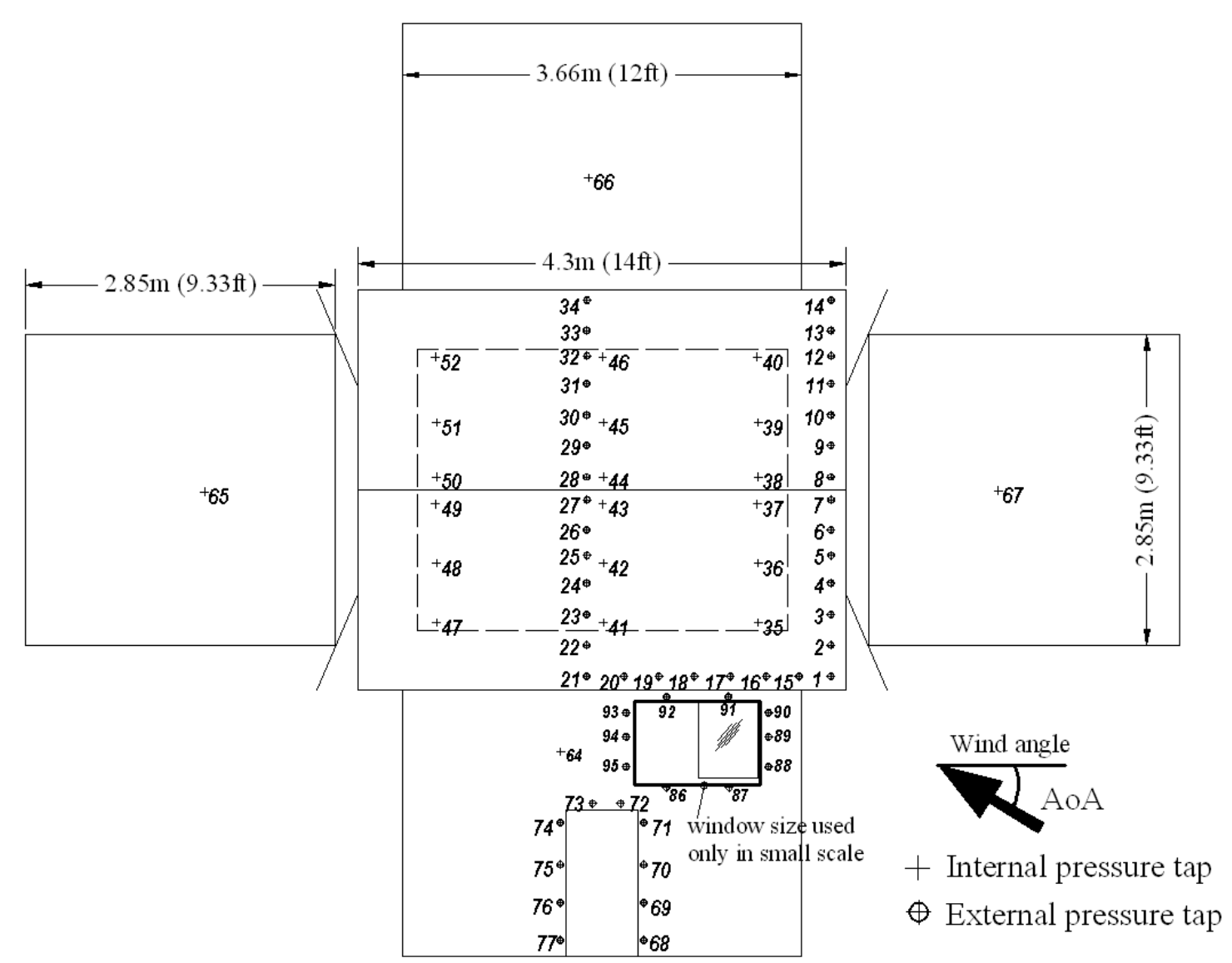

Figure 3.2: Exploded view of building model with external and internal pressure taps layout and location of dominant openings. Hip roof building has the same pattern of tap arrangement. (Dimensions given are full scale). 


\subsubsection{Boundary Layer Wind Tunnel (BLWT) setup}

A gable and hip roof low rise buildings with 4:12 roof slope constructed at a model scale of 1:9 was studied in a standard commercial boundary layer wind tunnel: Rowan Williams Davies \& Irwin Inc. (RWDI). The model was constructed using acrylic sheet made from a Plexiglas that has similar wall thickness as the 1:9 scale of the full scale building. The geometry of the model building has an equivalent full-scale plan dimensions of $L=3.66 \mathrm{~m}$ (12ft) by $W=2.85 \mathrm{~m}$ (9.33ft) with a roof slope of $4: 12$ and eave height of $h=2.11 \mathrm{~m}$ (6.94ft) as shown in Figure 3.2. The mean roof height of the building is taken as $2.33 \mathrm{~m}(7.65 \mathrm{ft})$. In order to replicate the full scale building with all the details that might affect the overall flow dynamics, all the claddings, ventilation systems, thickness of dominant openings were properly scaled.

Wind profile study was performed in the wind tunnel with different configuration of roughness length and spire shape in order to reproduce enough wind speed.

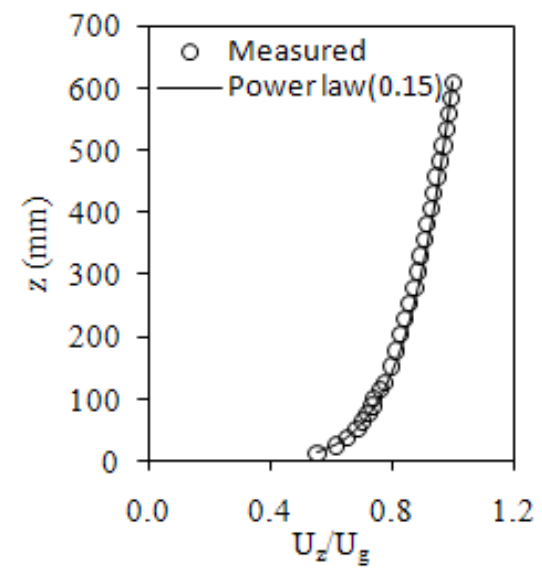

(a)

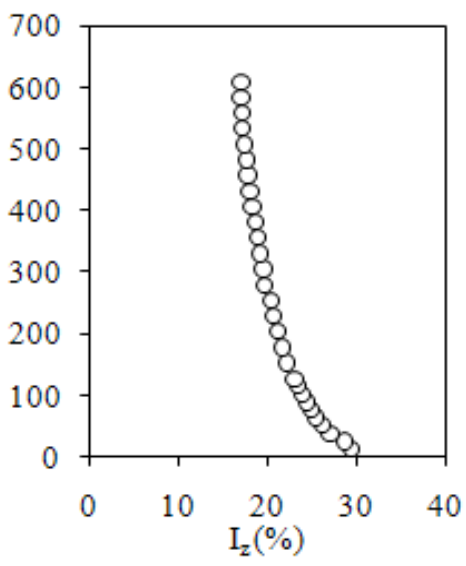

(b)

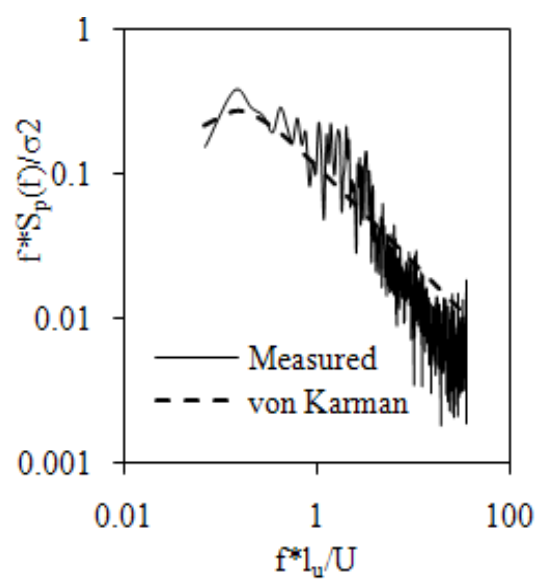

(c)

Figure 3.3: Normalized: a) wind velocity profile; b) Turbulence intensity profile; c) spectra. 
For the upstream terrain with open country exposure, the power law index (alpha) and the turbulence intensity were 0.154 and $21 \%$, respectively (Figure 3.3 ). In computing the mean wind speed, mid height between the eave and the ridge level was considered. Reference wind speed data was recorded in the absence of the model building for duration of $90 \mathrm{sec}$ at a frequency of $512 \mathrm{~Hz}$. A mean wind speed of $9.48 \mathrm{~m} / \mathrm{s}(21.2 \mathrm{mph})$ was used at a mid-height of the building. Since the velocity scale considered was 1:4, the mean wind speed computed corresponds to $37.92 \mathrm{~m} / \mathrm{s}$ ( $85 \mathrm{mph}$ ) full scale wind speed.

\subsubsection{Wind tunnel model internal volume scaling}

The provision of proper internal volume distortion (correction) of a building model in a wind tunnel experiment is necessary as explained in the introduction part, in order to maintain the dynamic similarity of the internal pressure fluctuations between wind tunnel and full scale models particularly for larger buildings with full scale internal volume greater than $10,000 \mathrm{~m}^{3}$ (Holmes 1979). For low-rise buildings of large volume, the implementation of velocity and length scale helps maintain realistic internal pressure measurement particularly the Helmholtz natural frequency and turbulence spectrum.

Some researchers attempted to model the dynamics of internal pressure response as a result of external pressure fluctuation through a dominant opening using the principles of Helmholtz acoustic resonator (Holmes 1979). The second order non-linear differential equation was used to model the wind induced internal pressure responses in the presence of dominant opening as shown in Eqn. 1. The first term in the equation represents the inertia of the mass of air-slug passing through the opening; while the second term represents the non-linear damping that takes care of the energy losses through the 
dominant opening and the third term represent the resistance of the internal pressure to the motion of the air-slug called stiffness. As can be seen from Eqn.1, the external pressure at periphery of the opening (i.e., $\Delta P_{e}$ ) govern the dynamic responses of the internal pressure. The technique used to scan the external pressure on the dominant opening (door or window) as well as the way the door or window opens during extreme windstorms is one major area that needs extensive studies as it is difficult to measure the flow characteristics without disturbing it. Equation 2 was obtained by rewriting Eqn.1 in terms of pressure coefficient (Holmes 1979). At a constant atmospheric pressure and density of air between full scale and boundary layer wind tunnel cases, the nondimensional analysis of Eqn. 2 results in Eqn. 4 \& 5.

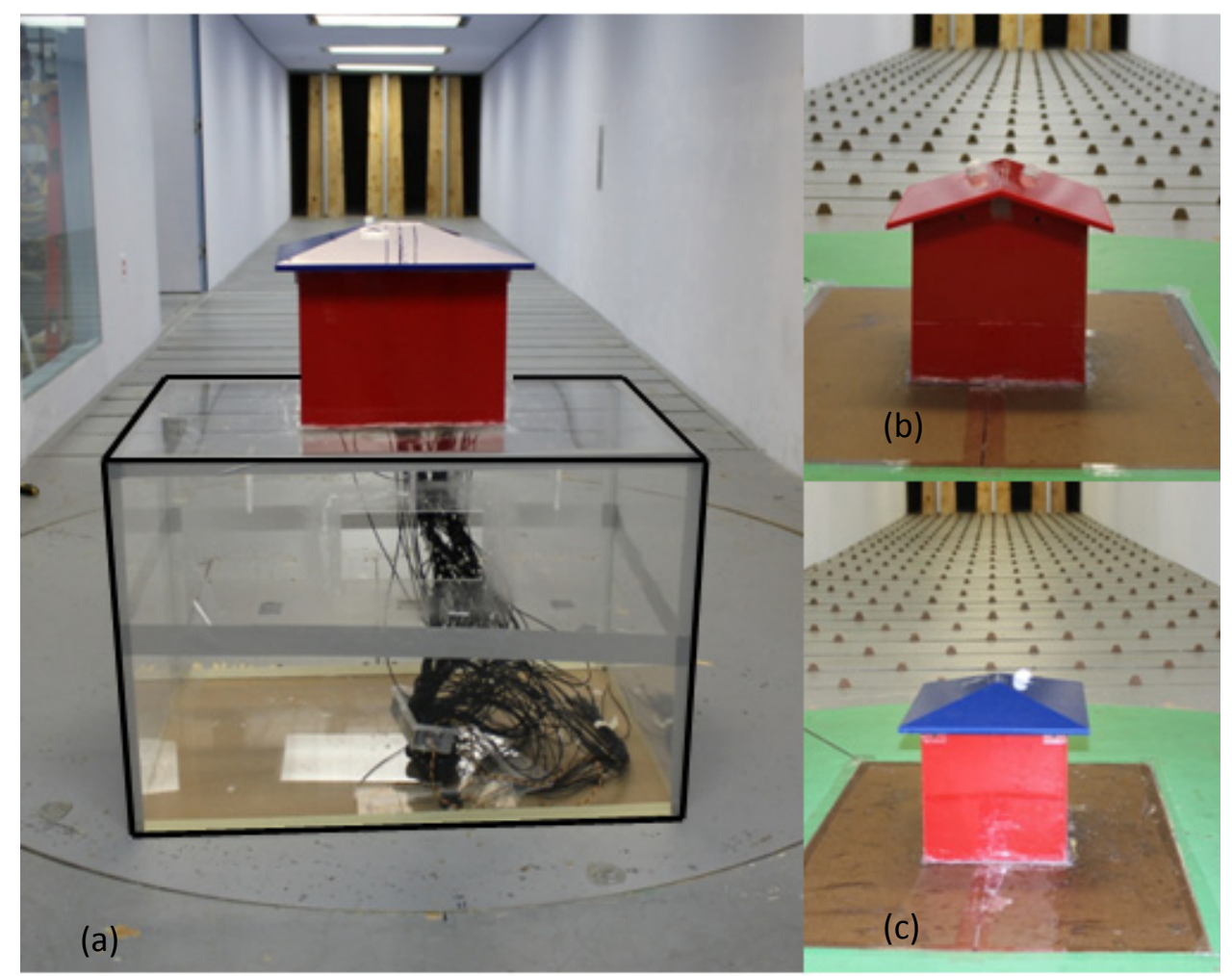

Figure 3.4: $B L W T$ model setup (1:9 scale): a) Volume correction chamber before final placement under the $B L W T$ floor, final test setup placement for gable (b) and hip (c). 
The undamped natural frequency (i.e., Helmholtz frequency) can be obtained from Eqn.2 and is given in Eqn. 3.

$$
\begin{aligned}
& \rho A l_{e} \ddot{X}+\frac{\rho A}{2 k^{2}} \dot{X}|\dot{X}|+\frac{n P_{o} A^{2}}{V_{o}} X=\Delta P_{e} A \\
& \frac{\rho l_{e} V_{o}}{n A P_{o}} \ddot{C}_{p i}+\frac{\rho V_{o}^{2} q}{2 k^{2} n^{2} A^{2} P_{o}^{2}} \dot{C}_{p i}\left|\dot{C}_{p i}\right|+C_{p i}=C_{p e} \\
& f_{h h}=\frac{1}{2 \pi} \sqrt{\frac{n A P_{o}}{\rho l_{e} V_{o}}} \\
& \frac{\left[\bar{U}^{2} V_{o}\right]_{m}}{\left[\bar{U}^{2} V_{o}\right]_{f}}=\frac{[A]_{m}^{\frac{3}{2}}}{[A]_{f}^{\frac{3}{2}}} x \frac{\left[P_{o}\right]_{m}}{\left[P_{o}\right]_{f}} x \frac{[\rho]_{m}}{[\rho]_{f}} \\
& \frac{\left[V_{o}\right]_{m}}{\left[V_{o}\right]_{f}}=\frac{[L]_{m}}{[L]_{f}} x \frac{[\bar{U}]_{f}^{2}}{[\bar{U}]_{m}^{2}}
\end{aligned}
$$

Where $\rho_{a}$ is the density of air inside the building, $A_{o}$ is the geometric area of the dominant opening, $l_{\mathrm{e}}$ is the characteristic length of the opening through which the air-slug moves, $P_{o}$ is the ambient pressure of air, $V_{o}$ is the effective volume of the cavity, $\gamma$ is the ratio of specific heat capacities (i.e., $\gamma=1.4), L=$ characteristic geometric length scale; $\bar{u}=$ eave height wind speed, $\mathrm{m} \& f=$ representation of model and full scale, respectively. For correct internal volume scaling and the appropriate measurement of the internal pressure fluctuations, the nominal volume obtained through length scale need to be magnified as given by Eqn. 5. This could be done by providing additional volume chamber underneath the wind tunnel turntable. 
In the present study, the model was prepared at a length scale of 1:9 and the test was conducted a velocity scale of 1:4. Thus, the volume was needed to be amplified by a factor of 16. A tight volume chamber box was attached to the base of the model building underneath the wind tunnel turntable, keeping in mind that the volume chamber should not be shallow and wider (Sharma et al. 2010).

\subsubsection{Sudden door or window opening test setup}

The mechanism implemented to create door/window sudden failure simulation was realized by incorporating a digital servo motor system as shown in Figure 3.5. Given the small scale size of the building model, simple mechanisms such as a spring loaded door accompanied by an activation pin could not be utilized.

In order to obtain reliable information, it was crucial to maintain control over the mechanism operating the door without interfering with the building's pressure taps. The option best suited for this application was the use of a remote controlled device.

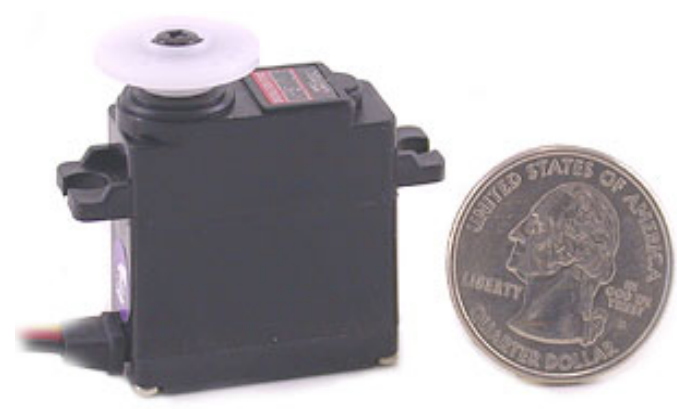

(a)

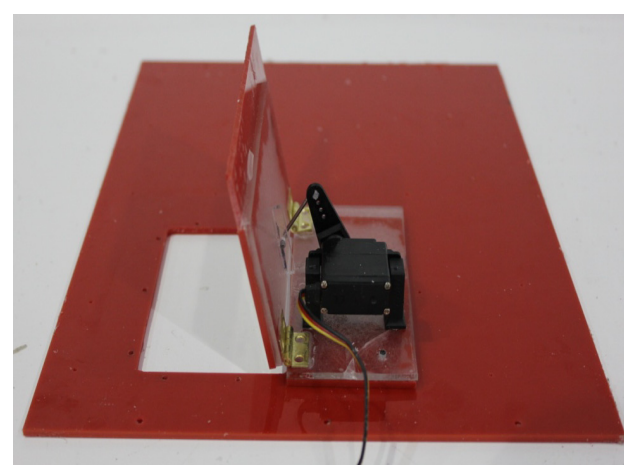

(b)

Figure 3.5: Sudden failure simulation technique: a) digital servo motor Hitec HSG-5084MG (Courtesy of ServoCity 
In order to open the door remotely, a radio control system normally used for model aircraft was used as part of the electro-mechanical system. A radio transmitter was used to send out a signal of instructions (open/close the door), which was collected and interpreted by a radio receiver. The receiver then translated these instructions to a servo, which carried out the instructions. Both the transmitting and receiving systems were powered by separate batteries allowing for independent systems. While all components were important, the servo was the most critical as it was the bridge for the gap between electrical control and mechanical work. Generally the servo provided high operational speed necessary to simulate rapid failure of the door/window being blown open and substantial torque to hold the door/window closed against the wind flow prior to opening. The servo was among the fastest available, with the ability to turn $60^{\circ}$ in 0.05 seconds. The door was mounted with hinges to a second piece of acrylic plastic. This piece would provide a mount for the servo. Using the included mounting hardware, the servo was attached to the assembly. A hole was drilled in a small piece of acrylic plastic which was then glued to the door. A steel connecting rod was bent to about 1 inch and linked the door to the servo arm. When the assembly was completed, the servo opened the door about $85^{\circ}$ in less than $1 / 10$ of a second.

\subsubsection{Building porosity arrangement}

The gable and hip roof buildings have three doors and two windows each with its own specific porosity. Inherent leakage due to cracks, joints and ducts was provided by incorporating uniformly distributed openings having circular holes (of diameter 1/16 in). In all the cases studied, the background leakage was taken to be $0.13 \%$ of the envelope 
surface area. Cross-ventilation of the attic space was provided through soffit openings, gable end, ridge, gooseneck and turbine vents based on the prevailing building codes (Table 3.1). Building performance guides such as Florida Building Code (2004 FBC R4409.13.3.2 ) and $A S H R A E$, require the provision of openings on the roof so as to effectively cross-ventilate attic space between ceiling joists and roof rafters. The guide stipulates that the ratio of total net free ventilating area to the area of ceiling shall not be less than $1 / 150$. Since the attic net free ventilation area is $0.07 \mathrm{~m}^{2}\left(104.625 \mathrm{in}^{2}\right)$, the area of the cross ventilation openings provided satisfy the minimum code requirements.

\subsubsection{Pressure tap allocation}

A total of 77 pressure scanning taps were placed both externally and internally. Since the building has a partition wall at ceiling level (i.e., dividing the room into living and attic), internal pressure taps were allocated on the wall (one at the center of each wall), on the ceiling for the living room as well as on the roof sheathing for the attic room. A total of 18 pressure taps were distributed uniformly inside each room.

Table 3-1: Dominant openings and background leakage distribution in model scale dimensions.

\begin{tabular}{|c|c|c|c|c|}
\hline $\begin{array}{c}\text { Description of } \\
\text { opening } \\
\end{array}$ & & Dimensions (in) & $\begin{array}{c}\text { Area } \\
\left(\mathrm{m}^{2} / \mathrm{in}^{2}\right)\end{array}$ & $\begin{array}{c}\text { Porosity } \\
(\%)\end{array}$ \\
\hline \multirow{5}{*}{ Windward wall } & Door D1, $(7.5 \%)$ & $4.125 \times 2$ & $0.0053 / 8.25$ & 7.5 \\
\hline & Door D2, (5\%) & $2.875 \times 2$ & $0.004 / 5.75$ & 5.2 \\
\hline & Door D3, (3\%) & $1.0 \times 3.3125$ & $0.0021 / 3.31$ & 3.0 \\
\hline & Window W $1,(3.75 \%)$ & $1.875 \times 2.24$ & $0.003 / 4.22$ & 3.75 \\
\hline & Window W2, $(9.0 \%)$ & $3.78 \times 2.52$ & $0.006 / 9.53$ & 9.0 \\
\hline \multirow{3}{*}{ Attic floor } & Ceiling hatch & $2 \times 2.06$ & $0.003 / 4.12$ & 4 \\
\hline & Soffit screen (4 pcs) & $1.625 \times 0.5$ & $0.0021 / 3.25$ & 3 \\
\hline & Gable end opening ( 2 pcs) & $1 \times 1$ & $0.0013 / 2$ & 2 \\
\hline \multirow{3}{*}{ Roof } & Ridge vent ( 2 strips $)$ & $0.06 \times 9.75$ & $8 \mathrm{E}-5 / 0.117$ & 0.11 \\
\hline & Turbine opening (dia. 1.1875") & & $1 \mathrm{E}-4 / 1.11$ & 1.06 \\
\hline & Goose neck & $0.44 \times 1.06$ & $3 \mathrm{E}-4 / 0.47$ & 0.45 \\
\hline
\end{tabular}


As shown in Figure 3.1, external pressure taps were allocated on the edge and mid of the roof as well as eave to evaluate the pressure fluctuations at those representative locations of the roof envelope. To capture the external pressure fluctuations at the dominant openings, a total of ten pressure taps were placed on each opening. In order not to disrupt the flow field, representative numbers of pressure taps were placed on the periphery of each opening. Area averaging technique was used to compute the characteristics of the flow field to a reasonable estimate. Measurements were obtained for a total of 21 wind angle of attack $(A O A)$ in $10^{\circ}$ increments (i.e., 19 wind angles and two $45^{\circ}$ angles). For symmetrical cases, tests were carried out for 11 wind angles ranging between $0^{\circ}$ and $90^{\circ}$. The wind direction is said to be $90^{\circ}$ when it is normal to the wall containing the dominant opening. The pressure signals from all taps were sampled at a rate of $512 \mathrm{~Hz}$ for 90 seconds. All the raw data collected were passed through a transfer function technique to correct the error due to tubing length used in the wind tunnel system.

\subsubsection{Test cases}

Table 3.2 describes the various test scenarios performed to investigate internal and external pressures. The experimental study undertaken is divided into four categories: a) Investigation of internal pressure with variable porosity size of dominant openings (see Table 3.2); b) comparison with full scale experiment; c) Investigation of transient internal pressure response due to sudden window and door breach with and without internal volume distortion (See Table 3.2); d) Comparison with ASCE 7-10. Test cases 1 to 6 represent the study on the effect of variable porosity dominant openings while test cases 7 and 8 represent the experiment on transient internal pressure response during a sudden 
opening of door and window, respectively. For test cases $7 \& 8$, the ceiling partition was removed so that the whole building act as a single room (i.e., attic and living rooms were combined). Test cases $8 \mathrm{a}$ and $8 \mathrm{~b}$ are of the same porosity window. The only difference is that Test $8 \mathrm{~b}$ was carried out without volume correction to evaluate the effect of internal volume distortion on the transient response.

Table 3-2: Summary of test cases for low-rise building with gable and hip roof.

\begin{tabular}{|c|c|c|c|c|c|c|}
\hline Description & $\begin{array}{l}\text { Test } \\
\text { cases }\end{array}$ & $\begin{array}{l}\text { Dominant } \\
\text { opening }\end{array}$ & $\begin{array}{l}\text { Inherent } \\
\text { leakage }\end{array}$ & $\begin{array}{l}\text { Ceiling } \\
\text { window }\end{array}$ & $\begin{array}{l}\text { Vents: } \\
\text { ridge/soffit }\end{array}$ & $\begin{array}{l}\text { volume } \\
\text { correction }\end{array}$ \\
\hline \multirow{3}{*}{$\begin{array}{l}\text { Background leakage } \\
\text { (blg) combination }\end{array}$} & Test 1a & - & $\checkmark$ & - & $\checkmark$ & $\checkmark$ \\
\hline & Test $1 \mathrm{~b}$ & - & $\checkmark$ & - & - & $\checkmark$ \\
\hline & Test 1c & - & $\checkmark$ & $\checkmark$ & - & $\checkmark$ \\
\hline \multirow{4}{*}{$\begin{array}{l}7.5 \% \text { Door opening } \\
\text { combination }\end{array}$} & Test $2 \mathrm{a}$ & $\mathrm{D}_{1}$ & $\checkmark$ & - & - & $\checkmark$ \\
\hline & Test $2 b$ & $D_{1}$ & $\checkmark$ & $\checkmark$ & - & $\checkmark$ \\
\hline & Test 2c & $\mathrm{D}_{1}$ & $\checkmark$ & $\checkmark$ & $\checkmark$ & $\checkmark$ \\
\hline & Test $2 d$ & $\mathrm{D}_{1}$ & $\checkmark$ & - & $\checkmark$ & $\checkmark$ \\
\hline \multirow{4}{*}{$\begin{array}{l}5 \% \text { Door opening } \\
\text { combination }\end{array}$} & Test 3a & $\mathrm{D}_{2}$ & $\checkmark$ & - & - & $\checkmark$ \\
\hline & Test $3 b$ & $\mathrm{D}_{2}$ & $\checkmark$ & $\checkmark$ & - & $\checkmark$ \\
\hline & Test $3 \mathrm{c}$ & $\mathrm{D}_{2}$ & $\checkmark$ & $\checkmark$ & $\checkmark$ & $\checkmark$ \\
\hline & Test 3d & $\mathrm{D}_{2}$ & $\checkmark$ & - & $\checkmark$ & $\checkmark$ \\
\hline $3 \%$ Door opening & Test $4 d$ & $\mathrm{D}_{3}$ & $\checkmark$ & - & $\checkmark$ & $\checkmark$ \\
\hline \multirow{4}{*}{$\begin{array}{c}3.75 \% \mathrm{~W} \text { indow } \\
\text { opening combination }\end{array}$} & Test 5a & $\mathrm{W}_{1}$ & $\checkmark$ & - & - & $\checkmark$ \\
\hline & Test $5 b$ & $\mathrm{~W}_{1}$ & $\checkmark$ & $\checkmark$ & - & $\checkmark$ \\
\hline & Test 5c & $\mathrm{W}_{1}$ & $\checkmark$ & $\checkmark$ & $\checkmark$ & $\checkmark$ \\
\hline & Test $5 d$ & $\mathrm{~W}_{1}$ & $\checkmark$ & - & $\checkmark$ & $\checkmark$ \\
\hline \multirow{4}{*}{$\begin{array}{c}9.0 \% \mathrm{~W} \text { indow } \\
\text { opening combination }\end{array}$} & Test $6 \mathrm{a}$ & $\mathrm{W}_{2}$ & $\checkmark$ & - & - & $\checkmark$ \\
\hline & Test $6 b$ & $\mathrm{~W}_{2}$ & $\checkmark$ & $\checkmark$ & - & $\checkmark$ \\
\hline & Test $6 \mathrm{c}$ & $\mathrm{W}_{2}$ & $\checkmark$ & $\checkmark$ & $\checkmark$ & $\checkmark$ \\
\hline & Test 6d & $\mathrm{W}_{2}$ & $\checkmark$ & - & $\checkmark$ & $\checkmark$ \\
\hline \multicolumn{7}{|c|}{ Sudden break age of door and window } \\
\hline $7.5 \%$ Door opening & Test $7 \mathrm{a}$ & $\mathrm{D}_{1}$ & $\checkmark$ & & - & $\checkmark$ \\
\hline \multirow{2}{*}{$9 \% \mathrm{~W}$ indow opening } & Test 8a & $\mathrm{W}_{2}$ & $\checkmark$ & & - & $\checkmark$ \\
\hline & Test $8 b$ & $\mathrm{~W}_{2}$ & $\checkmark$ & & - & - \\
\hline
\end{tabular}




\subsubsection{Internal and external pressure distribution}

The time history pressure coefficients $P(t)$ of each pressure tap (both for external and internal) were used to compute the non-dimensional internal $C_{p i}(t)$ and external pressure $C_{p e}(t)$ coefficients by referencing to the mean wind speed measured at mean roof height as given by Eqn.6. The mean value of coefficient of pressure for each tap was obtained by taking the average of the 90 second recorded pressure measurement as given in Eqn.7. Similarly, the peak pressure coefficient is obtained from the time history data (Eqn. 8). The root mean square $(\mathrm{rms})$ value of the pressure coefficient is obtained by making use of the standard deviation of the pressure coefficient as given by Eqn. 9 .

$$
\begin{aligned}
& C_{p i j}=\frac{P_{i j}-P_{r j}}{\frac{1}{2} \rho \bar{U}^{2}}, \quad C_{p e j}=\frac{P_{e j}-P_{r j}}{\frac{1}{2} \rho \bar{U}^{2}} \\
& C_{p_{\text {mean }}}=\frac{1}{n} \sum_{i=1}^{n} C_{p i} \\
& \hat{C}_{p i}=\frac{\hat{P}_{i}-P_{r i}}{\frac{1}{2} \rho \bar{U}^{2}} \\
& \widetilde{C}_{p i}=\sqrt{\frac{1}{2} \sum_{i=1}^{n}\left(C_{p i}-C_{p_{-} \text {mean }}\right)^{2}}
\end{aligned}
$$

Where $P_{i j}$ and $P_{e j}$ are the measured internal and external differential pressures, respectively at the $j^{\text {th }}$ tap; $\widehat{\mathrm{P}_{1}}$ represents the peak fluctuating pressure; $\rho$ is air density taken as $1.23 \mathrm{Kg} / \mathrm{m}^{3} ; U_{H}$ is the mean wind speed measured at mid height (i.e., between eave and ridge) of the building. 


\subsection{Results and discussion}

\subsubsection{Internal pressure variation with respect to dominant openings}

Figure 3.6 describes the distribution of internal pressure inside the building with dominant openings (door- $\mathrm{D}_{2}$ with $5 \%$ porosity and window- $\mathrm{W}_{1}$ with $3.75 \%$ porosity) as

well as background leakage $(b l g)$. The mean internal pressure coefficient $C_{p i}$ due only to background leakage was uniform in distribution but very low in magnitude and no significant disparity was observed with respect to wind direction. For Test 1a $(0.13 \%$ background leakage porosity and vent openings), the mean $C_{p i}$ obtained was -0.09 . However, when the building was only having background leakage (where the vent openings closed), the mean $C_{p i}$ becomes positive and ranges between $0.05-0.07$. In the presence of ventilation openings such as soffit, gable end, ridge and roof over the perimeter of the roof envelope, closing ventilation openings initiate the buildup of positive pressure inside the attic room, although very small in magnitude for the case studied. Observing the $r m s C_{p i}$ due to the dominant openings, even though $\mathrm{W}_{1}$ has lower porosity ratio as compared to that of the door $\mathrm{D}_{2}$, it caused higher turbulence because of its location with respect to the upstream corner of the building. The window $\mathrm{W}_{1}$ and door $\mathrm{D}_{1}$ are located $0.75 \mathrm{~m}(2.48 \mathrm{ft})$ and $1.8 \mathrm{~m}(6 \mathrm{ft})$ from the right edge, respectively. In addition to that, the window was located in the flow stagnation region. Irrespective of their size, the building with $3.75 \%$ window exhibited higher peak positive and suction internal pressure distribution (30-40\% higher) than the door with $5 \%$ porosity. The peak $C_{p i}$ occur at about $70^{\circ}$ wind angle of attack $(A O A)$ while the suction pressure occur at about $10^{\circ}$ wind $A o A$. 
This demonstrates that, besides the porosity of the dominant openings, the location and wind angle of attack $(A o A)$ play a significant role in determining the dynamics and characteristics of internal pressure.

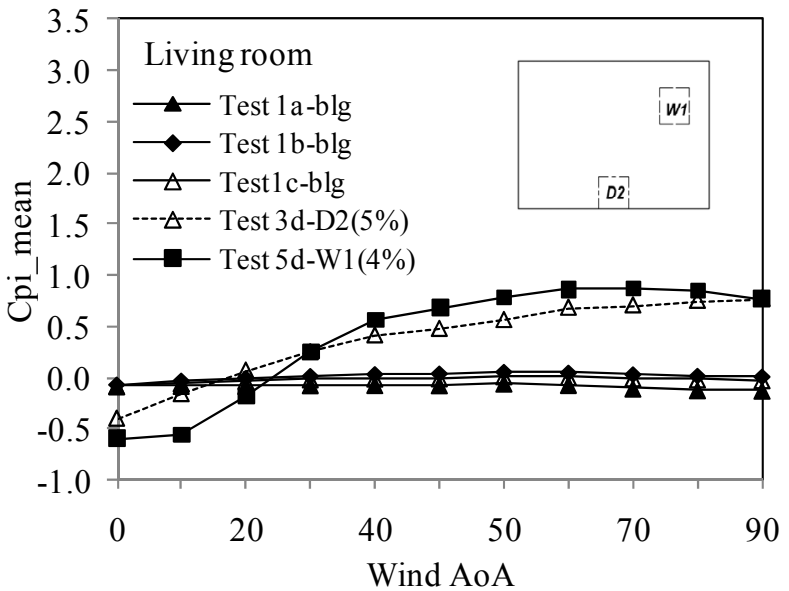

(a)

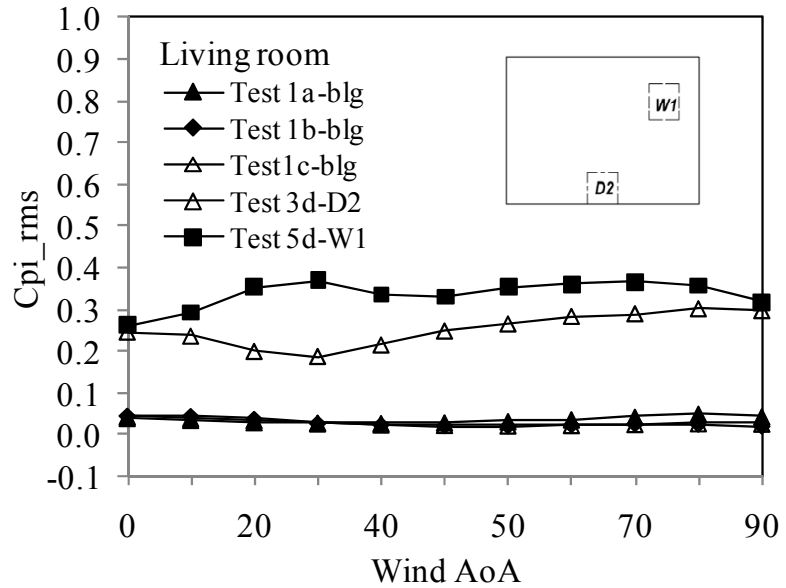

(b)

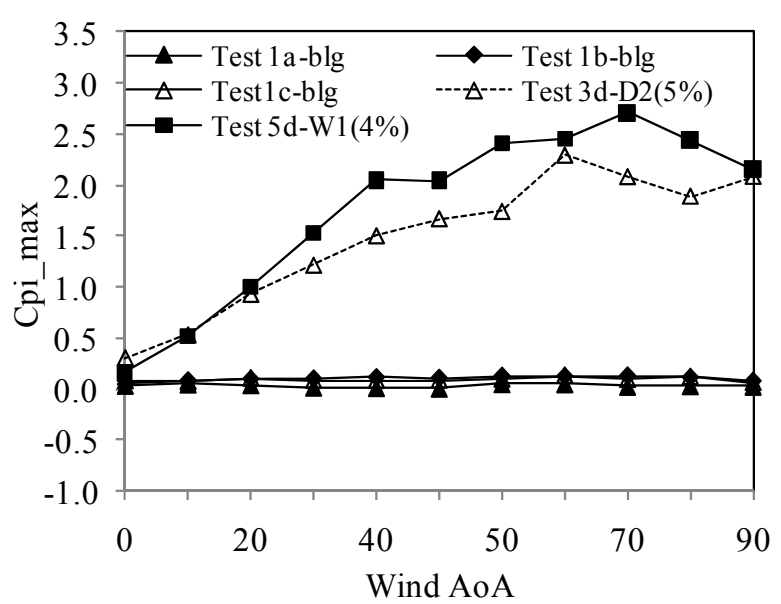

(c)

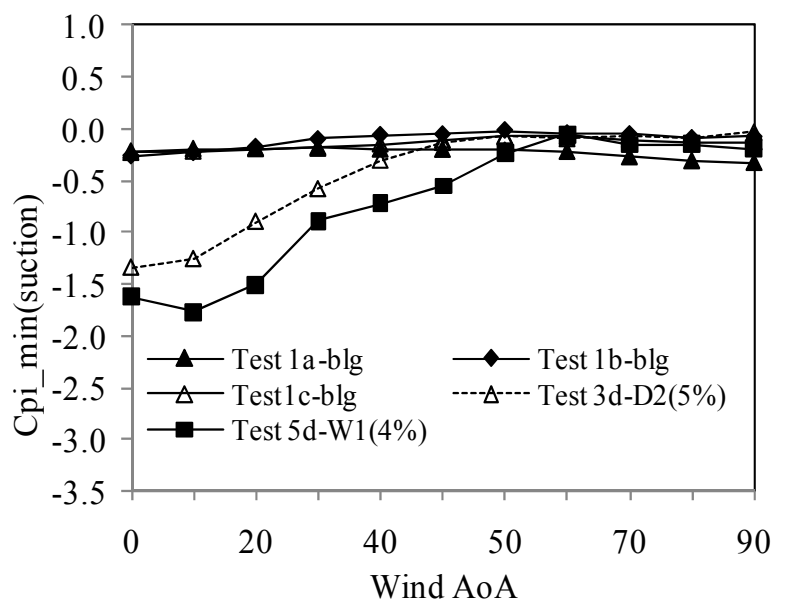

(d)

Figure 3.6: Internal pressure comparison between background leakage $(b l g), 5 \%$ porosity door and $4 \%$ porosity window. 

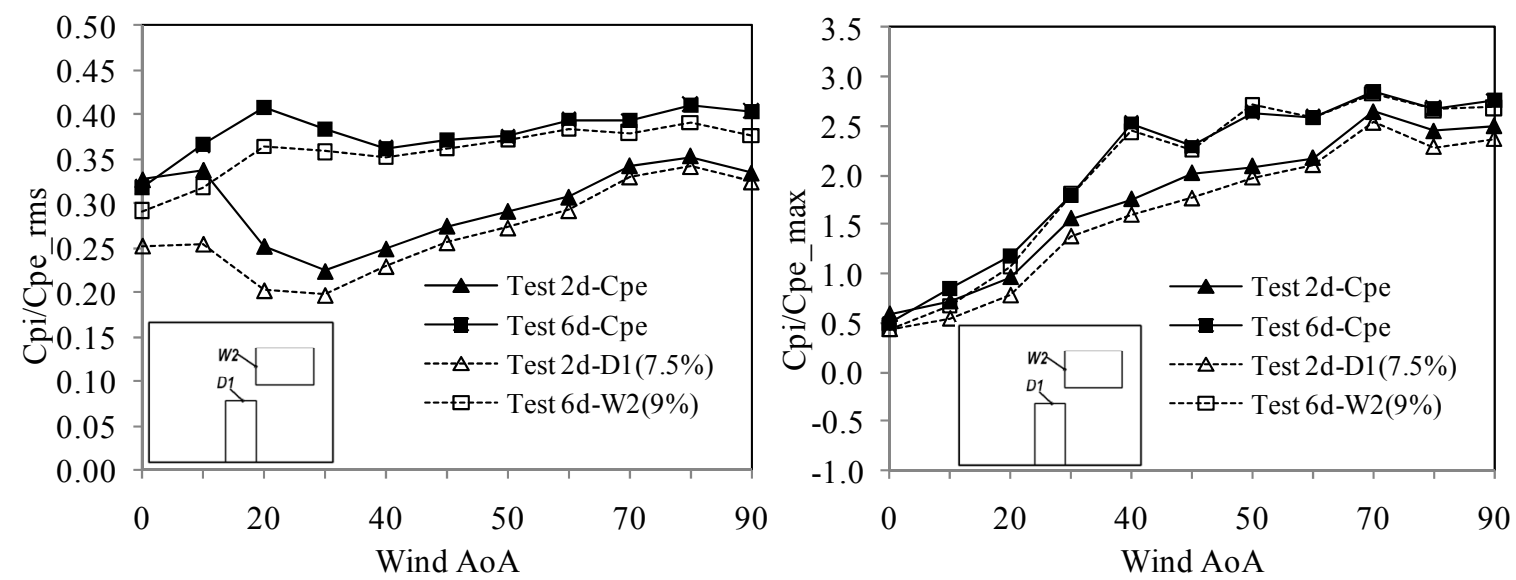

Figure 3.7: Correlation of $r m s$ external pressure at dominant opening periphery and internal pressure.

The presence of Helmholtz resonance was also checked by comparing the standard deviation of the internal and external pressure coefficient of the two dominant openings with the highest porosity ratio (i.e., $\mathrm{D}_{1}=7.5 \%$ and $\mathrm{W}_{2}=9 \%$ ). From Figure 3.7 , it can be deduced that the $7.5 \%$ and $9 \%$ porosity dominant openings didn't provide enough internal pressure excitation to cause Helmholtz resonance.

Significant Helmholtz resonance is expected to take place when the ratio of the rms value of $C_{p i}$ to that of $C_{p e}$ is greater than one (i.e., $\frac{C_{p i}{ }^{\prime}}{C_{p e}{ }^{\prime}}>1$ ) (Holmes, 1979; Kopp et al. 2008). In all of the wind $A o A$ examined, the internal pressure was lower by certain degree than the external pressure at the periphery of the respective dominant opening and that is believed to be due the uniform nominal background leakage which caused damping and hence reduction of the intensity of the internal pressure. The trend of the peak $C_{p i}$ and $C_{p e}$, however, illustrates correlation between the fluctuation of the internal pressure with that of the external pressure at the dominant opening which rectifies previously done experiments. The overall internal pressure comparison among all the dominant openings 
incorporated in the experiment was carried out to examine the distribution, the influence of building geometry, location and wind direction as well as the significance of one over the other. As can be seen from Figure 3.8, the windows are located towards the right side corner while the doors at the center. Even though the window $\mathrm{W}_{1}$ has porosity size smaller than that of $D_{1}$ and $D_{2}$, the building experienced higher fluctuation in internal pressure due to $\mathrm{W}_{1}$ than due to $\mathrm{D}_{1}$ or $\mathrm{D}_{2}$. This was observed in the mean internal pressure coefficient wherein which the window openings caused the formation of mean $C_{p i}=+0.9$ which was $50 \%$ higher than that due to the doors. From Figure 3.8b, it can be seen that the rms of the windows $\left(\mathrm{W}_{1}\right.$ and $\left.\mathrm{W}_{2}\right)$ was significantly higher than that of the doors particularly for the wind AoA between $0^{\circ}$ and $90^{\circ}$. This was mainly due to the nature of the external pressure at this particular location.

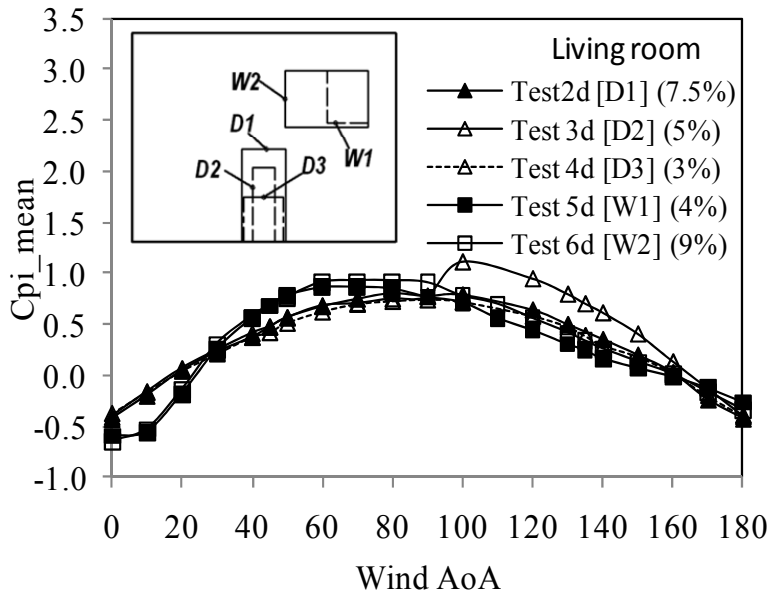

(a)

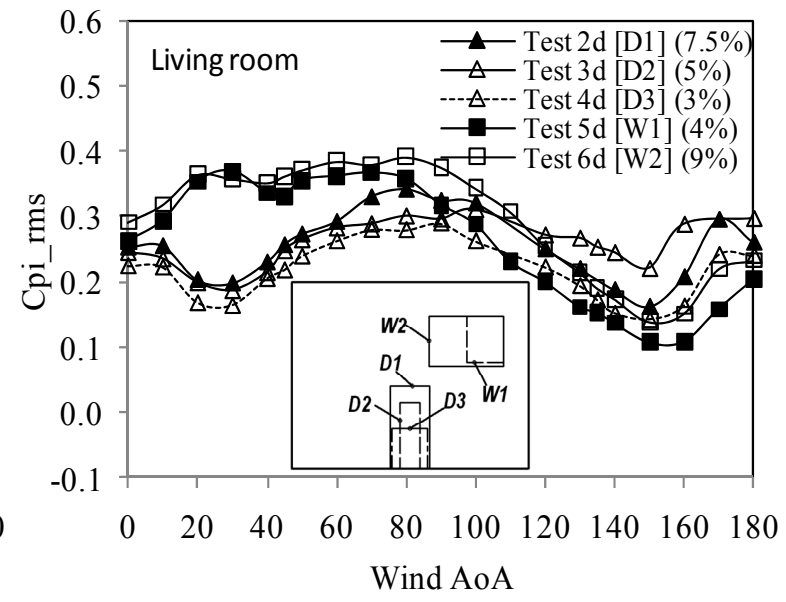

(b) 


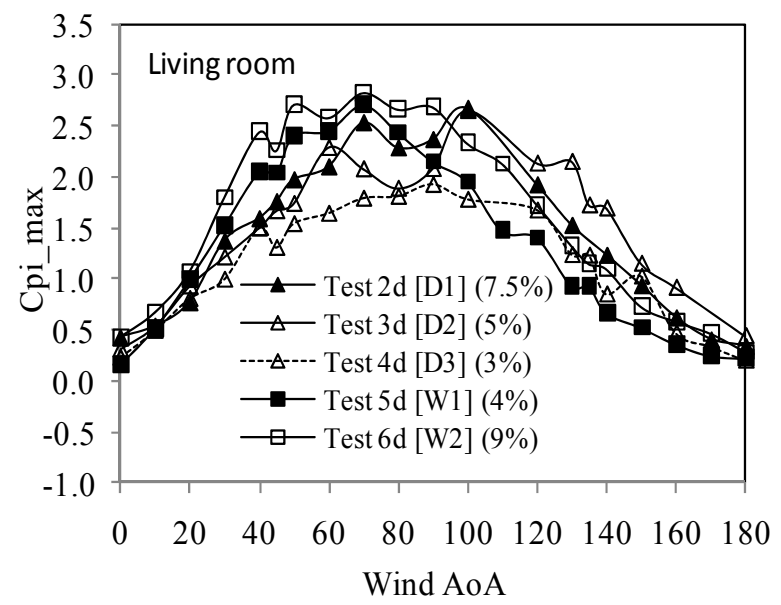

(c)

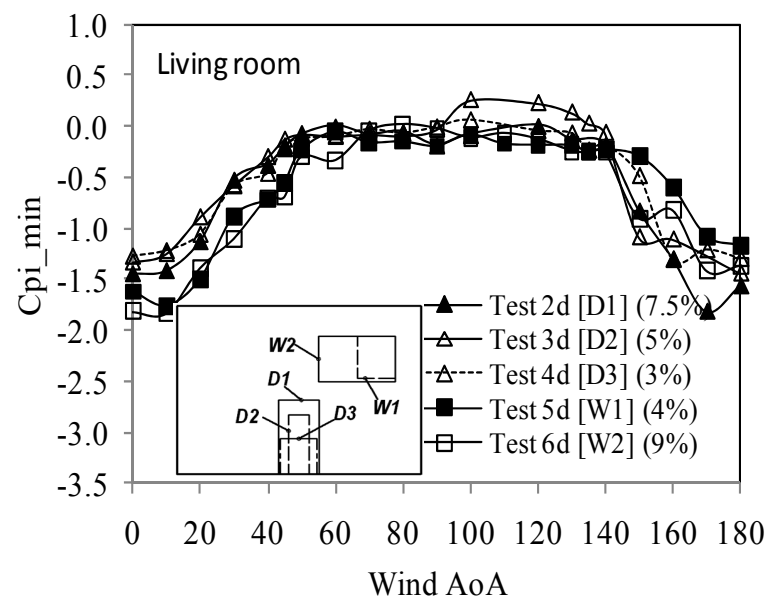

(d)

Figure 3.8: Living room internal pressure (mean, rms, max and min) distribution due to various dominant openings.

Both windows were located off-center from the windward edge and it is known that the corner region on the building is normally highly turbulent due to flow separation. This has a direct influence on the dynamics of the internal pressure. As can be seen in Figure $3.8 \mathrm{~b}$, the rms internal pressure due to the off-center windows was significantly higher than that of the doors located at the center, particularly for wind angles between $10^{\circ}$ and $40^{\circ}$. As a result, the peak internal pressure coefficient due to the windows and doors occur at different wind $A o A$. For wind $A o A$ between $10^{\circ}$ and $50^{\circ}$, both window openings exhibited fairly equivalent extreme internal pressure variation irrespective of the difference in porosity size (3.75\% vs $9 \%)$. A clear trend observed in the internal pressure fluctuation of the off-center windows was that the distance between the upstream wall corner and the opening has a significant impact on the rms intensity or specifically the wind angle of attack (whether it is acute or obtuse). For shorter distance between the upstream wall corner to the window opening (i.e., for acute angle), the rms fluctuation was considerably higher than that when the distance in between was longer (i.e., for obtuse angle). For instance, internal pressure $r m s$ for the $9 \%$ window $\left(\mathrm{W}_{2}\right)$ at $30^{\circ}$ wind 
$A o A$ was 0.36 while at $150^{\circ}$, the respective value was 0.1 . Thus, the former was $227 \%$ bigger. Similar trend was observed for $20^{\circ}$ and $160^{\circ}$. Figure $3.8 \mathrm{c}$ shows the internal pressure due to windows reaching peak value at about $70-75^{\circ}$ wind $A o A$ whereas in the case of doors, it occurred at about $100^{\circ}$ wind $A o A$. For wind $A o A$ above $90^{\circ}$, the location of the windows was far from the left corner (where upstream flow occurs) as compared to that of the doors located at the center. Consequently, the magnitude of the internal pressure due to both windows was lower than that due to the doors irrespective of the porosity. It was observed that the dominant openings located outside of the center region of the wall exhibited larger internal pressure for obtuse wind $A o A$. Thus, specifically, for wind $A o A$ less than $70^{\circ}$, the window $\mathrm{W}_{1}$ with $4 \%$ porosity generated bigger internal pressure than doors $\mathrm{D}_{1}(7.5 \%)$ and $\mathrm{D}_{2}(5 \%)$. On the other hand, for wind $A o A$ greater than $100^{\circ}$, the $7.5 \%$ and $5 \%$ porosity ratio doors $\left(D_{1} \& D_{2}\right)$ generated higher internal pressure than that due to windows $\mathrm{W}_{1}$ and $\mathrm{W}_{2}$. This verifies the significance of the dominant opening location with respect to the upstream wind direction. Peak positive pressures were observed to go lowest when the building was on a side wall (i.e., at wind $A o A 0^{\circ}$ and $\left.180^{\circ}\right)$. However, the suction internal pressure also went to the highest level when the building was on the side wall. Thus, proper care is needed in selecting design values as the suction could become more decisive than the positive pressure in some conditions.

\subsubsection{The effect of ventilation openings}

Ventilation openings are necessary to provide cooling solar heat gains and reducing the cost of energy consumption as well as create human comfort. During extreme wind flow conditions, most of the time, vent openings are required to be closed in a bid to 
prevent the intrusion of wind driven rain. The side effect is that it causes blockage of air exchange. In this experiment, the closing and opening of different types of mechanical ventilation systems commonly used in residential buildings was investigated to examine their interference with the internal pressure that develops inside the attic room. The attic room was separated from the living room by a horizontal ceiling and a typical attic opening that connects the living room to the attic space, commonly called hatch, was used.

As the attic area was opened to the living room, the volume of the model building was amplified by increasing the volume chamber underneath the turntable in accordance with the correction factor given in Eqn.2. To examine the effect of the vent openings, the attic hatch was left open along with door $\mathrm{D}_{1}, \mathrm{~W}_{1}$ or $\mathrm{W}_{2}$. All the ventilation openings included in the test were soffits around the perimeter of the roof, ridge, gable-end, goose neck and turbine vents.
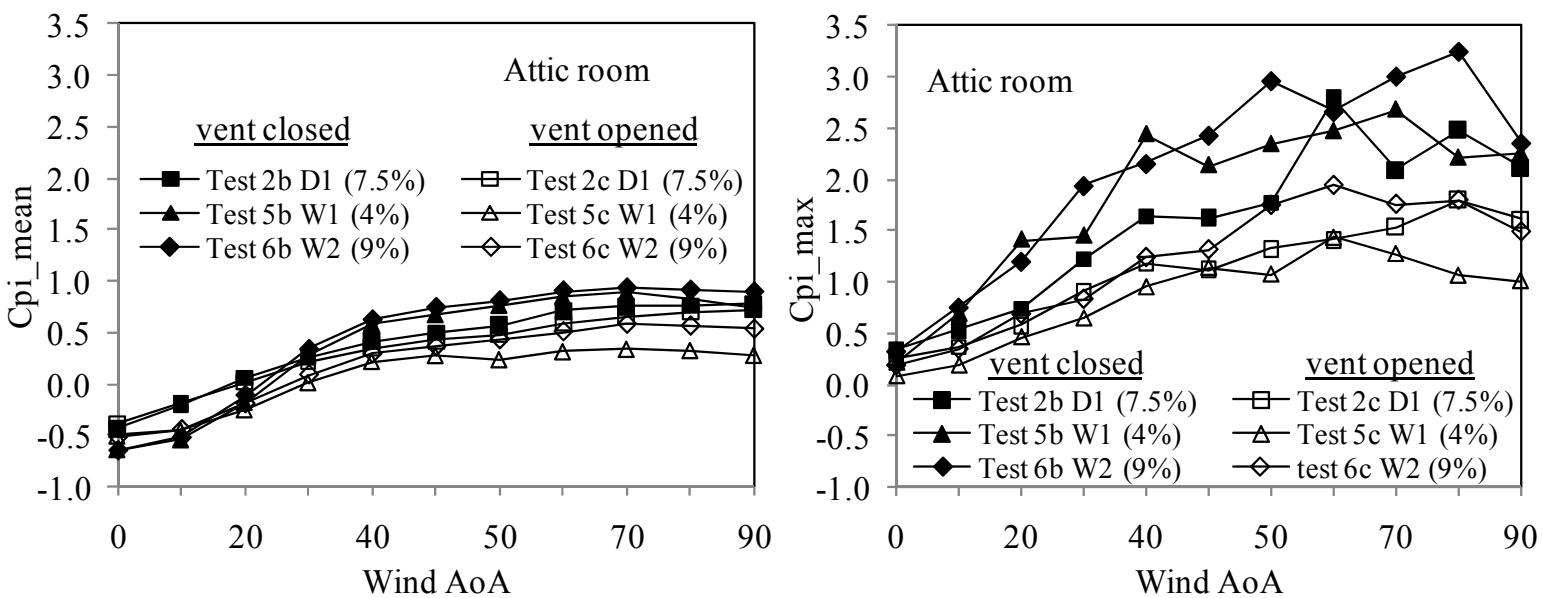

Figure 3.9: Comparison of internal pressure inside attic when vent is opened and closed. 
Figure 3.9 illustrates the distribution of mean and max attic internal pressure coefficients for a closed and open case of vent openings (i.e., Test $2 b, 5 b$ and $6 b$-vents closed while $2 c, 5 c$ and $6 c-$ vents opened). For the ventilation closed case, it was observed that the mean and peak attic internal pressures were $40-45 \%$ bigger than that of the ventilation opened case for Test case $2 \mathrm{~b}$ (i.e., while the dominant door $\mathrm{D}_{1}$ opened). Similarly, for test case $5 \& 6$, the mean and peak attic internal pressures were $90-140 \%$ bigger for the vent closed case than that of the opened case. This clearly demonstrates that ventilation openings have significant impact on the internal pressure of the attic in such a way that blocking the roof vent openings could exacerbate the internal pressure inside the attic. Since roof envelope is part of the attic room, the increase in internal pressure due to closure of ventilation openings during hurricane season can aggravate the net uplift force that develop on the roof surface as a result of the roof external and internal pressures.
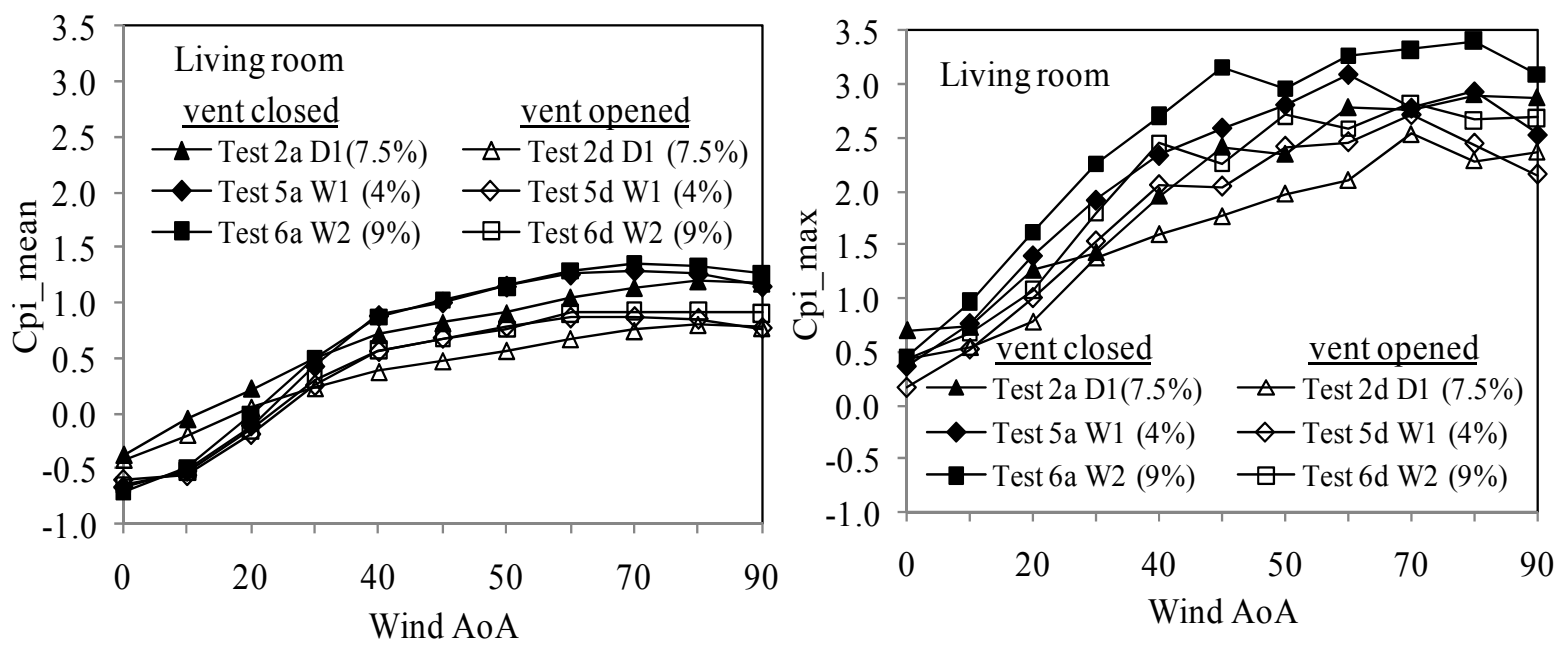

Figure 3.10: Comparison of internal pressure inside living room when vent is opened and closed. 
The effect of ventilation opening on internal pressure inside the living room in the presence of dominant openings $\mathrm{D}_{1}, \mathrm{~W}_{1}$ and $\mathrm{W}_{2}$ was also examined while the hatch was closed. The only connection between the two spaces was through the uniform background leakage. Figure 3.10 shows the distribution of internal pressure inside the living room when the ventilation openings in the attic are opened and closed. As can be seen from the figure, the mean internal pressure inside the living room while the vent openings closed, for both the door and window opening, was obtained to be $40-50 \%$ higher than that when the vents were left open. Similarly the peak values of living room internal pressure was $20-25 \%$ higher for the closed vent case compared to the opened case. This re-affirms that the ventilation openings have considerable effect not only to the space directly connected them (i.e., the attic in this case) but also the space which has no direct connection such as the living room. This depicts that, during hurricane or extreme wind events, ventilation openings need to be kept operating to facilitate the exchange of air. In order to optimize the effect of the vent openings from both the air exchange needed to minimize the buildup of positive internal pressure and prevent wind-driven rain intrusion, an effective mechanism should be sought that can deter rain intrusion while maintaining air exchange, simultaneously.

\subsubsection{Sudden opening breach}

During hurricane events, there is high probability for building envelope components such as doors and windows to be breached by either extreme wind pressure or wind borne debris. This generates peak internal pressure that can lead to the bursting of leeward side doors/windows or the failure of roof components. Since opening covers are fixed to walls 
with non-structural frames, they are highly vulnerable to wind borne missiles as tiny as pebbles. Post hurricane assessments have shown that most door and window breach result from wind borne debris such as broken tiles pieces, woods, stones and scrap metals that rip off from neighboring buildings. Even for cases where sudden building envelope breaching did not result in a major structural damages, it often create a path for the intrusion of rain water driven by wind force which can cause damage to internal building components such as carpets, paints, electrical and sanitary facilities, dry walls and furniture. Water held in between these utilities commonly create favorable environment for the formation of mold, rot and other health hazards. In some cases, houses become inhabitable from mold infestation and odor which at an extreme case becomes carcinogenic.

The experimental study on the transient response of wind induced internal pressure was carried out with the $7.5 \%$ (Test $7 \mathrm{a}$ ) and $9 \%$ (Test $8 \mathrm{a}$ ) dominant door located at the center and window opening located off-center, respectively, each with volume correction.

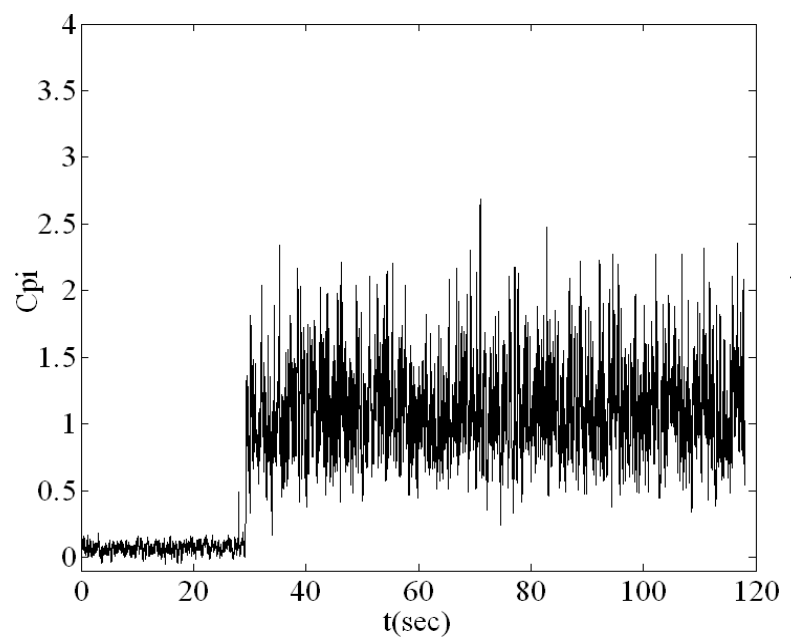

(a)

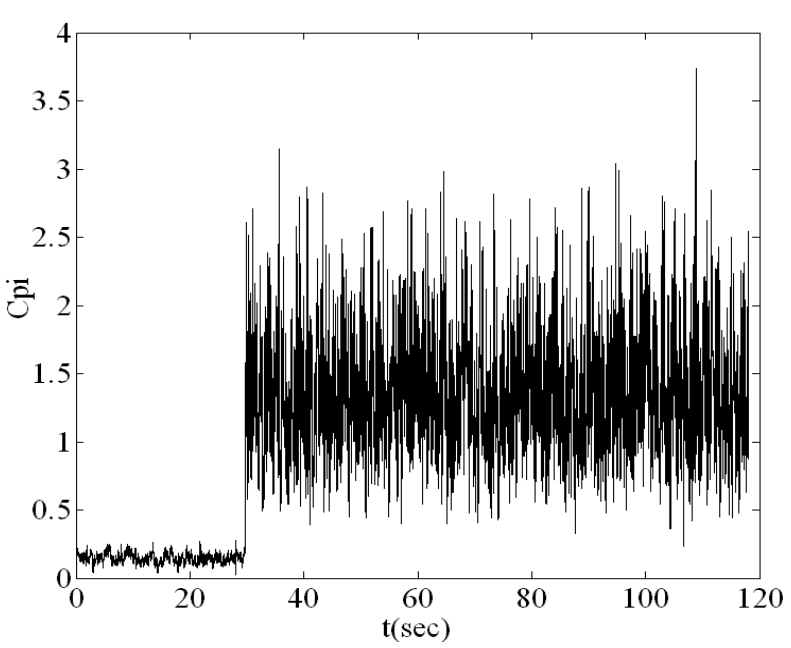

(b) 


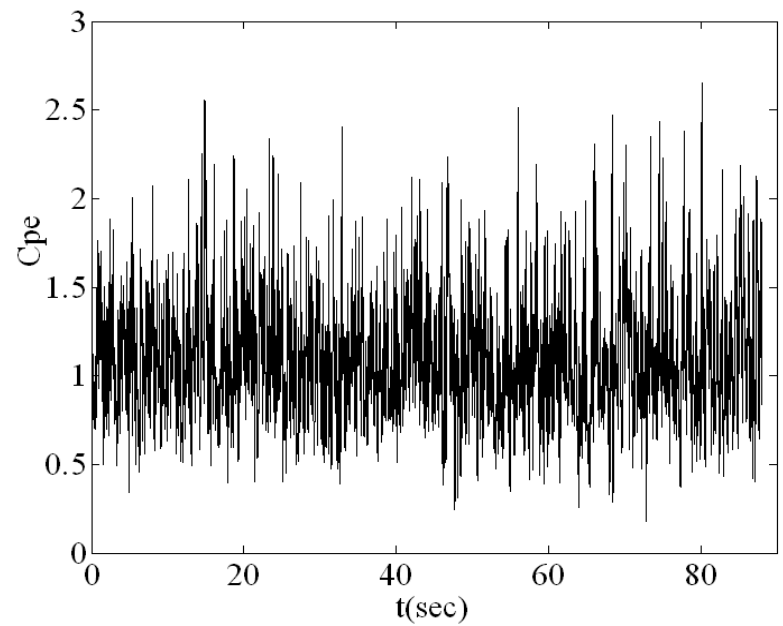

(c)

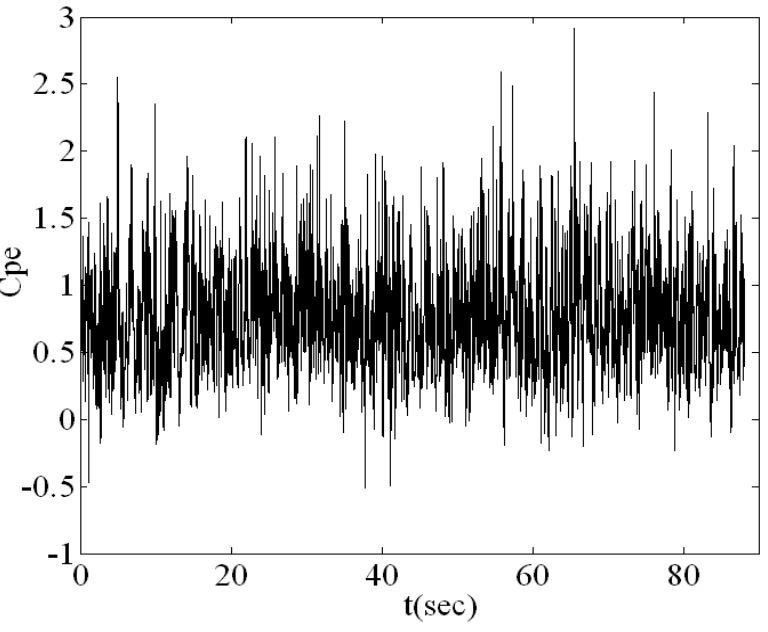

(d)

Figure 3.11: Time history of internal pressure coefficient for sudden breach of $7.5 \%$ door (a) and $9 \%$ window (b), external pressure coefficient at the periphery of $7.5 \%$ door (c) and $9 \%$ window (d).

Additional test was also performed without internal volume correction (i.e., Test $8 \mathrm{~b}$ ) to examine the sensitivity of the transient response to the internal volume correction. Each test was performed for $45^{\circ}, 75^{\circ}$ and $90^{\circ}$ wind $A o A$. A representative times history showing the dynamic response of internal pressure is given in Figure $3.11 \mathrm{a} \& \mathrm{~b}$ for $75^{\circ}$ wind $A o A$. The response can be divided into three regions: region 1: time before sudden breach (i.e., $0<\mathrm{t}<30$ s), region 2: time during the sudden breach $(30<\mathrm{t}<31$ s) and region 3 : time after the sudden breach $(31<\mathrm{t}<120 \mathrm{~s})$. Based on repeated tests, it was observed that the building experiences a nominal $C_{p i}$ in the range of 0.15 before the sudden opening (i.e., region 1). This was mainly due to the uniformly distributed background leakage. As the dominant opening was released within the specified period, the internal pressure responds by overshooting from a mean value of 0.15 to a new mean value of 1.2 for Test 7a and 1.4 for Test 8a. Since the flow was transient, the peak internal pressure response did not decay with time (see Figure $3.11 \mathrm{a} \& \mathrm{~b}$ ) as expected for laminar flow where the 
peak die out to the mean value with time. This phenomenon also verifies that the external pressure variations are consistently reflected in the internal pressure fluctuations. Comparing the distribution of internal pressure coefficient during and after the sudden breaching, there was a consistent trend that the transient response overshooting being lower than the steady state peak values. The observed internal pressure characteristics between the transient response immediately after the door or window breach and the steady state instantaneous values are in agreement with researches done previously by Stathopoulos and Luchian (1989).

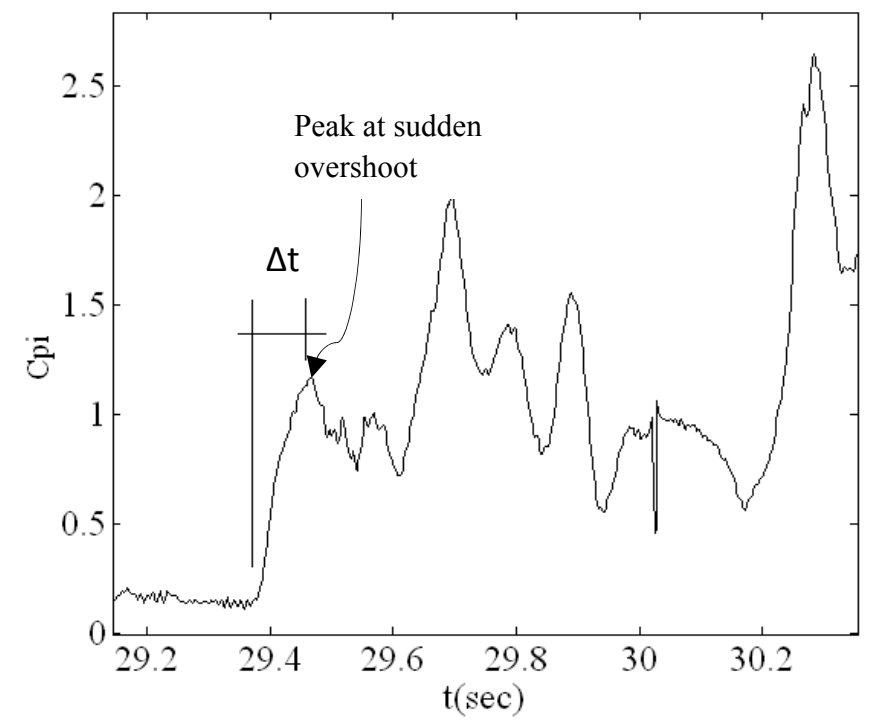

Figure 3.12: Internal pressure fluctuation at the moment of sudden door opening. 
Table 3-3: response time comparison.

\begin{tabular}{cccc}
\hline Test description & AoA & $\mathbf{C}_{\boldsymbol{p i}}$ overshoot & $\boldsymbol{\Delta t}$ (s) \\
\hline \multirow{2}{*}{ Test 7a } & 45 & 0.44 & 0.09 \\
& 75 & 1.23 & 0.09 \\
& 90 & 1.16 & 0.09 \\
\hline \multirow{2}{*}{ Test 8a } & 45 & 1.60 & 0.08 \\
& 75 & 1.56 & 0.07 \\
& 90 & 1.17 & 0.08 \\
\hline \multirow{2}{*}{ Test 8b } & 45 & 0.67 & 0.02 \\
& 75 & 1.38 & 0.05 \\
& 90 & 0.51 & 0.02 \\
\hline
\end{tabular}

The response time $(\Delta t)$, time between breach trigger and immediate peak transient overshoot response (as shown in Figure 3.12), was also investigated to examine the relationship between the sensitivity of the transient response to the dominant opening porosities and the internal volume distortion.

As described in Table 3.3, the response time for Test 7 a $(7.5 \%$ porosity door, located at the center of the windward wall) was $0.09 \mathrm{~s}$ for three wind $A o A$ s considered. For Test 8 a ( $9 \%$ porosity window located close to the right side of windward wall) was $0.08 \mathrm{~s}$ at $45^{\circ}$ and $90^{\circ}$ wind $A o A$ while $0.07 \mathrm{~s}$ for $75^{\circ}$ wind $A o A$. This reveals that the response time of transient internal pressure overshooting was comparatively faster for higher porosity dominant opening. Comparing the response time of building with and without internal volume correction, Test8b, the building with no volume correction, exhibited 4 times faster response than that of Test $8 \mathrm{a}$ (i.e., $0.03 \mathrm{~s}$ vs $0.08 \mathrm{~s}$ ) irrespective of their similar porosity size. This underlines the necessity of correct scaling of the internal volume when experimenting transient responses in a $B L W T$ with velocity ratio other than unity. 


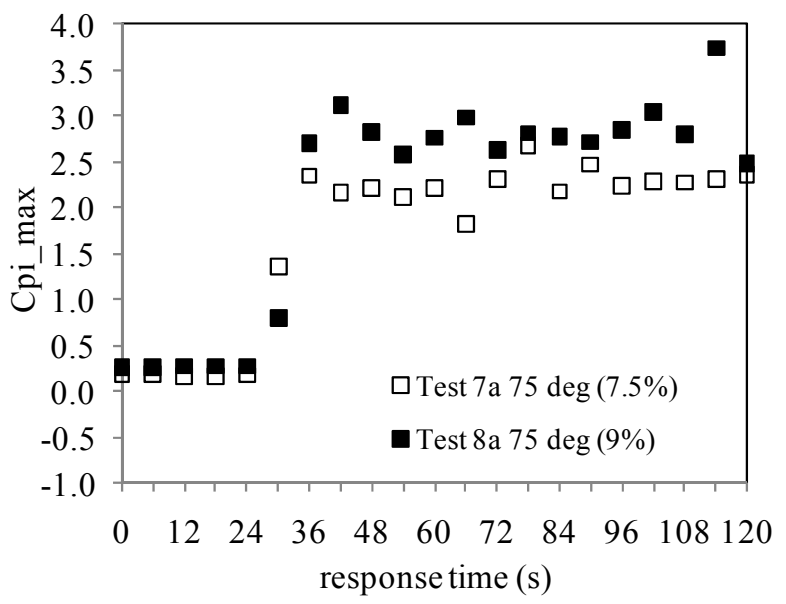

(a)

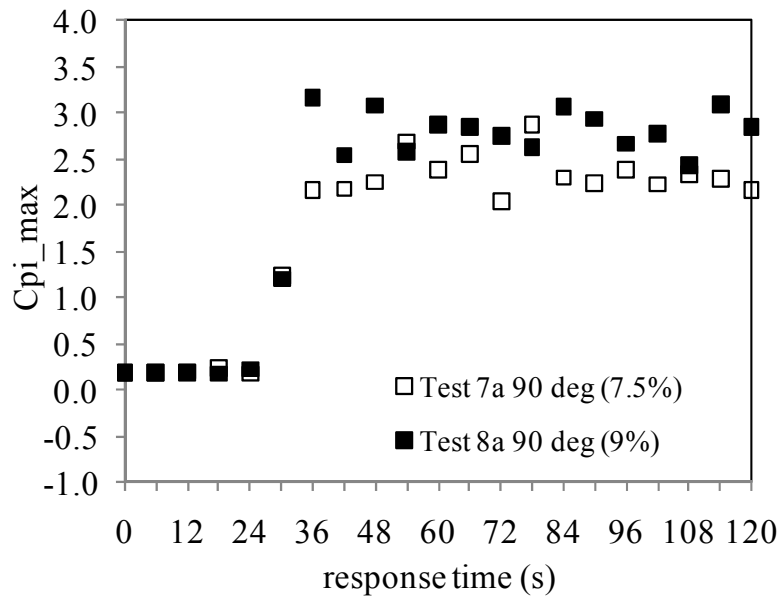

(b)

Figure 3.13: internal pressure response comparison due to sudden opening given in a block of $6 \mathrm{~s}$.

The overall characteristic of transient internal pressure was studied by using the peak and mean values with respect to their response time. The total 120 s time history was subdivided into 20 blocks, each block representing a 6s response data. The mean and peak values of each block data were extracted to trace the variation of the internal pressure with respect to time. Figure $3.13 \mathrm{a} \& \mathrm{~b}$ shows the peak internal pressure response time history for Test $7 \mathrm{a}$ and $8 \mathrm{a}$ at $75^{\circ}$ and $90^{\circ}$ wind $A o A$. The higher porosity dominant opening exhibits the higher internal pressure response before, during and after breach occurrence. Figure 3.14 demonstrates the effect of internal volume correction to be significant after the sudden occurrence compared to before breach. The big effect was observed at the moment of the breach. 


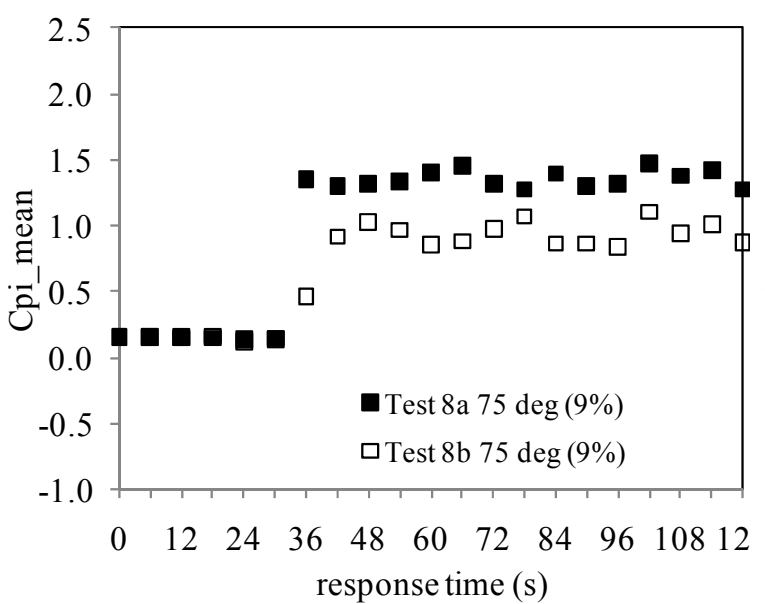

(a)

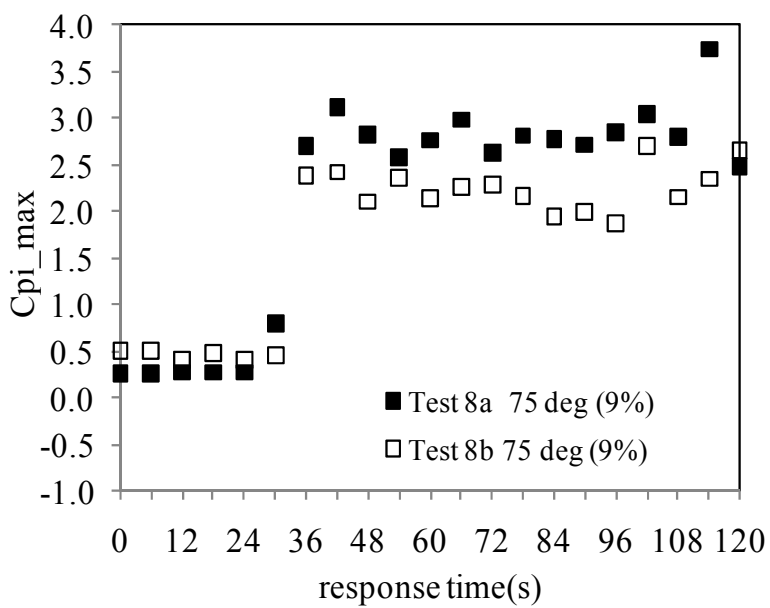

(c)

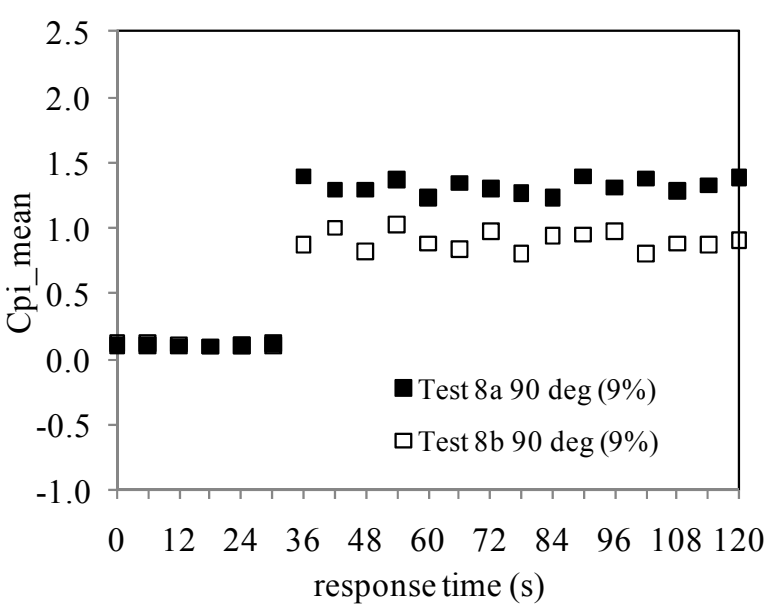

(b)

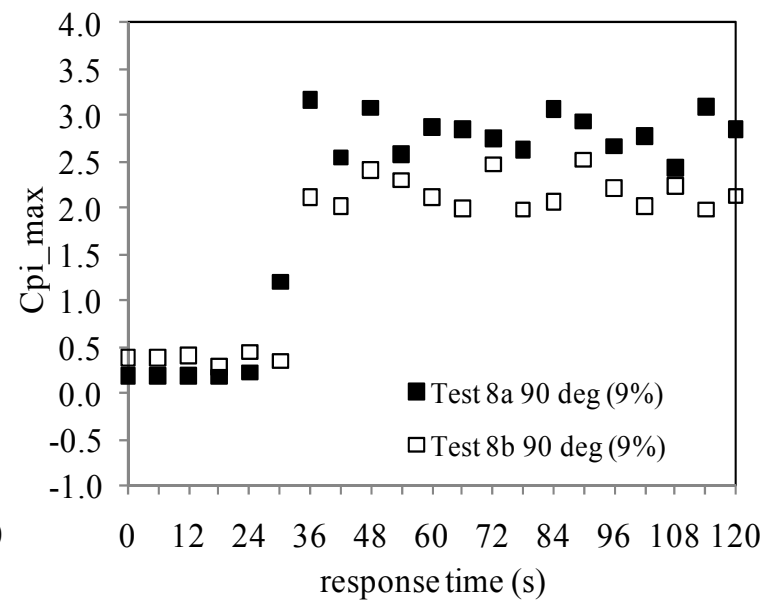

(d)

Figure 3.14: internal pressure response for off-center window in a block of $6 \mathrm{~s}$.

The effect of upstream wind direction on the sudden overshoot and the subsequent steady state internal pressure response was studied. Figure 3.15 displays the comparison of transient response of peak internal pressure coefficients at three wind $A o A$. The experiment have revealed that the $75^{\circ}$ wind $A o A$ causes an equivalent peak internal pressure response as that of $90^{\circ}$ in both the door ( $7.5 \%$ porosity) and the window ( $9 \%$ porosity). 

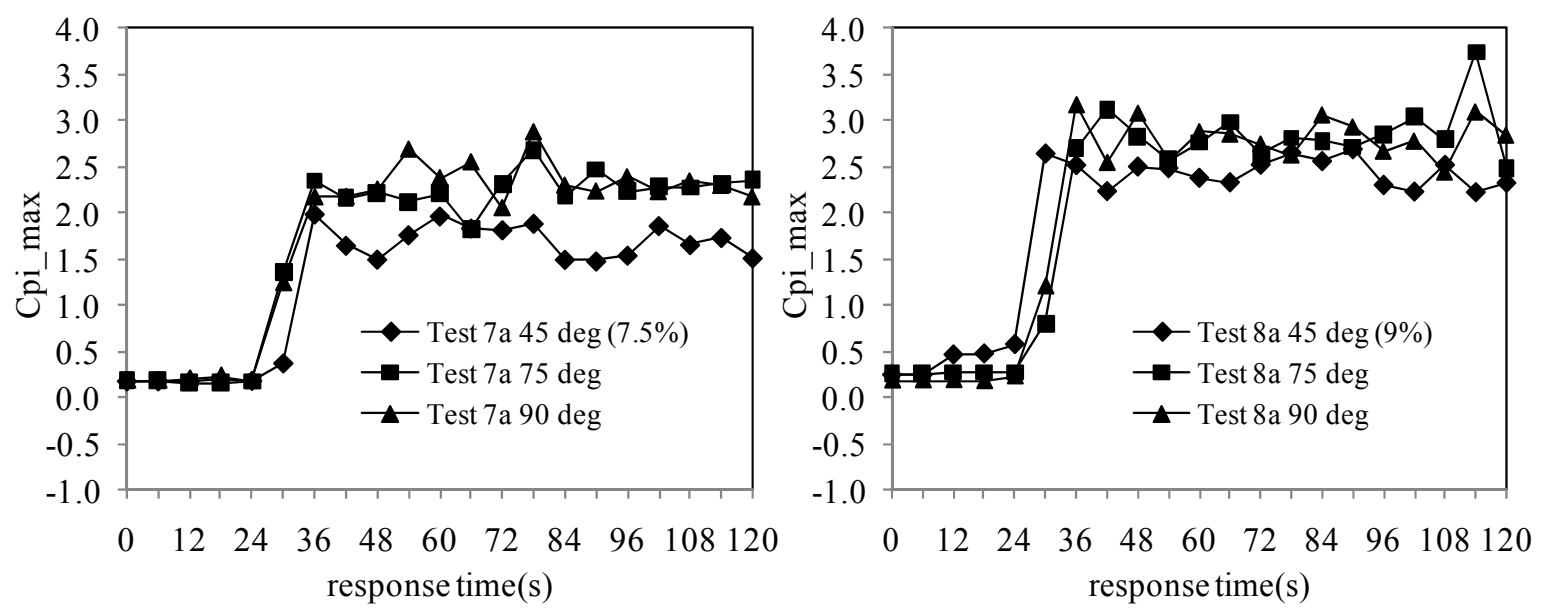

Figure 3.15: Internal pressure response for various wind $A o A\left(45^{\circ}, 75^{\circ}\right.$ and $\left.90^{\circ}\right)$.

Comparing the peak steady state internal pressure, Test $8 \mathrm{a}$ exhibits higher peak values than that of Test 7a as the window opening was located close to the upstream wall corner (right side corner). In other way, the oblique flow produced a competitively considerable response in transient and steady state internal pressure during sudden opening breach.

It is noteworthy to mention that the steady state response of internal pressure in sudden breach of openings was similar in magnitude to its respective internal pressure obtained in the presence of dominant opening (i.e., of partially enclosed building) of the same porosity. Comparing Test $7 \mathrm{a}$ of sudden opening phenomena with that of Test $2 \mathrm{a}$ of partially enclosed condition for wind direction $75^{\circ}$ and $90^{\circ}$, similar values were observed. For example, at $90^{\circ}$ wind $A o A$, the steady state response for Test 7 a $\left(\mathrm{D}_{1}\right.$ with $7.5 \%$ porosity) was 2.875 while for the same wind $A o A$, Test 2 a ( $\mathrm{D}_{1}$ with $7.5 \%$ but partially enclosed) gave peak internal pressure of 2.87 . For $75^{\circ}$ wind $A o A$, the peak internal pressures measured were 2.69 and 2.77 for the former and latter tests, respectively. 
The distribution of the peak internal pressure inside the building after sudden breach is shown in Figure 3.16 for tests 7 a $\& 8$ a. The data points starting from the time the door or window opened were taken in computing the peak values. The peak internal pressure was fairly uniform for all the tests undertaken.

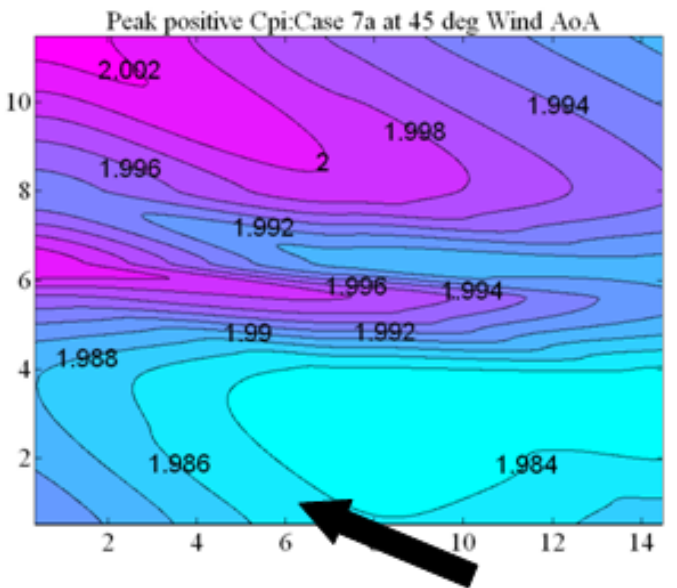

(a)

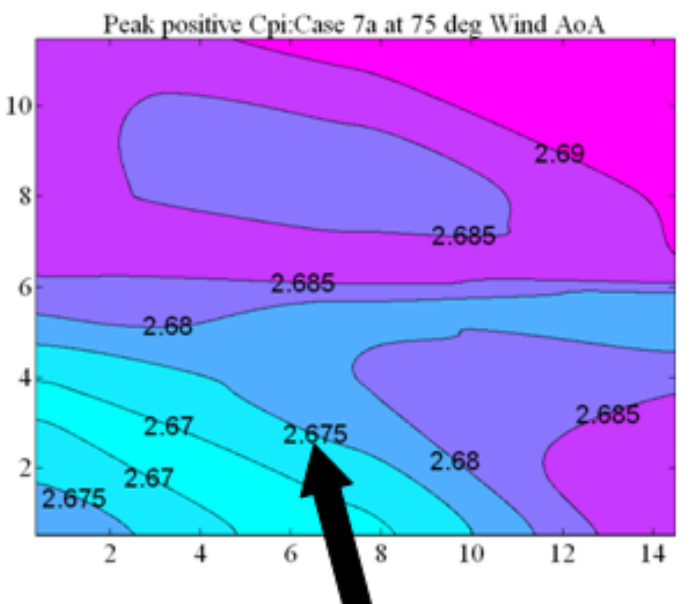

(c)

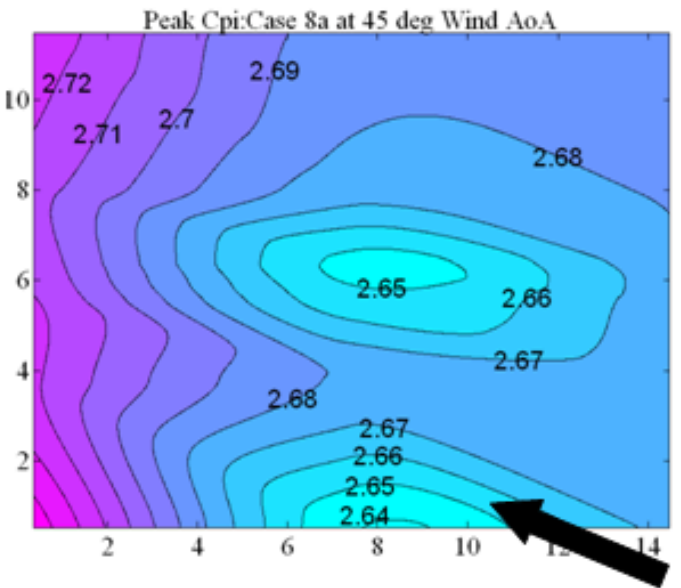

(b)

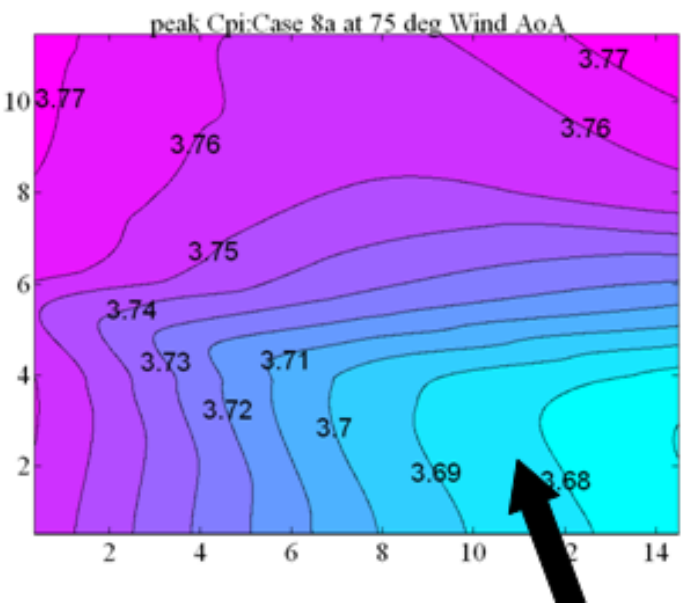

(d) 


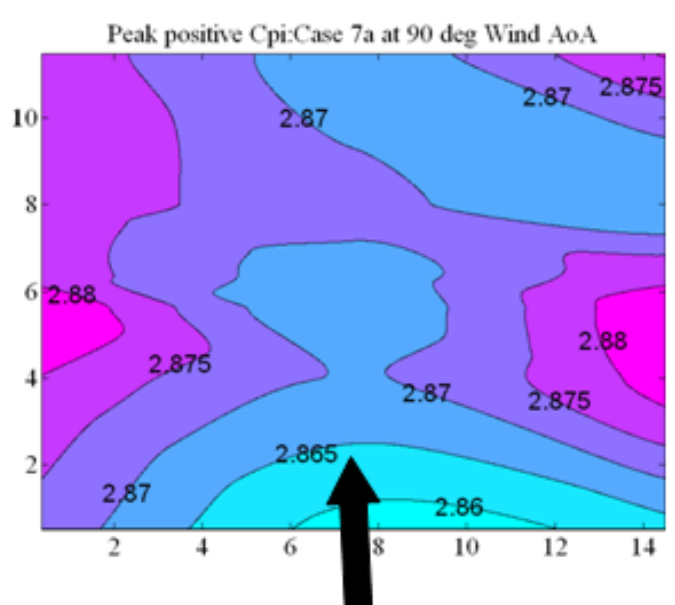

(e)

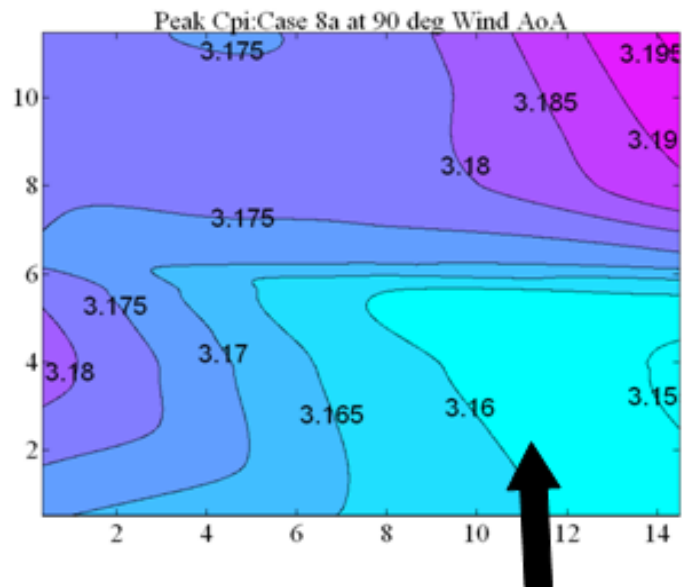

(f)

Figure 3.16: Uniformity of internal pressure distribution at various wind $A o A\left(45^{\circ}, 75^{\circ}\right.$ and $\left.90^{\circ}\right)$.

\subsubsection{Full scale to wind tunnel internal pressure comparison}

Full scale assessment of external and internal pressure commonly provide realistic data that relates to the actual aerodynamic phenomena with all the real-world building components such as opening size, opening wall thickness, background leakage, effective internal volume and other factors that govern the general flow conditions such as inertia and viscous forces. It categorically reduces the uncertainties that are involved in the fundamental fluid flow phenomena such as Reynolds number $(R e)$, characteristic length of the air-slug and Helmholtz frequency. However, the assessment of wind induced flow interaction using full scale building is costly.

Representative cases of internal pressure data obtained from the full scale and model scale building tests were compared. As described before, the model scale building used in the $B L W T$ was a 1:9 scale of the full scale building constructed at the Wall of Wind $(W o W)$. The comparison for dominant openings door $\mathrm{D}_{1}$ with $7.5 \%$ porosity and window $\mathrm{W}_{1}$ with $3 \%$ porosity are shown in Figure 3.17. 


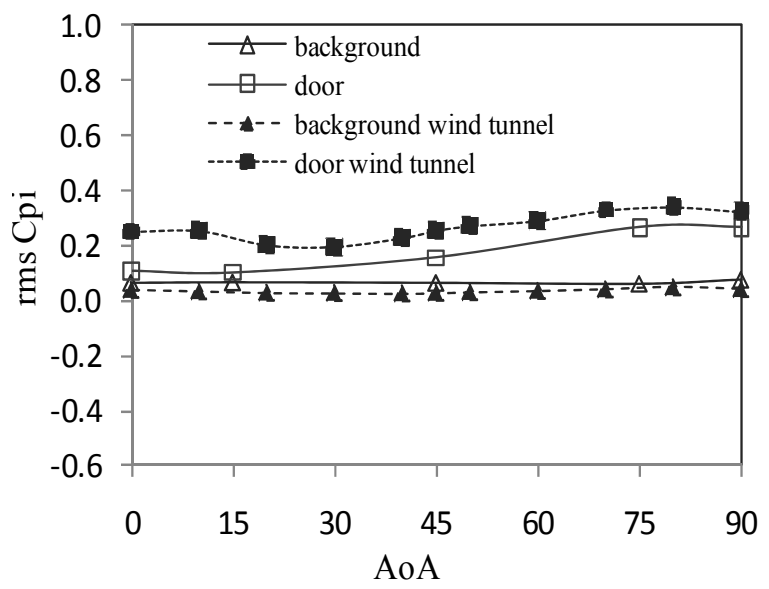

(a)

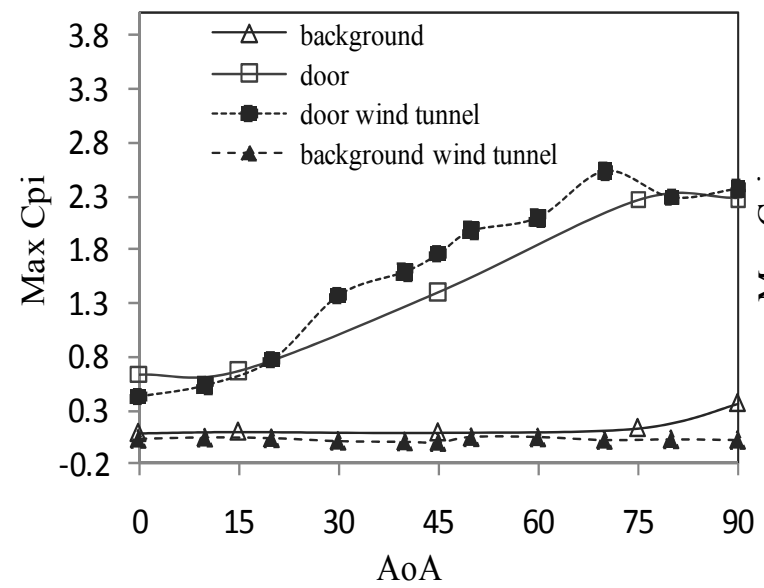

(c)

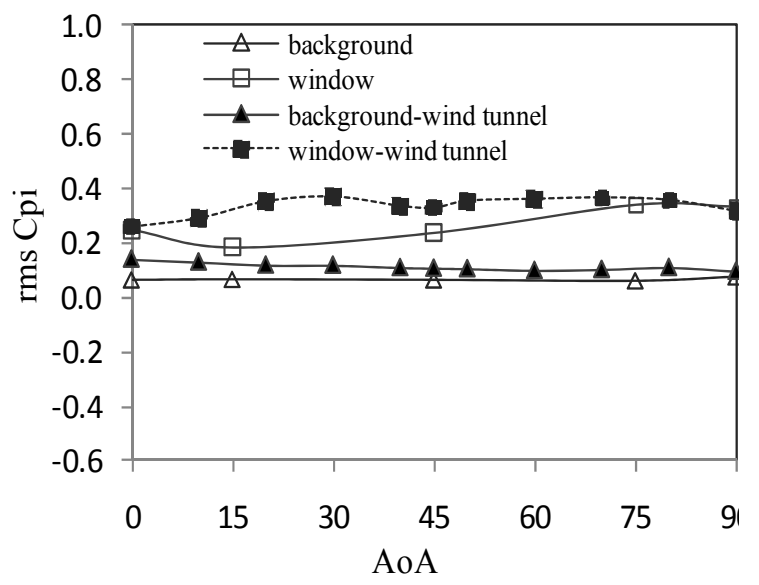

(b)

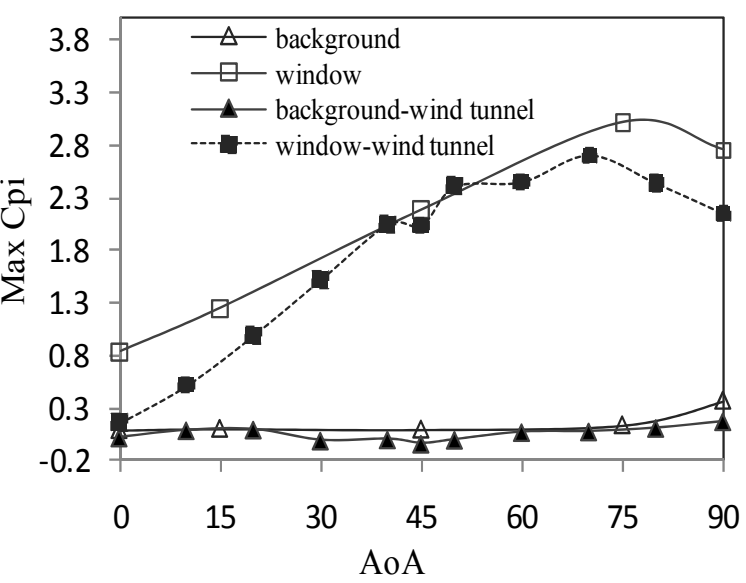

(d)

Figure 3.17: Full scale to small scale (BLWT) comparison of internal pressure.

Figure 3.17 a \& b show the comparison between the full and model scale gable building peak internal pressure inside the living room for a nominal background leakage as well as a dominant door with $7.5 \%$ porosity. Considering the differences in the flow field management, the type of model (for instance full scale incorporated actual construction materials), it can be inferred from the figure that there is a good agreement between the two test cases. In both cases studied, peak positive internal pressure was noticed at about 
$70^{\circ}-75^{\circ}$ wind $A o A$ instead of the usual $90^{\circ}$. Observing the rms internal pressure values of the full scale building, it exhibits certain degree of deviation from that of the wind tunnel data particularly for wind $A o A$ between $0^{\circ}$ and $50^{\circ}$. However, the agreement was better for windward opening compared with side opening.

\subsubsection{Comparison of internal pressure experimental vs ASCE 7-10}

Wind tunnel data obtained for different opening porosity at various wind $A o A$ were converted and recalculated to correspond to the current wind load provisions, ASCE 7-10. Two tier methods were applied to compute the equivalent pressure coefficients. Firstly, the peak internal pressure coefficient (from pressure time history) was divided into small blocks of data from which a reasonable value was extracted (i.e., $C_{\text {pi__hrly_BLWT) }}$ instead of taking the absolute peak at a point. Secondly, the peak hourly internal pressure coefficient from $B L W T$ was transformed to its equivalent $A S C E$ 7-10 (i.e., $G C_{p i}$ ) by multiplying it with a square of the ratio of the mean hourly to the $3 \mathrm{sec}$ gust speed which is 0.433 .

As shown in Table 3.4, the BLWT based internal pressure coefficient estimated by making use of the above two methods was compared with the internal pressure coefficients (i.e., $G C_{p i}$ ) in $A S C E$ 7-10. Only peak positive values at critical wind $A o A$ were considered as this one have a significant effect on the net uplift force on the building roof envelope from wind design perspective. As given in the code, $G C_{p i}= \pm 0.55$ for partially enclosed buildings and $G C_{p i}= \pm 0.18$ for enclosed buildings. In the present work, the building with the dominant openings of variable porosity and background leakages were in line with the definition of partially enclosed while the building with 
only inherent background leakage represents the enclosed case. For the Background leakage case, the experimental study was observed to be similar to the code, while for the dominant doors and windows the experimentally measured data consistently exceed those values based on $A S C E$ 7-10, in most cases by a factor of two or greater.

The building with the largest dominant openings experienced the largest difference and this shows that the peak internal pressure are not constant values as it consistently vary with respect to wind $A o A$, porosity size and volume of the building.

Table 3-4: Peak internal pressure coefficients $\left(G C_{p i}\right)$ in $A S C E$ 7-10 versus equivalent values measured in $B L W T$

\begin{tabular}{|c|c|c|c|c|c|}
\hline Description & $\begin{array}{c}\text { Porosity size } \\
(\%)\end{array}$ & $\begin{array}{l}\text { Wind } \\
\text { AoA }\end{array}$ & C $_{\text {pi_hrly_BLWT }}$ & $(\text { GCpi })_{\text {BLWT }}$ & ASCE7-10 \\
\hline \multicolumn{6}{|l|}{ Gable Building } \\
\hline \multirow{2}{*}{$\begin{array}{l}\text { Background } \\
\text { leakage }\end{array}$} & \multirow{2}{*}{$0.1 \%$} & 70 & -0.36 & -0.15 & -0.18 \\
\hline & & 90 & -0.38 & -0.17 & -0.18 \\
\hline \multirow{6}{*}{ Center doors } & \multirow{2}{*}{$7.5 \%$} & 90 & 2.37 & 1.02 & 0.55 \\
\hline & & 100 & 2.67 & 1.16 & 0.55 \\
\hline & \multirow{2}{*}{$5 \%$} & 90 & 2.08 & 0.90 & 0.55 \\
\hline & & 100 & 2.65 & 1.15 & 0.55 \\
\hline & \multirow{2}{*}{$3 \%$} & 90 & 1.93 & 0.84 & 0.55 \\
\hline & & 100 & 1.78 & 0.77 & 0.55 \\
\hline \multirow{4}{*}{ Corner windows } & \multirow{2}{*}{$3.5 \%$} & 70 & 2.71 & 1.17 & 0.55 \\
\hline & & 90 & 2.15 & 0.93 & 0.55 \\
\hline & \multirow{2}{*}{$9 \%$} & 70 & 2.83 & 1.22 & 0.55 \\
\hline & & 90 & 2.69 & 1.16 & 0.55 \\
\hline \multicolumn{6}{|l|}{ Hip roof building } \\
\hline Window & $6 \%$ & 270 & 2.13 & 0.92 & 0.55 \\
\hline Central door & $10 \%$ & 270 & 2.77 & 1.20 & 0.55 \\
\hline Door and windows & $22 \%$ & 270 & 3.16 & 1.37 & 0.55 \\
\hline \multicolumn{6}{|c|}{ Sudden door or window breach } \\
\hline \multirow{2}{*}{ Center door 1} & \multirow{2}{*}{$7.5 \%$} & 75 & 2.71 & 1.17 & 0.55 \\
\hline & & 90 & 2.90 & 1.26 & 0.55 \\
\hline \multirow{2}{*}{ Corner window } & \multirow{2}{*}{$9 \%$} & 75 & 3.78 & 1.63 & 0.55 \\
\hline & & 90 & 3.21 & 1.39 & 0.55 \\
\hline
\end{tabular}




\subsection{Conclusion}

This paper investigated the peak steady state $v s$ transient response of wind induced internal pressure for a low-rise building. Variable configuration of existing dominant openings, background leakage, soffit vents and compartmentalization were studied using a standard boundary layer wind tunnel. It compared the wind tunnel data with its corresponding full scale data. It also compared transient sudden overshooting with its subsequent peak steady state internal pressure to identify which one govern for wind load design. Finally, all experimental internal pressures data were compared with the corresponding (ASCE/SEI. 2010) values. The conclusions drawn are as follows:

- Commonly ventilation openings are closed during wind storms but this initiates the buildup of positive internal pressure inside the attic room. For a building having all round roof ventilation system, the mean and peak internal pressure underneath roof sheathing can be $40-140 \%$ bigger when the vents are closed.

- In addition to the porosity size of dominant openings, their locations with respect to the upstream wind direction play a significant role in determining the dynamics and characteristics of the internal pressure.

- An opening located off-center from a windward wall exhibits higher peak positive and suction $\mathrm{C}_{\mathrm{pi}}$ than its equivalent dominant opening located at the center wall. For instance, the window opening located at the right side corner of the windward wall exhibited $45 \%$ higher peak steady state internal pressure ;

- For critical loading, the location of the dominant opening with respect to upstream wind direction is highly significant than the porosity size; 
- The transient overshooting response was found to be lower than the subsequent steady state peak $C_{p i}$ consistently for all wind directions and porosity sizes examined;

- Correct internal volume scaling in $B L W T$ is necessary as incorrectly scaled internal volume experiences a response time 4 times faster and 30-40\% lower peak and mean $C_{p i}$ than the building with correct volume during a sudden opening;

- The comparison between the full-scale and BLWT internal pressure responses shows good agreement in both the peak and mean values investigated;

- The ASCE 7-10 significantly underestimates the peak positive internal pressure in all the configurations with dominant openings and building types considered.

\subsection{References}

ASCE/SEI (2010),"Minimum Design Loads for Buildings and Other Structures ", ASCE/SEI 7-10, Reston, Va.

Holmes, J.D. (1979). "Mean and fluctuating internal pressures induced by wind". Proc. 5th Int. Conf. on wind engineering, Colorado, USA.

Holmes, J.D. (2001). Wind Loading of Structures, Spon Press.

Irwin, P.A. and Sifton, V.L. (1998). "Risk Considerations for Internal Pressures." Journal Wind Engineering and Industrial Aerodynamics 77 \& 78: 715-723.

Kopp, G.A., Oh, J.H. and R.Inculet, D. (2008). "Wind-induced Internal Pressures in Houses." Journal of Structural Engineering 134(7): 1129-1138.

Liu, H. and Saathoff, P.J. (1981). "Internal pressure and building safety." Proceedings, Journal of Structural Division, ASCE, 108.

Liu, H. and Saathoff, P.J. (1983). "Internal pressure of multi-room buildings." Journal of Engineering Mechanics Division 109(EM3): 908-919. 
Oh, J.H., Kopp, G.A. and Inculet, D.R. (2007). "The UWO contribution to the NIST aerodynamic database for wind loads on low buildings. 3: Internal pressures." Journal of Wind Engineering Industrial Aerodynamics 95(8): 755-779.

Sharma, R. N. (2000). "Transient response of building internal pressure to a sudden opening in the turbulent wind," in: Proceedings of the Fourth International Colloquium on Bluff Body Aerodynamics \& Applications, 27-30, Bochum, Germany, 11-14th September, 2000.

Sharma, R.N., Mason, S. and Driver, P. (2010). "Scaling methods for wind tunnel modelling of building internal pressures induced through openings." Wind and Structures 13(4): 363-374.

Sharma, R.N. and Richards, P.J. (2003). "The influence of Helmholtz resonance on internal pressures in a low-rise building." Journal of Wind Engineering Industrial Aerodynamics 91: 807-828.

Sharma, R.N. and Richards, P.J. (2005). "Net pressure on the roof of a low-rise building with wall openings." Journal of Wind Engineering and Industrial Aerodynamics 93: 267291.

Simiu, E. and Scanlan, R.H. (1996). Wind Effects on Structures, John Wiley and Sons.

Simiu, E. and Stathopoulos , T. (1997). "Codification of wind loads on buildings using bluff body aerodynamics and climatological data bases." Journal of Wind Engineering and Industrial Aerodynamics 69-71: 497-506.

St.Pierre, L.M., kopp, G.A., Surry, D. and Ho, T.C.E. (2005). "The UWO contribution to the NIST aerodyamic database for wind loads on low buildings.2: Comparison of data with wind load provisions." Journal of Wind Engineering and Industrial Aerodynamics 93(1): 31-59.

Stathopoulos, T. and Luchian, H.D. (1989). "Transient Wind-Induced Internal Pressures." Journal of Engineering Mechanics, ASCE 115(7): 1501-1514.

Stathopoulos, T., Surry, D. and Davenport, A.G. (1979). Internal pressure characteristics of low-rise buildings due to wind action. In: Proc. 5th Int. Conf. on Wind Engineering, Fort Collins, Colorado, Pergamon Press, New York.

Vickery, B.J. (1986). "Gust factors for internal pressures in a low rise buildings." Journal of Wind Engineering and Industrial Aerodynamics 23: 259-271.

Vickery, B.J. and Bloxham, C. (1992). Internal Pressure Dynamics with a Dominant Opening. Eighth International Conference on Wind Engineering. London, Ontario, Canada. 
Whalen, T., Simiu, E., Harris, G., Lin, J. and Surry, D. (1998). "The use of aerodynamic databases for the effective estimation of wind effects in main wind-force resisting systems: application to low buildings." Journal of Wind Engineering and Industrial Aerodynamics 77-78: 685-693.

Yeatts, B.B. and Mehta, K.C. (1992). "Field experiments for building aerodynamics". Proceedings ofthe Second International Colloquim on Bluff Body Aerodynamics and Applications, Melbourne, Australia. 


\title{
4. WIND-INDUCED INTERNAL PRESSURE IN HIP ROOF LOW-RISE BUILDING: A BOUNDARY LAYER WIND TUNNEL STUDY
}

\author{
Amanuel S. Tecle ${ }^{1}$, Girma T. Bitsuamlak ${ }^{2}$, Arindam Gan Chowdhury ${ }^{3}$ \\ Submitted to ASCE, Journal of Engineering Mechanics
}

\begin{abstract}
The paper presents a boundary layer wind tunnel study on wind-induced internal pressure for a low rise building. A typical one-storey hip roof low-rise building with an attic space was constructed at a model scale of 1:20 with a roof slope of 5:12.
\end{abstract} The study adopted corrections for internal volume scaling, proper characteristic length (thickness) scaling of various type openings and implemented a realistic interior horizontal and vertical compartmentalization representing a typical low cost housing in Florida. Effects of different dominant openings, ventilation openings and background leakage under different wind angle of attack have been experimented and Helmholtz resonance examined. The results of the wind tunnel data analysis indicated: internal volume distortion didn't show significant impact on the rms internal pressure for the low rise building considered based on the comparative study with and without the volume correction but affected the mean and peak values considerably for the building with larger internal volume; the response in internal pressure highly correlated to the fluctuation in the external pressure at the dominant openings; an increase in opening area causes a significant change in the dynamics of the internal pressure; and keeping other factors constant, the presence of a small opening on the ceiling partition caused a dramatic increase in internal pressure under the roof sheathing which significantly increased the net wind load on the roof (for instance, the opening of $10 \%$ door porosity together with a $0.35 \%$ ceiling hatch led to $90 \%$ increase on the roof sheathing positive 
internal pressure coefficient). It was found that the internal pressure distribution inside multi rooms stays uniform in the presence of single dominant opening. In the presence of opposite side dominant openings, however, the internal pressure ceases its uniformity. The higher would be the internal pressure for rooms closer to the windward dominant opening. It was also noticed that soffit ventilation openings play a considerable role in dampening the attic peak internal pressure by $15 \%-27 \%$. For roof locations such as corners, hip and ridge lines, it was observed that the mean net uplift pressure coefficient can vary between -2.5 and -3.25 while the peak net pressure coefficient can vary between -8.5 and -9.05 .

Key words: Internal and external pressure, dominant openings, vents, compartmentalization, Helmholtz resonance, hip roof, volume correction, wind tunnel.

\subsection{Introduction}

Recent hurricane events have caused significant damage on infrastructure particularly in coastal regions which are highly prone to high wind loads. Post hurricane investigations have shown that low-rise buildings being exposed to majority of the damages. In most cases, low-rise buildings are either non-engineered or poorly designed to resist hurricane winds and the subsequent impacts from wind borne debris, wind driven rain, and interior pressurization. Low rise-buildings, relative to tall buildings, are also immersed within the layer of aerodynamic boundary layer on the earth's surface where the turbulence intensities are high (Holmes 2001). Investigations of major wind events have revealed that major damage to buildings is initiated due to failure of external building envelopes. The common damages often observed are to the roof components, windows, doors and roof vents (Minor and Mehta 1979; Stathopoulos et al. 1979; Kopp 
et al. 2008). The direct damage effects to these building components subsequently transfer to the internal part of the building leading to over pressurization and the intrusion of wind driven rain.

Wind produces both external and internal pressure on and within buildings. Internal pressure develops due to the infiltration/exfiltration of air through the building's envelope systems that have porosity. The porosity can, often, be due to defects such as cracks around doors and windows jamb; openings at soffits, utility ducts and vents; or windborne breach of a building envelope. The inflow of wind through the building envelope commonly leads to over pressurization of the internal dwellings unless otherwise there is an equivalent opening in the leeward side to relieve the pressurization. The major aerodynamic factors that govern the external pressure include: topography, upstream and surrounding conditions, shape of the building and wind direction. Many researchers have performed extensive studies to better understand the nature and characteristics of external pressure aerodynamics. As a result, an extensive database is available on wind induced external pressure for buildings. The major factors that govern the magnitude and direction of internal pressure in a building (in addition to those factors specified for external pressure) are: size and position of dominant openings, fluctuation of external pressure at the openings, the upstream wind direction with respect to the dominant openings, internal volume and compartmentalization, natural ventilation openings and background leakages due to crack and outlet ducts (or damages due to breach of building envelope) (Holmes 1979; Stathopoulos et al. 1979; Liu and Saathoff 1981; Liu and Saathoff 1983; Vickery 1986; Ginger et al. 1997; Sharma and Richards 2005; Oh et al. 
2007; Ginger et al. 2008; Kopp et al. 2008; Holmes 2009). Understanding the basic principles of internal pressure and knowing how it behaves with different aerodynamic factors involved becomes essential to properly design the main wind force resisting systems and components and claddings (Davenport and Surry 1984), as well as the computation of infiltration/exfiltration of building systems and the intrusion of water (moisture) through building envelopes.

Compared to external pressure, very few studies are available on internal pressure even though its contribution to the total load is significant (Holmes 1979; Stathopoulos and Luchian 1989; Irwin and Sifton 1998; Sharma and Richards 2003; 2005). According to $A S C E$ 7-10 (Section 26.4.2), the vector sum of the two forces (external and internal pressures) determine the magnitude and direction of the wind load on each envelope components. At critical condition, the net pressure (i.e., the algebraic sum of external pressure and internal pressure in the presence of dominant openings) could increase the suction pressure on the building roof by a factor of two. The local peak wind loads developing at building envelope (roof, wall, soffit corners) and other vulnerable locations may lead to the initiation of failure unless properly evaluated by considering both external and internal pressures into account during the design process.

Some of the earlier studies on internal pressure phenomena were carried out by Holmes (1979) in which a one room building with a single dominant opening was experimented in a boundary layer wind tunnel. The study analyzed the relation between internal pressure fluctuations and the effect of air compressibility and showed that buildings with a single dominant opening behave like a Helmholtz resonator. A wind 
tunnel study carried out by Stathopoulos et al. (1979) also showed the occurrence of critical positive internal pressure with openings in the windward wall. Studies performed to investigate the effect of compartmentalization on internal pressure showed that the peak internal pressure resulting from a sudden windward opening increase as the opening area increases or as the effective internal volume decreases (Liu and Saathoff 1983; Sharma and Richards 2003). The effect of background porosity on internal pressure was studied by (Bloxham and Vickery 1989). The study found that the porosity effect is of little significance if the leakage area is less than $10 \%$ of the windward dominant opening area. Higher percentage of background leakage works to attenuate the Helmholtz resonance. A full scale study was performed with and without dominant openings and it was observed that building leakage provided sufficient reduction in the excitation of internal pressure (Fahrtash and Liu 1990). Recently, a wind tunnel study was performed using models with two opening sizes and uniformly distributed background leakage (Oh et al. 2007). The study effectively applied internal volume scaling to maintain dynamic similarity. The study concluded that internal pressure fluctuations dramatically attenuate for building with leakage only. For building with leakage and single dominant opening, however, Helmholtz resonance occurs and peak internal pressures occur for wind direction normal to the wall having dominant opening. Moreover, the study found that peak internal pressure coefficients exceed the design loads recommended in wind loading standards such as ASCE7-02. The observation gathered in this experiment was further studied using a typical North American low-rise building (Kopp et al. 2008). The study examined the effects of dominant opening location and sizes, background leakage, compartmentalization of attic space from living space, roof and vents. The experiment 
showed that peak external roof pressures were highly correlated in time with the internal pressures. Decreasing the ratio of the internal volume to the opening area increased the peak internal pressures and Helmholtz resonance, particularly for wind directions normal to the opening. It also showed the significance of ceiling partition $-80 \%$ of peak pressure in the living room got transmitted into the attic space in the presence of ceiling opening as small as $0.4 \%$ of the attic floor area. A similar study was also performed but at full scale simulating the effect of variable dominant opening sizes and internal volume (Ginger et al. 2008). The study concluded that internal pressure fluctuations are significantly influenced by the size of the dominant opening and the size of the volume. It also showed the need for wind tunnel tests to correctly scale the internal volume of model buildings (by the square of the full scale to model scale velocity ratio) in order to obtain a reliable internal pressure fluctuations. A further study on model cavity volume distortion was performed to investigate the appropriate scaling methods (Sharma et al. 2010). Even though the internal volume distortion of wind tunnel model is necessary for correct simulation of internal pressure characteristics, the geometry of the additional volume chamber is not given proper attention. Sharma et al. (2010) found that the geometry of the box cavity through which the volume distortion was implemented had significant impact on the dynamics of the internal pressure. The study concluded that a deep but narrow volume chamber reproduces a realistic Helmholtz resonance frequency. 
The present study attempted to deal with the inherent scale issue related to the internal volume and its significance on the characteristics of internal pressure, as well as those related with background leakage by constructing an air-tight volume chamber. Proper attention was exercised in scaling of the chamber as well as the thickness of the dominant openings. The characteristics of internal pressure with and without volume distortion were investigated with the objective of assessing the effect of volume correction for low-rise building testing. The internal pressure distribution in the presence of realistic multi room partitioning (vertical) and ceiling compartmentalization (horizontal) representing a typical low-cost residential house was studied.

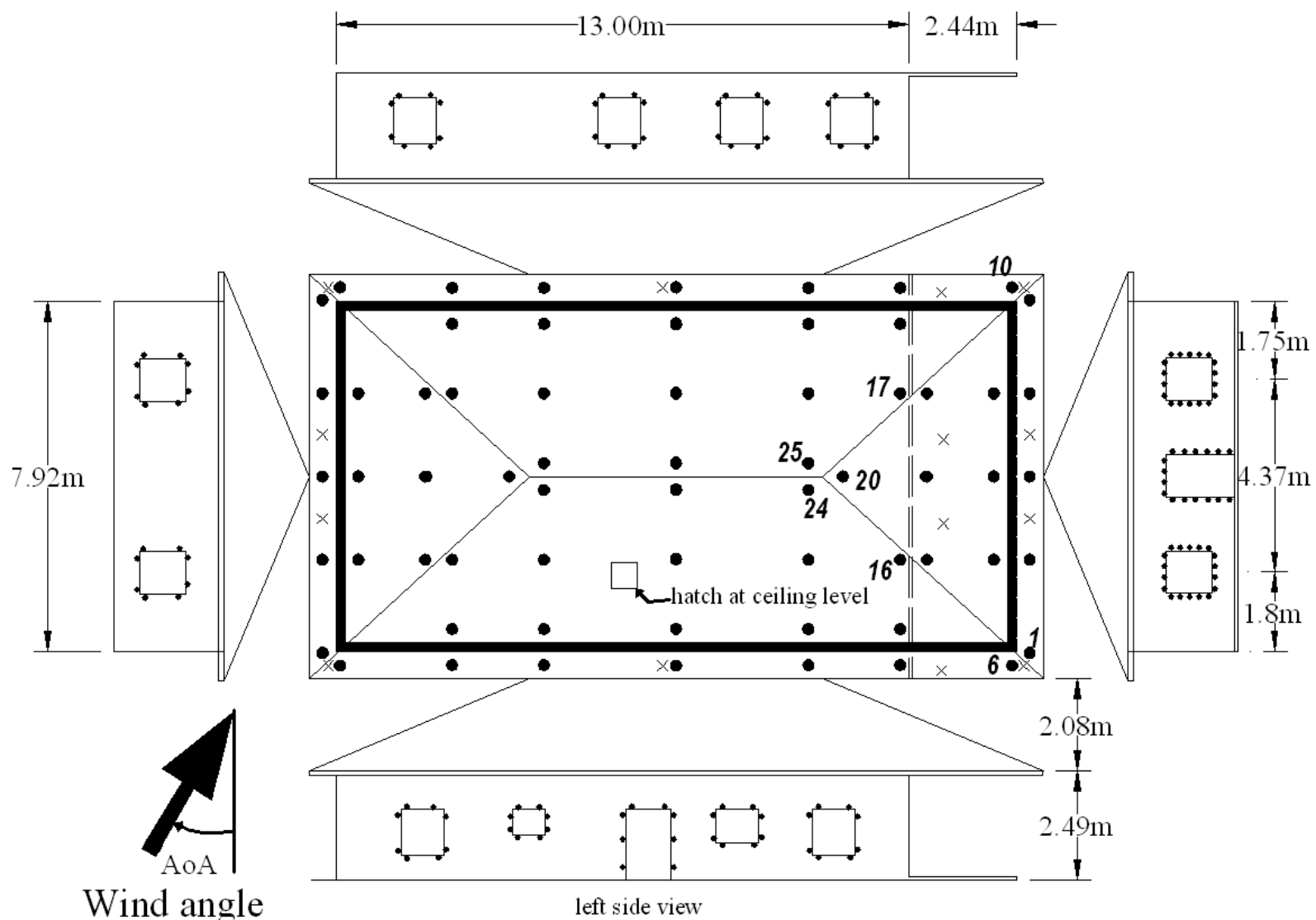

Figure 4.1: Exploded view of building model with external pressure taps layout and location of dominant openings. (Dimensions given are full scale) 


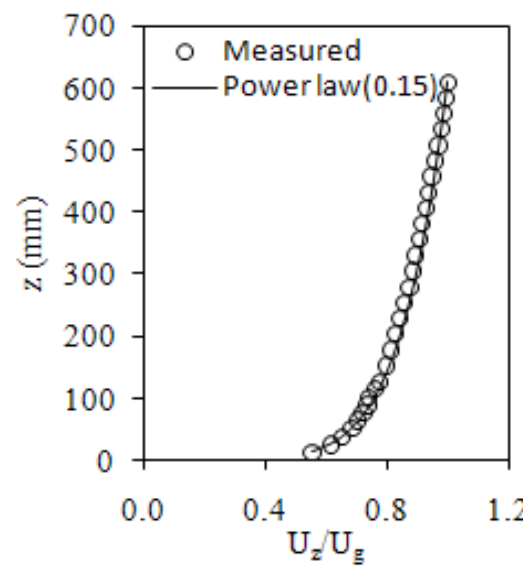

(a)

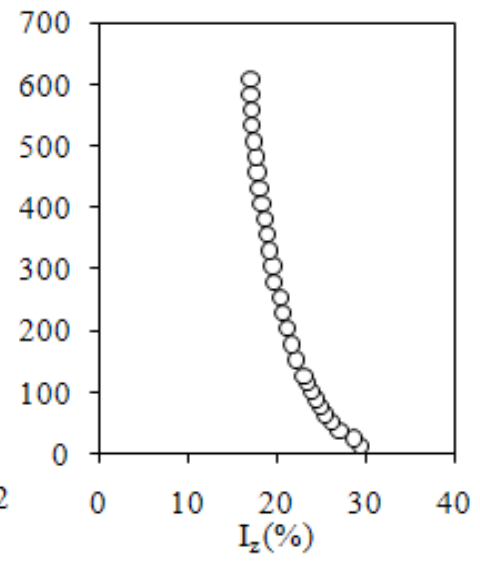

(b)

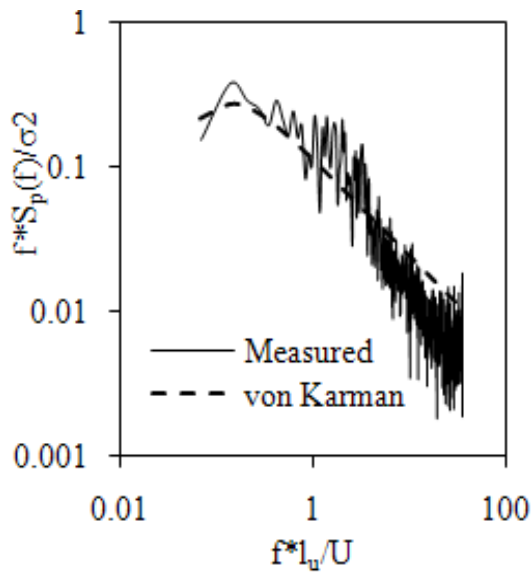

(c)

Figure 4.2: Open terrain profiles: a) wind velocity, b) Turbulence intensity, and c) spectra of wind velocity at mid roof height

The study also examined the net pressure loading due to internal and external pressure distribution at different location on the roof envelope and identified the range of wind angle of attack (AoA) that caused worst wind loading over the vulnerable areas of the building roof.

\subsection{Methodology}

A one-storey hip roof low-rise building (with an attic space) constructed at a model scale of 1:20 whose exploded view is given in Figure 4.1 was studied in a standard commercial boundary layer wind tunnel: Rowan Williams Davies \& Irwin Inc. (RWDI). The wind tunnel has a test section of width $2.44 \mathrm{~m}(8 \mathrm{ft})$ with an adjustable roof that varies between $1.5 \mathrm{~m}(5 \mathrm{ft})$ and $2.43 \mathrm{~m}(8 \mathrm{ft})$. The test section includes a fully indexed $2.43 \mathrm{~m}(8 \mathrm{ft})$ diameter turn table with a resolution of 0.1 degree. The model building has an equivalent full-scale plan dimensions of $L=15.44 \mathrm{~m}(50.67 \mathrm{ft})$ by $W=7.92 \mathrm{~m}(26.00 \mathrm{ft})$ with a roof slope of 5:12 and eave height of $h_{1}=2.49 \mathrm{~m}(8.17 \mathrm{ft})$. The total height of the building from 
ground to ridge level was $4.57 \mathrm{~m}$ (15ft) (i.e., the building has an attic with height $\left.h_{2}=2.08 \mathrm{~m}(6.83 \mathrm{ft})\right)$. The model was fabricated from a Plexiglas acrylic sheet. As shown in Figure 4.1, the model building was prepared by fabricating the major building components to simulate the realistic wind-building interaction governing the external and internal pressures. These include the vertical partitioning of the living room with proper scaling of the walls and openings, horizontal partitioning at ceiling level that separates the living room from the attic. A common practice in low-rise building is the provision of a window opening-access to the attic space. In this experiment a "hatch" was provided to connect the two compartments (i.e., living and attic space). All the claddings, ventilation system, thickness of door and window jambs were also properly scaled to replicate the full scale building.

\subsubsection{Test wind profile}

Wind tunnel experiments for low-rise buildings entail partial simulation of the entire atmospheric boundary layer $(A B L)$ and accurate modeling of wind turbulence in the lower reaches of the $A B L$, where these buildings are located. The $A B L$ wind profile was obtained through a trial and error procedure. Various configurations of roughness length and spire shapes were tested in order to reproduce the open terrain conditions. Specific wind profile parameters were selected that conform to the $A S C E$ 7-10 provisions.

For the upstream terrain with open country exposure, the power law index $(\alpha)$ and the turbulence intensity were 0.154 and $21 \%$ at $3.53 \mathrm{~m}$ (11.59ft) full scale mean roof height, respectively (Figure $4.2 \mathrm{a} \& \mathrm{~b}$ ). The most important turbulence component which is the longitudinal component $\mathrm{U}(\mathrm{t})$, expressed by the Von Karman spectrum was compared with 
the longitudinal turbulence spectra developed in the $A B L$ wind profile (Figure 4.2c). The roughness elements used on the upstream length of the wind tunnel was $0.038 \mathrm{~m}(1.5 \mathrm{in})$. The reference wind speed was recorded for $90 \mathrm{sec}$ in the absence of the model building. A mean reference wind speed of $8.95 \mathrm{~m} / \mathrm{s}(20.03 \mathrm{mph})$ was obtained at the mean roof height.

\subsubsection{Full scale to wind tunnel length and velocity ratio scaling}

A number of researchers have raised concern on the necessity of the provision of internal volume distortion while testing internal pressure in a boundary layer wind tunnel in order to accurately measure the internal pressure fluctuations. As explained in the introduction part, if the ratio of the full scale to wind tunnel velocity is different from unity, the volume scale is not simply dependent on geometrical length scale but also needs to consider the velocity scale. The consideration of both velocity and length scale, while determining the internal volume scale, helps maintain realistic internal pressure measurement, particularly the Helmholtz natural frequency and turbulence spectrum. Holmes (1979) explained the scaling parameters by using the non-linear single degree of freedom differential oscillation equation as given in Eqn.1. Writing the equation in terms of a non-dimensional pressure coefficient, one can obtain Eqn.2. From a dimensional analysis of Eqn. (1), the similarity of internal pressure measurement between full scale and wind tunnel model can be retained as given in Eqn. 3 (Holmes 1979). In cases where in which the atmospheric pressure and density of air are assumed similar, Eqn.3 can be re-written in the form given by Eqn. 4 
$\rho A l_{e} \ddot{X}+\frac{\rho A}{2 k^{2}} \dot{X}|\dot{X}|+\frac{n P_{o} A^{2}}{V_{o}} X=\Delta P_{e} A$

$\frac{\rho l_{e} V_{o}}{n A P_{o}} \ddot{C}_{p i}+\frac{\rho V_{o}^{2} q}{2 k^{2} n^{2} A^{2} P_{o}^{2}} \dot{C}_{p i}\left|\dot{C}_{p i}\right|+C_{p i}=C_{p e}$

$\frac{\left\lfloor\bar{U}^{2} V_{o}\right\rfloor_{m}}{\left.\bar{U}^{2} V_{o}\right]_{f}}=\frac{[A]_{m}^{\frac{3}{2}}}{[A]_{f}^{\frac{3}{2}}} x \frac{\left[P_{o}\right]_{m}}{\left[P_{o}\right]_{f}} x \frac{[\rho]_{m}}{[\rho]_{f}}$

$\frac{\left[V_{o}\right]_{m}}{\left[V_{o}\right]_{f}}=\frac{[L]_{m}}{[L]_{f}} x \frac{[\bar{U}]_{f}^{2}}{[\bar{U}]_{m}^{2}}$

Where $L=$ characteristic geometric length scale: $\bar{u}=$ eave height wind speed; $V_{o}=$ internal volume; $m \& f=$ model and full scale representation, respectively. Eqn. 4 emphasizes the significance of the square of the ratio of the full scale to model scale reference velocity on the internal volume of the model building. Thus, for correct internal volume scaling and the appropriate measurement of the internal pressure fluctuations, the nominal volume obtained by length scale should be magnified by a factor of the square of the velocity ratio, if the ratio is different from unity.

As shown in Figure 4.3, the model was prepared at a scale of 1:20 and the full to model scale velocity ratio taken was $3: 1$. Thus, the nominal volume obtained by scaling the characteristic length of the full scale building is required to be distorted by a factor of 9 based on the above relation (i.e., Eqn. 4). A volume chamber was constructed by considering the suggestion by (Sharma et al. 2010) to avoid shallow and wider volume chamber. The sealed volume chamber was constructed to accommodate the additional volume requirements of the attic and the living room. Accordingly, the additional volume 
introduced for the living room and the attic was $0.226 \mathrm{~m}^{3}\left(13787 \mathrm{in}^{3}\right)$ and $0.087 \mathrm{~m}^{3}(5315$ $\left.i^{3}\right)$ respectively. When both the attic and living room were merged as a single room, the total additional volume provided by the volume chamber became $0.313 \mathrm{~m}^{3}\left(19102 \mathrm{in}^{3}\right)$.

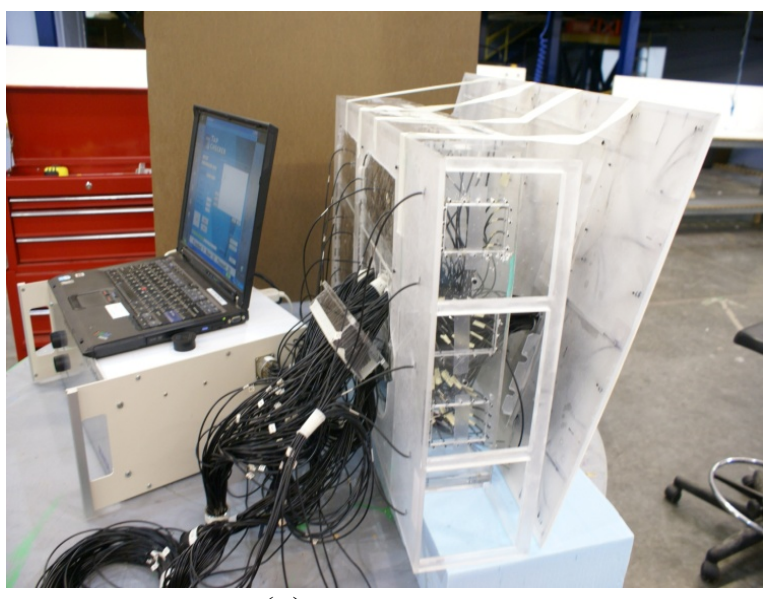

(a)

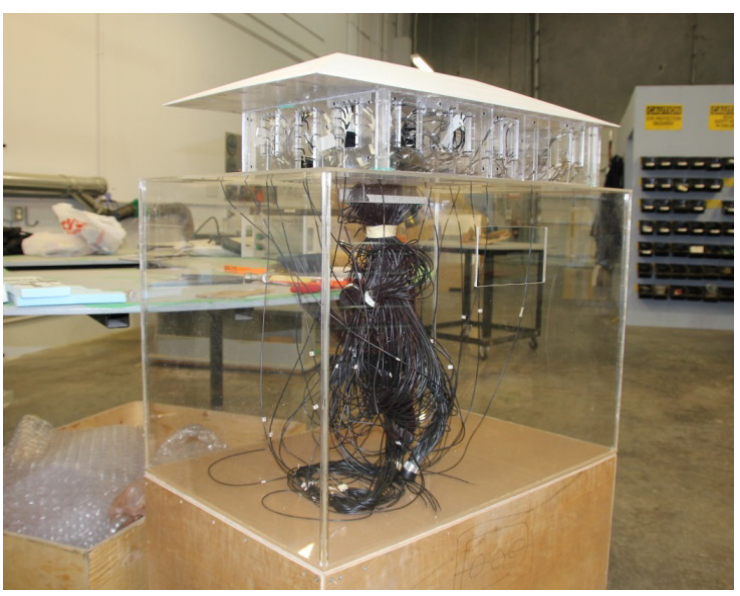

(b)

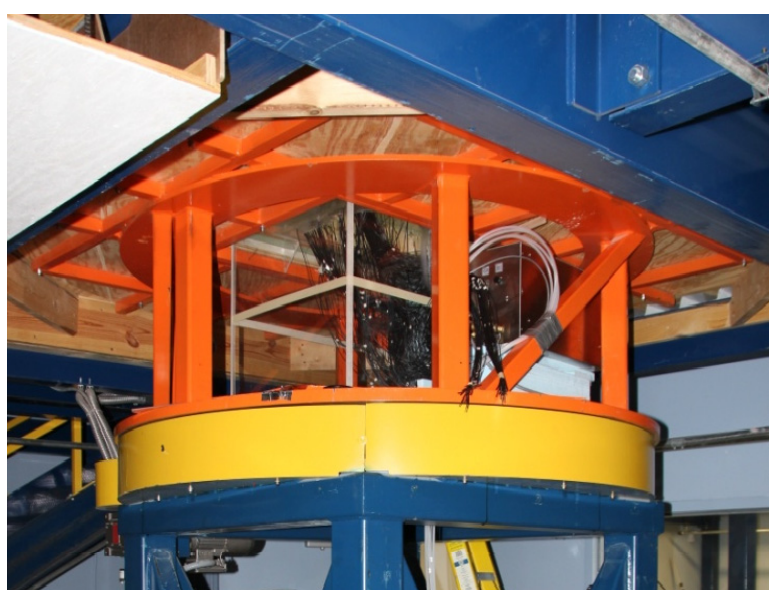

(c)

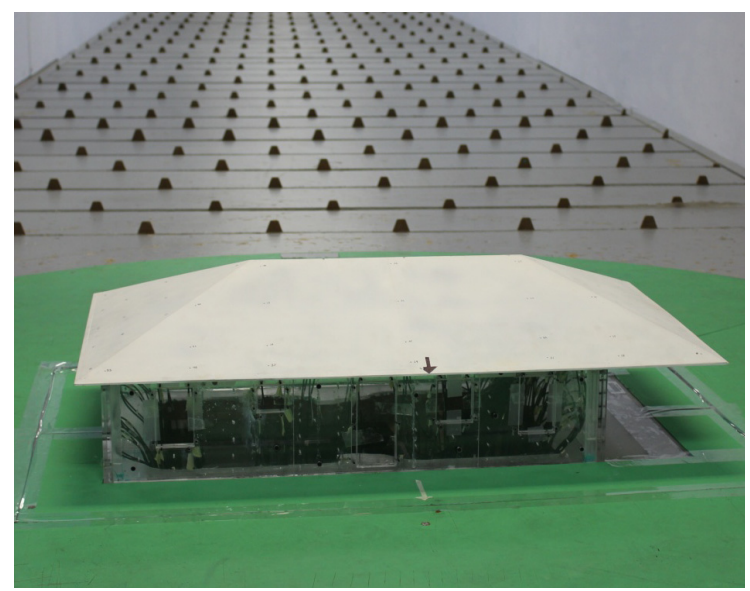

(d)

Figure 4.3: Model setup: a) Hip roof tube leakage inspection, b) Hip roof with volume chamber, c) Volume chamber set up underneath turntable, and d) Hip roof building model inside the wind tunnel. 
The hip roof building has a number of dominant openings, background leakages and soffit ventilations. The external envelope of the building has both dominant openings (door and windows) as well as uniformly distributed circular holes (of diameter $0.0016 \mathrm{~m}$ (1/16 in)) to simulate the background leakage due to cracks and joints. In all the cases studied, a background leakage of $0.1 \%$ of the respective envelope surface area (i.e., wall or ceiling) was considered. Similarly, the ceiling partition was provided with a ceilinghatch (a common opening in low-rise buildings that connect the living room to the attic for storage purpose) and a uniformly distributed background leakage. Cross-ventilation of the attic space was provided by implementing soffit openings based on the prevailing building codes. Building performance guides such as Florida Building Code (2004 FBC R4409.13.3.2 ) and ASHRAE require the provision of ventilation openings on the surface of roofing envelopes so as to effectively cross-ventilate attic space between ceiling joists and roof rafters. The guide stipulates that the ratio of total net free ventilating area to the area of ceiling shall not be less than $1 / 150$. Since the attic net free ventilation area is $0.36 \mathrm{~m}^{2}\left(558.17 \mathrm{in}^{2}\right)$, a total of 18 circular holes with diameter of $0.013 \mathrm{~m}$ (33/64in) were uniformly provided over the perimeter of the roof overhang. To replicate the screens used on soffits, an equivalent scaled down screen mesh was applied in each soffit opening. Details of the porosity arrangements are given in Table 1.

\subsubsection{Pressure tap distribution}

In order to examine the overall envelope pressure distribution on the building (both external and internal pressure), 272 Scanivalve pressure taps were installed. A total of 78 pressure taps were installed on the top surface of the roof as well as the overhang to 
capture external pressure fluctuations (Figure 4. 1). To evaluate the pressure fluctuations at the entrance of the dominant openings, pressure taps were placed at the periphery of each opening so as to have representative measurements for the respective area average analysis. For a similar reason, 4 pressure taps were installed at the periphery of the attic hatch. A total of 18 pressure taps were installed internally throughout the interior of the building attic space and 24 pressure taps in the living room (on the ceiling and floor) to capture the overall internal pressure fluctuations inside the building. The pressure signals from all taps were sampled at a rate of $512 \mathrm{~Hz}$ for durations of 90 seconds. Measurements were obtained for a total of 40 wind angle of attack $(A o A)$ in $10^{\circ}$ increments (i.e., 36 wind angles and additional four $45^{\circ}$ angles). For symmetrical cases, tests were carried out for 11 wind angles ranging between $270^{\circ}$ and $360^{\circ}$. Since the building has dominant openings on the front side and left side wall, the wind direction $270^{\circ}$ is normal to the dominant openings along the front side wall and $360^{\circ}$ or $0^{\circ}$ wind direction normal to the dominant opening along the left side of the building. All the raw data collected were passed through a transfer function technique to correct the error due to pressure tubing length. 
Table 4-1: Dominant openings and background leakage distribution in model scale dimensions.

\begin{tabular}{|c|c|c|c|}
\hline Description & Description & area $\left[\mathrm{m}^{2} / \mathrm{in}^{2}\right]$ & ratio [\%] \\
\hline \multirow{4}{*}{ Attic space } & Attic area to be ventilated & $0.36 / 558.20$ & \\
\hline & $\begin{array}{l}\text { Soffit opening ( } 18 \mathrm{pcs} \text {, dia. } 0.013 \mathrm{~m} \text {, } \\
33 / 64 \mathrm{in})\end{array}$ & $0.0024 / 3.76$ & 0.67 \\
\hline & Attic hatch at ceiling & $0.0013 / 1.97$ & 0.35 \\
\hline & $\begin{array}{l}\text { Ceiling background leakage (182 } \\
\text { holes with dia. }(0.0016 \mathrm{~m}), 1 / 16 \mathrm{in})\end{array}$ & $0.00036 / 0.56$ & 0.10 \\
\hline \multirow{10}{*}{$\begin{array}{l}\text { Living room } \\
\text { space }\end{array}$} & Front side Door, Df & $0.0051 / 7.85$ & 10 \\
\hline & Front window: Wf1, Wf2 & $0.0033 / 5.10$ & 6 \\
\hline & Left side door, D1 & $0.0056 / 8.63$ & 6 \\
\hline & Left side window, W11 & $0.0037 / 5.70$ & 4 \\
\hline & Left side window, W12 & $0.0013 / 1.98$ & 1 \\
\hline & Left side window, W13 & $0.002 / 3.10$ & 2 \\
\hline & Left side window, W14 & $0.0037 / 5.70$ & 4 \\
\hline & Right side window: Wr1, Wr2 & $0.0037 / 5.70$ & 4 \\
\hline & Rear side window: Wrr1, Wrr2 & $0.0037 / 5.70$ & 7 \\
\hline & $\begin{array}{l}\text { Uniformly distributed wall } \\
\text { background leakage (142 holes with } \\
\text { dia. }(0.0016 \mathrm{~m}), 1 / 16 \mathrm{in})\end{array}$ & $0.00028 / 0.44$ & 0.10 \\
\hline
\end{tabular}

\subsubsection{Test protocol}

\subsubsection{Effect of dominant openings with ceiling partitioning}

The test configurations incorporated in this experiment were divided into four major categories: a) building having attic and living space with horizontal ceiling partition but no vertical partitioning (i.e., with no room partitions), with and without volume chamber; b) building having attic and living space with horizontal ceiling partition and vertical partitioning (i.e., with room partitions), with and without volume chamber; c) building having single room (i.e., combined attic and living space), natural ventilations, with 
volume chamber; d) building with no attic space, no partitioning, with and without volume chamber.

Table 4-2: Summary of test protocol.

\begin{tabular}{|c|c|c|c|c|c|}
\hline Description & $\begin{array}{r}\text { Test } \\
\text { cases }\end{array}$ & $\begin{array}{c}\text { Dominant } \\
\text { opening }\end{array}$ & $\begin{array}{c}\text { Ceiling } \\
\text { hatch }\end{array}$ & $\begin{array}{l}\text { Vents: } \\
\text { soffit }\end{array}$ & Remark \\
\hline \multirow{3}{*}{ Background leakage } & Test 1A & - & - & $\checkmark$ & \multirow{3}{*}{$\begin{array}{c}\text { with uniform leakage } \\
\text { without uniform } \\
\text { leakage }\end{array}$} \\
\hline & Test 1B & - & - & $\checkmark$ & \\
\hline & Test $1 \mathrm{C}$ & - & - & - & \\
\hline \multirow{2}{*}{$10 \%$ front door opened case } & Test $2 \mathrm{~A}$ & $\mathrm{D}_{\mathrm{ft}}$ & - & $\checkmark$ & \\
\hline & Test 2B & $\mathrm{D}_{\mathrm{ff}}$ & $\sqrt{ }$ & $\checkmark$ & \\
\hline \multirow{2}{*}{$\begin{array}{l}22 \% \text { front door and windows } \\
\text { opening combination }\end{array}$} & Test 3A & DW & - & $\sqrt{ }$ & \\
\hline & Test 3B & DW & $\checkmark$ & $\checkmark$ & \\
\hline \multirow{2}{*}{$10 \%+6 \%$ door opened case } & Test 4A & $\mathrm{D}_{\mathrm{lf}}$ & - & $\checkmark$ & \\
\hline & Test 4B & $\mathrm{D}_{\mathrm{lf}}$ & $\checkmark$ & $\checkmark$ & \\
\hline \multirow{2}{*}{$10 \%$ front door opened case } & Test $5 \mathrm{~A}$ & $\mathrm{D}_{\mathrm{ff}}$ & - & $\checkmark$ & \multirow{2}{*}{ No ceiling } \\
\hline & Test 5A & $\mathrm{D}_{\mathrm{ff}}$ & - & - & \\
\hline \multirow{2}{*}{$\begin{array}{c}6 \% \text { front door } \& \text { right } \\
\text { window opening combination }\end{array}$} & Test 6A & $\mathrm{W}_{\mathrm{ft}_{-} \mathrm{r}}$ & - & $\checkmark$ & \multirow{2}{*}{ No ceiling } \\
\hline & Test 6A & $\mathrm{W}_{\mathrm{ff} \_\mathrm{r}}$ & - & - & \\
\hline \multirow{2}{*}{$\begin{array}{l}6 \% \text { front door \& left window } \\
\text { opening combination }\end{array}$} & Test 7a & $\mathrm{W}_{\mathrm{ft} \_1}$ & - & $\checkmark$ & \multirow{2}{*}{ No ceiling } \\
\hline & Test $7 \mathrm{~b}$ & $\mathrm{~W}_{\mathrm{ff} \_1}$ & - & - & \\
\hline \multicolumn{6}{|c|}{ Room partitioning } \\
\hline $10 \%$ front door opening & Test $8 \mathrm{~A}$ & $\mathrm{D}_{\mathrm{ft}}$ & - & $\checkmark$ & \\
\hline $\begin{array}{l}10 \% \text { front door and rear } \\
\text { windows opening }\end{array}$ & Test 8B & $\mathrm{D}_{\mathrm{ff}} \& \mathrm{~W}_{\mathrm{rr}}$ & - & $\sqrt{ }$ & \\
\hline $\begin{array}{c}22 \% \text { front door and windows } \\
\text { opening } \\
\end{array}$ & \multirow{2}{*}{$\begin{array}{l}\text { Test 9a } \\
\text { Test 9a }\end{array}$} & $\mathrm{D}_{\mathrm{ff}} \& \mathrm{~W}_{\mathrm{rr}}$ & - & $\sqrt{ }$ & \\
\hline $\begin{array}{c}22 \% \text { front door, windows }+ \\
\text { rear window opening }\end{array}$ & & $\mathrm{D}_{\mathrm{fft}}+\mathrm{W}_{\mathrm{rr}}+\mathrm{W}_{\mathrm{ff}}$ & - & $\checkmark$ & \\
\hline $\begin{array}{c}22 \% \text { front door and windows } \\
\text { opening }\end{array}$ & Test $10 \mathrm{a}$ & $\mathrm{D}_{\mathrm{ft}}+\mathrm{W}_{\mathrm{rr}}$ & - & $\checkmark$ & \\
\hline
\end{tabular}


Each test configuration specified above has a predetermined arrangement of different dominant openings and background leakages as stated in Table 4.2. The external and internal pressures, for each case, were measured simultaneously to assess the net wind loading on the building envelope with much emphasis on roof component.

\subsubsection{Effect of room compartmentalization (vertical partitioning)}

For a given dominant opening, the intensity of internal pressure is highly correlated to the effective internal volume of the building. In this particular experiment, the building interior was divided into six rooms (living-dining-kitchen, bed rooms $(B R-1, B R-2 \& B R$ 3), laundry, and bathroom) as shown in Figure 4.4. Test Case 8A represents a single front door opening (10\%) while test Case $8 \mathrm{~B}$ represents a single front door with two rear windows opening. Test $9 \mathrm{~A} \& 9 \mathrm{~B}$ were similar to that of $8 \mathrm{~A} \& 8 \mathrm{~B}$ except that two front windows were added raising the front porosity from $10 \%$ to $22 \%$. Test Case $10 \mathrm{~A}$ was similar to case 9A except that it involved a horizontal opening at the ceiling level (i.e., hatch). In all of the test cases, the internal door to each room was left open.

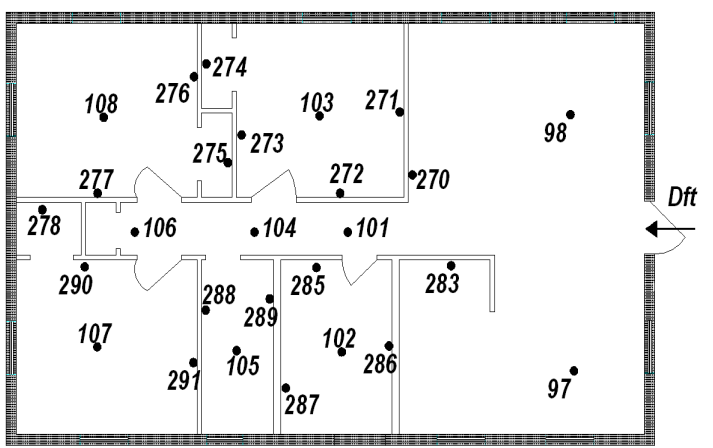

(a)

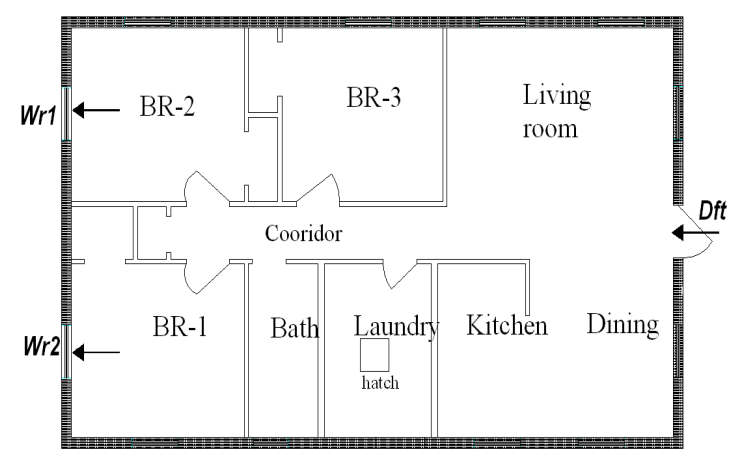

(b) 


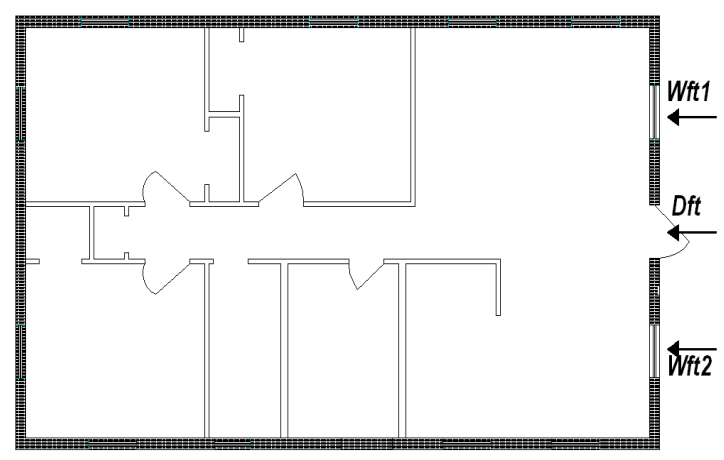

(c)

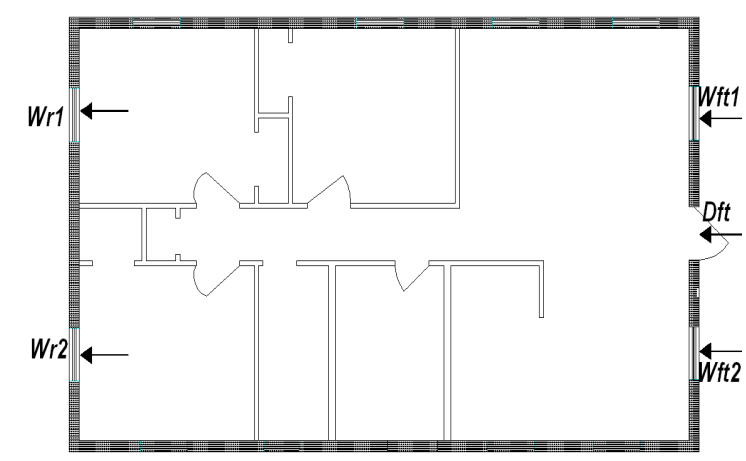

(d)

Figure 4.4: Room compartmentalization: a) Partitioning with tap layout for Case 8A; b) Case 8B; c) Case $9 A \&$ d) Case 9B.

\subsubsection{Internal and external pressure coefficients}

The non-dimensional internal $\left(C_{p i}\right)$ and external pressure $\left(C_{p e}\right)$ coefficients at each pressure tap location were calculated by referencing measured pressures to the mean free stream dynamic pressure at mean roof height as given in Eqn.5. The mean value of coefficient of pressure for each tap was obtained by taking the average of the 90 second recorded pressure time history as given in Eqn. 6. Similarly, the peak pressure coefficient was obtained from the time history data as shown in Eqn.7 while the root mean square $(r m s)$ value of the pressure coefficient was obtained by making use of the standard deviation of the pressure coefficient as shown in Eqn. 8.

$$
\begin{aligned}
& C_{p i j}=\frac{P_{i j}-P_{r j}}{\frac{1}{2} \rho \bar{U}^{2}}, \quad C_{p e j}=\frac{P_{e j}-P_{r j}}{\frac{1}{2} \rho \bar{U}^{2}} \\
& C_{p_{\text {mean }}}=\frac{1}{n} \sum_{i=1}^{n} C_{p i}
\end{aligned}
$$




$$
\begin{aligned}
& \hat{C}_{p i}=\frac{\hat{P}_{i}-P_{r i}}{\frac{1}{2} \rho \bar{U}^{2}} \\
& \widetilde{C}_{p i}=\sqrt{\frac{1}{2} \sum_{i=1}^{n}\left(C_{p i}-C_{p_{-} \text {mean }}\right)^{2}}
\end{aligned}
$$

Where: $P_{i j}$ and $P_{e j}$ are the measured internal and external differential pressures,

respectively at the $j^{\text {th }}$ tap; $P_{r j}$ is the mean reference pressure in the wind tunnel system; $\widehat{P l}$ is the peak pressure, $\rho$ is air density taken as $1.225 \mathrm{Kg} / \mathrm{m}^{3} ; \bar{U}$ is the mean wind speed measured at mean roof height (i.e., average of eave height and ridge height) of the building.

\subsection{Results and discussion}

\subsubsection{Internal pressure variation with and without volume correction}

For the hip roof low-rise building considered, three test cases (Case 2A, 3A, 5A \& 6A) were analyzed in order to investigate the characteristics of internal pressure fluctuations both in the presence and absence of the volume distortion chamber underneath the turntable. As can be seen from Figure 4.5, Case 2A represents the building with a sealed horizontal partition dividing the room into attic and living room having soffit ventilation and dominant opening $\left(\mathrm{D}_{\mathrm{ft}}\right)$ with $10 \%$ porosity. Case $3 \mathrm{~A}$ was similar to case $2 \mathrm{~A}$ except that additional two front windows were opened raising the dominant opening porosity to $22 \%$ (Figure 4.6). On the other hand, Case 5A was similar to case $2 \mathrm{~A}$ except that the horizontal partition was removed and the building presents the whole interior cavity as a single room. 


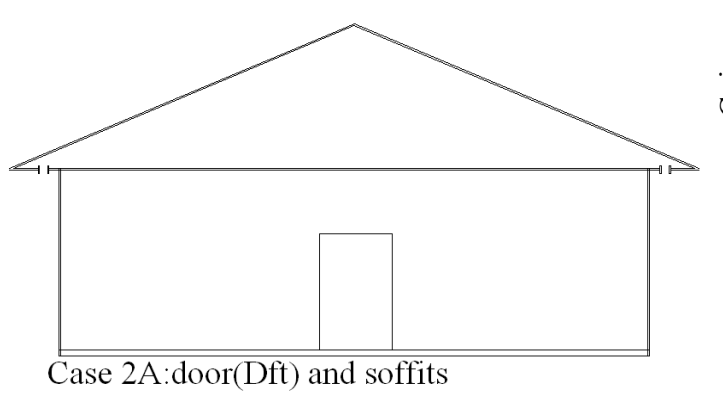

(a)

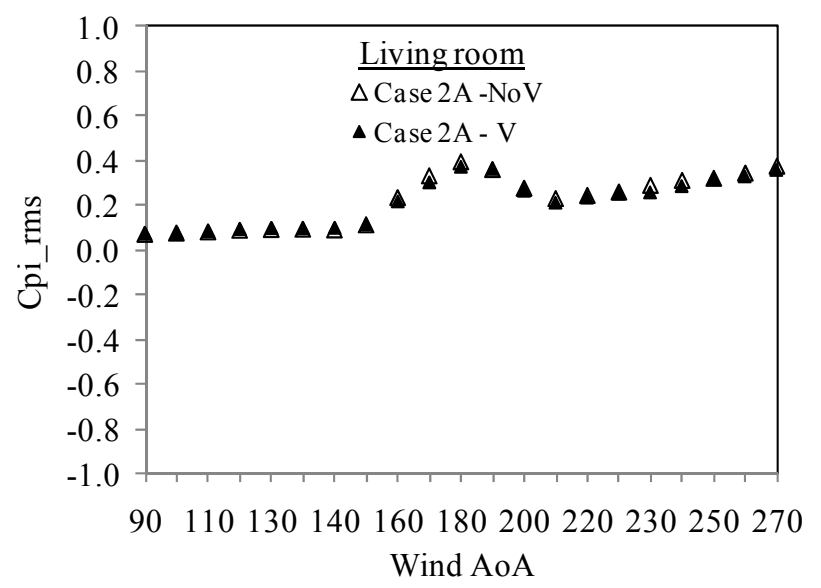

(b)

Figure 4.5: Case 2A: a) model setup with door, soffit openings and ceiling partition; b) internal pressure response, rms, for building with volume chamber $(V)$ and no volume chamber $(\mathrm{NoV})$.

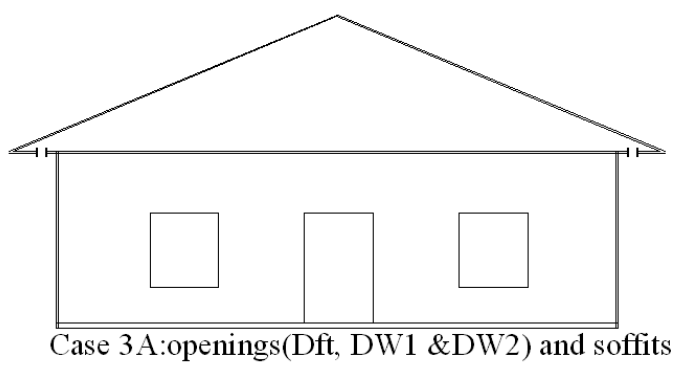

(a)

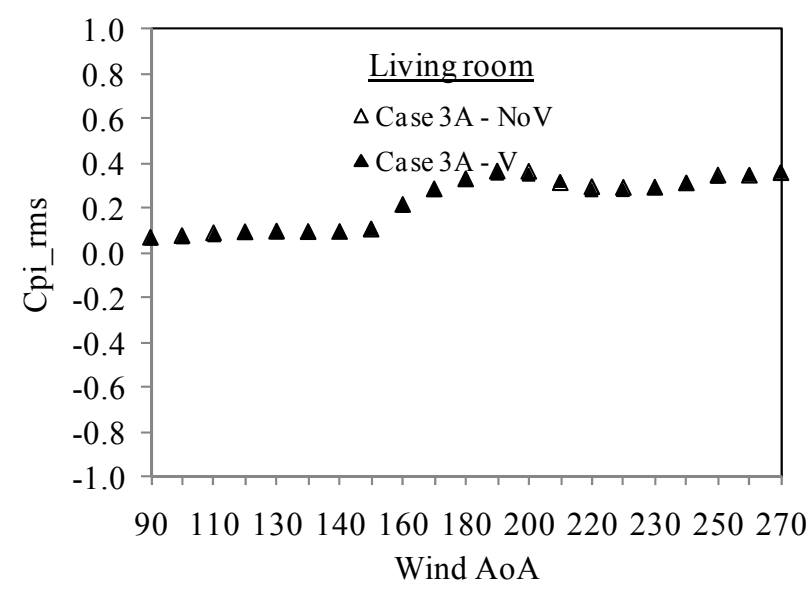

(b)

Figure 4.6: Case 3A: a) model setup with door, windows, soffit openings and ceiling partition; b) internal pressure response, $r m s$, for building with volume chamber $(V)$ and no volume chamber (NoV). 


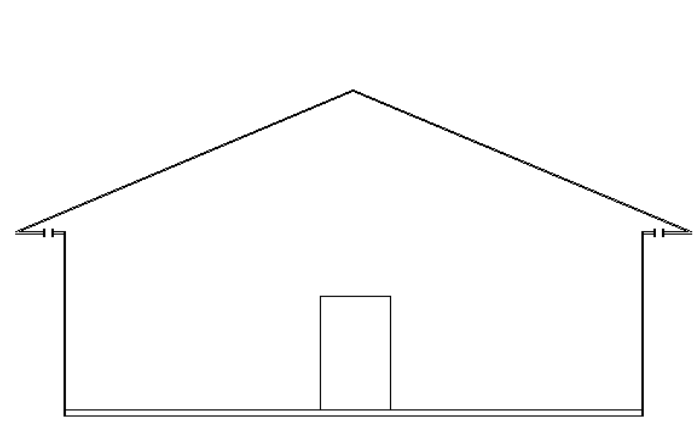

Case $5 \mathrm{~A}$ : door(Dft) and soffits

(a)

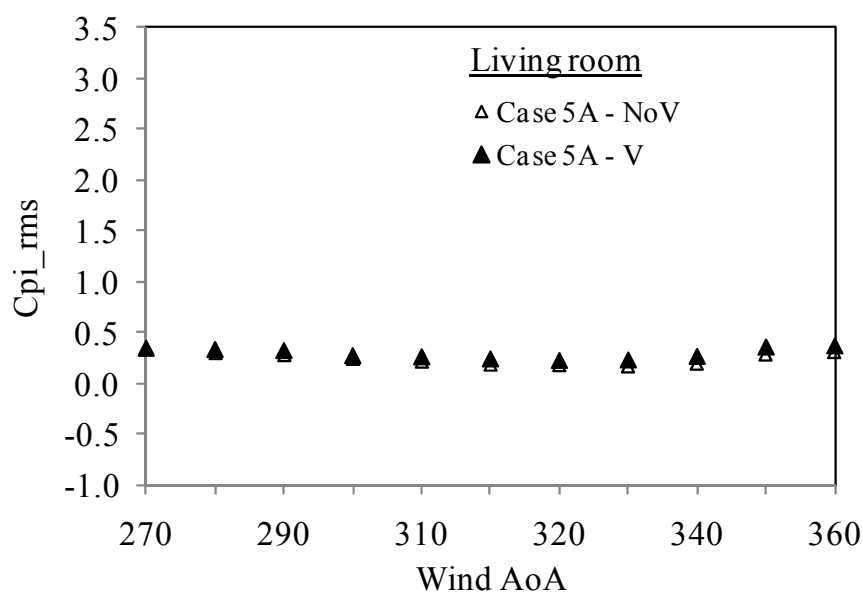

(b)

Figure 4.7: Case 5A: a) model setup with door, soffit openings and no ceiling partition; b) internal pressure response, rms, for building with volume chamber $(V)$ and no volume chamber $(\mathrm{NoV})$.

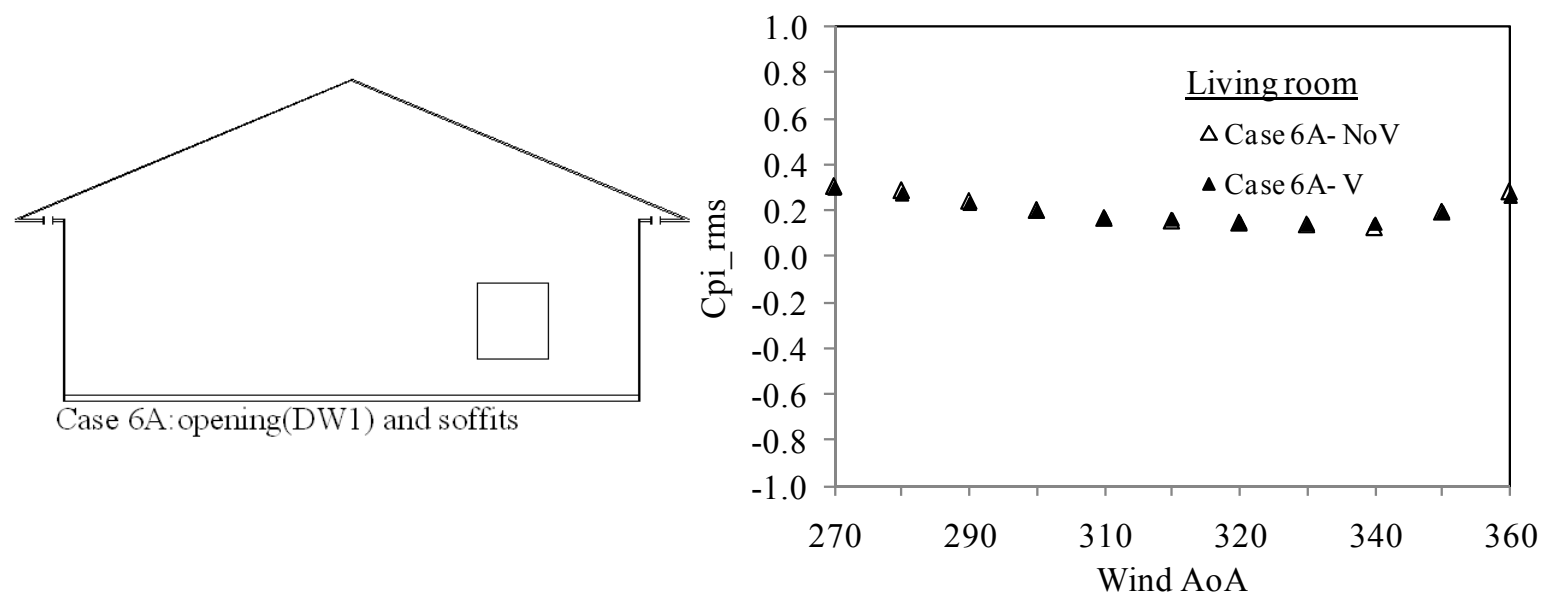

(a)

(b)

Figure 4.8: Case 6A: a) model setup with window, soffit opening and no ceiling partition; b) internal pressure response, rms, for building with volume chamber $(V)$ and no volume chamber $(\mathrm{NoV})$

In test Case $6 \mathrm{~A}$, the door $\left(\mathrm{D}_{\mathrm{ft}}\right)$ of Case $5 \mathrm{~A}$ was replaced by a right side window having $6 \%$ porosity. The size of the volume chamber was varied in accordance with the scaling 
ratio specified above. Figures $4.5 \mathrm{~b}, 4.6 \mathrm{~b}, 4.7 \mathrm{~b} \& 4.8 \mathrm{~b}$ reveals that the $r m s$ pressure measurements show no significant difference between the model with volume distortion chamber (specified as $V$ ) and the one without volume chamber (specified as NoV). In the absence of volume chamber, the ratio $V_{o} / a$ (i.e., the effective internal volume to dominant opening area ratio) for Case $2 \mathrm{~A}(10 \%$ porosity) was $5.5 \mathrm{~m}$. Whereas in test Case $3 \mathrm{~A}(22 \%$ porosity) the $V_{o} / a$ ratio was $2.4 \mathrm{~m}$. When the volume chamber was connected to the model, the $V_{o} / a$ ratios were $50 \mathrm{~m}$ and $22 \mathrm{~m}$ for Case $2 \mathrm{~A}$ and $3 \mathrm{~A}$, respectively. Even though the $V_{o} / a$ ratio for the building with volume chamber was nine times larger than that of the building without the volume chamber, no major difference in the rms internal pressure was observed. For test Case 5A, the porosity of the dominant opening (i.e., door $D f t$ ) was the same as that of the Case $2 \mathrm{~A}$. However, the $V_{o} / a$ ratio obtained was $7.6 \mathrm{~m}$ with no volume chamber and $61.4 \mathrm{~m}$ when the volume chamber was connected. One typical observation in these test cases was that the $r m s$ variation between the model with and without volume distortion less significant for the low-rise building under consideration. This is related to the damping term in Eqn. 1 which is directly proportional to the ratio of $\left(V_{o} / a\right)^{2}$. The volume of the building under study could be small such that the volume scaling couldn't provide enough damping to cause reduction in response of internal pressure. This is in line with the suggestion provided by (Holmes 1979) stating that the effect of rms internal pressure due to incorrect velocity scaling is small for low rise buildings (typical of houses) and smaller industrial buildings. 
Statistical comparison was also carried out to examine the internal pressure characteristics with and without volume distortion. As shown in Figure 4.9, the mean and peak $C_{p i}$ values for test Case 2A didn't show considerable variation between the model with and without volume chamber correction. However, in test Case 5A, the case with volume distortion exhibits higher internal pressure coefficient: mean $C_{p i}$ higher by $20 \%$ and the peak $C_{p i}$ higher by $35 \%$ particularly for wind $A o A$ between $270^{\circ}$ and $320^{\circ}$. Table 3 compares $r m s$ and peak values of internal pressure coefficients normalized with their respective mean values for test Case $2 \mathrm{~A}, 3 \mathrm{~A}, 5 \mathrm{~A}$ and $6 \mathrm{~A}$ for cases with and without volume distortion. The values obtained illustrate the significance of the volume distortion chamber as the effective internal volume increases. Even though the normalized rms did not vary considerably, the normalized peak between the model with volume $(V)$ and without volume $(\mathrm{NoV})$ was significant for larger internal volumes. This emphasizes the need for proper scaling of model scale building's internal volume so as to maintain the dynamic similarity and correctly represent the full scale characteristics, particularly for buildings with larger size effective internal volume.

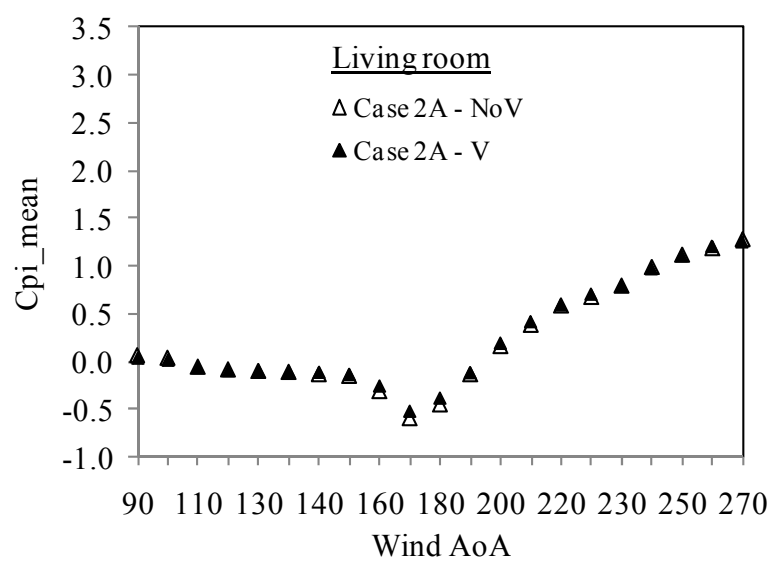

(a)

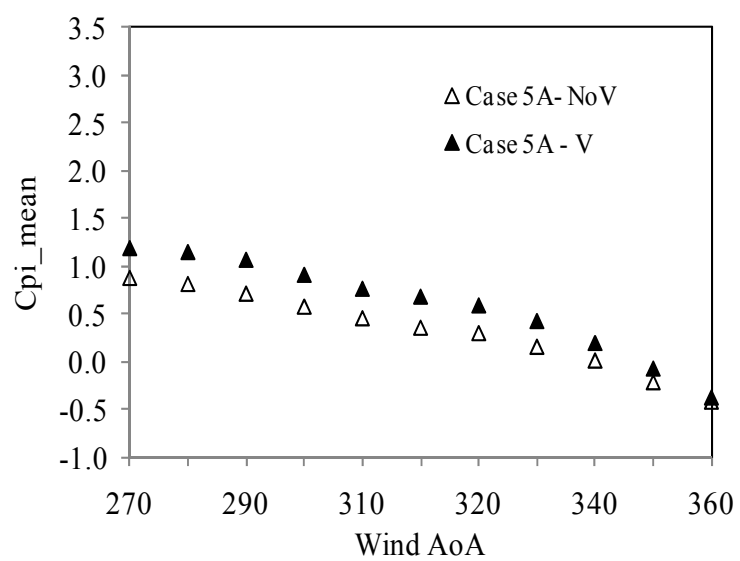

(b) 


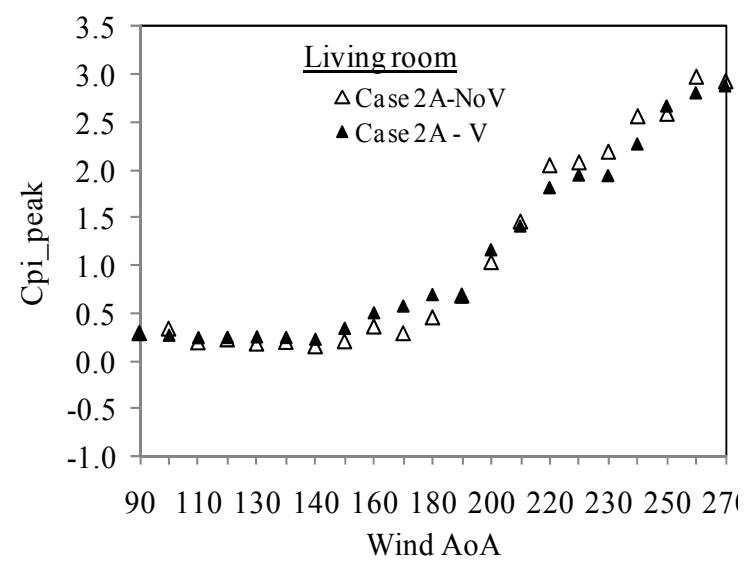

(c)

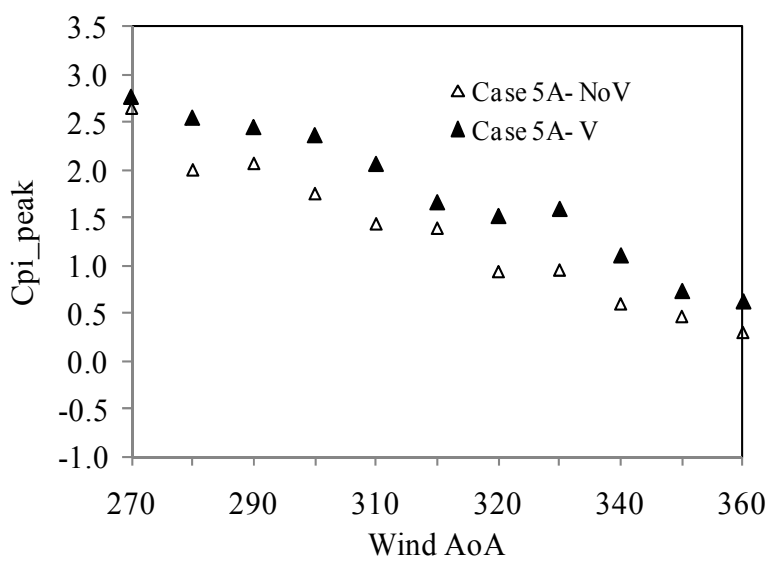

(d)

Figure 4.9: Mean and peak internal pressure coefficient for test cases 2A and 5A: With and without volume chamber.

Table 4-3: Statistical variation of internal pressure coefficient: NoV vs V.

\begin{tabular}{crcccc}
$\mathbf{C}_{\mathbf{p i}}$ & & $\mathbf{2 A}$ & $\mathbf{3 A}$ & $\mathbf{5 A}$ & $\mathbf{6 A}$ \\
\hline \multirow{2}{*}{$\mathrm{RMS} / \mathrm{MEAN}$} & $\mathrm{NoV}$ & 0.292 & 0.276 & 0.393 & 0.302 \\
& $\mathrm{~V}$ & 0.289 & 0.277 & 0.283 & 0.299 \\
MAX/MEAN & $\mathrm{NoV}$ & 2.40 & 2.66 & 3.048 & 2.523 \\
& $\mathrm{~V}$ & 2.31 & 2.42 & 2.334 & 2.175 \\
\hline
\end{tabular}
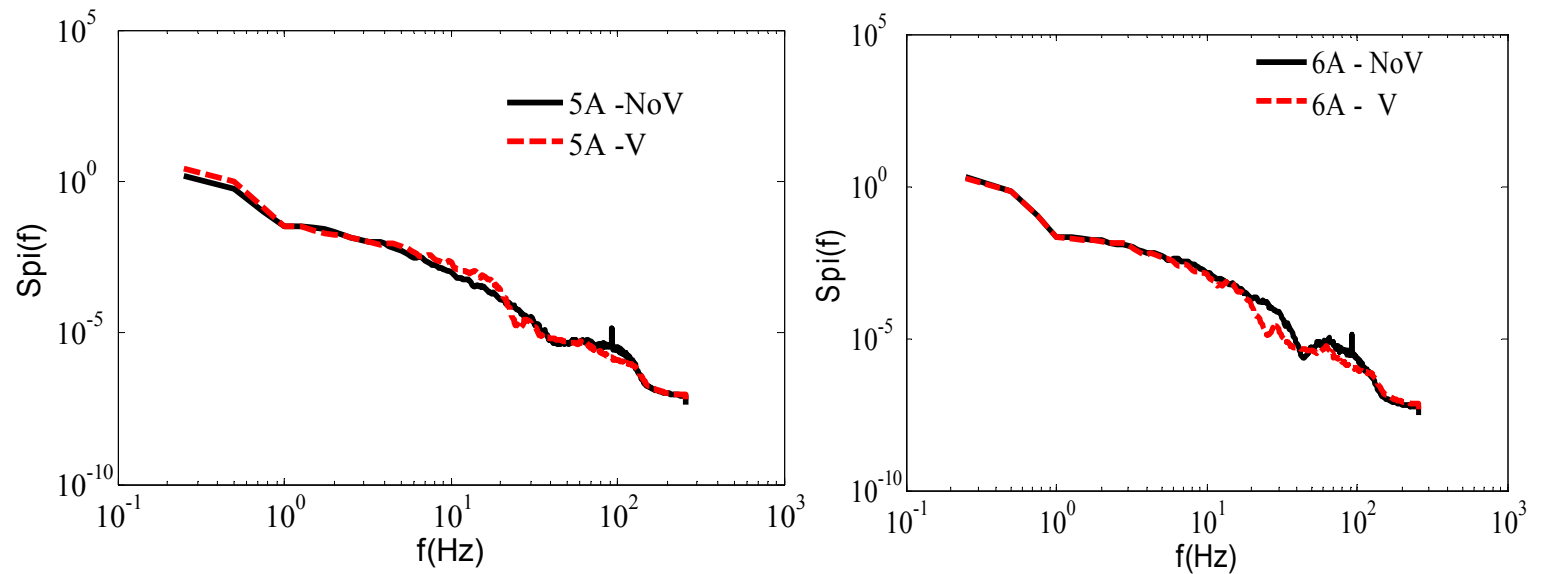

Figure 4.10: Power spectra of internal pressure Spi(f) in $\mathrm{Pa}^{2} \mathrm{~s}$ for test Case 5A for $270^{\circ}$ wind angle of attack. 
The Helmholtz resonance frequency of the building was also studied by comparing the results of the experiment with that of the values obtained from equation (Eqn. 9).

$$
f_{h h}=\frac{1}{2 \pi} \sqrt{\frac{n A P_{o}}{\rho l_{e} V_{o}}}
$$

The values of the parameters for the hip roof low-rise building considered in this section are as follows: $\gamma=1.4$ (ratio of specific heat for air; adiabatic condition is considered); $A$ $=0.0051 \mathrm{~m}^{2}$ for door and $0.0033 \mathrm{~m}^{2}$ for window; $P_{o}=101284.6 \mathrm{~Pa} ; \rho=1.225 \mathrm{Kg} / \mathrm{m} 3$, air density; $L_{e}=L_{o}+0.89 \sqrt{A}=0.07 \mathrm{~m}$ (door) and $0.0575 \mathrm{~m}$ (window). Figure 4.10 depicts the internal pressure spectra for test Case $5 \mathrm{~A}$ and $6 \mathrm{~A}$ with and without volume chamber. As can be seen from the figure, the peak Helmholtz resonance occurs around $85 \mathrm{~Hz}$ for Case $5 \mathrm{~A}$ with no volume distortion chamber and around $29 \mathrm{~Hz}$ when the volume chamber was applied. Similarly, a resonance frequency of $80 \mathrm{~Hz}$ and $26 \mathrm{~Hz}$ were recorded for the model without and with volume distortion chamber of Case 6A, respectively. The theoretical Helmholtz resonance from Eqn.9 closely resembles that of the experiment with volume distortion chamber.

\subsubsection{Internal pressure sensitivity to external pressure}

The measurements of pressure distribution through the dominant openings were carried out by placing pressure taps at the periphery of the door or window (as shown in Figure 4.1). To study the sensitivity of internal pressure response to that of the external, the test cases with single dominant openings equipped with volume distortion chamber were selected. Figure 4.11 shows the response of the internal to the external pressures. 


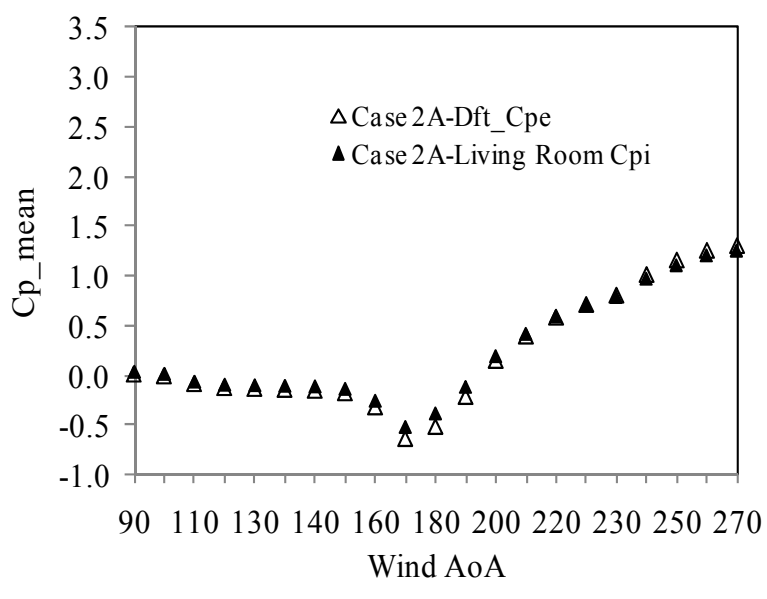

(a)

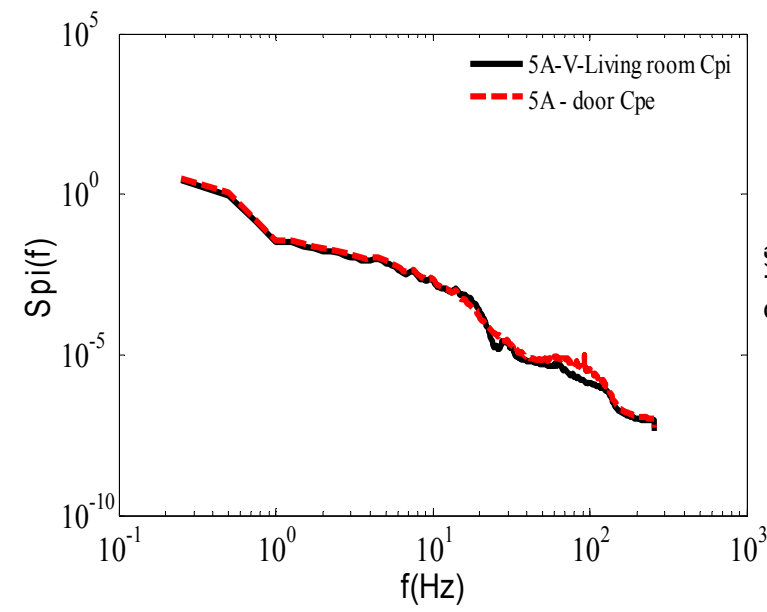

(c)

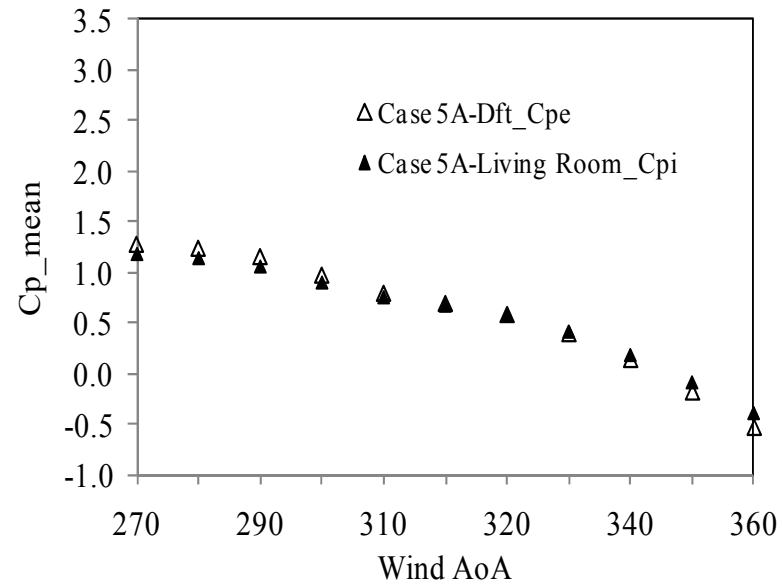

(b)

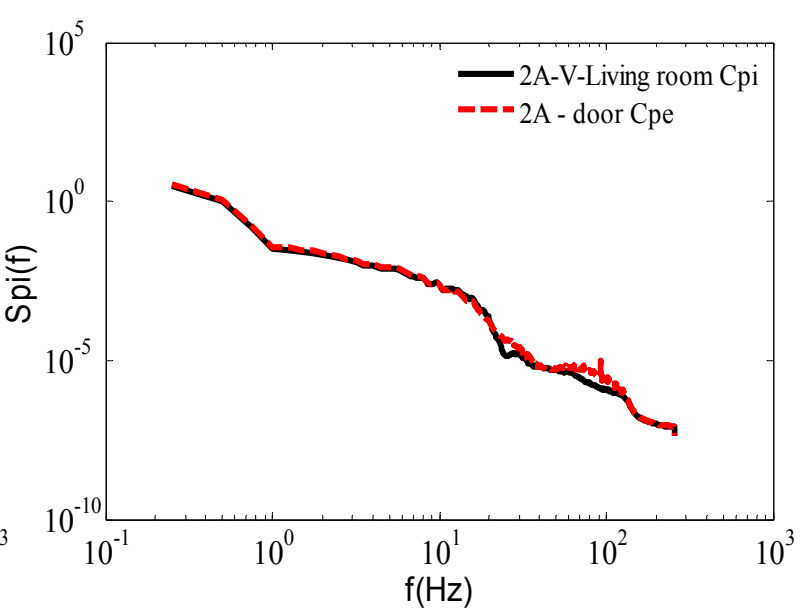

(d)

Figure 4.11: Internal to external pressure coefficient comparison.

Both test Cases $2 \mathrm{~A}$ and $5 \mathrm{~A}$ have the same dominant opening door $\left(\mathrm{D}_{\mathrm{ft}}=10 \%\right.$ porosity $)$ but with different volume.

As can be observed from Figures $4.11 \mathrm{a}$ and $4.11 \mathrm{~b}$, the mean internal pressure of the building responds to the mean external pressure and the correlation between the two was very strong. Figure $4.11 \mathrm{c}$ and $4.11 \mathrm{~d}$ also shows the spectral characteristics of tests Case 2A \&5A for $270^{\circ}$ wind angle of attack. It can be observed that greater part of the spectral 
energy was contained in the lower range of the frequency domain (i.e., below $15 \mathrm{~Hz}$ ) which was in the range of the natural frequency of common low-rise buildings.

\subsubsection{Influence of envelope opening on internal pressure}

This section focused on assessment of the impact of the size of the dominant openings and their location on internal pressure. Case $1 \mathrm{~A}$ represents the sealed building with only $0.1 \%$ porosity background leakage and soffit openings while Case $1 \mathrm{~B}$ represent the model completely sealed from the outside except soffit opening. Test case $1 \mathrm{D}$ represents the model completely sealed with no background leakage and no soffit at all. As can be observed from Figures.4.12a to 4.12d, the background leakages both with and without soffit have no significant contribution to the internal pressure. Internal pressure coefficients for Case 1 (i.e., 1A, 1B \& 1D) due to background leakage were relatively small compared to all other cases studied. On the other hand, peak $C_{p i}$ were measured when the windward side of the building was normal to the direction of the wind flow for all cases except for the background leakage tests.

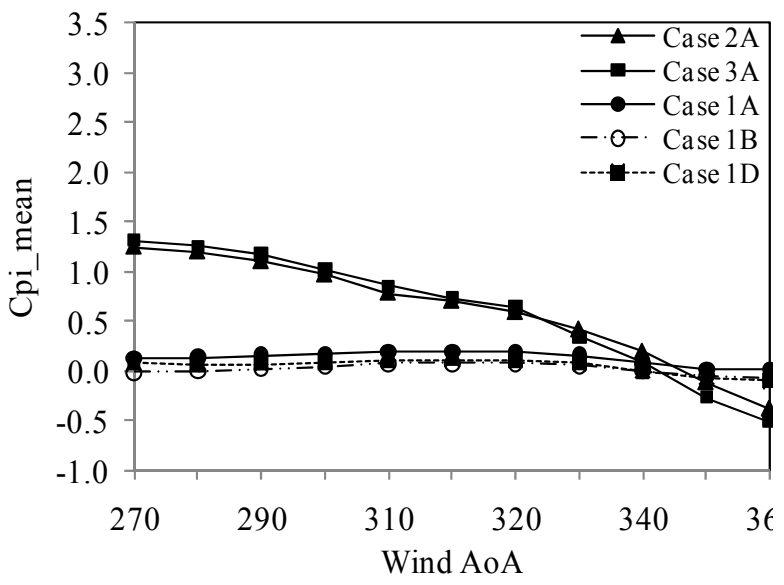

(a)

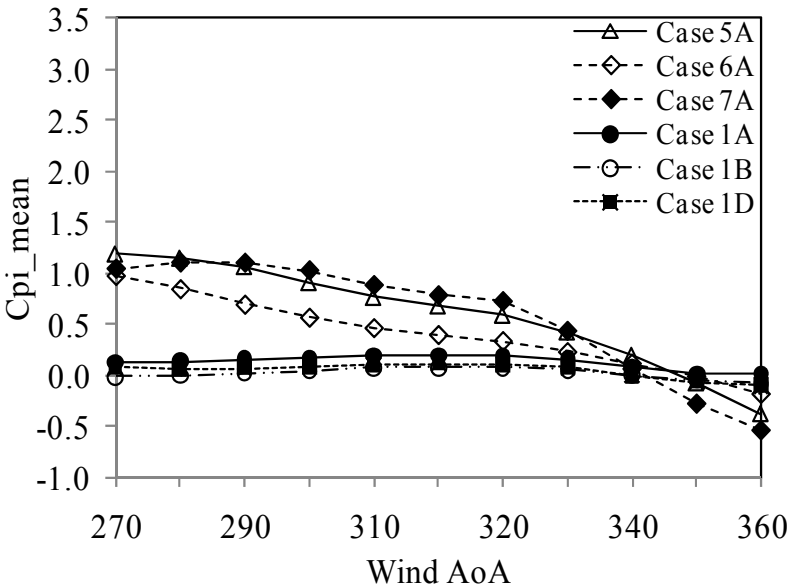

(b) 


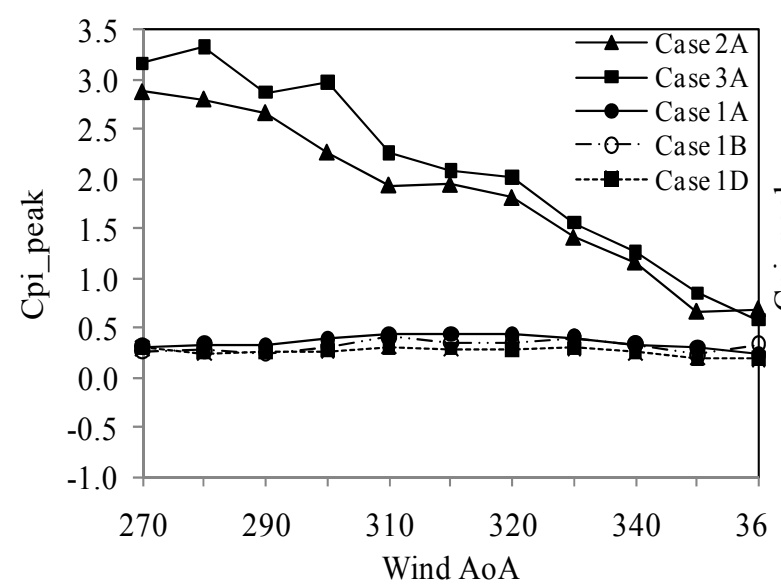

(c)

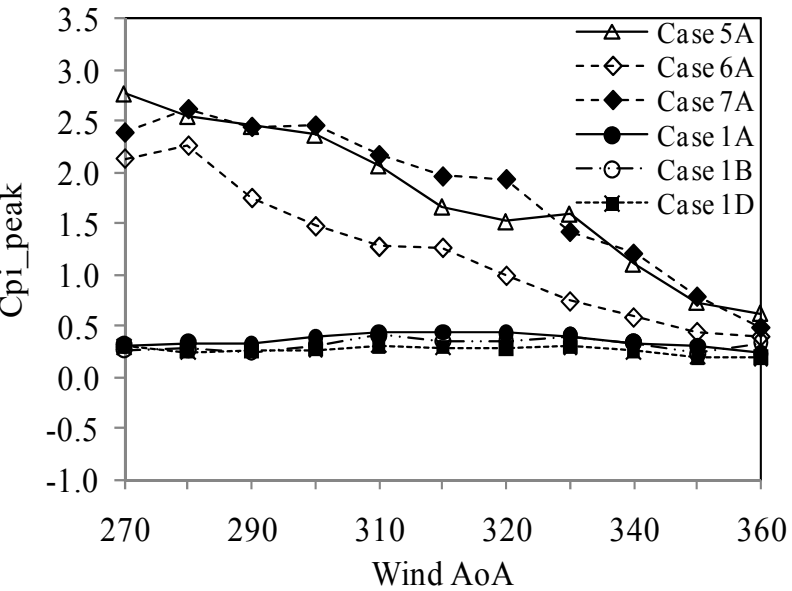

(d)

Figure 4.12: Effect of variable openings on internal pressure with respect to wind $A o A$.

When the dominant openings and wind direction was parallel (i.e., $360^{\circ}$ ), the mean internal pressure turned out to be negative and a mean suction pressure coefficient as low as -0.5 was measured. Irrespective of the wind direction, the internal pressure due to background leakage, however, remained constant. Peak internal pressure produced for the case with higher porosity dominant opening (Case $3 \mathrm{~A}$ with $22 \%$ porosity) was higher as compared to Case $2 \mathrm{~A}$ with $10 \%$ porosity by $10 \%-35 \%$.

The location of the dominant opening with respect to the upstream wind flow has also significant impact on the internal pressure. For instance, the window for test Case $7 \mathrm{~A}(6 \%$ porosity) was closer to the left side corner (i.e., $1.8 \mathrm{~m}$ in full scale from left corner) compared to the door for Case $5 \mathrm{~A}(10 \%$ porosity) located at the center and the window for Case $6 \mathrm{~A}(6 \%$ porosity) at the right side corner (i.e., $6.2 \mathrm{~m}$ in full scale from left corner). Even if the porosity of window (Case 7A) was lower than that of Case 5A, the mean and peak pressure coefficients were comparable and in fact higher at certain wind 
directions (e.g. between $300^{\circ}$ and $330^{\circ}$ AoA). This could be related to the location of the window from the leading edge and the ground. The center point of the left side window was almost at $2 / 3^{\text {rd }}$ of the building height (where stagnation develops). Comparing the three cases studied, Case $6 \mathrm{~A}$ presented the lowest peak pressure coefficient which could also be related to its further distance from the upstream wind direction.

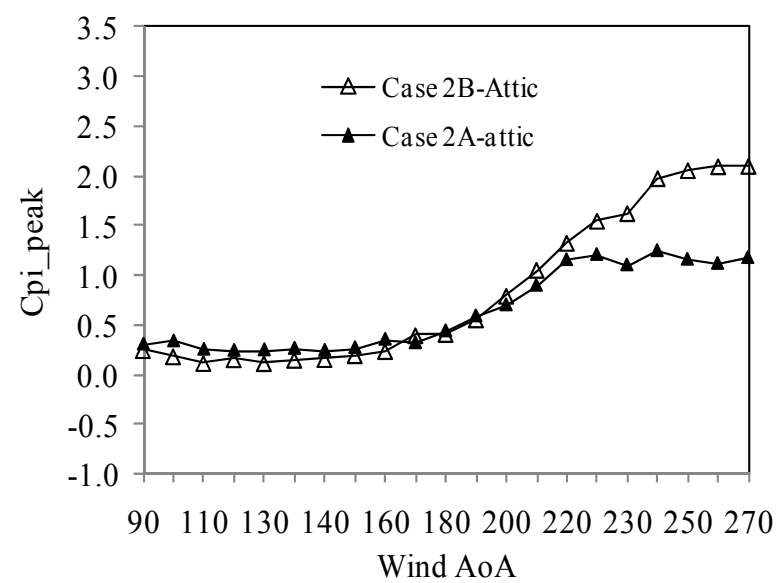

(a)

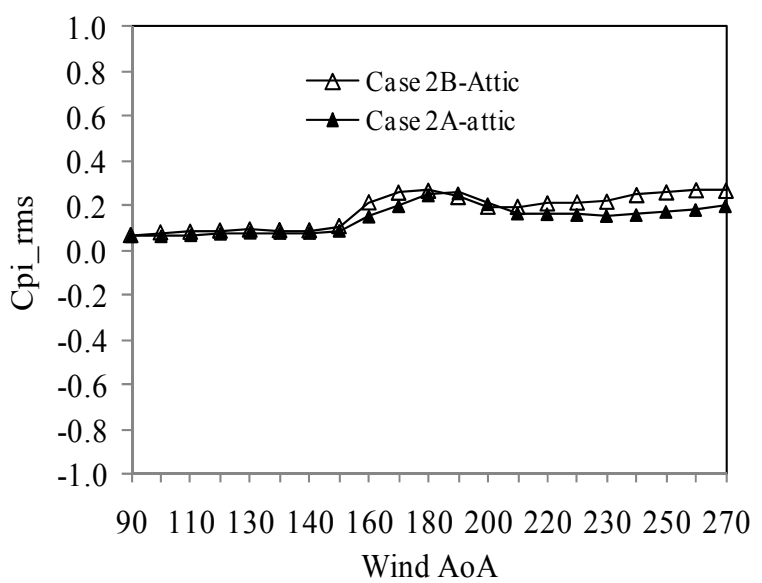

(b)

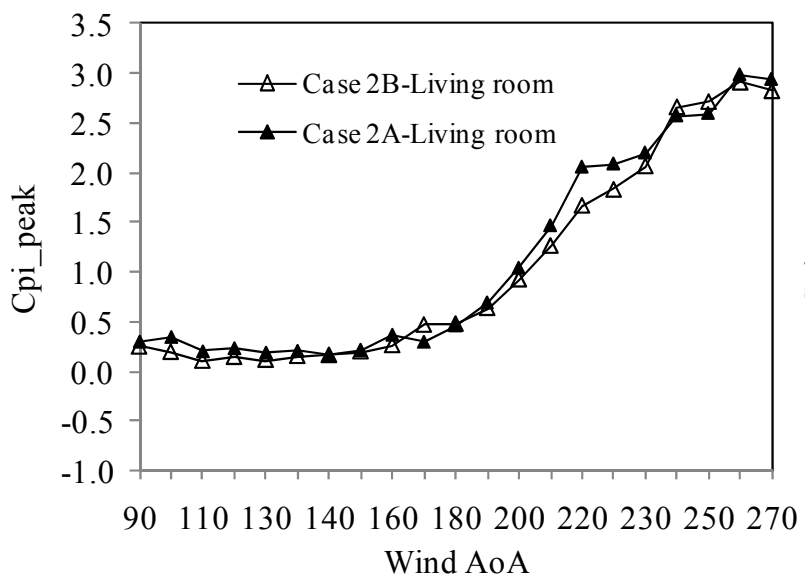

(c)

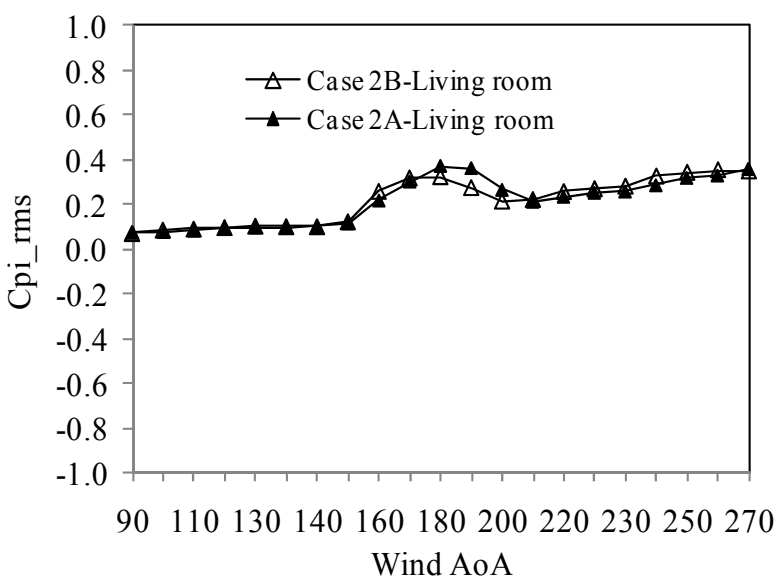

(d)

Figure 4.13: Internal pressure coefficient, closed vs opened hatch for test Case 2: a\&b) Attic space, c\&d) Living room space. 


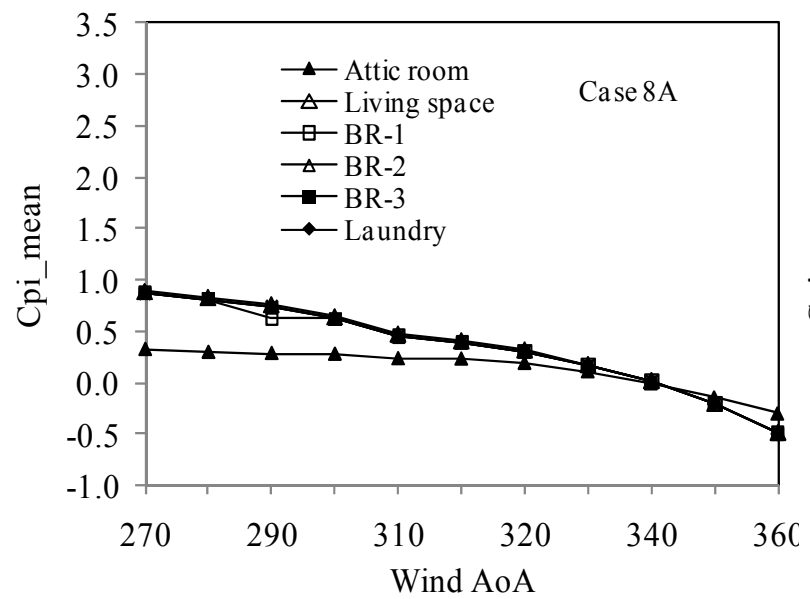

(a)

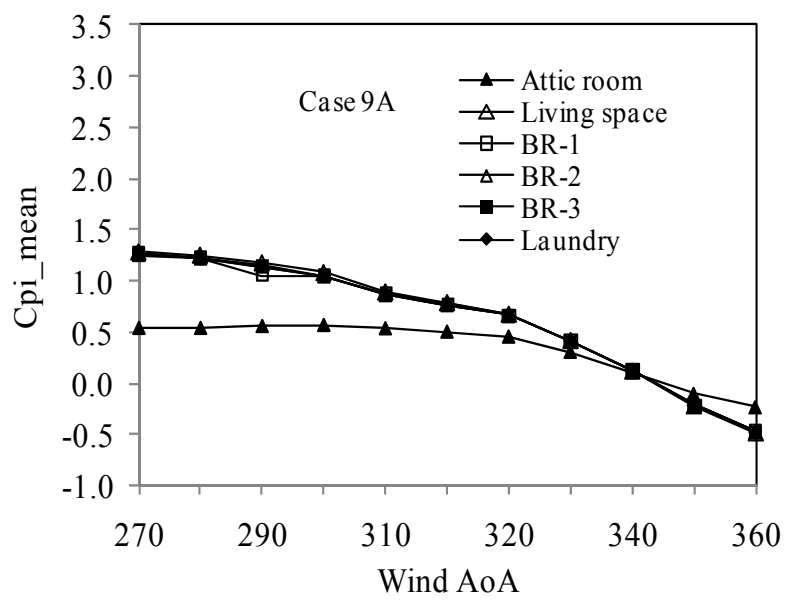

(c)

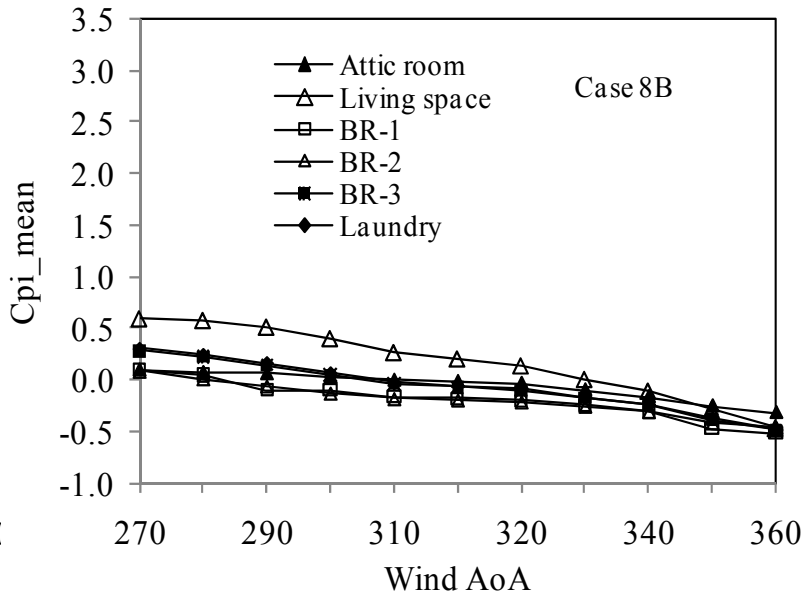

(b)

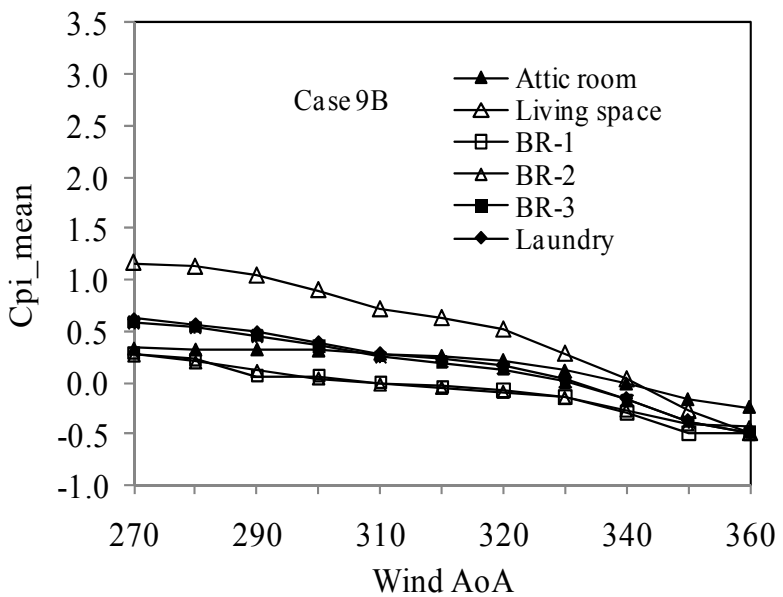

(d)

Figure 4.14: Internal pressure distribution for multi-room partitioning: a\&b) Case 8; c\&d) Case 9.

\subsubsection{Effect of interior compartmentalization}

\subsubsection{Ceiling partitioning (horizontal)}

Few test cases were performed to investigate the sensitivity of internal pressure in the attic (i.e., underneath roof sheathing) due to opening/closing of ceiling hatch in the 
presence of dominant opening. Case 2A has no ceiling opening and Case 2B similar to that of Case 2A except the hatch was left opened allowing the infiltration/exfiltration of air between the living and attic rooms. The porosity of the hatch at the ceiling level was $0.35 \%$ of the overall attic ventilated area. The attic room accounted for a volume of $V_{\text {attic }}$ $=0.011 \mathrm{~m}^{3}\left(664 \mathrm{in}^{3}\right)$ while the volume of the living room $V_{l i}=0.028 \mathrm{~m}^{3}\left(1706 \mathrm{in}^{3}\right) . \mathrm{In}$ percentile, the attic room accounts for $39 \%$ of the living room volume or in other words, when the hatch was opened, the volume of the living room increased in volume by $39 \%$. The major impact of opening the attic hatch was the significant increase in internal pressure inside the attic for certain wind angle of attack. As can be seen in Figures 4.13a and $4.13 \mathrm{~b}$, the attic internal pressure was not affected by opening the hatch for the wind $A o A$ between $0^{\circ}$ and $180^{\circ}$ (i.e., leeward side, half left and right side walls with respect to the front door opening). From $180^{\circ}$ on ward, however, the pressure coefficients in the attic and living room start to separate and the one with the hatch opened case causes the development of higher internal wind load. The peak value occurred at $270^{\circ} \mathrm{AoA}$ where the door opening faces the wind flow at right angle. A hatch having only $0.35 \%$ porosity caused a $90 \%$ increase in internal pressure coefficient inside the attic for a critical wind direction of $270^{\circ}$. On the other hand, the additional attic volume to the living room due to hatch opening along with the door (test case $2 \mathrm{~A}$ ) led to reduction in the living room internal pressure (but not that significant). The same observation was seen for the window opening cases. Generally, the hatch opening causes the propagation of pressure from the living room to the attic, resulting in a higher internal pressure in the attic while causing dampening of internal pressure in the living room. From the point of view of the net design wind load (i.e. combined external and internal pressure), the magnitude of the 
internal pressure that develops inside the attic roof is significant as it leads to an increased peak wind load on the roof sheathing. Thus, it is preferable to keep a ceiling hatch sealed during strong wind induced events.

\subsubsection{Room partitioning (vertical)}

The effect of dominant openings (both on the windward and leeward) was studied for the building model with multi-room partitioning. As can be observed in Figures 4.14a and 4.14c, the internal pressure distribution inside the multi-room is uniform for a single dominant room. The living room, bed rooms and laundry experiences similar pressure. However, in the presence of opposite side dominant openings, the uniformity of distribution reduces according to the location of the room with respect to the dominant opening (Figures 4.14 b \& 4.14d). For instance, the living room, being close to the windward door experienced comparatively higher mean internal pressure coefficient. The peak response of the internal pressure inside the different rooms with respect to the external pressure variation at the periphery of the dominant opening was also examined.

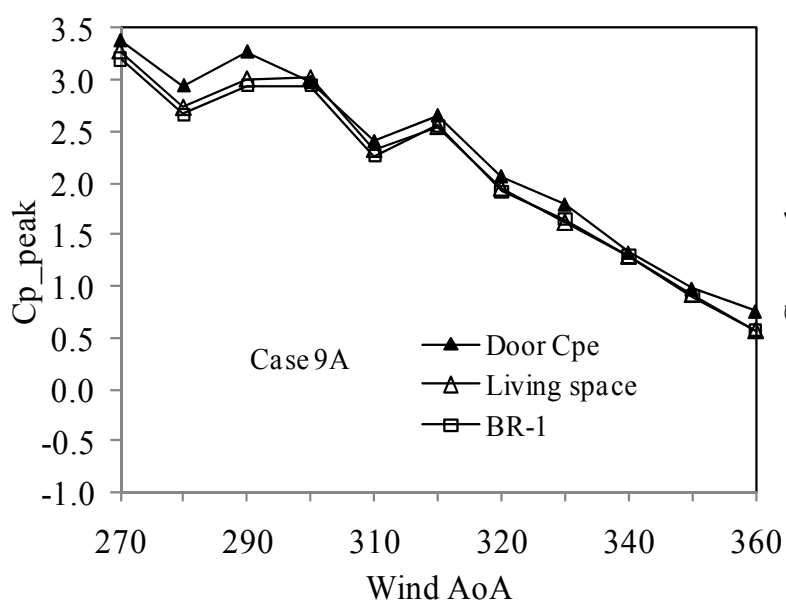

(a)

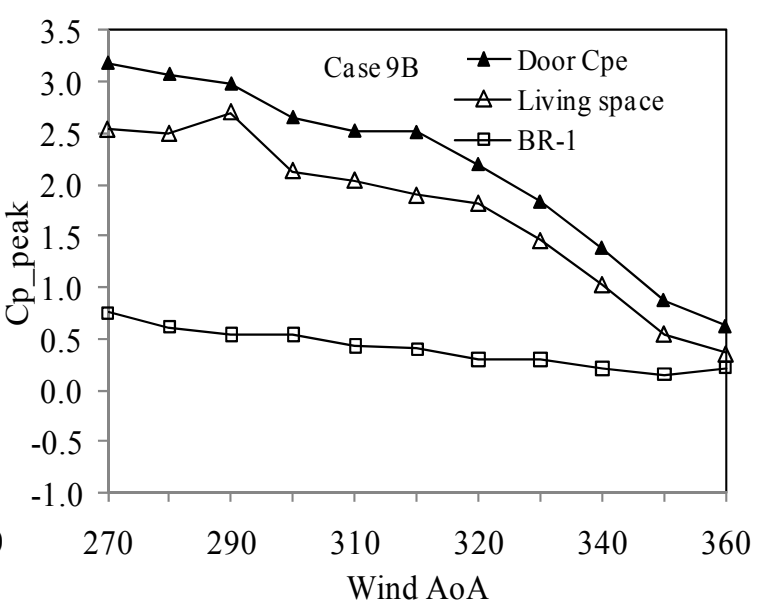

(b)

Figure 4.15: Peak internal and external pressure distribution for: a) Case 9A; b) Case 9B. 
The internal pressure inside the living room as well as the bed rooms $(B R-1, B R-2 \& B R$ 3) was highly correlated to the area averaged external pressure variation at the dominant opening when there was only one sided dominant opening (Figure 4.15a). The peak response of the internal pressure in different rooms, however, was considerably variable from the external pressure in the presence of dominant openings on opposite side of the building like that of Case 9B (Figure 4.15b). This illustrates that vertical partitions have significant effect on the distribution of internal pressure inside rooms when there exists dominant openings on opposite sides. The effect is large when the dominant openings are in the windward and leeward faces. The rooms further down from the windward opening responds weakly than those rooms which are closer.

The response of internal pressure for a building having vertical partitioning (i.e. for rooms) as well as horizontal partitioning at ceiling level was also examined (Case 9A vs Case 10A). The opening to the attic (i.e., hatch) was located inside the laundry room (Figure 4.4b). As illustrated in Figure 4.16, even though the location of hatch was away from the direct path of the wind flow coming through the dominant opening, the response of the internal pressure inside the attic was significant when the hatch was left open as compared to that when it was closed. As a consequence, the mean internal pressure coefficient underneath the roof sheathing for Case 10A was 70\% higher than that of Case 9A. On the other hand, opening the hatch and thus connecting the two compartments has no significant effect on the living rooms and bed rooms as shown in Figure 4.16b. 


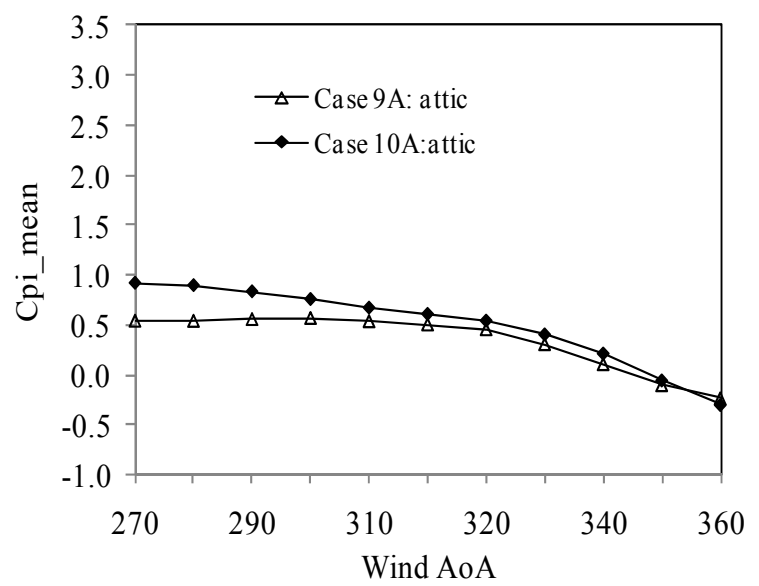

(a)

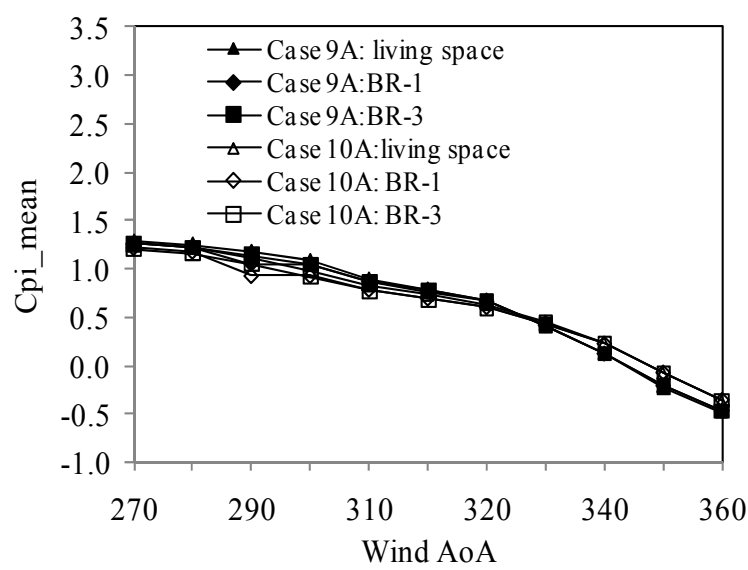

(b)

Figure 4.16: Internal pressure comparison in the presence of horizontal and vertical partitioning.

\subsubsection{Effect of Ventilation openings on internal pressure}

The effect of the ventilation openings on internal pressure was studied by performing two separate tests (i.e., Case $5 \& 7$ ) having different dominant opening sizes. Each test was carried out with and without the ventilation (i.e., soffit). As shown in Table 1, the soffit porosity area ratio was $0.67 \%$ of the total ventilated surface area. Case $5 \mathrm{~B}$ was similar to that of Case 5A except that its soffit openings were blocked. The same is true with Case 7B and 7A. Test Case 5 has a door with a porosity of $10 \%$ while test Case 7 has a window with $6 \%$ porosity. Their location with respect to the upstream wind direction was also different as explained in the previous section.

Observing the mean and peak internal pressure coefficients that develop underside of the roof sheathing, soffit ventilation systems provided along the perimeter of the roof overhang as in this case study have significant contribution as depicted in Figure 4.17. In both test cases, the internal pressure coefficient was higher when the soffit vents were 
blocked. There was $7-10 \%$ pressure increase for Case 5 and more than $33 \%$ increase for Case 7 (as the location of the opening with respect to its height from the ground and its distance from the leading edge has significant impact on the internal pressure that develop inside the building). Even though sealing soffit vent openings obviously provide security from the intrusion of wind driven rain, it doesn't play any significant role to alleviate the internal pressure by itself as shown in Figure 4.12 of Case 1A vs. 1D. In the presence of dominant openings, however, it is shown here that sealing the soffit vents off could aggravate the internal pressure on the roof sheathing. This observation will not apply for one sided ventilation opening such as goose neck or turbine vents. An intermediate solution, hence, should be sought to minimize the intrusion of wind driven rain and simultaneously accommodate the exfiltration of air to diminish the stress from internal pressure. Rain repulsive mechanical system should be encouraged as an intermediate solution.

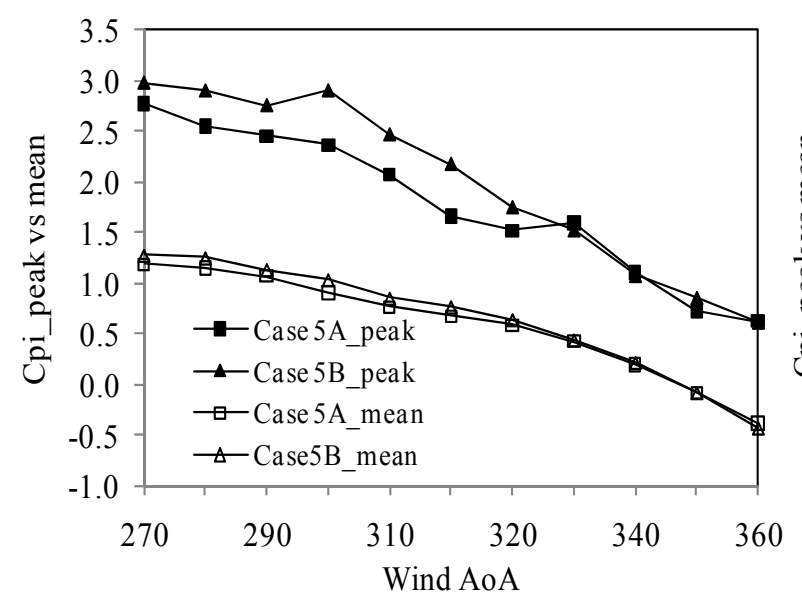

(a)

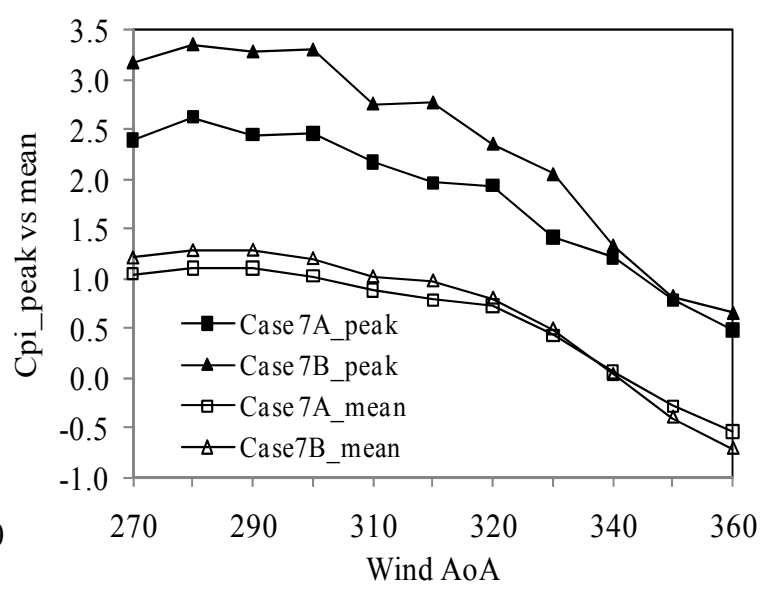

(b)

Figure 4.17: Internal pressure coefficient, closed versus opened soffit for: a) test Case $5 \&$ b) test Case 7. 


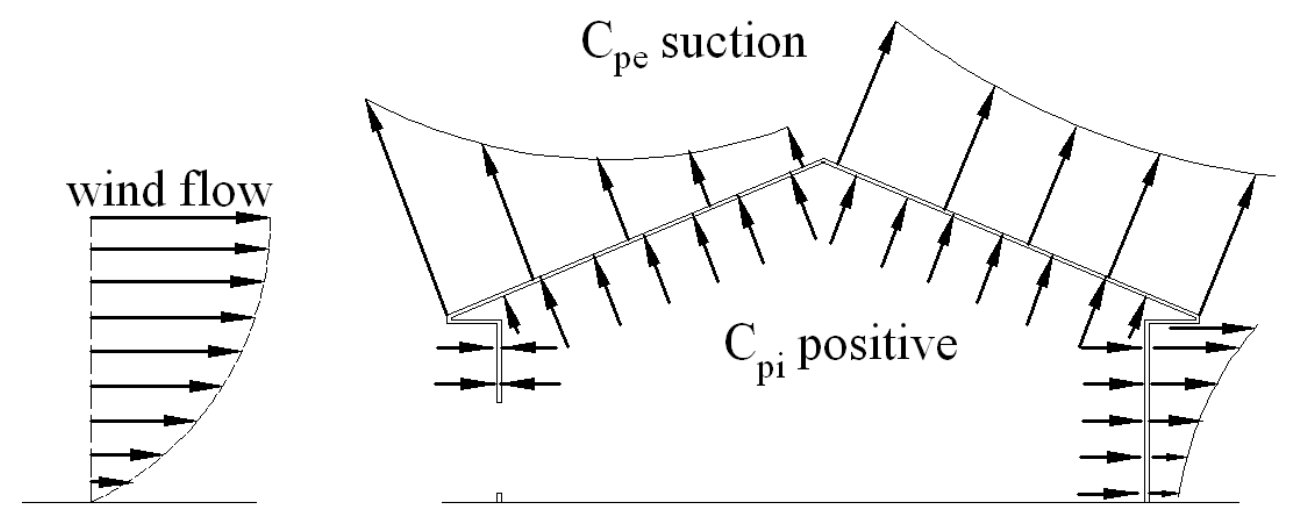

Figure 4.18: Schematics showing the interaction of wind and building (hip/gable) and net pressure direction.

\subsubsection{Net pressure on roof envelope}

The external pressure coupled with the positive internal pressure that act in the same direction as that of the external, as shown in Figure 4.18, instigates the worst net pressure that could cause overloading of the envelopes (i.e., windward and leeward roof as well as leeward wall). This could initiate failure under strong wind induced storms.

Cases 5B and 7B were considered in the analysis of the net pressure on roof sheathing. These two tests provide a realistic scenario of hurricane events wherein which it involves $10 \%$ and $6 \%$ porosity dominant openings; vents were sealed off to prevent intrusion of wind driven rain as well as the rush of air into the interior of the building. A total of 18 pressure taps distributed uniformly inside the roof surface were used to compute the area average internal pressure. In computing the external pressure, specific external roof taps (i.e., taps \#10,\#17 \& \#25) were used. Tables 4 \& 5 illustrate the mean and peak values of internal and external pressure coefficients for Cases 5B and 7B with its respective wind $A o A$. As depicted in the tables, the critical mean and peak values of internal pressure occur at $270^{\circ}$ wind $A o A$ (i.e., when the wind and the dominant opening are at right angle 
to each other). For external pressure, however, these values occur at different wind $A o A$ depending on the location of the taps with respect to the upstream wind direction. This shows that even if the peak internal pressure occurs when the dominant opening is at right angle to the wind flow, the net pressure coefficient that determines the design wind load could result from other oblique angles.

Table 4-4: Test Case 5B: mean, peak and suction pressure coefficients.

\begin{tabular}{|c|c|c|c|c|c|c|c|c|c|c|c|c|c|}
\hline \multirow{2}{*}{ Descri. } & \multirow{2}{*}{$\operatorname{tap} \#$} & \multirow{2}{*}{ Cp type } & \multicolumn{11}{|c|}{ Wind AoA } \\
\hline & & & $270^{\circ}$ & $280^{\circ}$ & $290^{\circ}$ & $300^{\circ}$ & $310^{\circ}$ & $315^{\circ}$ & $320^{\circ}$ & $330^{\circ}$ & $340^{\circ}$ & $350^{\circ}$ & $360^{\circ}$ \\
\hline \multirow[b]{2}{*}{$\mathrm{C}_{\mathrm{pi}}$} & & & 1.28 & 1.25 & 1.13 & 1.04 & 0.85 & 0.77 & 0.64 & 0.44 & 0.22 & -0.08 & -0.43 \\
\hline & 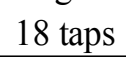 & & 2.97 & 2.89 & 2.75 & 2.90 & 2.46 & 2.17 & 1.75 & 1.52 & 1.07 & 0.86 & 0.61 \\
\hline \multirow{8}{*}{$\mathrm{C}_{\mathrm{p}}$} & & $m$ & -0.15 & 0.11 & 0.33 & 0.45 & 0.49 & 0.47 & 0.43 & 0.29 & 0.10 & -0.22 & -0.67 \\
\hline & & & -2.35 & -1.67 & -1.30 & -1.14 & -0.78 & -0.96 & -0.61 & -0.95 & -2.02 & -2.57 & -4.48 \\
\hline & \multirow{2}{*}{$\# 10$} & mean & -0.35 & -0.61 & -0.89 & -1.17 & -1.36 & -1.43 & -1.54 & -1.40 & -0.91 & -0.56 & -0.46 \\
\hline & & suction & -2.20 & -3.74 & -3.26 & -4.29 & -4.66 & -4.52 & -4.60 & -3.84 & -3.39 & -2.35 & -1.68 \\
\hline & \multirow{2}{*}{$\# 17$} & mean & -1.18 & -1.51 & -1.70 & -1.84 & -1.80 & -1.78 & -1.74 & -1.57 & -1.29 & -0.95 & -0.63 \\
\hline & & suction & -3.61 & -4.15 & -3.89 & -4.61 & -4.32 & -4.30 & -3.77 & -3.73 & -3.23 & -2.87 & -3.14 \\
\hline & \multirow{2}{*}{ \#25 } & & -0.68 & -0.89 & -1.23 & -1.65 & -2.02 & -2.15 & -2.36 & -1.92 & -0.72 & -0.51 & -0.44 \\
\hline & & suction & -2.43 & -3.42 & -3.80 & -4.73 & -5.64 & -5.98 & -6.49 & -5.72 & -3.16 & -2.06 & -1.91 \\
\hline
\end{tabular}

Table 4-5: Test Case 7B: mean, peak and suction pressure coefficients.

\begin{tabular}{|c|c|c|c|c|c|c|c|c|c|c|c|c|c|}
\hline \multirow{2}{*}{ Descri. } & \multirow{2}{*}{$\operatorname{tap} \#$} & \multirow{2}{*}{ Cp type } & \multicolumn{11}{|c|}{ Wind AoA } \\
\hline & & & $270^{\circ}$ & $280^{\circ}$ & $290^{\circ}$ & $300^{\circ}$ & $310^{\circ}$ & $315^{\circ}$ & $320^{\circ}$ & $330^{\circ}$ & $340^{\circ}$ & $350^{\circ}$ & $360^{\circ}$ \\
\hline \multirow{2}{*}{$\mathrm{C}_{\mathrm{pi}}$} & Avg. of & mean & 1.20 & 1.28 & 1.28 & 1.20 & 1.02 & 0.97 & 0.80 & 0.49 & 0.03 & -0.40 & -0.71 \\
\hline & 18 taps & peak & 3.17 & 3.35 & 3.28 & 3.30 & 2.76 & 2.77 & 2.35 & 2.05 & 1.33 & 0.82 & 0.65 \\
\hline \multirow{8}{*}{$\mathrm{C}_{\mathrm{pe}}$} & \multirow{2}{*}{$\# 1$} & mean & -0.15 & 0.13 & 0.32 & 0.45 & 0.48 & 0.49 & 0.43 & 0.31 & 0.09 & -0.24 & -0.70 \\
\hline & & suction & -2.15 & -1.98 & -1.73 & -1.16 & -0.47 & -0.96 & -1.25 & -1.00 & -1.88 & -2.64 & -4.36 \\
\hline & \multirow{2}{*}{$\# 10$} & mean & -0.36 & -0.61 & -0.91 & -1.13 & -1.37 & -1.49 & -1.48 & -1.46 & -0.93 & -0.57 & -0.48 \\
\hline & & suction & -2.01 & -3.61 & -3.35 & -5.06 & -4.47 & -4.78 & -4.33 & -4.06 & -2.85 & -2.38 & -1.81 \\
\hline & \multirow{2}{*}{$\# 17$} & mean & -1.19 & -1.51 & -1.75 & -1.81 & -1.80 & -1.85 & -1.72 & -1.63 & -1.31 & -0.94 & -0.66 \\
\hline & & suction & -3.98 & -4.10 & -4.29 & -4.75 & -4.88 & -4.51 & -4.36 & -4.23 & -3.28 & -2.96 & -2.50 \\
\hline & \multirow{2}{*}{$\# 25$} & mean & -0.69 & -0.90 & -1.25 & -1.63 & -2.04 & -2.22 & -2.27 & -2.03 & -0.76 & -0.50 & -0.46 \\
\hline & & suction & -2.81 & -3.22 & -3.75 & -4.56 & -5.67 & -5.47 & -6.15 & -7.03 & -4.04 & -2.12 & -2.18 \\
\hline
\end{tabular}




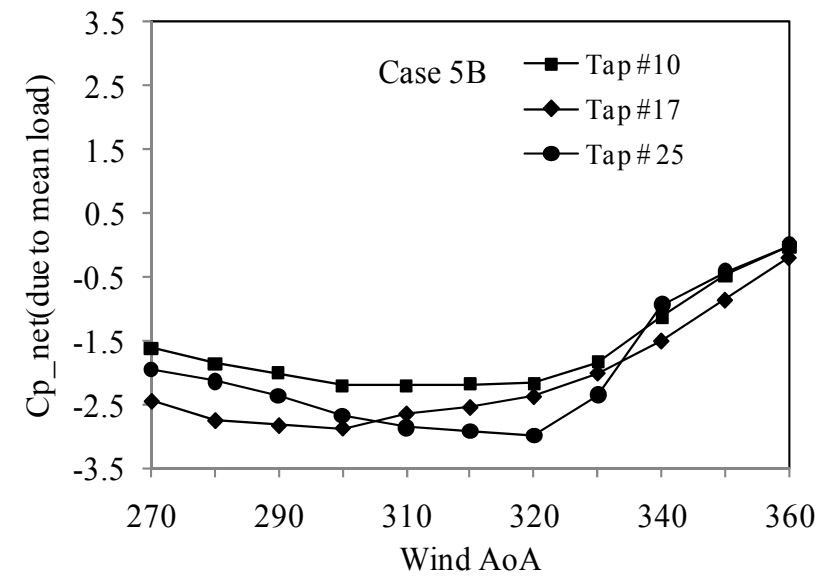

(a)

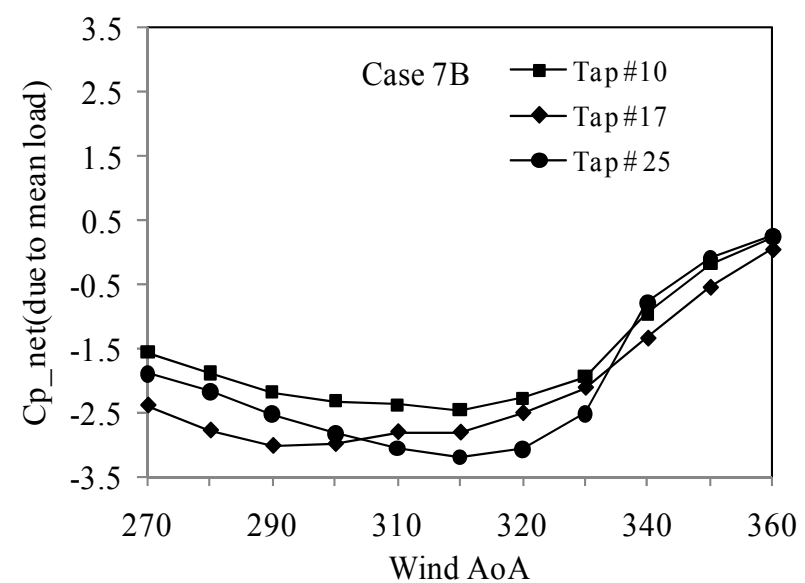

(c)

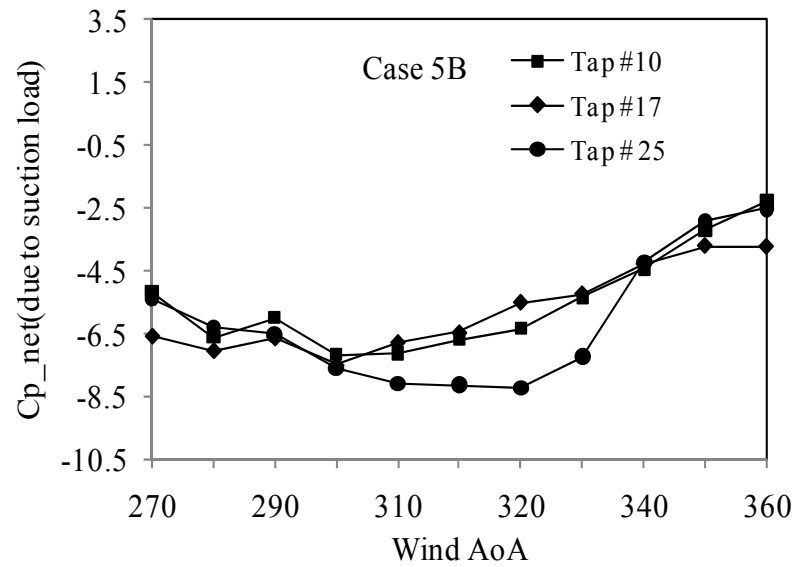

(b)

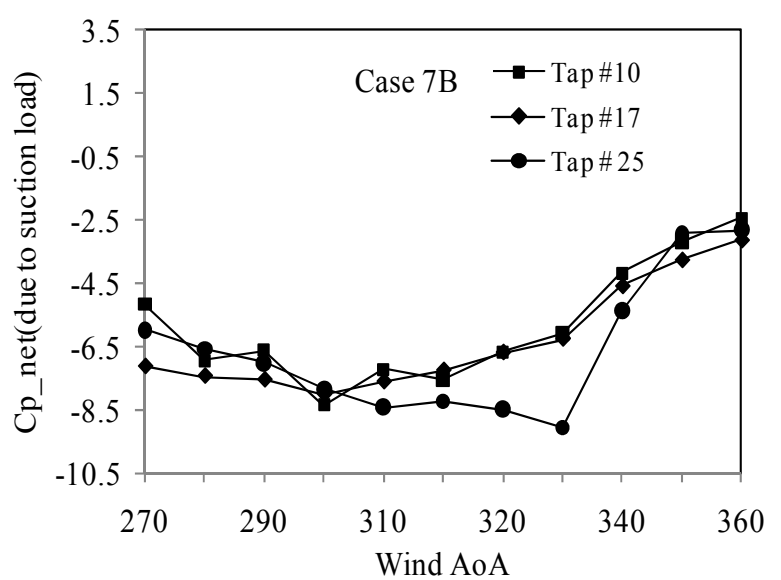

(d)

Figure 4.19: Mean and suction net pressure for test: a) Case 5B and b) Case 7B

Figure $4.19 \mathrm{a}-\mathrm{d}$ depicts the results of the net pressure computation for each test case simulated with its respective wind $A o A$. Since the positive internal pressure was more or less uniform, the suction pressure that developed on the downwind side of the roof ridge or hip was dominant and played crucial role towards generating critical net uplift force for both test cases. The experiment has also revealed that wind directions between $300^{\circ}$ and $330^{\circ} \mathrm{AoA}$ with respect to the dominant opening lead to the formation of those extreme net pressures on the building roof envelope. 
As can be examined from Figures 4.18 a-d, the critical mean and suction net uplift pressure occurred immediately behind the windward hip and ridge line. The components of the net pressure coefficients were obtained as given in Eqn, 10:

Net uplift pressure $=$ roof surface $\mathrm{C}_{\mathrm{pe}(\operatorname{mean} / \min )}$-roof $\mathrm{C}_{\mathrm{pi}(\operatorname{mean} / \max )}$

\subsection{Conclusion}

Assessments of internal pressure of a low-rise building for variable configuration of dominant openings, leakage, soffit vent and compartmentalization have been performed using a standard boundary layer wind tunnel. The present study dealt with the inherent scale issue related to the internal volume, as well as background leakage, variable dominant openings, correlation of external and internal pressure, interior compartmentalization, influence of vent opening on internal pressure and net pressure loads.

From the present study it is concluded that the internal volume distortion in wind tunnel study is significant for the building with large internal volume. Even though the rms values between the building with and without volume chamber don't show any considerable variation due to the small volume of the building, there was significant variation in mean and peak internal pressure, $25 \%$ and $35 \%$ respectively. This emphasizes the need for proper scaling of wind tunnel models in the study of internal pressure to maintain the dynamic similarity and correctly represent the full scale internal pressure characteristics, particularly for building with large internal volume. 
The intensity of the internal pressure is directly related to the size of dominant openings and their location with respect to the ground level, wind angle of attack and the effective internal volume. Peak positive internal pressures occur when a dominant opening of the building faces the oncoming wind flow while suction internal pressures occur when a dominant opening of the building is parallel to the upstream wind flow.

The internal pressure is also highly dependent on compartmentalization and the presence of openings on ceiling partition. For instance, an external door with $10 \%$ porosity together with a $0.35 \%$ ceiling hatch opening led to $90 \%$ increase in positive internal pressure coefficient underneath the roof sheathing. This underscores the necessity of closing ceiling hatch during strong storms and any other dominant openings such as doors and windows. With respect to vertical partitioning, it is also observed that the internal pressure inside multi-rooms remains uniform and highly correlated to the area average external pressure in the presence of single dominant opening. The response of the internal pressure in different rooms, however, is considerably variable from the external pressure in the presence of dominant openings on opposite sides of the building. The effect is significant when the dominant openings are in the windward-leeward direction. The rooms further down from the windward opening responds weakly than those rooms which are closer.

Even though blocking soffit vent openings provide security from the intrusion of wind driven rain, it doesn't play any significant role to alleviate the internal pressure by itself (i.e., when dominant openings are closed). In the presence of dominant openings, however, sealing the soffit vents off could aggravate the internal pressure on the roof 
sheathing. There was $7-33 \%$ internal pressure coefficient increase depending on the porosity of the dominant opening and its location with respect to the upstream wind.

The combined effect of the external and internal wind pressure acting simultaneously in the same direction often generate a worst net pressure. For roof locations such as corners, hip and ridge lines, it is observed that the mean net uplift pressure coefficients can range between -2.5 and 3.25 while the peak suction pressure coefficients between -8.5 and 9.05 .

\subsection{References}

Davenport, A.G. and Surry, D. (1984). "The estimation of internal pressures due to wind with application to cladding pressures and infiltration." Proc., Wind pressure workshop, Brussels, Belgium.

Ginger, J.D., Holmes, J.D. and Kopp, G.A. (2008). "Effect of building volume and opening size on fluctuating internal pressures." Wind and Structures 11(5): 361-376.

Ginger, J.D., Mehta, K.C. and Yeatts, B.B. (1997). "Internal pressures in a low-rise fullscale building." Journal of Wind Engineering and Industrial Aerodynamics 72: 163-174.

Holmes, J.D. (1979). Mean and fluctuating internal pressures induced by wind. Proc. 5th Int. Conf. on wind engineering, Colorado, USA.

Holmes, J.D. (2001). Wind Loading of Structures, Spon Press.

Holmes, J.D. (2009). "Discussion of: 'Net pressures on the roof of a low-rise building with wall openings' by R.N.Sharma and P.J.Richards,[J.WindEng.\&Ind.Aerodyn. Vol. 93,pp.267-291,2005]." Journal of Wind Engineering and Industrial Aerodynamics 97: 320-321.

Irwin, P.A. and Sifton, V.L. (1998). "Risk Considerations for Internal Pressures." J. Wind Engineering and Industrial Aerodynamics 77 \&78: 715-723.

Kopp, G.A., Oh, J.H. and R.Inculet, D. (2008). "Wind-induced Internal Pressures in Houses." Journal of Structural Engineering 134(7): 1129-1138.

Liu, H. and Saathoff, P.J. (1981). "Internal pressure and building safety." Proceedings, J.Struct. Div., ASCE, 108. 
Liu, H. and Saathoff, P.J. (1983). "Internal pressure of multi-room buildings." J. Engineering Mechanics Division 109(EM3): 908-919.

Minor, J.E. and Mehta, K.C. (1979). "Wind Damage Observations and Implications." Journal of the Structural Division." ASCE, ST 11: 2279-2291.

Oh, J.H., Kopp, G.A. and Inculet, D.R. (2007). "The UWO contribution to the NIST aerodynamic database for wind loads on low buildings. 3: Internal pressures." J. Wind Eng. Ind. Aerodyn. 95(8): 755-779.

Sharma, R.N., Mason, S. and Driver, P. (2010). "Scaling methods for wind tunnel modelling of building internal pressures induced through openings." Wind and Structures 13(4): 363-374.

Sharma, R.N. and Richards, P.J. (2003). "The influence of Helmholtz resonance on internal pressures in a low-rise building." Journal of Wind Engineering Industrial Aerodynamics 91: 807-828.

Sharma, R.N. and Richards, P.J. (2005). "Net pressure on the roof of a low-rise building with wall openings." Journal of Wind Engineering and Industrial Aerodynamics 93: 267291.

Stathopoulos, T. and Luchian, H.D. (1989). "Transient Wind-Induced Internal Pressures." Journal of Engineering Mechanics, ASCE 115(7): 1501-1514.

Stathopoulos, T., Surry, D. and Davenport, A.G. (1979). Internal pressure characteristics of low-rise buildings due to wind action. In: Proc. 5th Int. Conf. on Wind Engineering, Fort Collins, Colorado, Pergamon Press, New York.

Stathopoulos , T., Surry, D. and Davenport, A.G. (1979). Internal pressure characteristics of low-rise buildings due to wind action. In: Proc. 5th Int. Conf. on Wind Engineering, Fort Collins, Colorado, Pergamon Press, New York.

Vickery, B.J. (1986). "Gust factors for internal pressures in a low rise buildings." Journal of Wind Engineering and Industrial Aerodynamics 23: 259-271. 


\title{
5. WIND-DRIVEN NATURAL VENTILATION IN HIP ROOF LOW RISE BUILDING: A BOUNDARY LAYER WIND TUNNEL STUDY
}

\author{
Amanuel Tecle ${ }^{1}$, Girma T.Bitsuamlak ${ }^{2}$, Teshome E. Jiru ${ }^{3}$ \\ Submitted to Building and Environment
}

\begin{abstract}
The paper presents a boundary layer wind tunnel study on wind driven natural ventilation for a low rise building with multi-room partitioning, variable porosity size openings (door, windows and soffit) and uniformly distributed background leakage under different wind angle of attack at a model scale of 1:20. For the size of the building and openings considered, the experimental analyses indicated that internal volume distortion (using correct velocity scaling) is important, although this criterion could be relaxed for cross-ventilation in with opening in opposite walls. The internal pressure due to cross ventilation was 1.5-2.5 times higher when the ratio Ainlet/Aoutlet $>1$. Generally, the lower the porosity ratio (or inlet to outlet ratio), the higher the pressure drop inside the building; and for equivalent porosity ratio, cross-ventilation with opposite side openings generated higher pressure drop compared to adjacent side openings. The presence of room partitioning significantly affected the distribution of internal pressure and hence the pressure drop. Additionally, the total discharge coefficient Cd_total and the ventilation rate $\mathrm{Q} /(\mathrm{VrA})$ increased with increase in the porosity ratio. The inlet discharge coefficients obtained in this experiment ranged between $0.65-1.08$ which is similar to the results of numerous experiments carried out previously.
\end{abstract}


KEYWORDS: Natural ventilation, low-rise building, internal and external pressure, dominant openings, vents, multi-room partitioning, volume correction, porosity ratio, discharge coefficient, wind tunnel.

\section{$5.1 \quad$ Introduction}

Most households today involve equipment and appliances that operate with electric energy generated using non-renewable sources. Active (mechanical) ventilation system is one of the common appliances that modern residential sector use for indoor air quality and human comfort at the cost of expensive energy consumption. Most historical buildings incorporate passive and natural ventilation system that harnesses thermal buoyancy and wind flow. Today, with the awareness of global warming and the rising cost of non-renewable energy sources, wind-driven cross-ventilation can be considered as one of the possible and effective alternatives to reduce the cost of energy consumption and create indoor environmental quality (IEQ). Wind driven air circulation inside building depends on pressure differences and the design process of buildings. A thorough understanding and assessment of airflow mechanisms is required to effectively and optimally utilize wind-driven natural ventilation.

Wind and temperature differences between building environment are the major natural driving forces that natural ventilation systems rely on (BSI:1991). For wind speeds beyond $1.8 \mathrm{~m} / \mathrm{s}$, however, thermal buoyancy can be neglected (Papadakis et al. 1996). Full scale measurement and numerical simulations show that buildings with wind driven cross ventilation have their indoor environment more comfortable than those 
without cross-ventilation (Papadakis et al. 1996). Computational fluid dynamics (CFD) and field studies performed on a $3 \& 4$-room public housings have also shown that the houses with their doors opened for cross-ventilation achieve a reasonable ventilation performance than those with closed doors (Papadakis et al. 1996; Wong and Loke 2001). Moreover, the geometry and location of the building exhibited significant effect on the level of effective ventilation. Previous research has shown that the effective ventilation of buildings and airflow in the built environment is highly correlated to the arrangement and configuration of the buildings, the way rooms are partitioned, location and porosity of dominant openings (i.e., doors and windows), topography and wind direction(Ayad 1999; Karava et al. 2007; Karava and Stathopoulos 2009). This reveals that the potential of cross-ventilation for maximum indoor air quality and human comfort requires careful consideration of the inlet and outlet openings (with respect to their size and location), vents and location of rooms (Heiselberg et al. 2001; Heiselberg et al. 2002; Mochida et al. 2005).

The wind-building interaction often creates variation of pressure inside the building and on the surface of a building envelope. A number of Boundary Layer Wind Tunnel (BLWT) and full scale studies have been carried out to examine the external aerodynamics and its effect on indoor air quality and natural ventilation. However, detail internal aerodynamic information is limited in literature. Several parameters are involved in the study of internal pressure, both for effective natural ventilation and design wind load (Liu 1990). These includes but not limited to shape of the building, location and porosity of dominant openings, fluctuation of external pressure at the openings, the 
relative upstream wind direction with respect to the dominant openings, internal volume and compartmentalization, natural ventilation openings and background leakages due to construction crack and outlet ducts (Holmes 1979; Stathopoulos et al. 1979; Liu and Saathoff 1983; Vickery 1986; Ginger et al. 1997; Sharma and Richards 2005; Oh et al. 2007; Sharma 2007; Kopp et al. 2008; Karava and Stathopoulos 2009). While effects of compartmentalization due to room partitioning on internal pressure was studied by Liu and Saathoff (1983), Kopp et al. (2008) studied ceiling portioning effects. Bloxham and Vickery (1989) also showed that the effect of porosity is of little significance if the leakage area is less than $10 \%$ of the windward dominant opening area. A full scale, boundary layer and numerical studies performed separately showed the sensitivity of internal pressure characteristics to the size of the dominant openings and the size of the internal volume (Ginger et al. 2008; Holmes 2009; Sharma et al. 2010). While the study by Holmes (1979), Kopp et al. (2008) incorporated internal volume scale correction to maintain dynamic similarity of wind tunnel model with its respective full scale model, the studies by Karava et al. (2009) relaxed the volume corrections. Most of the previous studies were limited to a single internal volume case.

The main objective of this paper was to study the internal pressure dynamics for a low rise building with a focus on cross ventilation for variable porosity of door and windows along with soffit opening and uniformly distributed background leakage, and with realistic room partitioning. Internal volume correction was also systematically investigated to examine its relevance for low-rise cross ventilation application studies. Effects of window and door screens were also investigated. 


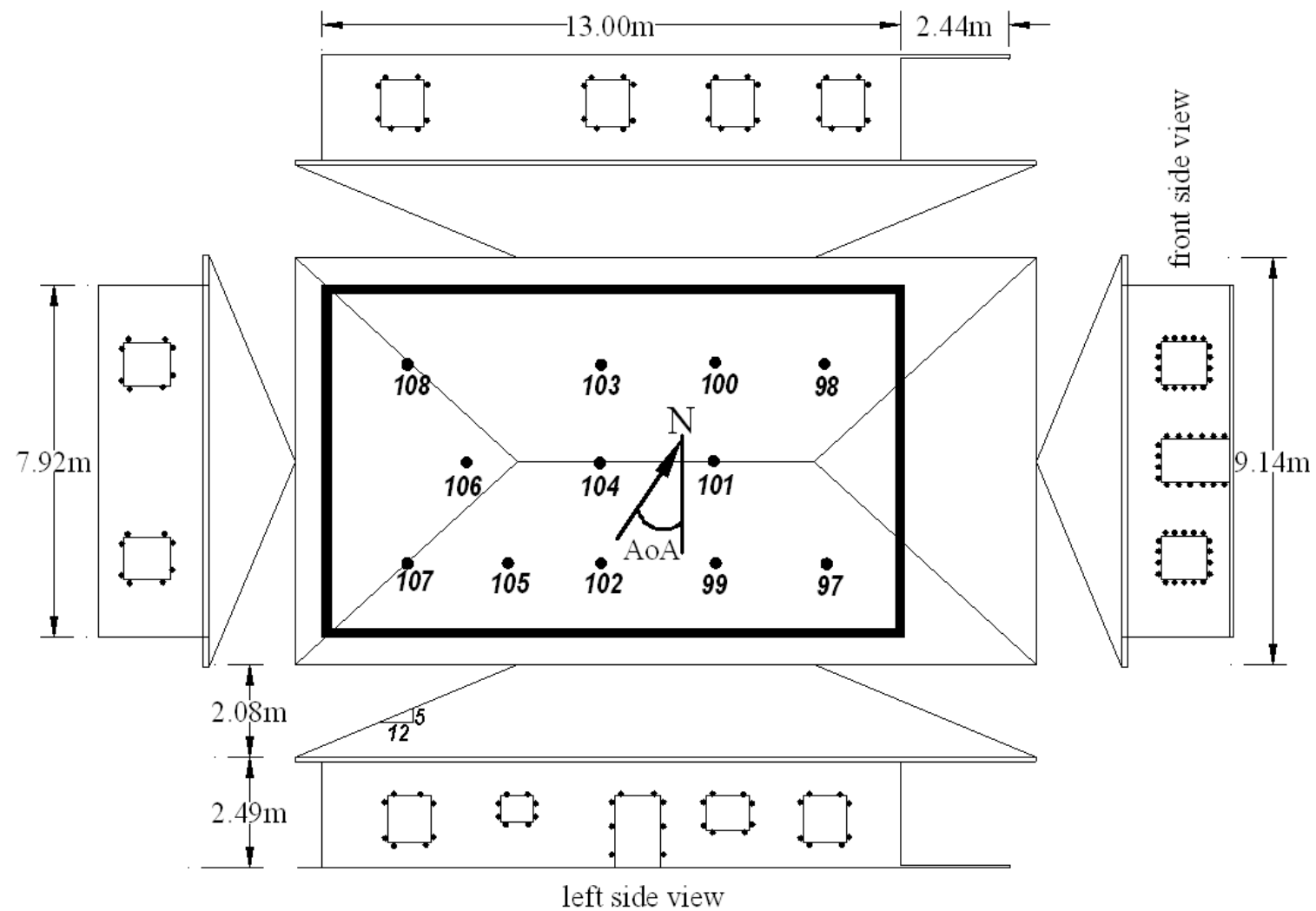

Figure 5.1: Exploded view of building model with external and internal pressure taps layout and location of dominant openings. (Dimensions given are full scale)

\subsection{Methodology}

\subsubsection{Test building, porosity and pressure tap layout}

A typical low-cost low rise building with 5:12 hip roof slope constructed at a model scale of 1:20 was studied in RWDI USA Inc. BLWT in Miramar, Florida. The model was constructed from a Plexiglas acrylic sheet. The model building has an equivalent full-scale plan dimensions of $\mathrm{L}=15.44 \mathrm{~m}(50.67 \mathrm{ft})$ by $\mathrm{W}=7.92 \mathrm{~m}(26.00 \mathrm{ft})$ with a roof eave height of $\mathrm{h} 1=2.49 \mathrm{~m}(8.17 \mathrm{ft})$. The total effective height of the building level was $4.57 \mathrm{~m}(15 \mathrm{ft})$ (i.e., the building has an attic room with height $\mathrm{h} 2=2.08 \mathrm{~m}(6.83 \mathrm{ft})$ (refer to Fig. 5.1). 
The building has a number of dominant openings (door and window openings), soffit ventilations, and uniformly distributed background leakages. All the dominant openings and the ventilations were replica of a typical low-cost full-scale low-rise building in Florida, USA. In addition, the external envelope of the building has uniformly distributed circular holes (of diameter 1/16 in) to simulate the background leakage due to cracks and joints. In all the cases studied, the background leakage was set at $0.1 \%$ of the respective envelope surface area. Similarly, the ceiling partition was provided with a uniformly distributed background leakage. Cross-ventilation of the attic space was provided by implementing soffit openings based on the prevailing building codes. Building performance guides such as Florida Building Code (2004 FBC R4409.13.3.2 ) and ASHRAE, require the provision of ventilation openings on the roof so as to effectively cross-ventilate attic space between ceiling joists and roof rafters. The guide stipulates that the ratio of total net free ventilating area to the area of ceiling shall not be less than 1/150. Since the attic net free ventilation area was $0.36 \mathrm{~m} 2$ (558.17 in2), a total of 18 circular holes with diameter of $0.013 \mathrm{~m}$ (33/64in) were uniformly provided over the perimeter of the roof overhang. To replicate the screens used on window, doors and soffits, an equivalent scaled down screen mesh was applied on each window, door and soffit openings. Details of the porosity arrangements are given in Table 5.1. 
Table 5-1: Dominant openings and background leakage distribution in model scale dimensions.

\begin{tabular}{|c|c|c|c|}
\hline Description & Description & area $\left[\mathrm{in}^{2}\right]$ & ratio [\%] \\
\hline \multirow{4}{*}{ Attic space } & Attic area to be ventilated & 558.20 & \\
\hline & $\begin{array}{l}\text { Soffit opening ( } 18 \text { pcs, dia. } 0.013 \mathrm{~m}, 33 / 64 \\
\text { in) }\end{array}$ & 3.76 & 0.67 \\
\hline & Attic hatch at ceiling & 1.97 & 0.35 \\
\hline & $\begin{array}{l}\text { Ceiling background leakage ( } 182 \text { holes with } \\
\text { dia. }(0.0016 \mathrm{~m}), 1 / 16 \text { in })\end{array}$ & 0.56 & 0.10 \\
\hline \multirow{10}{*}{$\begin{array}{l}\text { Living room } \\
\text { space }\end{array}$} & Front side Door, $D f$ & 7.85 & 10 \\
\hline & Front window: $W f 1, W f 2$ & 5.10 & 6 \\
\hline & Left side door, $D l$ & 8.63 & 6 \\
\hline & Left side window, $W l 1$ & 5.70 & 4 \\
\hline & Left side window, $W l 2$ & 1.98 & 1 \\
\hline & Left side window, $W l 3$ & 3.10 & 2 \\
\hline & Left side window, $W l 4$ & 5.70 & 4 \\
\hline & Right side window: $W r 1, W r 2$ & 5.70 & 4 \\
\hline & Rear side window: $W r r 1, W r r 2$ & 5.70 & 7 \\
\hline & $\begin{array}{l}\text { Uniformly distributed wall background } \\
\text { leakage (142 holes with dia. }(0.0016 \mathrm{~m}) \text {, } \\
1 / 16 \text { in) }\end{array}$ & 0.44 & 0.10 \\
\hline
\end{tabular}

\subsubsection{Pressure tap distribution}

In order to examine the overall envelope pressure distribution on the building (both external and internal pressure), 156 pressure taps were used. A total of 132 taps were placed to evaluate the pressure fluctuations at the entrance of the dominant openings. Since it is difficult to capture wind flow characteristics at a dominant opening without disrupting the flow field, only representative numbers of pressure taps were placed at the periphery of each opening. Area averaged pressure reading was considered 
rather than measuring the external pressure on sealed body as the latter one cause major discrepancies for dominant openings with porosity greater than 10\% (Snykers 1970; Vickery and Karakatsanis 1987; Ernest et al. 1992). A total of 24 pressure taps were uniformly placed inside the living room (on the ceiling and floor) to capture the overall internal pressure fluctuations inside the building. For the model building with room partitioning, additional pressure taps were installed at the center of each wall. Measurements were obtained for a total of 40 wind angle of attack $(A o A)$ in $10^{\circ}$ increments i.e., all the 36 wind directions in $10^{\circ}$ increments and an additional four $45^{\circ}$ angles to capture oblique winds in high resolution. For symmetrical cases, however, tests were carried out for eleven wind angles ranging between $270^{\circ}$ and $360^{\circ}$. Wind $A o A 270^{\circ}$ is normal to the East facing wall and $360^{\circ}$ is normal to the South facing wall. The pressure time histories from all taps were sampled at a rate of $512 \mathrm{~Hz}$ for duration of 90 seconds.

\subsubsection{Test wind profile}

For the present study only the lower $40 \mathrm{~m}$ of the atmospheric boundary layer (ABL) was simulated in the wind tunnel with a length scale of 1:20. The RWDI USA LLC wind tunnel has a cross-section of $2.13 \mathrm{~m} \times 2.44 \mathrm{~m}(7 \mathrm{ft} \times 8 \mathrm{ft})$ and the test model was placed on a turntable at $13.3 \mathrm{~m}(43.5 \mathrm{ft})$ distance from the tunnel entrance. The 1:20 scale was adopted due to the small size of the openings and external and internal architectural features such as room partitioning. This scale is relatively large compared to a typical scale used in BLWT studies (1:100 to 1:400) thus requiring customized velocity and turbulence profiles that replicated only the bottom $40 \mathrm{~m}$ of the ABL. 


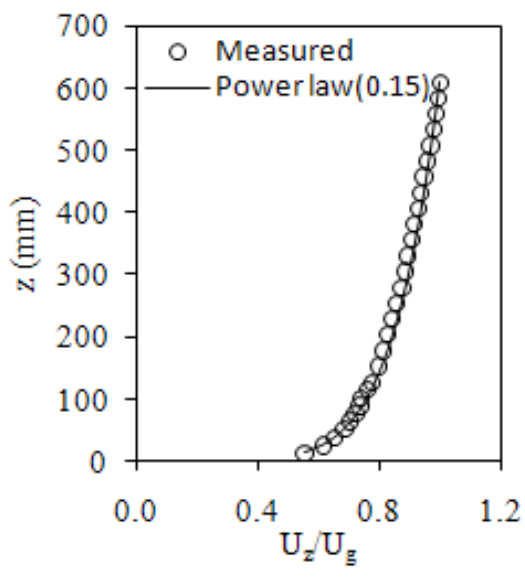

(a)

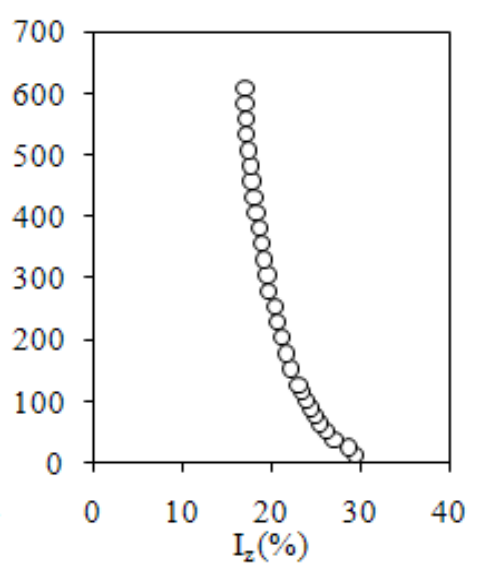

(b)

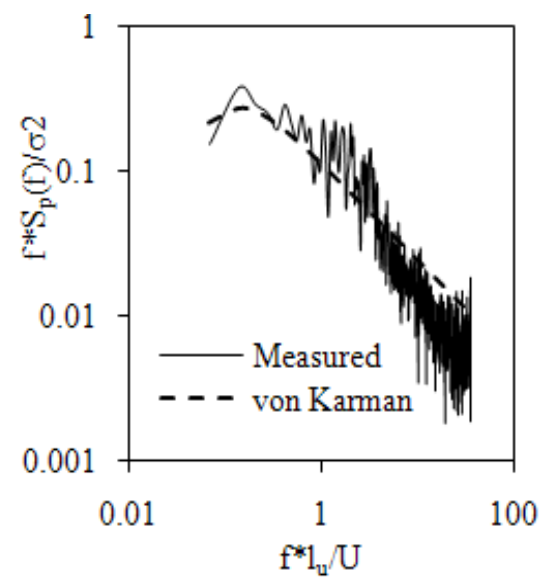

(c)

Figure 5.2: Normalized open terrain: a) wind velocity, b) turbulence intensity profiles, and c) spectra.

The development of mean wind speed and turbulence intensity profiles approaching the modeled area of the BLWT were carried out through a trial and error procedure, by using a combination of turbulence-generating spires installed at the upwind end of the tunnel and a long working section with floor roughness elements. The target open terrain profile was finally generated by a final configuration of 2-dimensional trapezoidal spires (19 inches wide at the floor, 15 inches wide at the ceiling) and 1.5 inch high planar-triangular floor roughness elements (Fig. 5.2a). The open wind profile developed with this combination produced a 0.15 power-law profile and a turbulence intensity of $20 \%$ at mean roof height. Kopp et al. (2008) have used similar procedure but at a 1:50 scale. The approach mean velocity and turbulence intensity profiles are shown in Figs. 5.2b and 5.2c, respectively. Longitudinal turbulence spectra of the open profile developed was also compared with von-Karman spectra as shown in Fig. 5.2d. Reference wind speed data was recorded in the absence of the model building for 90 sec duration at a 
frequency of $512 \mathrm{~Hz}$. A mean reference wind speed of $8.95 \mathrm{~m} / \mathrm{s}(20.03 \mathrm{mph})$ was considered at a mid-height of the building.

\subsubsection{Full scale to wind tunnel length scaling}

Providing proper internal volume distortion of a building model for a low-wind speed wind tunnel study is necessary in order to accurately measure the internal pressure fluctuations, particularly for larger buildings with full scale internal volume of 5,00010,000m3 (Holmes 1979). For low-rise buildings of large volume, the implementation of velocity and length scale helps maintain realistic internal pressure measurement particularly the Helmholtz natural frequency and turbulence spectrum. Holmes (1979) represented the dynamics of internal pressure by a time dependent non-linear oscillation equation and provided a volume correction given in Eqn. (1).

$$
\frac{\left[V_{o}\right]_{m}}{\left[V_{o}\right]_{f}}=\frac{[L]_{m}}{[L]_{f}} x \frac{[\bar{U}]_{f}^{2}}{[\bar{U}]_{m}^{2}}
$$

Where $L$ represents characteristic geometric length scale; $\bar{U}$ represents eave height wind speed, $V_{O}$ represents internal volume, and $m$ and $f$ represent model and full scale, respectively. According to Eqn. 1, the nominal volume obtained using length scale should be magnified by a factor of the square of the velocity ratio if the ratio is different from unity. In $B L W T$ studies, the full scale to model scale wind velocity is higher than three in most cases. Thus, for correct internal volume scaling and the appropriate measurement of the internal pressure fluctuations, the nominal volume need to be exaggerated which is 
usually done by providing additional volume chamber underneath the turntable (Fig. 5.3). The applicability of the above approach to buildings with more than one dominant opening requires more in-depth study. In the present study, based on the above relation (Eqn. 1), additional volume chamber was constructed. The model was prepared at a scale of 1:20 and the approximate full scale to model scale velocity ratio considered was 3:1. Thus, the nominal volume obtained by scaling the characteristic length of the full scale building was required to be distorted by a factor of 9 . A tight volume chamber box was connected to the model building underneath the wind tunnel turntable following the recommendation that the volume chamber should not be shallow and wider (Sharma et al. 2010).

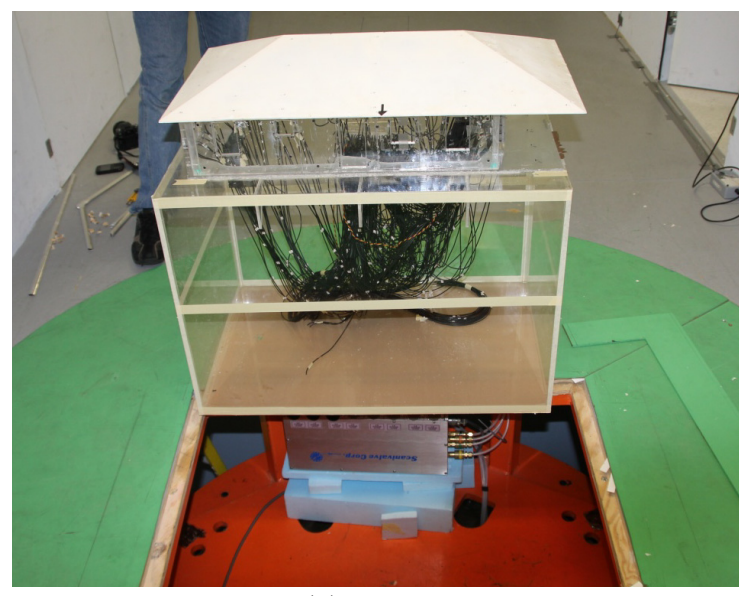

(a)

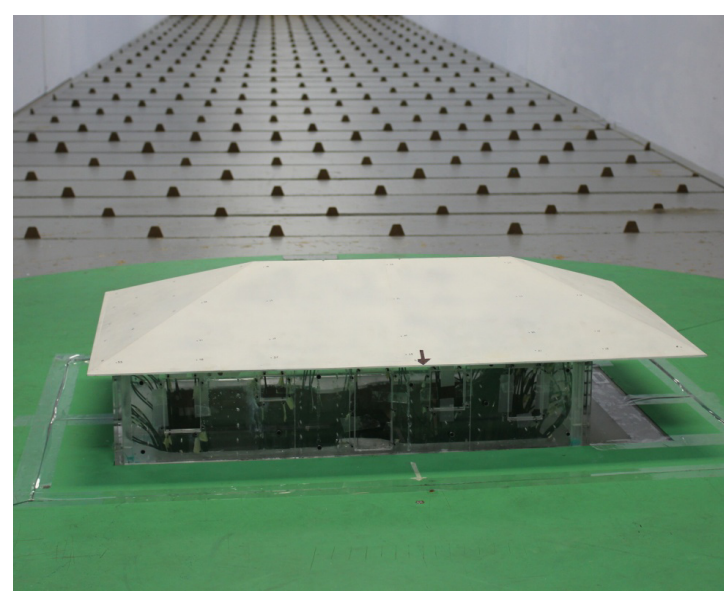

(b)

Figure 5.3: 1:20 scale model setup: a) model with volume chamber, and b) model inside wind tunnel in a final testing position. 


\subsubsection{Experimental plan}

Three wind-driven cross ventilation test configurations were considered: Case 1: adjacent side wall openings; Case 2: opposite side wall openings; and Case 3: one sided wall openings. In addition Case 2 was tested with screens on doors and windows, and Cases 2 and 3 were tested with room partitioning walls. Table 5.2 summarizes the experimental plan. Further, Cases 1 and 2 (i.e. opening on adjacent and opposite side walls, respectively) were tested with and without volume correction to assess the sensitivity of cross-ventilation application studies for volume correction. It is to be noted that all cases were tested with nominal background leakage and soffit openings that were covered with mesh screens.

\subsubsection{Internal and external pressure distribution}

The non-dimensional internal pressure and external pressure coefficients at each pressure tap location were calculated by referencing measured pressures to the mean free stream dynamic pressure as given in Eqn. 2. The mean and the root mean square (rms) values of coefficient of pressure for each tap was obtained by taking the average and the standard deviation of the 90 second recorded differential pressure as given in Eqn. 3, respectively. Similarly, the peak pressure coefficient was obtained from the time history data as shown in Eqn.4.

$$
C_{p i j}=\frac{P_{i j}-P_{0}}{\frac{1}{2} \rho U_{H}{ }^{2}} \quad C_{p e j}=\frac{P_{e j}-P_{0}}{\frac{1}{2} \rho U_{H}{ }^{2}}
$$


where $P_{i j}$ and $P_{e j}$ are the measured internal and external differential pressures, respectively at the $j^{\text {th }}$ tap; $P o$ is the mean static pressure at the reference height, $\rho$ is air density taken as $1.225 \mathrm{Kg} / \mathrm{m} 3 ; U_{H}$ is the mean wind speed measured at mid height (i.e., between eave and ridge) of the building.

Wind driven natural ventilation flow computation is often carried out using the Bernoulli's equation for steady and incompressible flow and conservation of mass. The discharge coefficient is introduced to account for the losses due to friction, turbulence and other related factors in the opening. For wind driven cross-ventilation in low rise buildings, the equivalent opening area is computed by taking the arithmetic sum of those openings in parallel and the sum of the reciprocal of the squares of those openings in series as shown in Table 5.3.

Similarly, the total discharge coefficient was obtained by rearranging the inlet and outlet discharge coefficients obtained in Eqns.3-5 as shown in Table 5.3.

$$
\begin{aligned}
& C_{d}=\frac{Q}{A}\left(\frac{2 \Delta P}{\rho}\right)^{-0.5} \\
& C_{d_{-} \text {inlet }}=C_{d 1}=\frac{u}{V\left(C_{p e w}-C_{e l}\right)^{0.5}} \\
& C_{d_{-} \text {outlet }}=C_{d 2}=\frac{u}{V\left(C_{p i}-C_{e l}\right)^{0.5}}
\end{aligned}
$$


Table 5-2: Summary of experimental plan.

\begin{tabular}{|c|c|c|}
\hline Des cription & Test cases & $\begin{array}{c}\text { Dominant } \\
\text { opening }\end{array}$ \\
\hline \multicolumn{3}{|l|}{ Case 1 - Adjacent side opening } \\
\hline $10 \% E+6 \% \quad S$ door opening & Case 1a & \\
\hline $\begin{array}{l}\text { All } E(22 \%) \text { and } S(18 \%) \text { doors and windows } \\
\text { open }\end{array}$ & Case 1b & \\
\hline \multicolumn{3}{|l|}{ Case 2 - Oppos ite side ope ning } \\
\hline $10 \% E$ door and $14 \% \mathrm{~W}$ windows opening & Case $2 \mathrm{a}$ & \\
\hline $10 \% E$ door and $14 \% W$ windows opening & \multicolumn{2}{|l|}{ Case $2 \mathrm{a}$ with screen } \\
\hline $10 \% E$ door and $14 \% W$ windows opening & Case $2 \mathrm{a}$ with partition & \\
\hline All $E(22 \%)$ and $14 \% W$ windows opening & Case $2 b$ & \\
\hline All $E(22 \%)$ and $14 \% W$ windows opening & \multicolumn{2}{|l|}{ Case $2 b$ with screen } \\
\hline All $E(22 \%)$ and $14 \% W$ windows opening & Case $2 \mathrm{~b}$ with partition & \\
\hline $6 \% S$ door and $8 \%$ two $\mathrm{N}$ windows opening & Case 2c & $\int_{4}^{4}$ \\
\hline $6 \% S$ door and $8 \%$ two $N$ windows opening & \multicolumn{2}{|l|}{ Case $2 c$ with screen } \\
\hline $\begin{array}{l}\text { All } S \text { openings }(18 \%) \text { and } N \text { side windows } \\
(17 \%)\end{array}$ & Case $2 d$ & $\vec{N}$ \\
\hline $\begin{array}{l}\text { All } S \text { openings }(18 \%) \text { and } N \text { side windows } \\
(17 \%)\end{array}$ & \multicolumn{2}{|l|}{ Case $2 \mathrm{~d}$ with screen } \\
\hline \multicolumn{3}{|l|}{ Case 3 - One sided opening } \\
\hline $10 \% E$ door opening & Case 3a (no ceiling) & \\
\hline $10 \% E$ door opening & Case $3 a$ with partition & \\
\hline $10 \% E$ door opening & Case $3 a$ with ceiling & \\
\hline $22 \% E$ door and windows opening & Case $3 b$ with ceiling & \\
\hline
\end{tabular}

Subscripts $E=$ east side, $\mathrm{W}=$ west side, $\mathrm{S}=$ south side, $\mathrm{N}=$ north side 
Table 5-3: Total discharge coefficient and equivalent area.

\begin{tabular}{c|c|c}
\hline Equivalent opening area & $A_{e q}=\frac{\left(A_{1}+A_{2}\right)\left(A_{3}+A_{4}\right)}{\sqrt{\left(A_{1}+A_{2}\right)^{2}+\left(A_{3}+A_{4}\right)^{2}}}$ \\
\hline Total discharge coefficient & $C_{d_{-} \text {total }}=\frac{C_{d 1} C_{d 2}}{\sqrt{\left(C_{d 1}\right)^{2}+\left(C_{d 2}\right)^{2}}}$ \\
\hline
\end{tabular}

\subsection{Results and discussion}

\subsubsection{Effect of volume distortion on mean and rms internal pressure coefficients}

A number of researchers have raised their concern with regard to correct internal pressure measurements in low-wind speed $B L W T$. The suggestion was that a geometrically scaled volume of the model building in $B L W T$ should be distorted by a square of the ratio of full scale to wind tunnel velocity (if different from unity) in order to maintain dynamic response similarity as shown by Eqn. 1 (Holmes 1979). This was reported to be particularly important for large size buildings. To assess the need for such volume distortions for small residential houses such as the one considered in the present study, a systematic study was carried out for the following conditions.

The first condition dealt with size and location of openings where the basic configurations of Case 1 (with adjacent openings), Case 2 (with opposite openings) and Case 3 (with one sided openings) were tested with and without volume correction (refer Table 5.2 for detail definitions of these cases). 

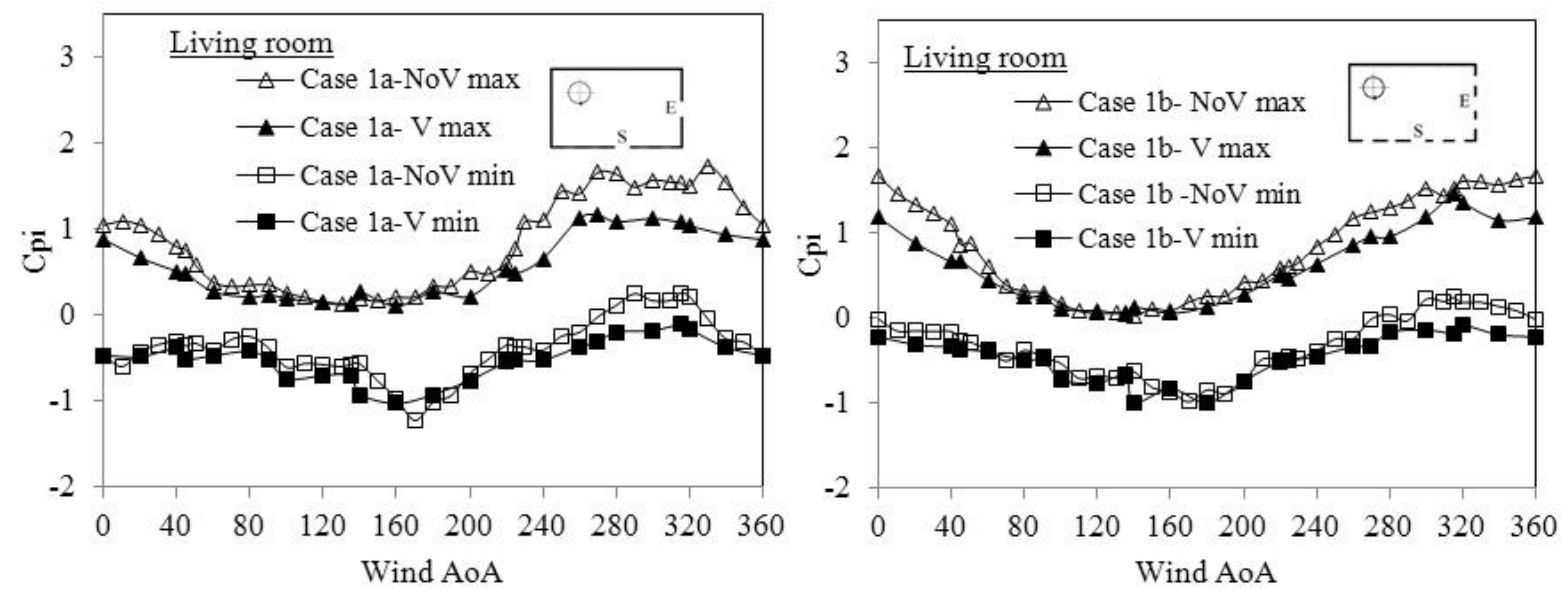

Figure 5.4: Cross ventilation with adjacent openings: a) Case $1 \mathrm{a}, \mathrm{E}=10 \%$ and $\mathrm{S}=6 \%$; b) Case $1 \mathrm{~b}$, $\mathrm{E}=22 \%$ and $\mathrm{S}=18 \%$.

In all cases, a uniform background leakage of $0.1 \%$ (applied over the surface of the building envelope) and soffit ventilation openings were considered. The opening sizes are described in Table 5.1. The second condition studied the effect of size of internal volume of a building by considering a building "shell" for Case 3 (i.e. only with external building envelope walls and roof) with and without a ceiling for both volume $(V)$ and no volume correction $(\mathrm{NoV})$ cases.

Figure 5.4a shows results for Case 1 (i.e. adjacent dominant opening crossventilation with $10 \%$ porosity on east wall and $6 \%$ porosity on south wall). Similar comparison was given in Figure. 5.4b but with additional two front side windows and four left side windows opened, increasing the dominant opening porosity to $22 \%$ and $18 \%$, on east and south wall respectively. For Case 1, the max and $\min C_{p i}$ for the model with no volume distortion produces higher values compared to the case with volume distortion for wind $A O A$ between $270^{\circ}-360^{\circ}$ and $0^{\circ}-20^{\circ}$, for both high and low porosity 
conditions as shown in Figures. 5.4a \& 5.4b, respectively. However, when the adjacent side openings were on leeward side, the internal pressure values for the volume distortion and without volume distortion cases were in close agreement (eg. for wind $A o A$ between $\left.40^{\circ}-200^{\circ}\right)$.

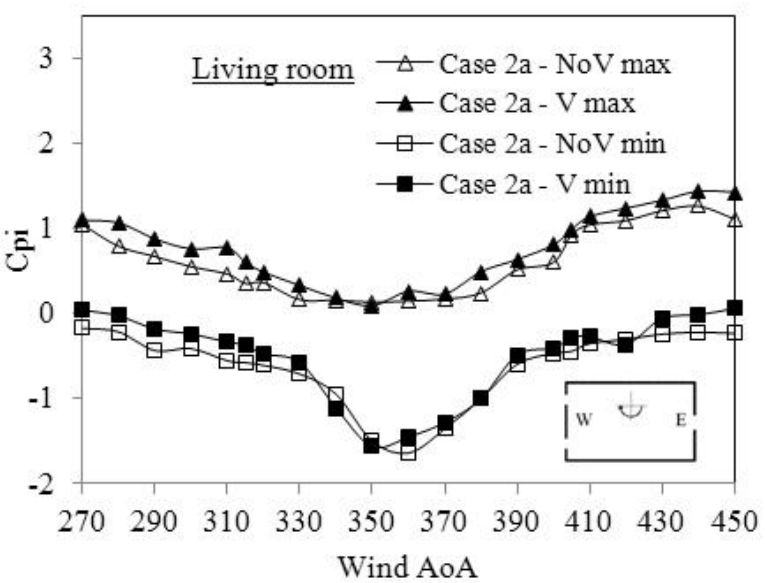

a)

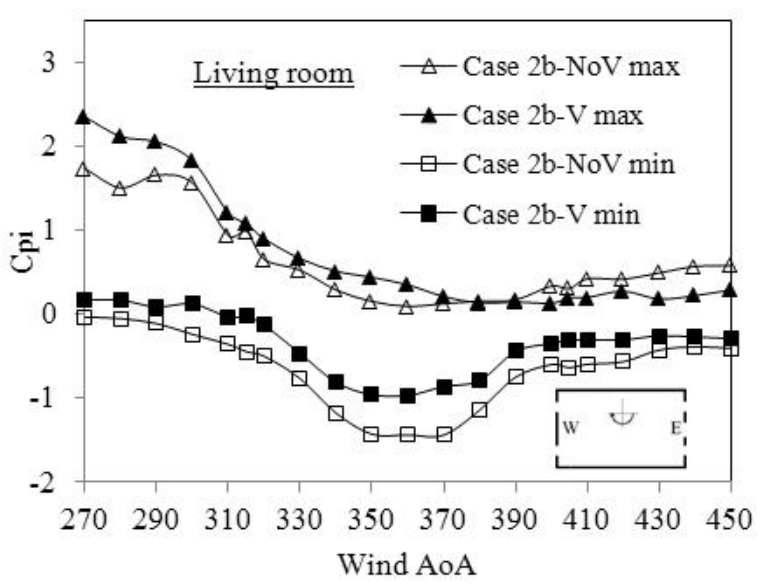

b)

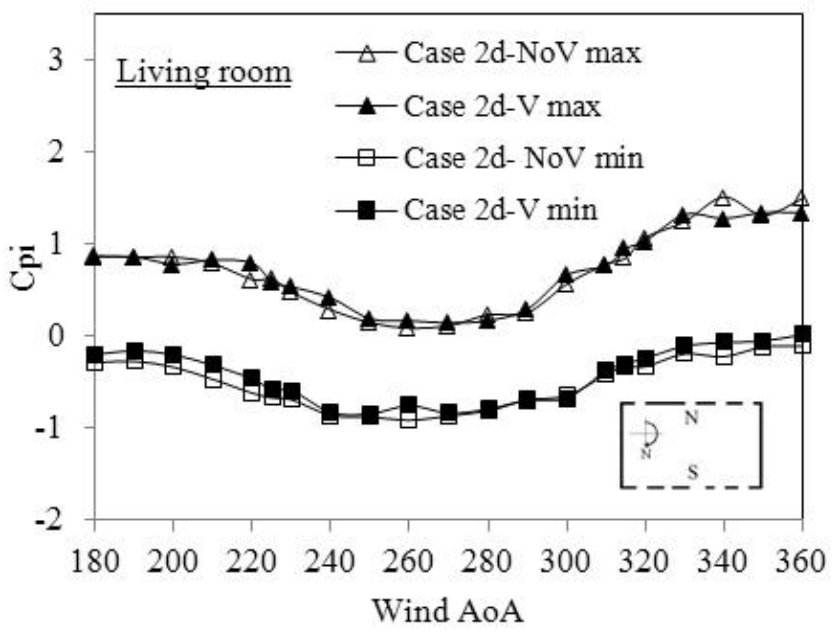

c)

Figure 5.5: Case 2 cross ventilation with opposite side openings: a) Case $2 \mathrm{a}, \mathrm{E}=10 \%$ and $\mathrm{W}=14 \%$; b) Case $2 \mathrm{~b}, \mathrm{E}=22 \%$ and $\mathrm{W}=14 \%$, c) Case $2 \mathrm{~d}, \mathrm{~S}=18 \%$ and $\mathrm{N}=17 \%$. 
Figure 5.5a shows similar results but for Case 2 (i.e. opposite side dominant opening cross-ventilation on the longer side with $10 \%$ porosity on east wall and $14 \%$ porosity on west wall). Similar comparison was given in Figure 5.5b but with additional two east side windows, increasing the dominant opening porosity to $22 \%$ and $14 \%$, on east and west wall, respectively. Figure 5.5c shows the results for opposite side openings along the shorter side having a south side opening with porosity of $18 \%$ and north side openings of $17 \%$. Irrespective of the porosity size, the result depicts that, the internal pressure characteristics for opposite side openings in the long direction does vary significantly with and without volume correction (Figures 5.5a \& 5.5b). However, for opposite side openings in the short direction, the variation is insignificant (Figure 5.5c) as the wind comes in and goes out easily without causing much oscillation.
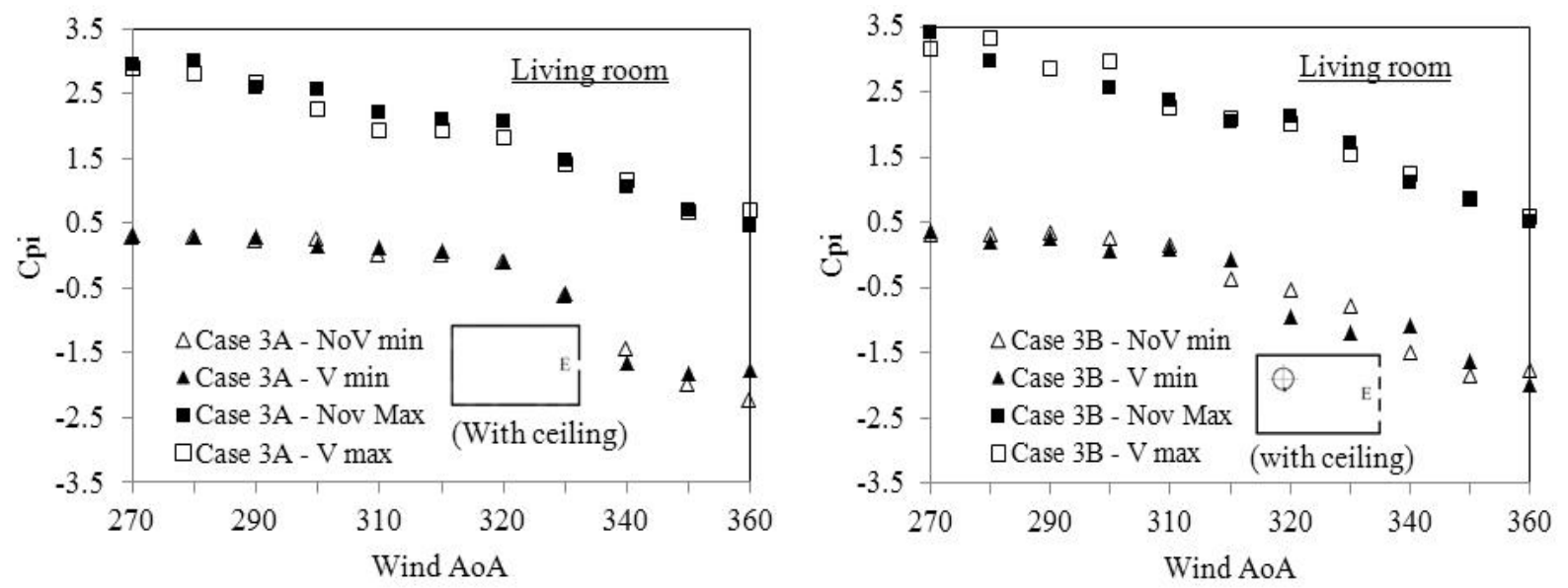

Figure 5.6: Maximum and minimum internal pressure characteristics for the building with only East opening: a) Case 3A having ceiling (10\% porosity), b) Case $3 \mathrm{~A}$ with no ceiling (22\% porosity). 

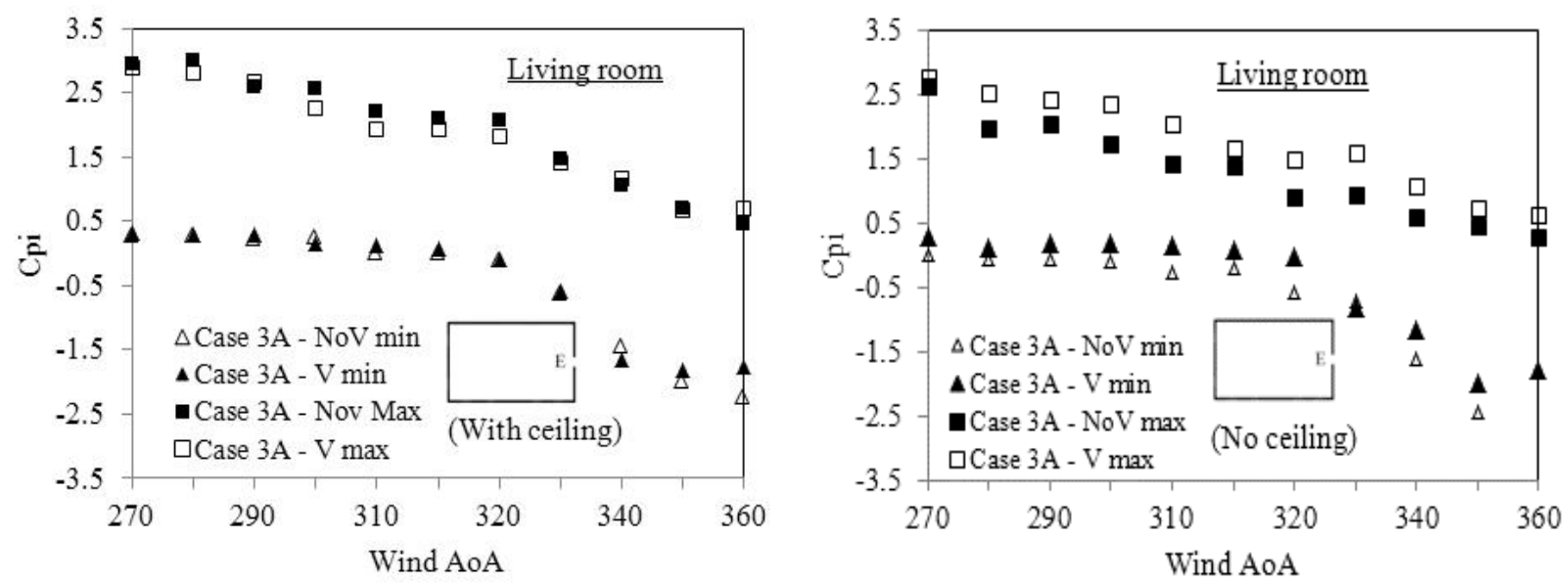

Figure 5.7: Maximum and minimum internal pressure characteristics for the building with only East opening $=0.0051 \mathrm{~m}^{2}\left(7.85 \mathrm{in}^{2}\right)(10 \%)$; a) Case 3A having ceiling, b) Case $3 \mathrm{~A}$ with no ceiling.

Figure 5.6 compares the volume correction effect for a building having $10 \%$ and $22 \%$ porosity. As can be depicted from the figure, the increase in porosity from $10 \%$ to $22 \%$ equally affects both the building with and without volume correction. There was no significant variation between the building with and without volume correction even though the porosity increases by a factor of 2 . Thus, it can be concluded that for onesided and short distance opposite wall opening ventilation studies on residential low-rise buildings the volume correction could be relaxed while it is important to consider volume correction for adjacent side openings.

Figure 5.7 depicts comparison of max and min Cpi for a building "shell" with ceiling (Case 3A) and without ceiling (Case 3B), each with and without volume correction. The effective internal volume to dominant opening area ratio $(\mathrm{V} / \mathrm{a})$ for Case 3A was $5.5 \mathrm{~m}$ when no volume correction was used. For Case $3 \mathrm{~B}$, the $V / a$ ratio was $7.6 \mathrm{~m}$. However, when the internal volume correction was applied, the $V / a$ ratio for Cases $3 \mathrm{~A}$ and $3 \mathrm{~B}$ were $50 \mathrm{~m}$ and $61.4 \mathrm{~m}$, respectively. The volume of the living room for Case $3 \mathrm{~A}$ was smaller than that of Case 3B. The results of the experiment depicted that the max 
and $\min C_{p i}$ values are less variable in case of smaller internal volume (i.e., for Case 3A) as shown in Figure 5.7a. However, as the volume increases, the $C_{p i}$ values without volume correction and with volume correction varies significantly as shown in Figure 5.7b. Thus it can be inferred that when the smaller internal volume of a building either due to smaller overall building dimensions or due to internal partitioning, the volume correction could be relaxed.

\subsubsection{The effects of relative opening size: Dominant openings porosity}

The impact of various porosity sizes of dominant openings on the internal distribution was analyzed using Cases 1 and 2 with and without internal volume correction.

For the adjacent side cross-ventilation, Case 1 a has a porosity of $E=10 \%$ and $\mathrm{S}=6 \%$ while for Case $1 \mathrm{~b}$, the porosity was $\mathrm{E}=22 \%$ and $\mathrm{S}=18 \%$ (Table 2 ). As shown in
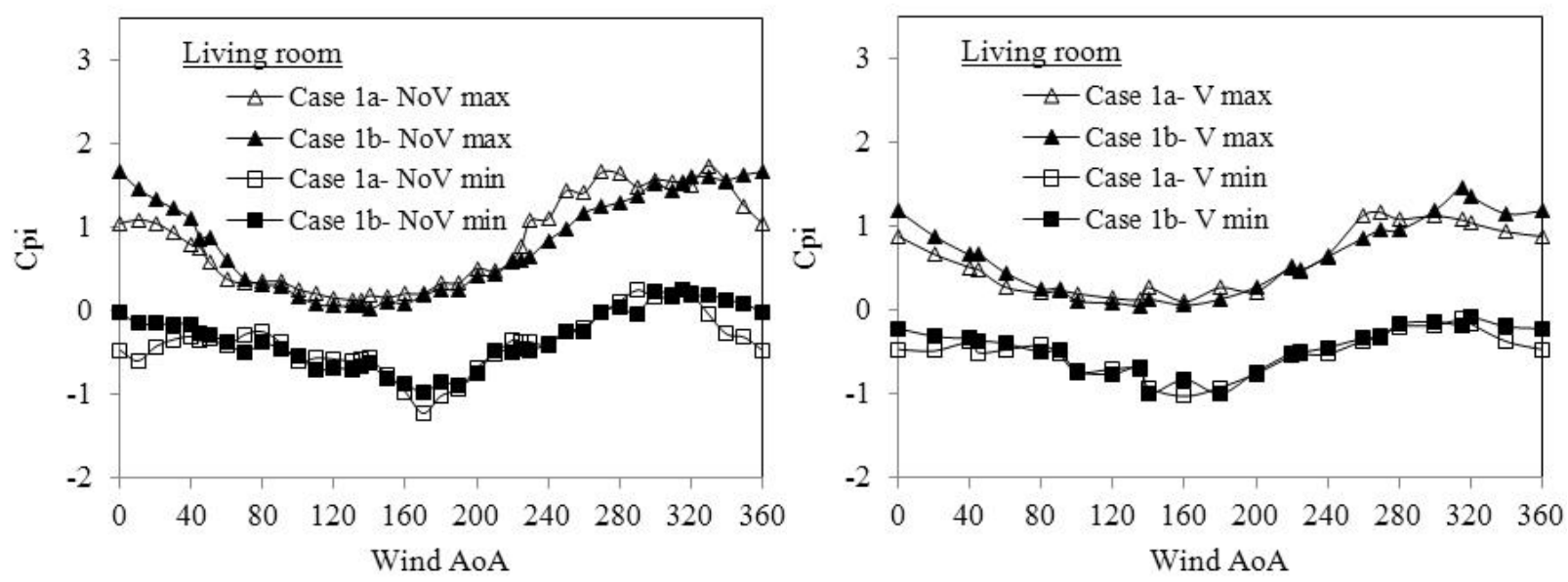

Figure 5.8: Effect of dominant opening porosity on internal pressure. 

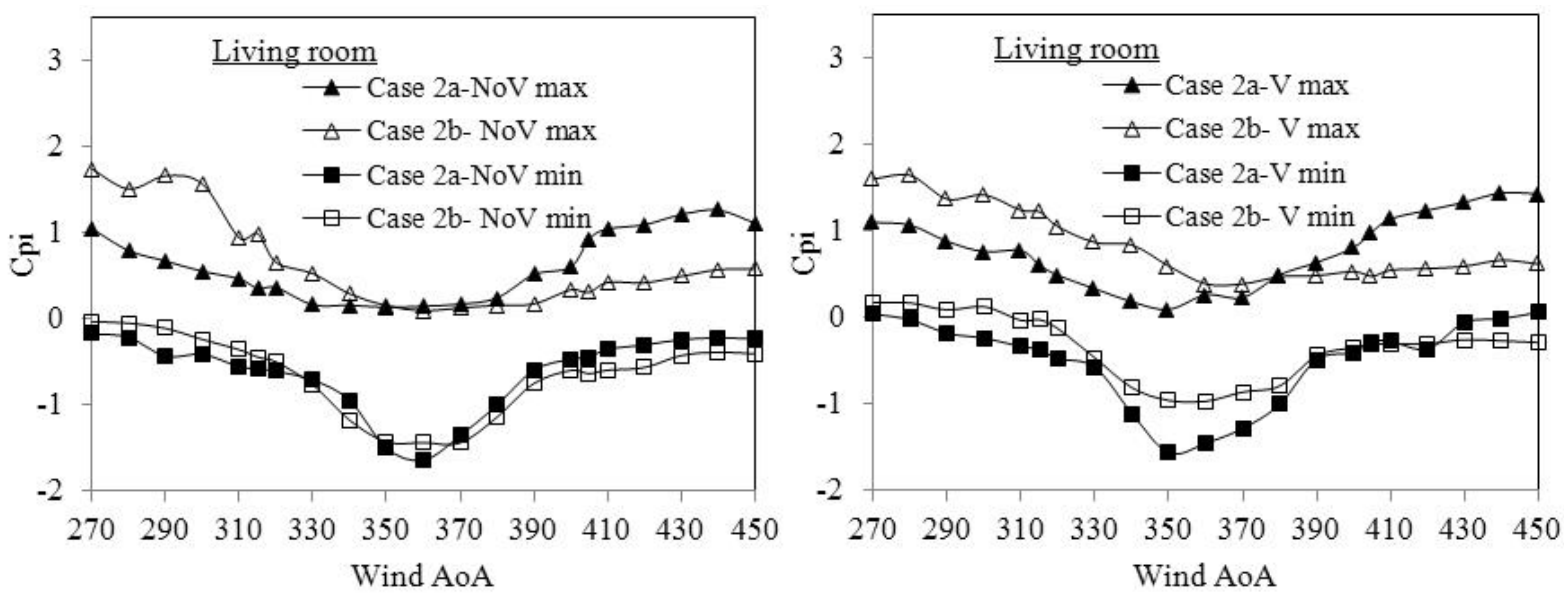

Figure 5.9: Internal pressure due to cross-ventilation for opposite direction dominant openingalong length.

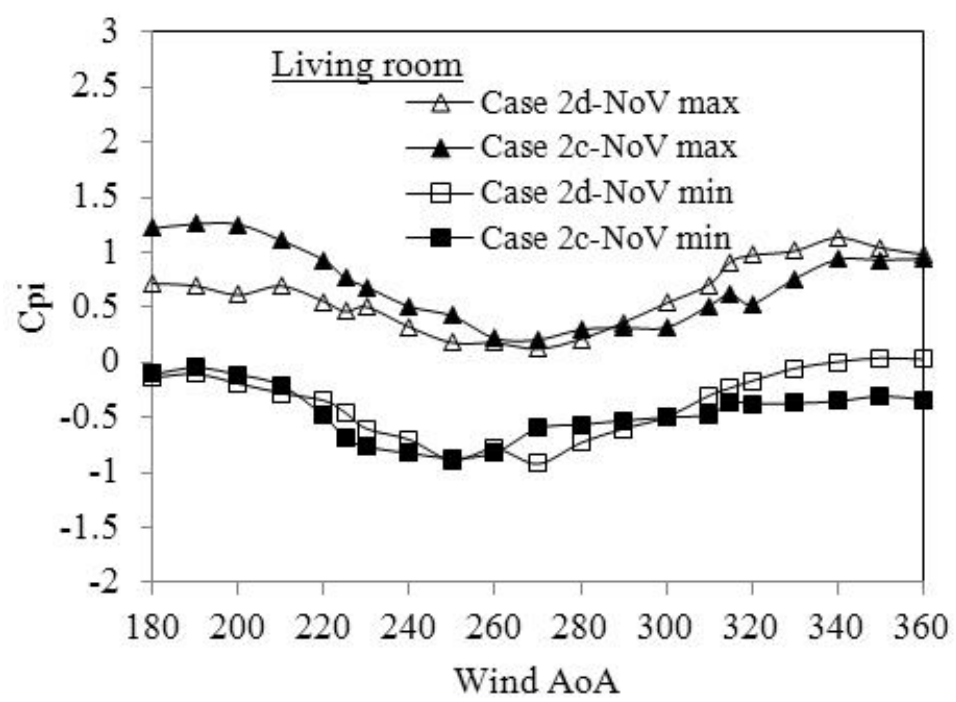

Figure 5.10: Internal pressure due to cross-ventilation for opposite direction dominant openingalong width.

Figure 5.8, there was no significant internal pressure variation between test Cases 1a and $1 \mathrm{~b}$ for most of the wind flow directions examined e.g. $30^{\circ}$ to $320^{\circ}$ wind AoA.

For $360^{\circ}$ wind $A o A$, however, the max and min internal pressure coefficient for Case $1 \mathrm{~b}$ was bigger than that of Case $1 \mathrm{a}$, which could be due to the higher inlet porosity $(18 \%)$ and inlet to outlet openings ratio $\mathrm{S} / \mathrm{E}=1.4$ for Case $1 \mathrm{~b}$ compared to Case 1a (with 
inlet porosity of $6 \%$ and inlet to outlet openings ratio, $\mathrm{S} / \mathrm{E}=1.02$ ). Similar trends were observed for the minimum values of the internal pressure.

For opposite side cross-ventilation, the relative difference in internal pressure between Case $2 \mathrm{a}$ and $2 \mathrm{~b}$ depended on the wind direction $(A o A)$, which were distinctively categorized into two: Region $1\left(270^{\circ}\right.$ to $\left.360^{\circ}\right)$ and Region $2\left(360^{\circ} / 0^{\circ}\right.$ to $\left.90^{\circ}\right)$ (Figure 5.9). As a reference, the wind $A O A$ between $0^{\circ}$ and $90^{\circ}$ was represented as $360^{\circ}$ to $450^{\circ}$ on the figures. In region 1 , the internal pressure for case $2 \mathrm{~b}$ was higher than that of Case $2 \mathrm{a}$. At $270^{\circ}$ wind $A o A$, the ratio of the porosity of the windward opening to the leeward opening was 1.58 and 0.69 for Case $2 \mathrm{~b}$ and Case 2a, respectively. In Region 2, the internal pressure for Case $2 \mathrm{a}$ was higher than that of Case $2 \mathrm{~b}$. In Region 2, the rear windows W acted as windward opening and the ratio of the porosity of the windward opening to the leeward opening (i.e., W/E) became 1.45 and 0.63 for Case $2 \mathrm{a}$ and Case $2 \mathrm{~b}$, respectively. In this region, the internal pressure for Case $2 a$ was higher than that of Case $2 b$, particularly at $90^{\circ} / 450^{\circ}$ wind $A o A$.

Similar differences in the relative values of IP, with respect to the Wind $A o A$ and the ratio of the windward to leeward opening, were also observed for Cases $2 \mathrm{c}$ and $2 \mathrm{~d}$ (Figure 5.10). When the ratio $A_{\text {inlet }} A_{\text {outle }}>1$, the IP due to cross ventilation was found to be 1.5-2.5 times higher than that of $A_{\text {inlet }} / A_{\text {outlet }}<1$. As shown in the Figures 5.9 and 5.10, when cross-ventilation dominant openings were on a side view with respect to the wind $A o A$ (i.e., between $340^{\circ}$ to $390^{\circ}$ for Cases $2 \mathrm{a}$ and $2 \mathrm{~b}$ and between $240^{\circ}$ to $300^{\circ}$ for Cases $2 \mathrm{c}$ and $2 \mathrm{~d}$ ), the value of IP was not affected by the cross ventilation opening size. 


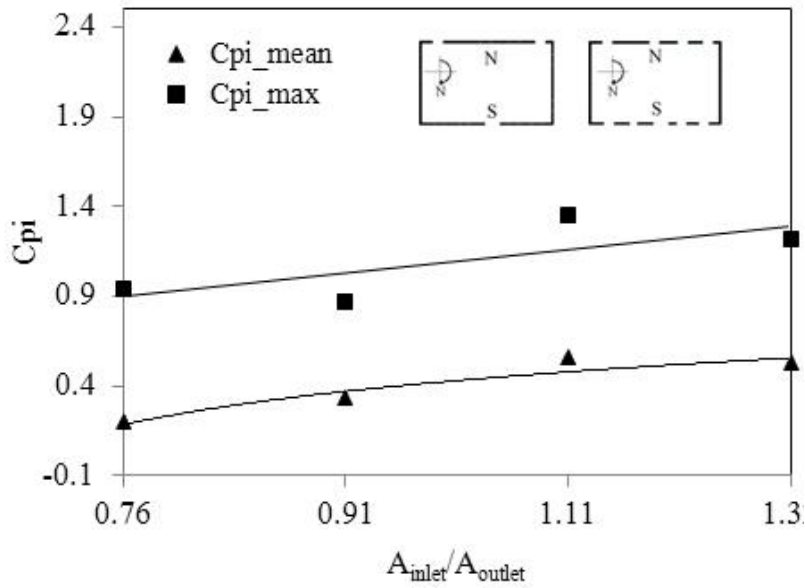

a)

c)

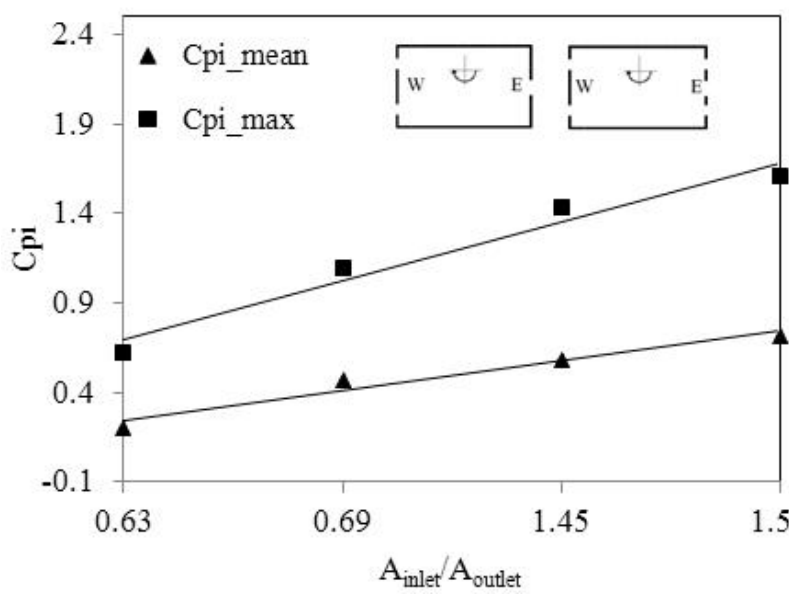

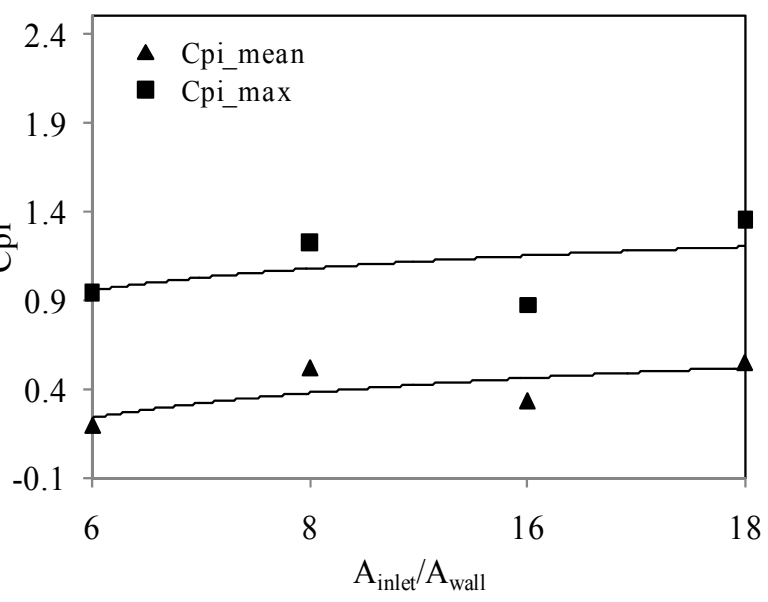

b)

d)

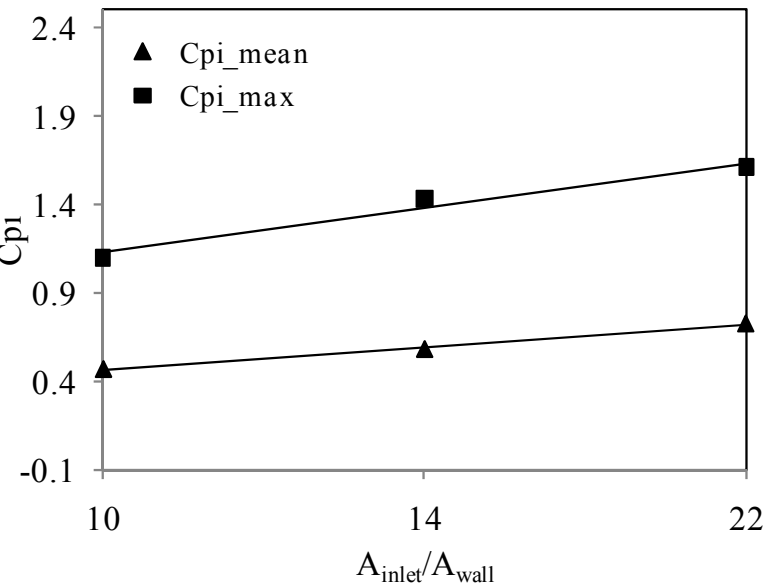

Figure 5.11: Internal pressure due to cross-ventilation in opposite direction vs inlet to outlet ratio and windward porosity: a \& b) along the width of building, c \& d) along the length of building.

\subsubsection{The effects of relative opening size: Inlet-outlet area ratio}

The sensitivity study of wind-driven cross-ventilation to inlet-outlet ratio of the openings was divided into two groups: (i) along the length and width of the building, and (ii) along adjacent side walls. For the building under consideration, the inlet opening was different from the outlet opening (i.e., $A_{\text {inlet }} \neq A_{\text {oulet }}$ ). The building model with volume correction was considered to keep the dynamic similarity of the model with the full scale 
building. The average of 12 pressure taps considered in computing the statistical characteristics of the IP was found to be uniform for the cases under consideration. Figure 5.11 illustrates the internal pressure variation with respect to windward wall porosity and inlet to outlet opening area ratio. As shown in Figure 5.11, both the mean and maximum $C_{p i}$ increase as the inlet to outlet ratio $A_{\text {inlet }} / A_{\text {oulet }}$ and the windward porosity ratio increases.

This relationship was observed for both the cross-ventilation through opposite and adjacent side walls. The max $C_{p i}$ was $120 \%-150 \%$, and $250 \%-310 \%$ higher than the mean for a cross-ventilation through opposite sides and for adjacent sides, respectively. This is mainly due to the lower mean internal pressure that develops in the crossventilation through adjacent sides (Figure 5.12). Additionally, the mean $C_{p i}$ assumed a value of 0.35 , which was half of the $C_{p i}$ for cross-ventilation through opposite sides (Figures 5.11 and 5.12).
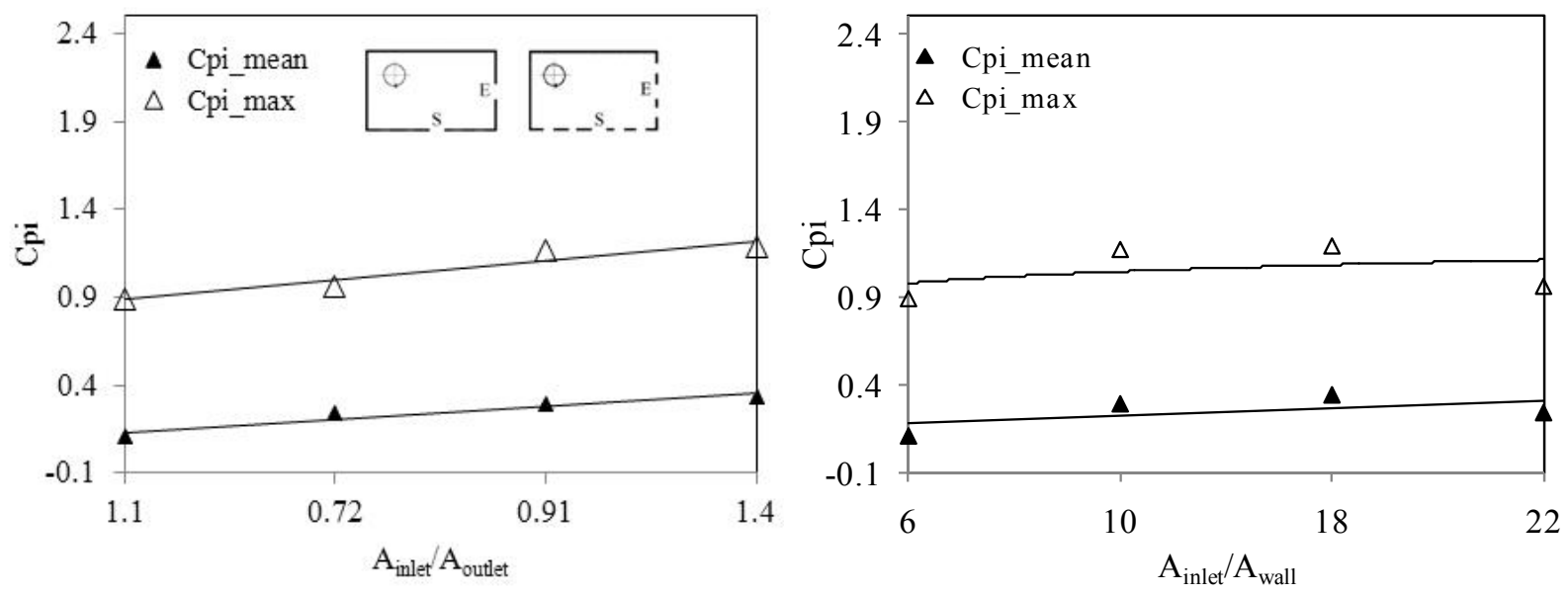

Figure 5.12: Internal pressure due to cross-ventilation in adjacent side vs inlet to outlet ratio and windward porosity. 
Table 5-4: Mean internal and external pressure distribution with respect to wind AoA.

\begin{tabular}{|c|c|c|c|c|c|c|c|}
\hline \multirow{2}{*}{\multicolumn{2}{|c|}{ Description }} & & \multicolumn{2}{|c|}{ Mean Cpe } & \multicolumn{2}{|c|}{ Cpi } & \multirow{2}{*}{ Remark } \\
\hline & & & Windward & Side/Leeward & Mean & Max & \\
\hline \multirow{2}{*}{ Case 1} & 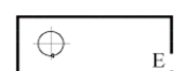 & $270^{\circ}$ & $0.78-0.89$ & $-0.19-(-0.32)$ & 0.29 & 1.17 & \multirow{4}{*}{$\begin{array}{l}\text { Adjacent } \\
\text { side }\end{array}$} \\
\hline & & $0^{\circ}$ & $0.66-0.87$ & $-0.44-(-0.54)$ & 0.11 & 0.89 & \\
\hline \multirow{2}{*}{ Case 2} & 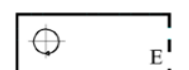 & $270^{\circ}$ & $0.77-0.83$ & $-0.20-(-0.27)$ & 0.24 & 0.96 & \\
\hline & $\mathrm{s}$ & $0^{\circ}$ & $0.71-0.84$ & $-0.30-(-0.45)$ & 0.34 & 1.19 & \\
\hline \multirow{2}{*}{ Case 3} & $\checkmark$ & $270^{\circ}$ & $1.16-1.22$ & $0.02-0.03$ & 0.47 & 1.10 & \multirow{8}{*}{$\begin{array}{l}\text { Opposite } \\
\text { side }\end{array}$} \\
\hline & & $90^{\circ}$ & $1.00-1.08$ & $-0.01-0.04$ & 0.58 & 1.43 & \\
\hline \multirow{2}{*}{ case 4} & \multirow{2}{*}{$\begin{array}{llll}\mathrm{w} & \ddots & \mathrm{E}_{1}^{\prime} \\
\end{array}$} & $270^{\circ}$ & $1.21-1.28$ & $0.00-0.03$ & 0.72 & 1.61 & \\
\hline & & $90^{\circ}$ & $1.02-1.07$ & $0.02-0.03$ & 0.20 & 0.62 & \\
\hline \multirow{2}{*}{ Case 5} & \multirow{2}{*}{ 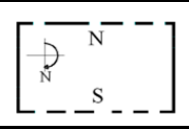 } & $0^{\circ}$ & $1.01-1.19$ & $-0.27-(-0.36)$ & 0.55 & 1.35 & \\
\hline & & $180^{\circ}$ & $0.93-1.10$ & $-0.29-(-0.35)$ & 0.33 & 0.87 & \\
\hline \multirow{2}{*}{ Case 9} & & $0^{\circ}$ & $0.92-1.16$ & $-0.33-(-0.36)$ & 0.19 & 0.94 & \\
\hline & & $180^{\circ}$ & 0.87-1.09 & $-0.26-(-0.30)$ & 0.52 & 1.22 & \\
\hline \multirow{3}{*}{\multicolumn{2}{|c|}{ Sealed building }} & $0^{\circ}$ & $0.94-1.13$ & $-0.20-(-0.32)$ & & & \multirow{3}{*}{$\begin{array}{c}\text { Windward vs } \\
\text { leeward }\end{array}$} \\
\hline & & $90^{\circ}$ & $1.04-1.14$ & $0.02-0.05$ & & & \\
\hline & & $270^{\circ}$ & $1.20-1.27$ & $0.02-0.03$ & & & \\
\hline
\end{tabular}
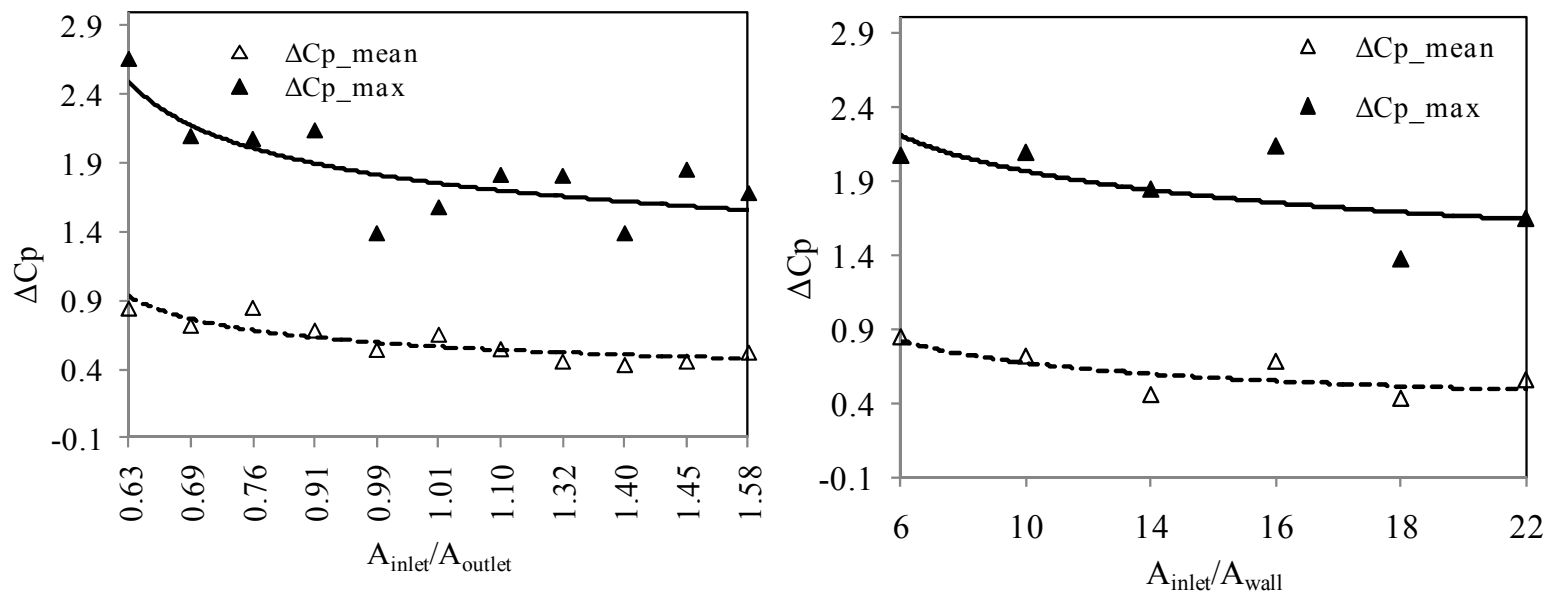

Figure 5.13: Pressure drop inside building as a function of: a) inlet to outlet opening ratio, b) windward wall porosity. 


\subsubsection{Pressure drop $(\triangle C p)$}

In the study of wind driven natural ventilation, pressure drop as a result of windward and leeward pressure on building envelope plays an important role in the effectiveness of natural ventilation. To this end, the windward $\left(C_{p e w}\right)$ and leeward external pressure $\left(C_{p e l}\right)$, which develops on the building envelope when it is sealed as well as in the presence of dominant openings, and the characteristics of the windward and leeward pressure drop i.e., $\Delta C_{p_{-} w w}$ and $\Delta C_{p_{-} l w}$, respectively were examined. Where $\Delta \mathrm{Cp}_{\mathrm{ww}}=\mathrm{Cp}_{\mathrm{ew}}-\mathrm{Cp}_{\mathrm{i}}$ and $\Delta \mathrm{Cp}_{\mathrm{lw}}=\mathrm{Cp}_{\mathrm{i}}-\mathrm{CP}_{\mathrm{el}}$.

In the present study, all the external pressure coefficients were obtained from area average computation at the periphery of each dominant opening. As shown in the Table 5.4, the windward $C_{p e}$ for cross-ventilation through adjacent side openings was significantly lower than that of the sealed building and the opposite sides openings. The mean and max internal pressure coefficient of the building with adjacent sides opening were $50-75 \%$ lower than that with opposite side opening (Figure 5.13). This could be attributed to the short air flow path developed in the presence of openings on the adjacent side walls.

All analyzed cases were for dominant openings at normal wind $A o A$ as given in Table 5.3. As illustrated in Figure 5.13, the lower the porosity (or inlet to outlet ratio), the higher would be the pressure drop inside the building. Observing the trend of pressure drop in Figure 5.13, the cross-ventilation with opposite side openings generate higher pressure drop compared to that of adjacent side opening of equivalent porosity ratio. This phenomenon increases the mixing of air inside the building and hence the ventilation 
effectiveness for the cross-ventilation with opposite side openings. The difference between the mean and peak pressure drop i.e., $\Delta C_{p_{-} g r a d}=\Delta C_{p_{-} \max }-\Delta C_{p_{-} \text {mean }}$ affects the comfort level due to cross-ventilation. Observing the mean and peak pressure drops, for porosities used in this study, the building with adjacent side openings experienced an average $\Delta C_{p_{-} \text {grad }}=0.95$, which is equivalent to a $47 \mathrm{~Pa}$ pressure variation and the building with opposite side openings experienced an average $\Delta C_{p \text { grad }}=1.37$, equivalent to a pressure of $67 \mathrm{~Pa}$. Additionally, the higher the porosity ratio $\left(A_{\text {inlet }} / A_{\text {wall }}\right)$, the lower was the difference between max and mean pressure coefficient. For $A_{\text {inlet }} / A_{\text {wall }}<16 \%$, average $\Delta C_{p_{-g r a d}}=1.36(67 \mathrm{~Pa})$ and for $A_{\text {inlet }} / A_{\text {wall }}>16 \%$, average $\Delta C_{p_{- \text {grad }}}=1.02(50 \mathrm{~Pa})$. This illustrates that buildings with adjacent side openings and/or buildings with higher porosity ratio experience small differences between the peak and mean pressure. The values of the windward $C_{p e w}$ and leeward $C_{p e l}$ external pressures, and internal pressure coefficients $C_{p \mathrm{i}}$ obtained for the cross-ventilation cases reflect the presence of pressure variation inside the building.

For instance, considering Case 1 which was a cross-ventilation through adjacent openings with $10 \%$ and $6 \%$ porosity, it was obtained that the $C_{p e w}=0.78, C_{p e l}=-0.29$ and $C_{p i}=0.29$ at $270^{\circ}$ wind $A o A$. Similarly for Case 3 at $270^{\circ}$ wind $A o A$, the corresponding values obtained were $C_{p e w}=1.16, C_{p e l}=0.025$ and $C_{p i}=0.47$. This showed that there was pressure driven flow wherein which air enters through the windward dominant opening and discharges through either the side or the leeward openings. This wind-induced ventilation generates variable intensity of volumetric flow rate to cause the development of passive ventilation. 


\subsubsection{Effect of room partitioning on cross-ventilation}

Three additional cases, involving multi-room partitioning and cross-ventilation through opposite side openings, were investigated to demonstrate the overall characteristics of flow dynamics inside each room in a building during cross-ventilation. Figure 5.14 describes the internal pressure distribution for a building with $10 \%$ single dominant opening without room partitioning (i.e., Case 3) compared to a building with similar setup but having multi-room partitioning (i.e., Case 3 with partitioning). As can be observed, the distribution of the internal pressure was uniform in both cases.

Figures $5.15 \mathrm{a} \& 5.15 \mathrm{~b}$ show the comparison of pressure distribution for crossventilation through opposite side openings (10\% porosity) with and without multi-room partitioning. From Figures 5.14 and 5.15, it can be observed that for a building with cross-ventilation openings, the presence of room partitioning has a significant effect on the distribution of internal pressure and hence the pressure drop.
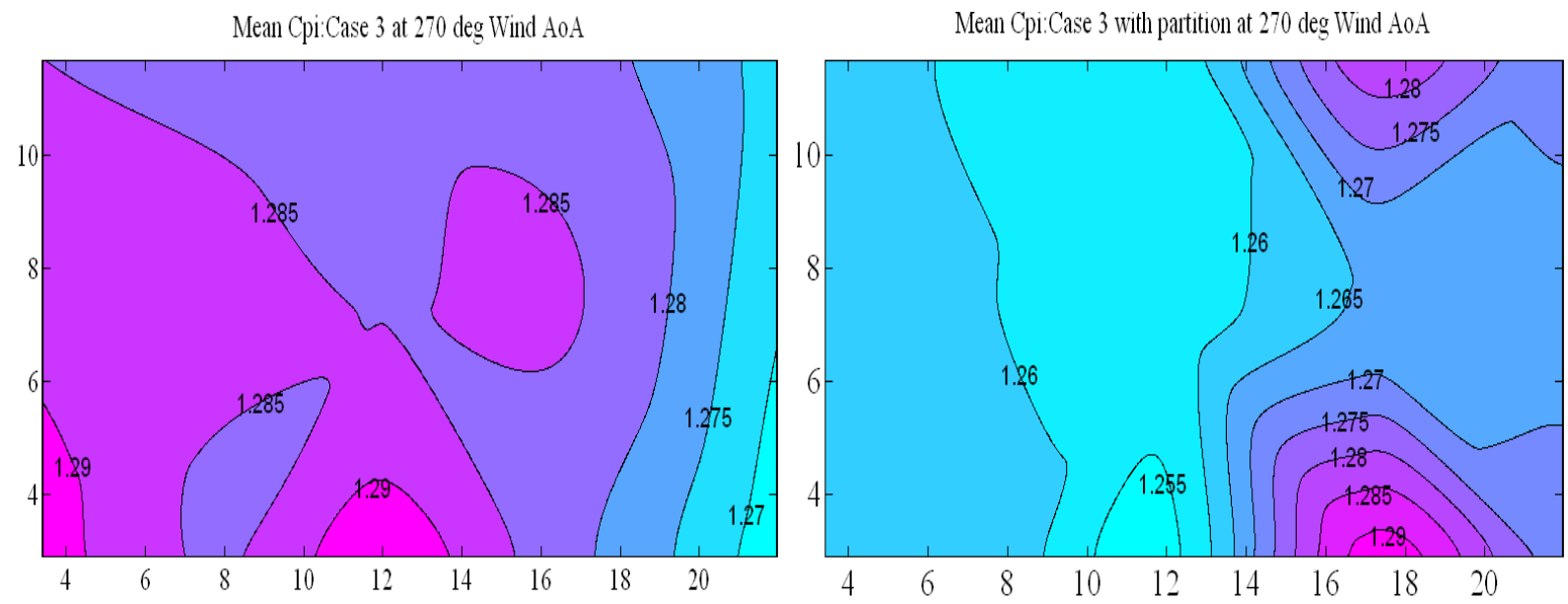

Figure 5.14: Internal pressure distribution comparison: a) single dominant opening (10\%), b) cross-ventilation with multi-room partitioning. 


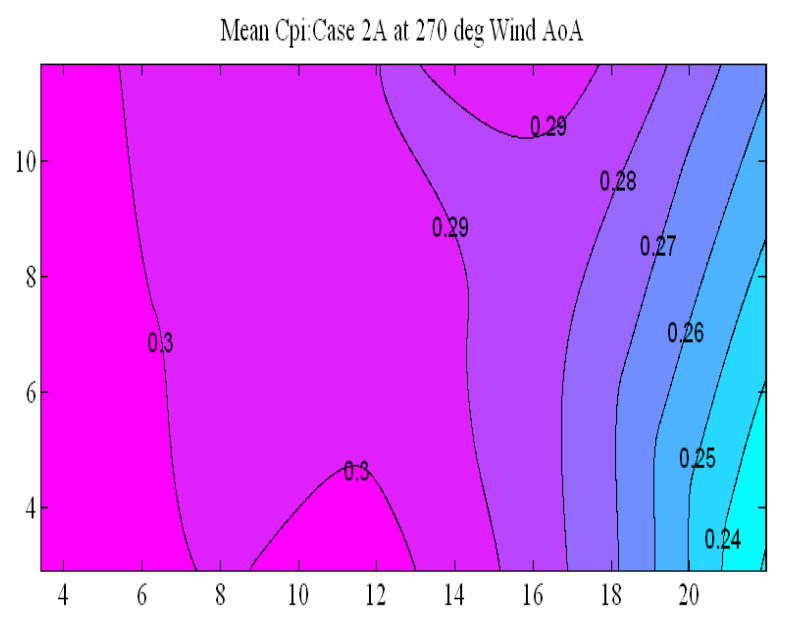

a)

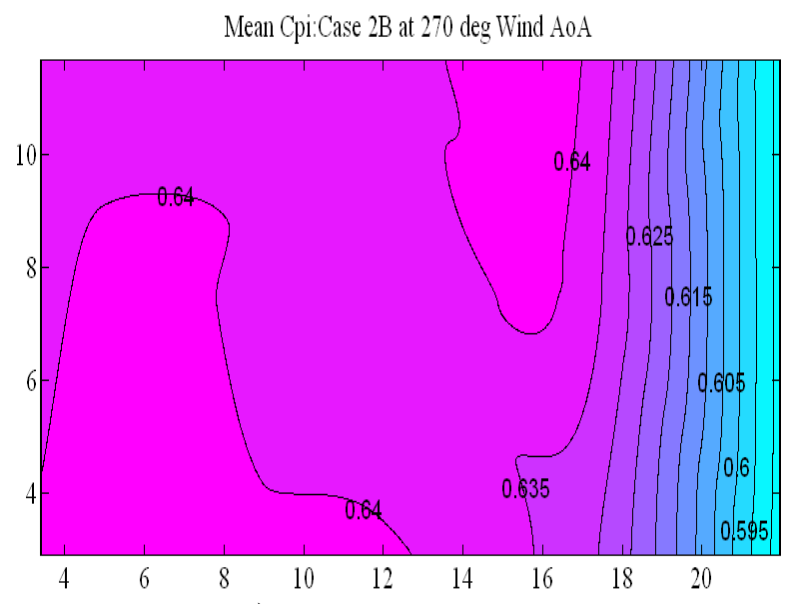

c)

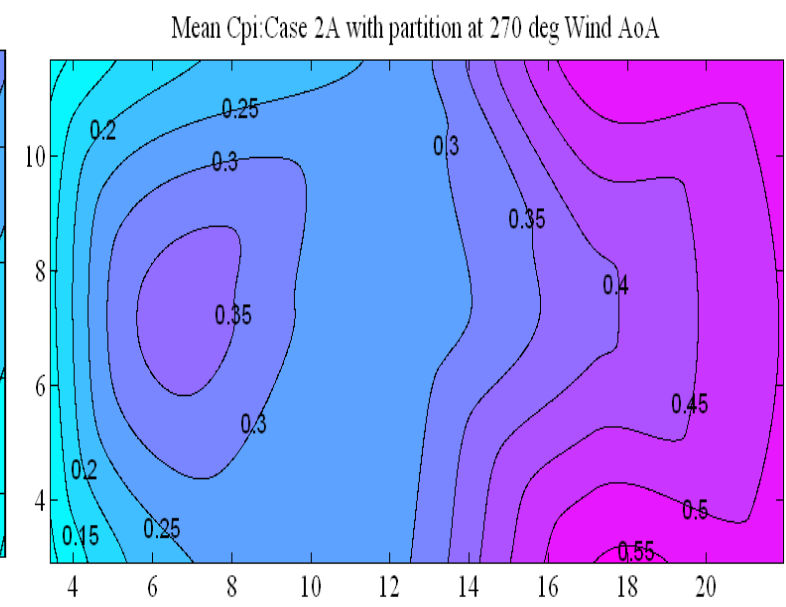

b)

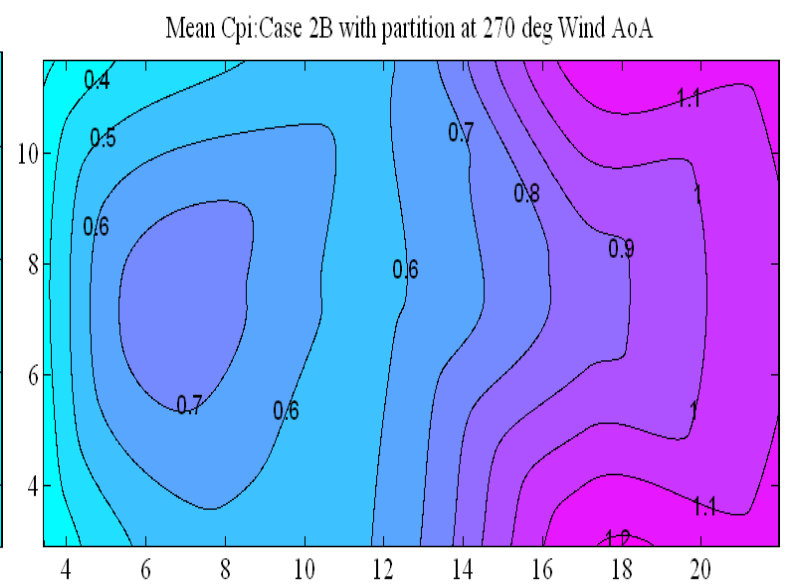

d)

Figure 5.15: Internal pressure distribution comparison: a \& b) cross-ventilation for $10 \%$ porosity without (Case 2A) and with room partitioning, respectively; c \& d) cross-ventilation for $22 \%$ porosity without (Case $2 \mathrm{~B}$ ) and with room partitioning, respectively.

For Case 2a, where there is no room partitioning, the internal pressure showed minor change from a $C_{p i}=0.24$ at the inlet to a $C_{p i}=0.3$ towards the rear side. For the building with room-partitioning (i.e., Case $2 \mathrm{a}$ with partitioning), however, the internal pressure at the inlet was 2-3 times higher than that at outlet side. 
The inlet pressure coefficient for case with partitioning was almost twice that of case without partitioning. This was mainly due to the reduction of internal volume $V o$ because of the partition rooms.

Although all the rooms were left open, there was a considerable variation in internal pressure around the rear side of the building (where the bed rooms are located) compared to that without partitioning at the same location.

Similar results were obtained for cross-ventilation with $22 \%$ porosity, as shown in Figures $5.15 \mathrm{c}$ and $5.15 \mathrm{~d}$. In this case, because of the increase in porosity size, the mean internal pressures doubled for both buildings with and without multi-room partitioning (compare Figures 5.15a \& 5.15b versus Figures 5.15c and 5.15d). In test Case 2b with

partitioning, the reduction in internal volume due to room partitioning resulted in a gradual reduction in the internal pressure from a high value around the inlet to a low value around the outlet. In test Case $2 \mathrm{~b}$ without partitioning, however, the internal pressure increased steadily showing only a $7 \%$ change between the inlet and the outlet region. This clearly shows that the high gradient (pressure drop) and hence the cross ventilation inside the building, which was considerably influenced by the multi-room partitioning eventually played a role in increasing the flow rate and air exchange inside the building.

\subsubsection{Inlet and total discharge coefficient}

The pressure drop between the inside and outside of the building envelope is the driving force for the volumetric airflow rate $(Q)$ and effective ventilation between the inlet and outlet openings during wind-induced natural ventilation of a building. Thus, the 
characteristic of the pressure drop determines the potential of the natural ventilation to provide comfort as well as indoor air quality. As stated earlier, the theoretical volumetric flow rate was computed from mass and momentum conservation principles (Eqns. 3 - 5). The discharge coefficient $C_{d}$ accounts for the frictional, turbulence and viscous related losses and it depends on the geometry of the building, shape and geometry of the opening, wind $A o A$, porosity ratio of the inlet $A_{\text {inlet }} / A_{\text {wall }}$ as well as the ratio of inlet to outlet opening $A_{\text {inlet }} / A_{\text {oulet }}$.

In the present study, a building with various ranges of porosity and local to midheight roof reference velocity $u / V_{r}$ was employed to examine the characteristics of discharge coefficient and its effect on the volumetric flow rate during cross ventilation. The local velocity at the center of each dominant opening was obtained using a cobra-eye tube. The ratio $u / V_{r}$ obtained in this experiment and from previous research works are provided in Table 5.5.

Table 5-5: velocity ratio $\left(\mathrm{u} / \mathrm{V}_{\mathrm{r}}\right)$ for present and previous studies.

\begin{tabular}{lll}
\hline \multicolumn{1}{c}{ Study } & $\mathbf{u} / \mathbf{V}_{\mathbf{r}}$ & $\mathbf{V}_{\mathbf{r}}(\mathbf{m} / \mathbf{s})$ \\
\hline & $0.55-$ & \\
Present study & 0.78 & 8.954 \\
Karava et al. (2007) & $0.5-0.63$ & 7.2 \\
Hu et al. (2005) & 0.45 & 7.0 \\
Etheridge (2004) & 0.6 & 4.0 \\
Sawachi et al. (2004) & 0.5 & 3.0 \\
Murakami et al. (1991) & $0.64-1.0$ & Not available \\
\hline
\end{tabular}

The range of values of local to mid-height roof velocity obtained in this experiment falls into the range of data obtained in literature (Murakami et al. 1991; Etheridge 2004; Sawachi et al. 2004; Hu et al. 2005; Karava et al. 2007). 
In this experiment, the opening configurations that affect the local velocity and discharge coefficients are prepared in such a way that the openings represent the full scale building openings characteristics such as rectangular doors and windows with their respective practical jamb thickness. The wider spectrum of the ratio observed gives an idea on how it can influence the variation of discharge coefficient.

For different $u / V_{r}$ ratio tested, both the inlet, outlet and total discharge coefficients and the ventilation rate $Q /\left(V_{r} A\right)$ were computed by utilizing all the external and internal pressures at the respective wind $A o A$. Equations 14-18 were implemented to compute the variable discharge coefficients and ventilation rate as given in Table 5.6. All the data given are for the building with internal volume distortion. As shown in the table, the total discharge coefficient $C_{d_{-} \text {total }}$ and the ventilation rate $Q /\left(V_{r} A\right)$ were highly dependent on the porosity ratio. The higher the porosity ratio, the higher was the $C_{d_{-} \text {total }}$ and $Q /\left(V_{r} A\right)$.

Table 5-6: Porosity ratio, discharge coefficients and ventilation rate.

\begin{tabular}{ccccccc}
\hline Test case & AoA & $\mathrm{A}_{\text {inlet }} / A_{\text {wall }}$ & Cd_in & Cd_out & Cd_total & Q/VrA \\
\hline Case 1(V) & $270^{\circ}$ & 10 & 1.08 & 0.99 & 0.73 & 0.76 \\
& $0^{\circ}$ & 6 & 0.74 & 0.70 & 0.51 & 0.55 \\
Case 2(V) & $270^{\circ}$ & 22 & 1.03 & 1.08 & 0.74 & 0.75 \\
& $0^{\circ}$ & 18 & 1.25 & 0.93 & 0.74 & 0.78 \\
Case3(V) & $270^{\circ}$ & 10 & 0.65 & 0.80 & 0.50 & 0.54 \\
Case4(V) & $270^{\circ}$ & 22 & 1.07 & 0.93 & 0.70 & 0.78 \\
Case9(V) & $0^{\circ}$ & 6 & 0.80 & 0.93 & 0.61 & 0.69 \\
Case5(V) & $0^{\circ}$ & 18 & 0.99 & 0.73 & 0.59 & 0.69 \\
\hline
\end{tabular}



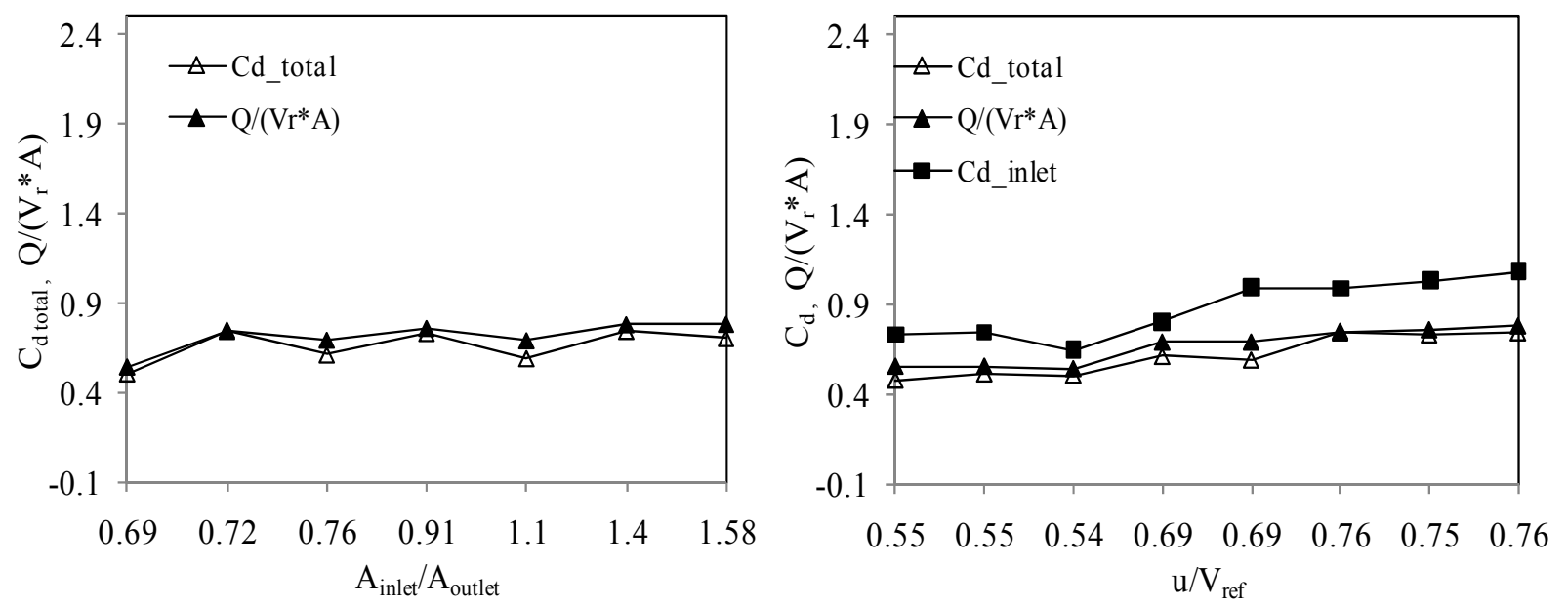

Figure 5.16: Inlet, total discharge coefficient and ventilation rate with respect to: a) inlet to out let ratio, b) velocity ratio.

The inlet to outlet discharge coefficient obtained range between 0.6-1.08. The building with the bigger windward opening porosity experienced largest inlet and outlet discharge coefficient. For instance, in test case 1 , the ratio of $A_{\text {inlet }} / A_{\text {outlet }}$ was close to 1 but the porosity size is $10 \%$ and $6 \%$. The discharge coefficient obtained for the $10 \%$ porosity ratio was $40-45 \%$ higher than that of the $6 \%$. Similar observation was observed for the other porosity ratios as well. As shown in Figure 5.16, the total discharge coefficient obtained ranged between $0.5-0.74$ which falls into the range of values observed in other related research works (Murakami et al. 1991; Karava et al. 2007). The discharge coefficients obtained in this experiment discloses the coefficient's sensitivity to dominant opening porosity, inlet outlet ratio, wind $A o A$, internal volume correction for $B L W T$ test, the cross ventilation's dominant opening location (opposite side vs adjacent side), the local to mid-height reference velocity and geometry of the opening. This reveals that the discharge coefficient, a factor that plays a significant role in determining the airflow rate, cannot be generalized by a single constant value for every type of buildings. 

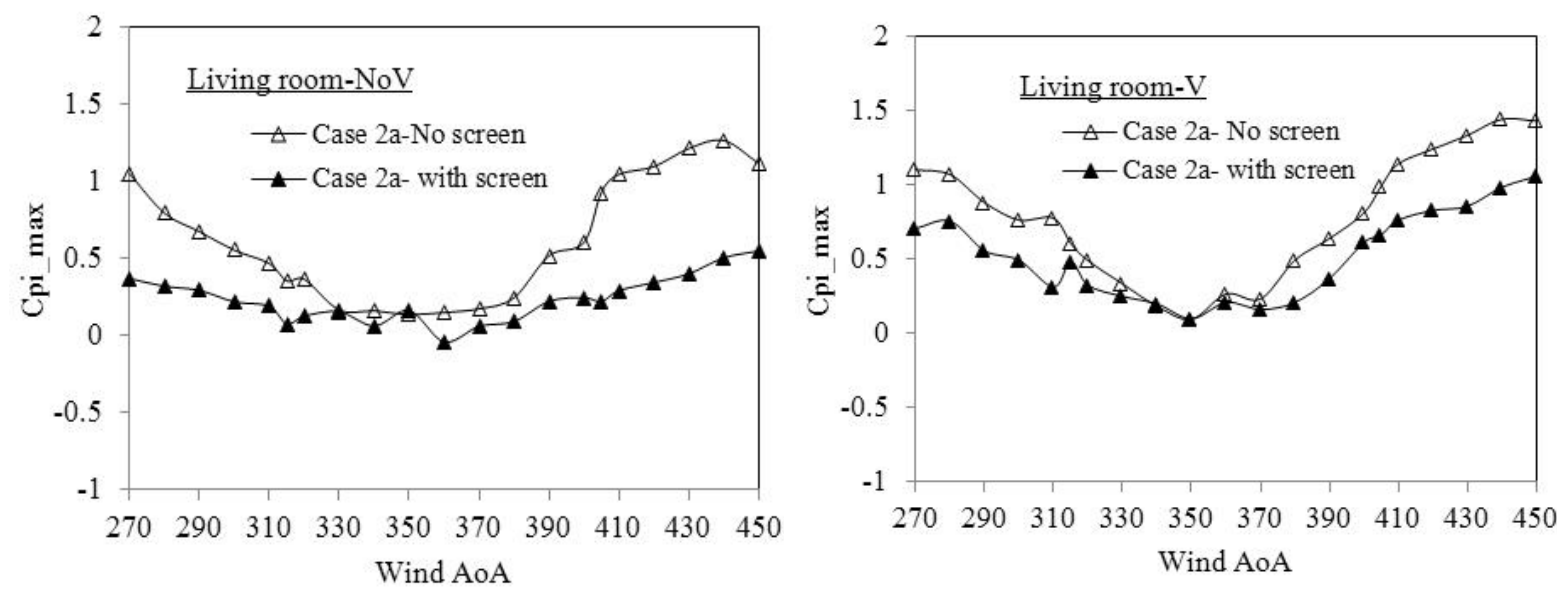

Figure 5.17: Internal pressure variation with and without screen on dominant openings.

As shown in this study, the $C_{d}$ values vary considerably for different size of openings, their location with respect to upstream wind direction and the level of $u / V_{r}$. This, in return, illustrates the airflow rate miscalculations that can arise by considering $C_{d}$ as a constant value. The selection of discharge coefficient, thus, needs to be specific to the particular building under consideration by incorporating most of the above mentioned influencing factors as illustrated in this study.

\subsubsection{The effect of screen on cross ventilation}

Wind driven cross ventilation as a favorable method of cooling and human thermal comfort has a side effect which is the side effect is the intrusion of insects and birds through the opening. One method that deters the intrusion without affecting the natural ventilation is the application of insect screens. In order to distract the entrance of insects and bugs wire mesh screens are often used on the openings.

This study has examined the effect of mesh screens on the internal pressure due to cross-ventilation. As shown in Figure 5.17, the effect of the screen was significant when 
the wind flow was in the windward direction for both the $N o V$ as well as $V$ condition experimented. There was no any considerable difference in internal pressure when the wind direction was on the side to the dominant openings.

Comparing the significance of the screens on the windward direction, the mean internal pressure coefficient for no screen case was 5-8 times higher than that of the case with screen for the case of no internal volume correction (Figure 5.17a) and 2-4 times higher for the case with internal volume correction (Figure 5.17b). This depicts that the wire mesh screens cause a loss of wind speed at the openings but still provide a desirable room cooling environment through natural ventilation by distracting insects, bugs and birds.

\subsection{Conclusion}

The paper presents evaluations of wind driven natural ventilation in a low-rise building having variable configuration of dominant openings, background leakage and room compartmentalization using a standard boundary layer wind tunnel. The present study dealt with the inherent volume scaling issue related to the internal volume distortion as well as background leakage as applied to cross-ventilation studies. The characteristics of internal and external pressures were computed for different wind AoA to analyze the crucial factors that play significant role in the prediction of airflow rate of purely wind driven cross-ventilation such as discharge coefficient and volumetric flow rate.

The following conclusions are drawn from the investigation carried out: 
- For one-sided and short distance opposite wall opening ventilation studies on residential low-rise buildings the volume correction could be relaxed while it is important to consider volume correction for adjacent side openings.

- With regard to effects of porosity on cross-ventilation and it was obtained that the higher the ratio of the inlet to outlet opening or windward porosity ratio, the higher would be the internal pressure. It was also obtained that the internal pressure due to cross ventilation was 1.5-2.5 times higher when the ratio $A_{\text {inlet }} / A_{\text {outlet }}>1$.

- With regard to the pressure drop that drives the wind induced cross-ventilation, it was shown that the lower the porosity ratio or inlet to outlet ratio, the higher would be the pressure drop inside the building. Moreover, the cross-ventilation with opposite side openings generate higher pressure drop as compared to that of adjacent side opening of equivalent porosity ratio.

- The study also examined the characteristics of discharge coefficient with respect to porosity ratio and adjacent vs opposite side openings. It was shown that the total discharge coefficient $C_{d_{-} \text {total }}$ and the ventilation rate $Q /\left(V_{r} A\right)$ are highly dependent on the porosity ratio. The higher the porosity ratio, the higher is the $C_{d_{-} \text {total }}$ and $Q /\left(V_{r} A\right)$. For the same inlet to outlet opening ratio, the discharge coefficient obtained for the building with $10 \%$ porosity ratio was $40-45 \%$ higher than that of the building with $6 \%$ porosity. The total discharge coefficient obtained varied between 0.5-0.74 while the inlet/outlet discharge coefficients range between 0.65-1.08. 
- The use of mesh screens on dominant openings has considerable effect on crossventilation particularly when wind flow is in the windward direction. The mean internal pressure coefficient for no screen case is $2-4$ times higher.

- For building with single dominant openings, the internal pressure was observed to be uniform and equal for both buildings with and without multi-room partitioning. However, in the presence of cross-ventilation openings, it was shown that the presence of room partitioning has a significant effect on the distribution of internal pressure and hence the pressure drop. The internal pressure distribution ceases its uniformity and depends on each room's location with respect to the inlet opening and wind AoA.

\subsection{References}

Ayad, S.S. (1999). "Computational study of natural ventilation." Journal of Wind Engineering and Industrial Aerodynamics 82: 49-68.

Bloxham, C. and Vickery, B.J. (1989). "An experimental investigation of internal pressure dynamics with a dominant front wall opening." University of Western Ontario, Faculty of Engineering and Science. Report No. BLWTL-SS46-1989.

Ernest, D.R., Bauman, F.S. and Arens, E.A. (1992). "The effects of external wind pressure distributions on wind induced air motion inside buildings." Journal of Wind Engineering and Industrial Aerodynamics 41-44: 2539-2550.

Etheridge, D.W. (2004). "Natural ventilation through large openings-measurments at model scale and envelope theory." International Journal of Ventilation 2(4): 325-342.

Ginger, J.D., Holmes, J.D. and Kopp, G.A. (2008). "Effect of building volume and opening size on fluctuating internal pressures." Wind and Structures 11(5): 361-376.

Ginger, J.D., Mehta, K.C. and Yeatts, B.B. (1997). "Internal pressures in a low-rise fullscale building." Journal of Wind Engineering and Industrial Aerodynamics 72: 163-174.

Heiselberg, P., Bjorn, E. and Nielsen, P.V. (2002). "Impact of Open Windows on Room Air Flow and Thermal Comfort." International Journal of Ventilation 1(2): 91-100. 
Heiselberg, P., Svidt, K. and Nielsen, P.V. (2001). "Characteristics of airflow from open windows." Building and Environment 36: 859-869.

Holmes, J.D. (1979). "Mean and fluctuating internal pressures induced by wind." Proc. 5th Int. Conf. on wind engineering, Colorado, USA.

Holmes, J.D. (2009). "Discussion of: Net pressures on the roof of a low-rise building with wall openings by R.N.Sharma and P.J.Richards,[J.WindEng.\&Ind.Aerodyn. Vol. 93,pp.267-291,2005]." Journal of Wind Engineering and Industrial Aerodynamics 97: 320-321.

Hu, H.C., Kurabuchi, T. and Ohba, M. (2005). "Numerical Study of wind induced ventilation with the local dynamic similarity model." Proceedings of the 4th European \& African Wind Engineering Conference (EACWE4), Prague.

Karava, P. and Stathopoulos, T. (2009). "Wind-induced internal pressures in buildings with large facade openings." 11th Americas Conference on Wind Engineering, San Juan, Puerto Rico.

Karava, P., Stathopoulos, T. and Athienitis, A.K. (2007). "Wind-driven natural ventilation analysis." International Journal of the Solar Energy Society 81: 21-30.

Kopp, G.A., Oh, J.H. and R.Inculet, D. (2008). "Wind-induced Internal Pressures in Houses." Journal of Structural Engineering 134(7): 1129-1138.

Liu, H. (1990). Wind Engineering: A Handbook for Structural Engineers, Prentice Hall, USA.

Liu, H. and Saathoff, P.J. (1981). "Internal pressure and building safety." Proceedings, J.Struct. Div., ASCE, 108.

Liu, H. and Saathoff, P.J. (1983). "Internal pressure of multi-room buildings." J. Engineering Mechanics Division 109(EM3): 908-919.

Mochida, A., Yoshimo, H., Takeda, T., kakegawa, T. and Miyauchi, S. (2005). "Methods for controlling airflow inand around a building undercross-ventilation to improve indoor thermal comfort." Journal of Wind Engineering and Industrial Aerodynamics 93: 437449.

Murakami, S., kato, S., Akabash, I.S., Mizutani, K. and Kim, Y.D. (1991). "Wind tunnel test on velocity-pressure field of cross-ventilation with open windows." ASHRAE Trans. 97(1): 525-538. 
Oh, J.H., Kopp, G.A. and Inculet, D.R. (2007). "The UWO contribution to the NIST aerodynamic database for wind loads on low buildings. 3: Internal pressures." J. Wind Eng. Ind. Aerodyn. 95(8): 755-779.

Papadakis, G., Mermier, M., Meneses, J. and Boulard, T. (1996). "Measurement and analysis of air exchange rates in a greenhouse with continuous roof and side openings." Journal of Agricultural Engineering and Resources 63: 219-228.

Sawachi, T., Narita, K., Kiyota, N., Seto, H., Nishizawa, S. and Ishikawa, Y. (2004). "Wind pressure and airflow in a full-scale building model under cross ventilation." international Journal of Ventilation 2(4): 343-357.

Sharma, R.N. (2007). "Internal and net envelope pressures in a building having quasistatic flexibility and a dominant opening." Journal of Wind Engineering and Industrial Aerodynamics 91: 807-828.

Sharma, R.N., Mason, S. and Driver, P. (2010). "Scaling methods for wind tunnel modelling of building internal pressures induced through openings." Wind and Structures 13(4): 363-374.

Sharma, R.N. and Richards, P.J. (2005). "Net pressure on the roof of a low-rise building with wall openings." Journal of Wind Engineering and Industrial Aerodynamics 93: 267291.

Snykers, W.A.(1970)."Wind tunnel studies of the flow through rectangular openings with application to natural ventilation of buildings", MSc thesis, University of Pretoria, South Africa.

Stathopoulos , T., Surry, D. and Davenport, A.G. (1979). "Internal pressure characteristics of low-rise buildings due to wind action." In: Proc. 5th Int. Conf. on Wind Engineering, Fort Collins, Colorado, Pergamon Press, New York.

Vickery, B.J. (1986). "Gust factors for internal pressures in a low rise buildings." Journal of Wind Engineering and Industrial Aerodynamics 23: 259-271.

Vickery, B.J. and Karakatsanis, C. (1987). "External wind pressure distributions and induced internal ventilation flow in low-rise industrial and domestic structures." ASHRAE Trans. 93(2): 2198-2213.

Wong, N.H. and Loke, A. (2001). "A study of natural ventilation of piblic housing in Singapore using computational fluid Dynamics (CFD) simulation." International Journal on Architectural Science 2: 35-45. 


\title{
6. RIDGE AND FIELD TILE AERODYNAMICS FOR A LOW-RISE \\ BUILDING: A FULL-SCALE STUDY
}

\author{
Amanuel Tecle, ${ }^{1}$ Girma T. Bitsuamlak ${ }^{2}$, Nakin Suskawang ${ }^{3}$, Arindam Gan Chowdury ${ }^{4}$, \\ Serge Fuez ${ }^{5}$ \\ Submitted to Wind \& Structures journal
}

\begin{abstract}
:
Recent major post-hurricane damage assessments in the United States have reported that the most common damages result from the loss of building roof coverings and subsequent wind driven rain intrusion. In an effort to look further into this problem, this paper presents a full-scale (Wall of Wind --WoW--) investigation of external and underneath wind pressures on roof tiles installed on a low-rise building model with various gable roofs. The optimal dimensions for the low-rise building that was tested with the $W_{o} W$ are $2.74 \mathrm{~m}(9 \mathrm{ft})$ long, $2.13 \mathrm{~m}(7 \mathrm{ft})$ wide, and $2.13 \mathrm{~m}(7 \mathrm{ft})$ high. The building was tested with interchangeable gable roofs at three different slopes $(2: 12 ; 5: 12$ and 7:12). The field tiles of these gable roofs were considered with three different tile profiles namely high $(H P)$, medium $(M P)$, and low profiles $(L P)$ in accordance with Florida practice. For the ridge, two different types namely rounded and three-sided tiles were considered. The effect of weather block on the "underneath" pressure that develops between the tiles and the roof deck was also examined. These tests revealed the following: high pressure coefficients for the ridge tile compared to the field tiles, including those located at the corners; considerably higher pressure on the gable end ridge tiles compared to ridge tiles at the middle of the ridge line; and marginally higher pressure on barrel type tiles compared to the three-sided ridge tiles. The weather blocking
\end{abstract}


of clay tiles, while useful in preventing water intrusion, it doesn't have significant effect on the wind loads of the field tiles. The case with weather blocking produces positive mean underneath pressure on the field tiles on the windward side thus reducing the net pressures. On the leeward side, reductions in net pressure to a non-significant level were observed due to the opposite direction of the internal and external pressures. The effect of the weather blocking on the external pressure on the ridge tile was negligible.

Keywords: Full-scale, ridge tiles, field tiles, tile profile, wind pressure, turbulence, mitigation, low-rise building, underneath pressure.

\subsection{Introduction}

Hurricanes have often caused extensive economic losses and human fatalities in communities along its path (Hooke 2007). On the other hand, over the last 50 years America's coastal regions have experienced significant growth in population and infrastructure development, making these areas more vulnerable to hurricane. The losses have increased from $\$ 1.3 \mathrm{~B} / \mathrm{yr}$ pre-1990 to $\$ 36 \mathrm{~B} / \mathrm{yr}$ post-2000 (Rappaport 2000) with 1,400 fatalities in 2004-05 (Cutter et al. 2007) and losses exceeding \$100B (Lott and Ross 2006) in 2005 alone.

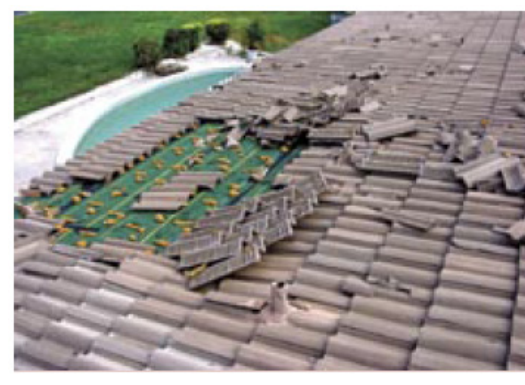

(a)

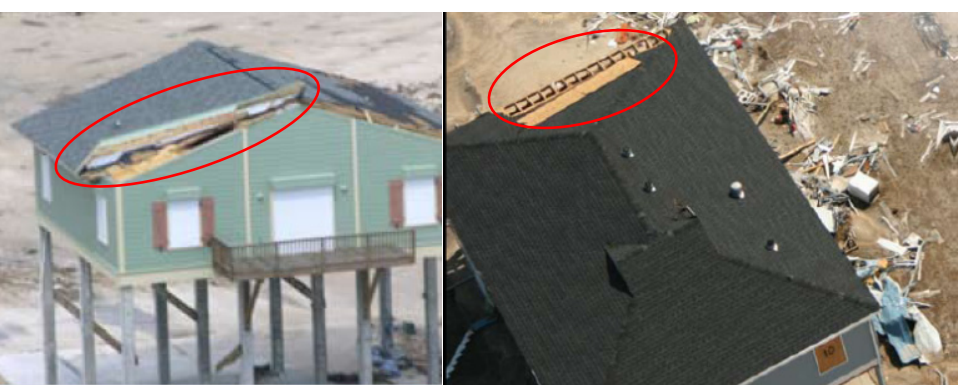

(b) (c)

Figure 6.1: Damage to roof hip and ridge tiles: a) Hurricane Charley (FEMA 2005); b \& c) Hurricane Ike (IHBS 2009). 
Even though a number of mitigation techniques have been introduced to improve the performance of building envelopes, the damage to roofs and roof components is still the major cause of building performances during hurricanes (FEMA 2005). For instance, a team deployed by $I B H S$ reported a pattern of failure from Hurricane Ike $(80-90 \mathrm{mph})$ "Aerial photos taken after Ike showed close to 90 percent of the homes near the coast toward the western part of Bolivar Peninsula had an extensive loss of hip and ridge shingles" (IBHS 2009) (Figure 6.1). Among the different pattern of wind-induced damages to building envelops, wind damage initiated at roof corners, edges, ridges and hips appears to be the most dominant cause for frequent loss occurrences as reported in FM (1985), IBHS (1999) [1] and [2], IBHS (2009), FEMA (2004) and FEMA (2007).

Because of vortex formation, the uplift forces are excessive at the corners of the roof. The corner roof vortices often generate extreme suction pressures along the leading edges. The severity of vortex-induced uplift observed on roofs is well documented by the following researchers (Stathopoulos 1987; Kramer and Gerhardt 1989; Saathoff and Melboume 1989; Stathopoulos et al. 1990; Cochran and Cermark 1992; Gerhardt and Kramer 1992; Mehta and Levitan 1992; Cochran et al. 1993; Tieleman et al. 1994; Lin et al. 1995; Kawai and Nishimura 1996; Lin and Surry 1998; Banks and Meroney 2001; Robertson et al. 2007). Once the roof corner is ripped off, the damage usually cascades to other areas and cause subsequent damage due to water intrusion, change in internal aerodynamics, etc. Research have shown that immediately after the first roof panel has been removed by wind uplift, the magnitude of losses could be in the range of $80 \%$ of the total insurance claims (Sparks et al. 1994). 
A significant effort has been made to address these interrelated issues. For example, widespread hurricane damage to hip and ridge tiles resulted in the development of an intensive set of guidelines for hip and ridge tile installation, which was adopted into the Florida Building Code $(F B C)$ as provided in section 1507.3 of the code. The $F B C$ regulation for installation of clay and concrete roof tiles is in compliance with the recommendation of the Florida Roofing, Sheet Metal and Air Conditioning Contractors Association (FRA) and the Tile Roofing Institute (TRI). These code recommendations are prescriptive in nature and more research is needed to relate the recommended installation details with the expected magnitude of wind pressures on different roof slopes, ridge types, and wind angles of attack etc. Industry approved testing protocols, such as $F M$ 4470, ASTM E1592, and UL 1897 are used to investigate the uplift resistance of roofing materials statically by applying pneumatic pressure. To this effect, a group of researchers recently evaluated the resistance of hip and ridge tiles through a detailed experimental and analytical study for clay and concrete tiles with adhesive-set, mortar-set as well as mechanical attachments by using static tests on a single clay tile (Mirmiran 2006; Mirmiran et al. 2007; Huang et al. 2009). A further study was performed using monotonic and cyclic uplift tests for multiple clay tiles (three at a time), as well as dynamic wind simulation tests using a 2-fan Wall of Wind ( $\mathrm{WoW})$ apparatus on small mono-slope roof specimens that have clay field tiles (Huang et al. 2009). Their study was limited to mono-slope tests because of the limitation of the wind field size generated by the 2-fan $W o W$.

This paper presents an investigation of the aerodynamic performance of roof tiles (both ridge and field tiles) installed on gable roofs with three different slopes (i.e.7:12, 
5:12, and 2:12), three different field tile profiles (i.e. high, medium and low) and two types of ridge tiles (barrel and three sided), with each experiment being performed under weather block $(W B)$ and no weather block $(N W B)$ conditions. The new 6-fan $W o W$ facility at Florida International University (FIU) was used to test these buildings. This 6fan $W o W$ was $4.88 \mathrm{~m}(16 \mathrm{ft})$ high and $7.31 \mathrm{~m}(24 \mathrm{ft})$ wide and is capable of testing a large low-rise building model. The performance of the roof tiles under different wind angles of attack $(A o A)$ was studied to capture the critical wind loading that may lead to roof failure. In order to evaluate the net pressure on the roof tiles, the distribution of external pressure on the top surface of the tiles as well as the "internal" pressure underneath the tiles (i.e. between tile and roof deck) was measured and analyzed. The aim was to investigate the "internal" pressure that may develop underneath the field tiles due to porosity and the discontinuous nature of the roof system. In addition, the effect of weather blocking was investigated to understand its influence on the aerodynamic performance of the field and ridge tiles.

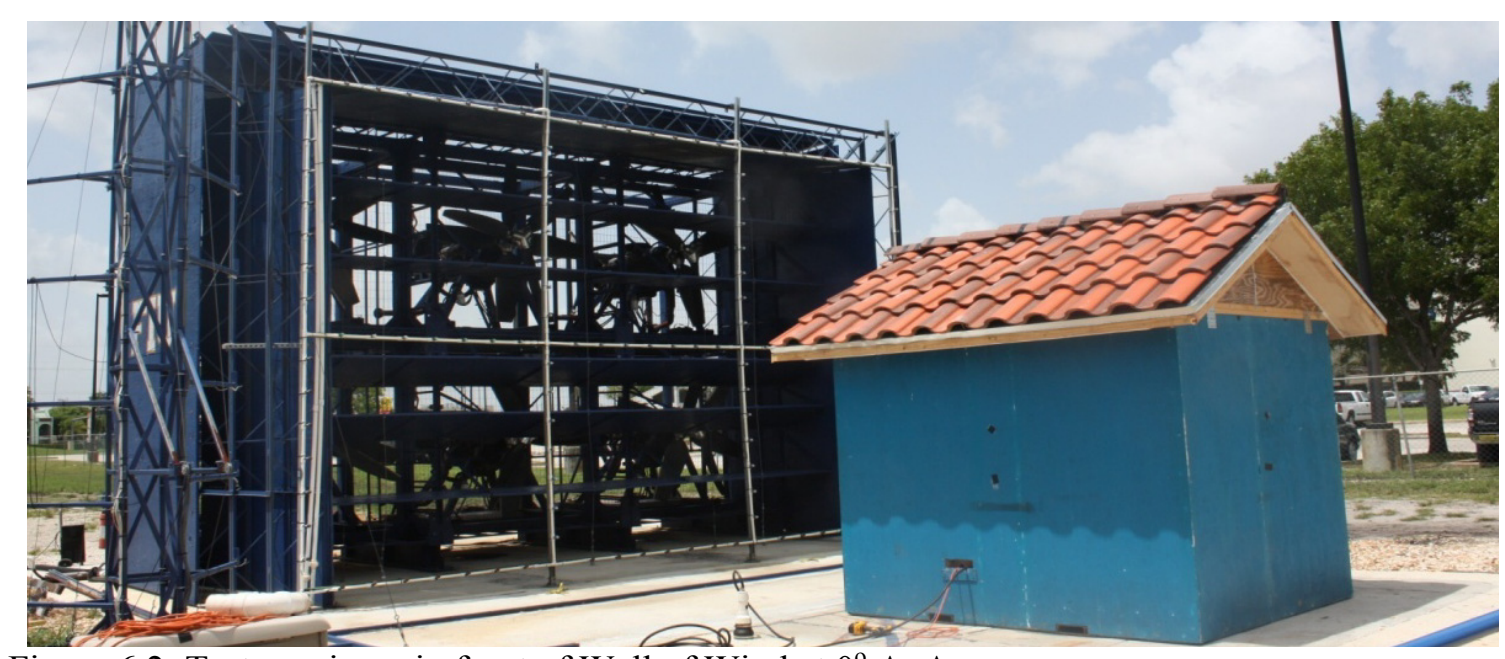

Figure 6.2: Test specimen in front of Wall of Wind at $0^{\circ} \mathrm{AoA}$ 


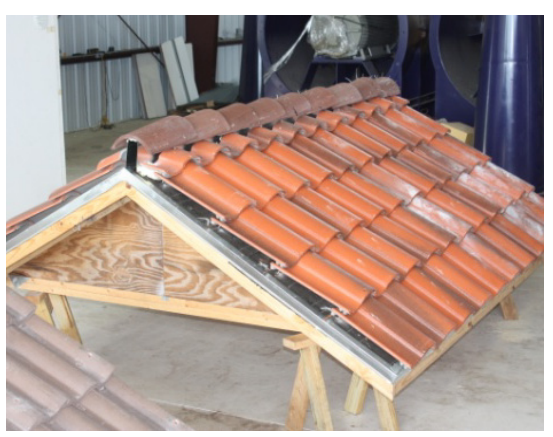

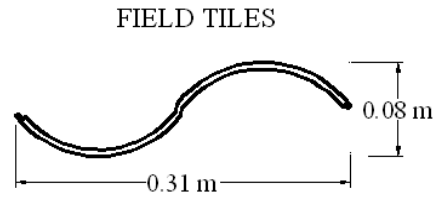

High profile

(a)
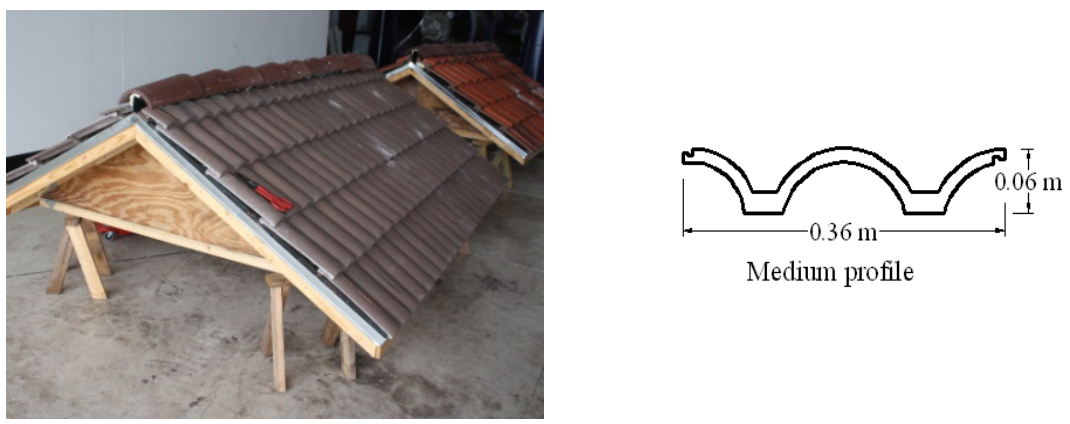

Medium profile

(b)
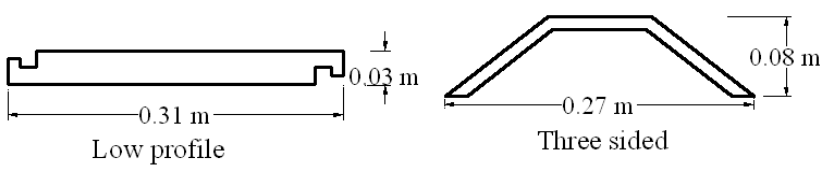

(c)

Figure 6.3: Field and ridge tile combinations a) High profile field with barrel ridge tiles; b) Medium profile field with barrel ridge tiles; c) Low profile field with three sided ridge tiles

The study generated high resolution aerodynamic data for field and ridge tiles installed on roofs with different slopes and tile profiles as well as using different construction details that will provide useful insight to the failure mechanism of roof components as described in the following sections. 


\subsection{Methodology}

The present study has adopted a full-scale experiment using the $W o W$ testing facility aimed at acquiring high resolution aerodynamic data for gable roof ridges and field tiles. The $W o W$ testing facility involves the experimental setup of larger size models that were assembled with industry standard construction materials that create a direct resemblance to actual wind-to-tile interactions. However, testing larger specimens within the finite WoW wind field, either to produce larger Reynold's number flows or to assess the performance of full-scale building components, may entail blockage issues. The concerning blockage effect in this experiment was the size of the test specimen in relation to the size of the wind field generated by the $W o W$ at the inlet. The initial model size of the test building specimen was obtained through a computational blockage and proximity assessment simulation in the Wall of Wind (Bitsuamlak et al. 2009). Based on the experimental result of that simulation a $2.13 \mathrm{~m}(7 \mathrm{ft})$ dimension was chosen for the depth

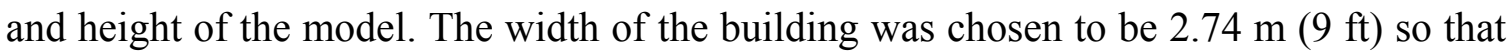
the test building would have a representative rectangular foot print as shown in Figure6.2. Following Florida's building code of practice, barrel ridge tiles were used with high and medium field tiles and three-sided ridge tiles were used for the low profile field tiles. All field and ridge tiles used in this study are schematically shown in Figures $6.3 \mathrm{a}$ to $6.3 \mathrm{c}$. While the field tiles were nailed to the roof deck, the ridge tiles were attached to a metal channel by using adhesive foams. Since the present $W_{o} W$ experiment was purely an aerodynamic study (dealing with shapes, porosity or openings and their interaction with wind), adhesive foams were used for the weather blocking instead of mortar due to their ease of application and reuse of the model. 


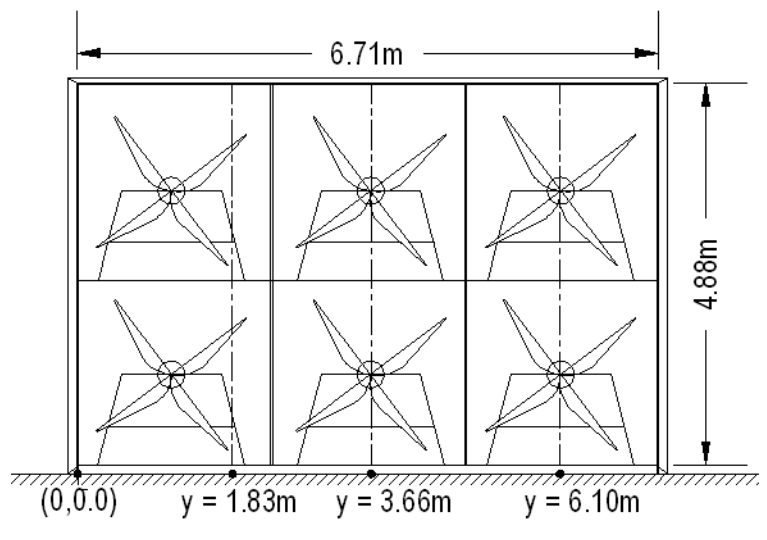

(a)

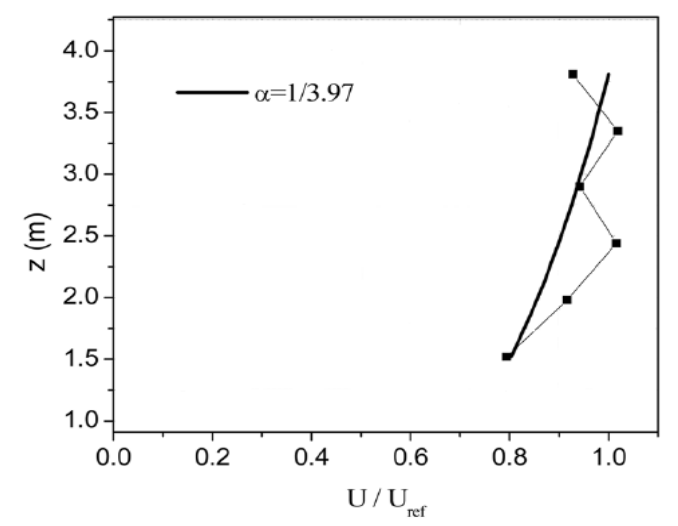

(c)

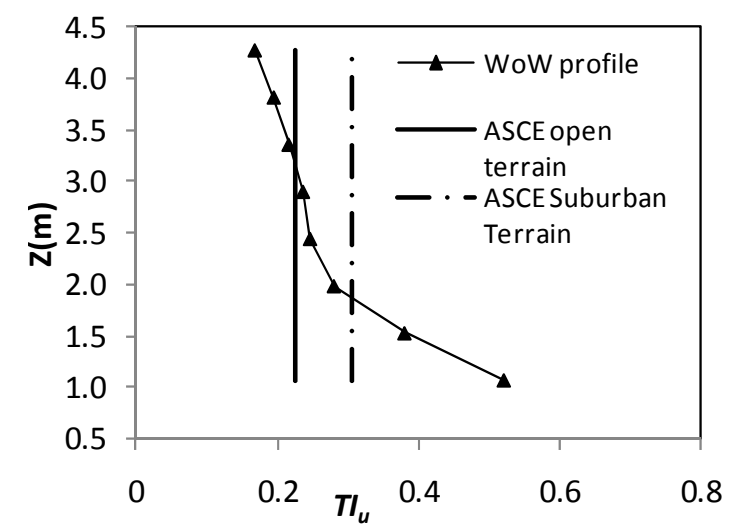

(e)

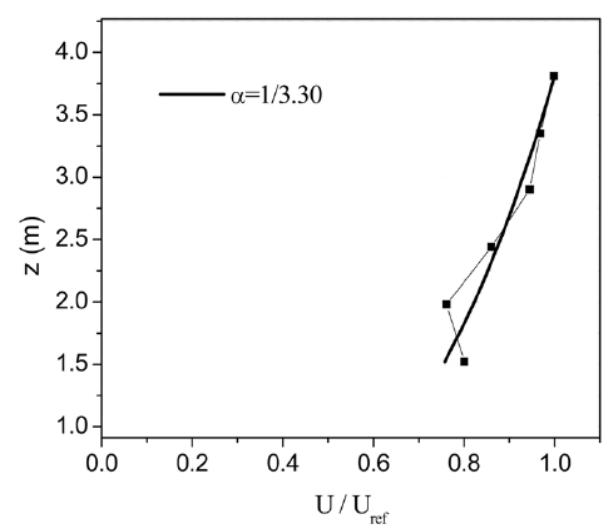

(b)

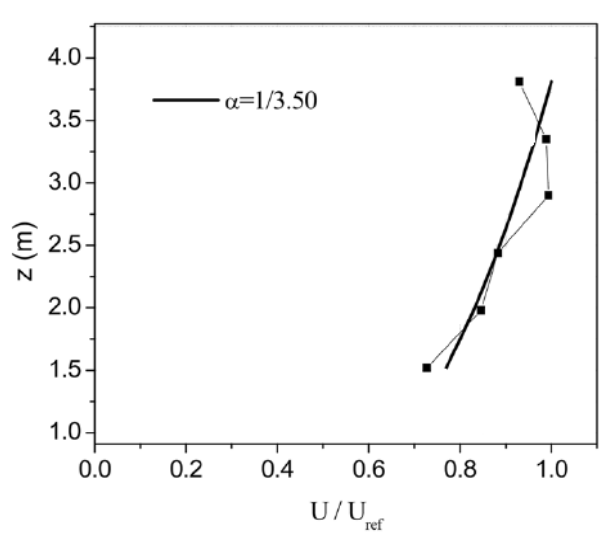

(d)

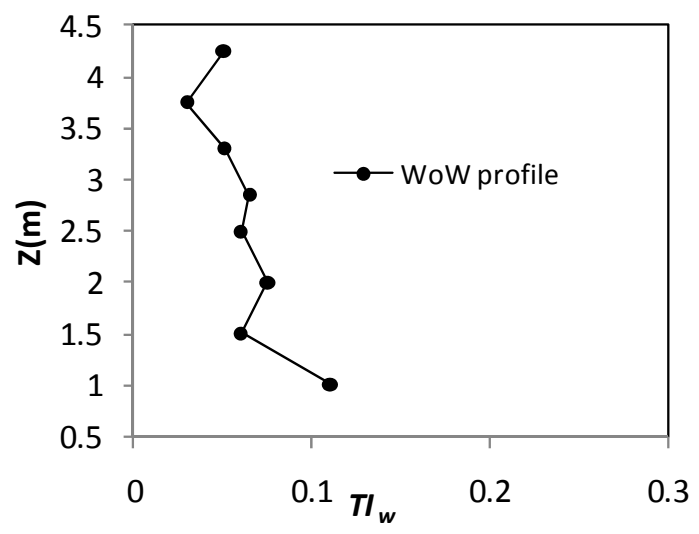

(f))

Figure 6.4: Full-scale 6-fan $W o W(a)$, non-dimensional mean velocity profiles at $\mathrm{y}=1.22 \mathrm{~m}--4$ $\mathrm{ft}--(\mathrm{b})$, at $\mathrm{y}=3.66 \mathrm{~m}--12 \mathrm{ft}$-- (c), at $\mathrm{y}=4.27 \mathrm{~m}$-- $14 \mathrm{ft}$-- (d), and longitudinal (e) and vertical turbulence profile (f) at $\mathrm{y}=3.66 \mathrm{~m}(12 \mathrm{ft})(\alpha=$ power law exponent). 


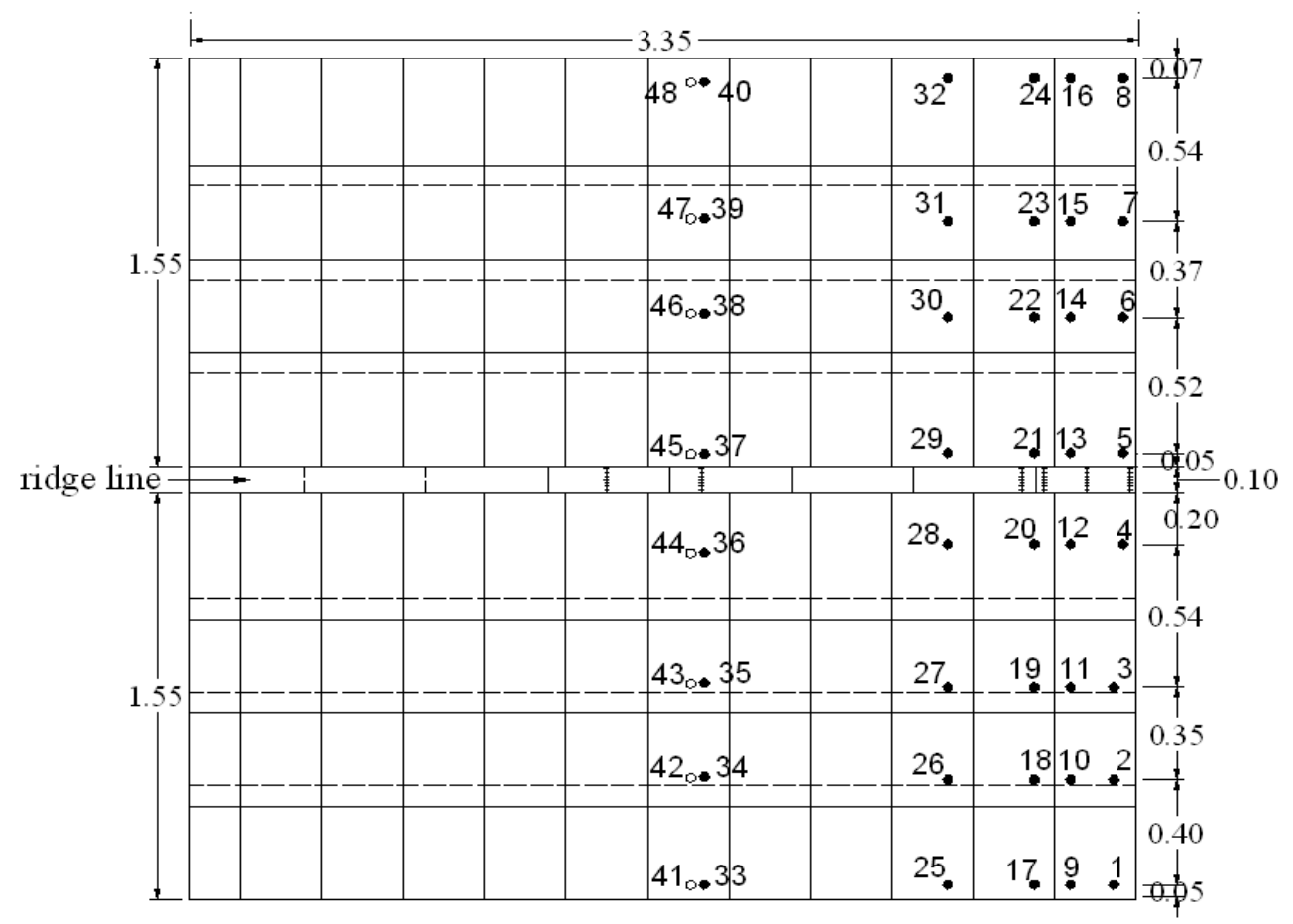

a)

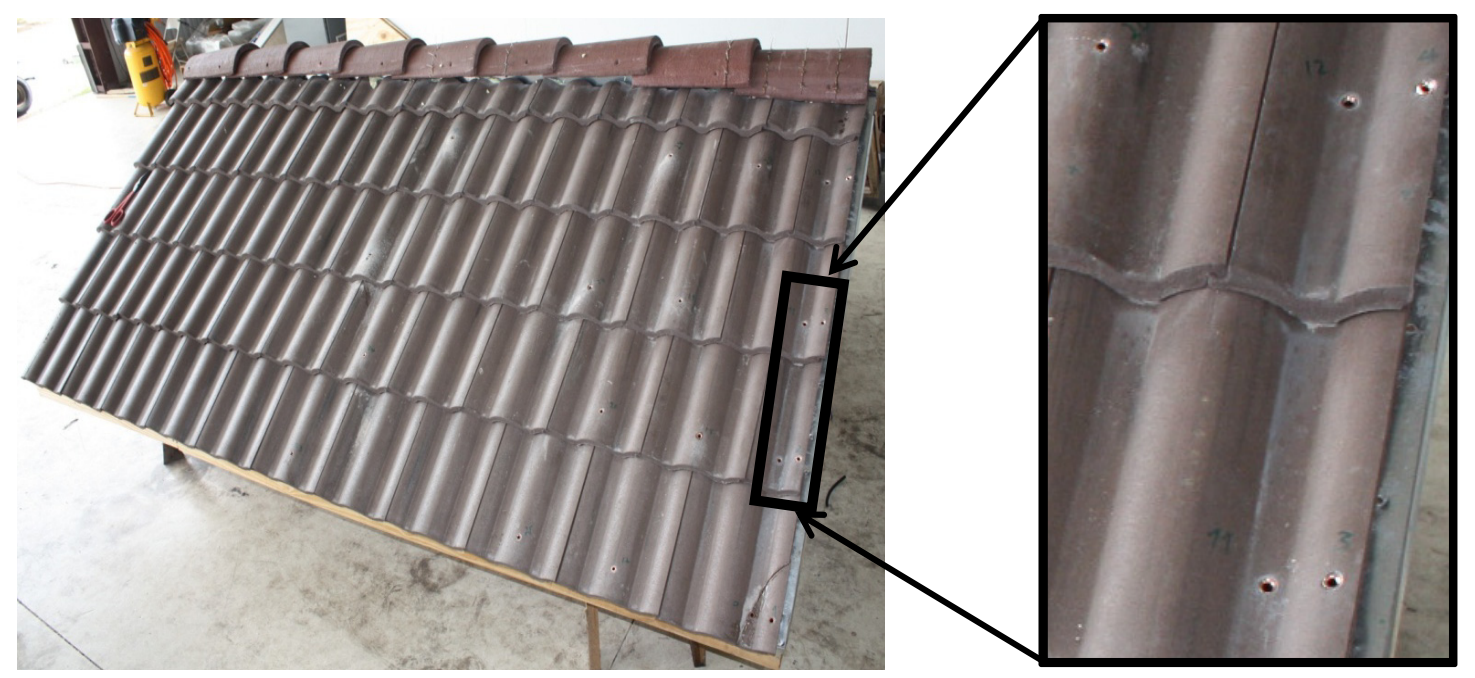

b)

Figure 6.5: Pressure tap distribution on the field tiles (plan view): a) tap layout; b) tap placement. 
A mean wind speed of $22.3 \mathrm{~m} / \mathrm{s}(49.79 \mathrm{mph})$ and turbulence intensity of $22 \%$ measured at an eave height of $2.18 \mathrm{~m}(7.16 \mathrm{ft})$ from the ground was used. A 3-minute wind speed was recorded in the absence of the model building for use as a reference wind speed. The reference mean wind speed was obtained by averaging three cobra probe measurements. The probes were equally spaced, coinciding along the front eave line of the building. The mean wind speed and turbulence intensity profiles are shown in Figures 6.4a to $6.4 \mathrm{f}$. For more details on the wind flow generation methods, refer (Huang et al. 2009). As can be seen in the wind profile plots, the wind profile was not as smooth as expected in a standard wind tunnel wind field. However, the larger wind field and higher wind speed provide for useful insight into the tile aerodynamics that might not have been possible in a standard wind tunnel tests.

A total of ninety four pressure taps were installed on each gable roof to capture the external pressure distribution on the tiles and the internal pressure developing in the space between the tiles and the roof deck. SETRA low pressure differential transducers (model 265) were used. Each transducer was supplied with two factory-installed 1/4" (outside diameter) pressure ports: a reference (low) pressure port and a positive (high) pressure port. The positive (high) pressure ports measure the fluctuating pressure at a specified location. Forty eight SETRA transducers were used on the field tiles whose distribution is shown in Figure 6.5. The remaining forty six transducers were used on the ridge tiles whose distribution is shown in Figure 6.6. Six rows of pressure taps were placed on the external surface of the ridge tiles, each row having seven taps (Figures 6.6a $\& 6.6 b)$. For high spatial resolution pressure measurements, a total of 21 transducers were allocated for the edge ridge tile. Four pressure taps were installed on the ridge support to 
capture any internal pressure developing underneath the ridge tiles. Eight pressure taps at the center, perpendicular to the ridge of the building, were also installed between the field tiles and the roof deck (Figure 6.5). In order to keep the accuracy of the measurements and avoid the uncertainty that arise from wiring, the pressure transducers were calibrated each time a new set of tests were performed. Reference pressures were taken twice for each test: before and after test and eventually the mean of the two was taken in the analysis. The pressure signals from all taps were sampled at a rate of $100 \mathrm{~Hz}$ for 180 seconds.

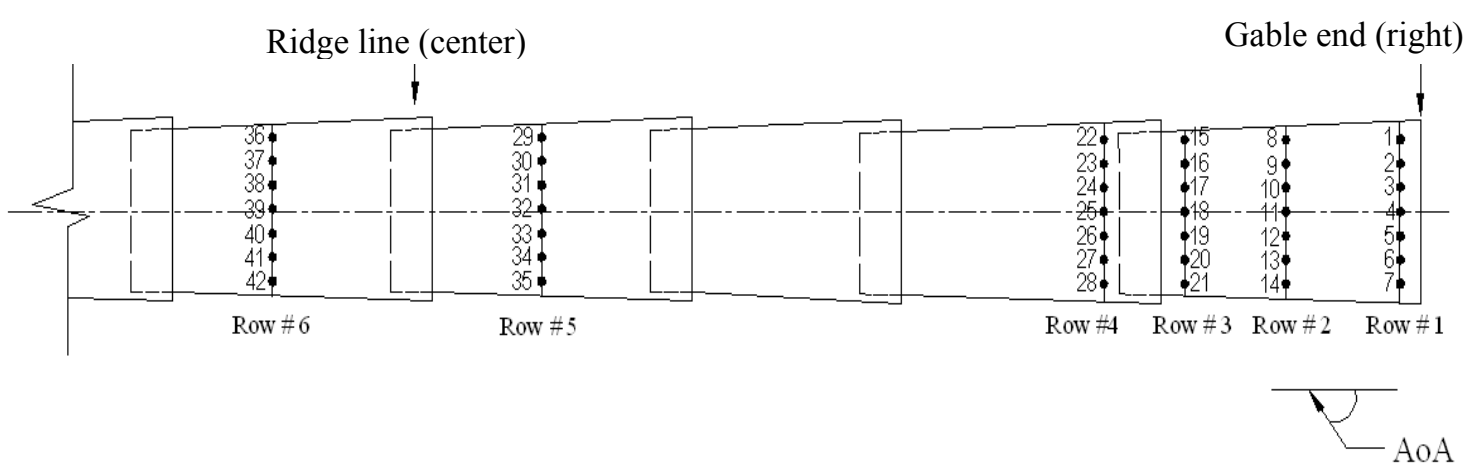

a)
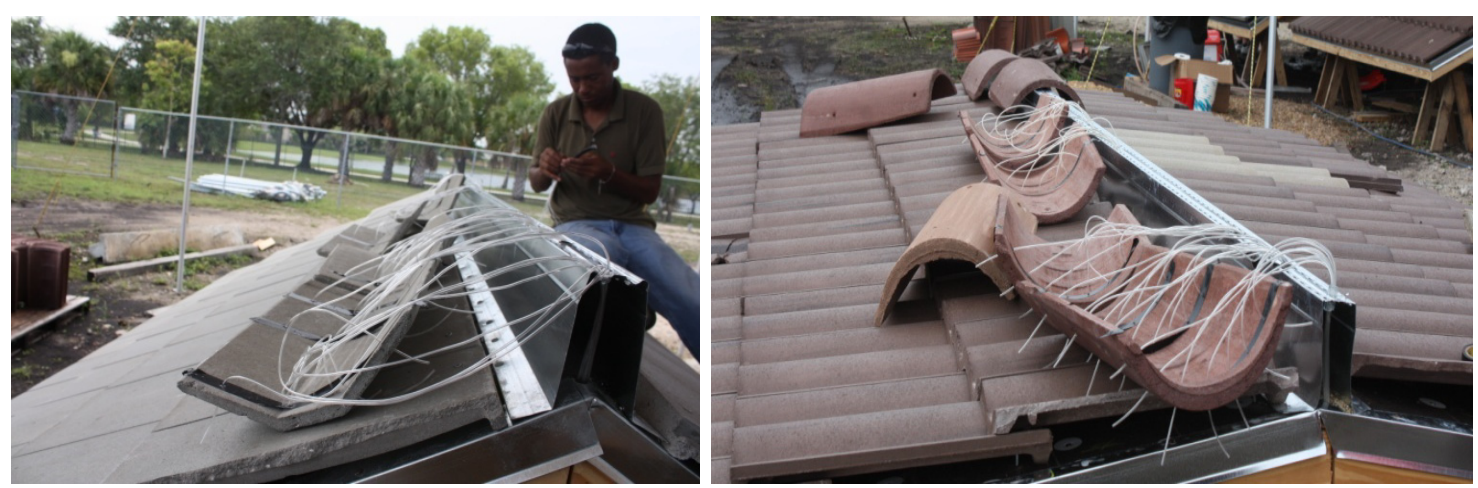

b)

Figure 6.6 Ridge tile Pressure tap distributions: Pressure tap layout along ridge line

Each of the six gable roofs was tested for five different wind $A o A$ (i.e., $0^{\circ}, 30^{\circ}, 45^{\circ}, 75^{\circ}$ and $90^{\circ}$ ). The $0^{\circ}$ wind $A O A$ corresponds to the orientation of the building when the gableend was facing the windward wall (as shown in Figure 6.2). The $A o A$ increases as the 
building rotates counterclockwise. Once the tests without weather blocking were completed, the weather block was applied and the tests were repeated to assess the effect of the weather blocking.

\subsection{Results and discussions}

The non-dimensional coefficient of pressure $\left(C_{p}\right)$ for each tap on the building was calculated by referencing all measured pressures to the mean free stream dynamic pressure (Eqn.1). The mean pressure coefficient for each tap was obtained by taking the average of the 3 minute recorded differential pressure (Eqn.2). Similarly, the peak positive and suction pressure coefficients are obtained from the time history data as shown in Eqn.3. The root mean square (rms) value of the pressure coefficient was obtained by making use of the standard deviation of the pressure coefficient (Eqn.4):

$$
\begin{aligned}
& C_{p i j}=\frac{P_{i j}-P_{r j}}{\frac{1}{2} \rho \bar{U}^{2}}, \quad C_{p e j}=\frac{P_{e j}-P_{r j}}{\frac{1}{2} \rho \bar{U}^{2}} \\
& C_{p_{\text {mean }}}=\frac{1}{n} \sum_{i=1}^{n} C_{p i} \\
& \hat{C}_{p i}=\frac{\frac{\hat{P}_{i}-P_{r i}}{2} \rho \bar{U}^{2}}{\widetilde{C}_{p i}=\sqrt{\frac{1}{2} \sum_{i=1}^{n}\left(C_{p i}-C_{p_{-} \text {mean }}\right)^{2}}}
\end{aligned}
$$

Where $C_{p e j}$ is computed external pressure coefficient; $C_{p i j}$ is computed internal pressure coefficient, $P_{e j}$ and $P_{i j}$ are the measured external and internal fluctuating pressures, 
respectively at the $j^{\text {th }}$ tap; $P_{r j}$ is the average reference pressure taken before and after the test; $\rho$ is air density (taken as $1.1644 \mathrm{Kg} / \mathrm{m}^{3}$ taken at $85^{\circ} \mathrm{F}$ average temperature); $V$ is the mean reference wind speed. Different parametric analyses were conducted as discussed below.

\subsubsection{Pressure distribution along ridge tile}

The external pressure coefficient distribution over the surface of the ridge tile was evaluated for the three roof slopes with medium profile $(M P)$ along the length of the ridge line spanning from the gable-end to the center of the ridge line. As shown in Figure6.6a, six rows of pressure taps across the ridge line were used. The pressure taps at the crest of the ridge were selected for the discussion on the pressure distribution along the ridge line (i.e., tap \#4, 11, 18, 25, 32 \& 39). In most cases, the ridge tiles experience the worst separated flows at their crest as observed during the experiment. For this particular discussion, $0^{\circ} A o A$ and the worst $A o A$ cases (i.e., $30^{\circ}$ and $45^{\circ} A o A$ ) are considered. As illustrated in Figures 6.7a-f, it was observed that critical suction pressure occurred at the edge of the gable-end ridge tile. Pressure taps at row \#1 experienced the maximum suction pressure both at $30^{\circ}$ and $45^{\circ} \mathrm{AoA}$ for all roof slopes tested under both the $W B$ and $N W B$ conditions. This was mainly attributed to the onset of a conical vortex and separation bubble at this particular region for the specified wind angle of attack. Moving from the windward edge to the mid-section (i.e., from row \#1 to row \#6), a

significant reduction in suction pressure (i.e., a reduction of $C_{p \min }$ from -9 to -3 ) was observed. 


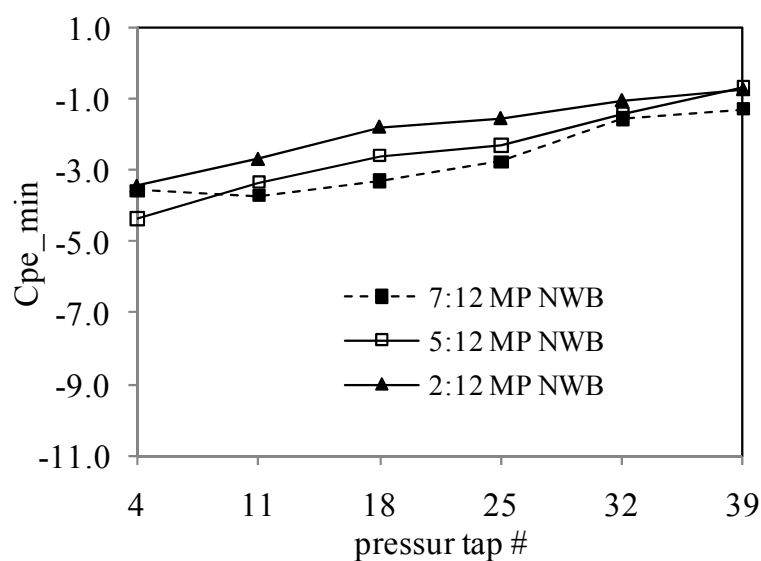

(a) $0^{\circ}$ AoA $N W B$ barrel ridge tile

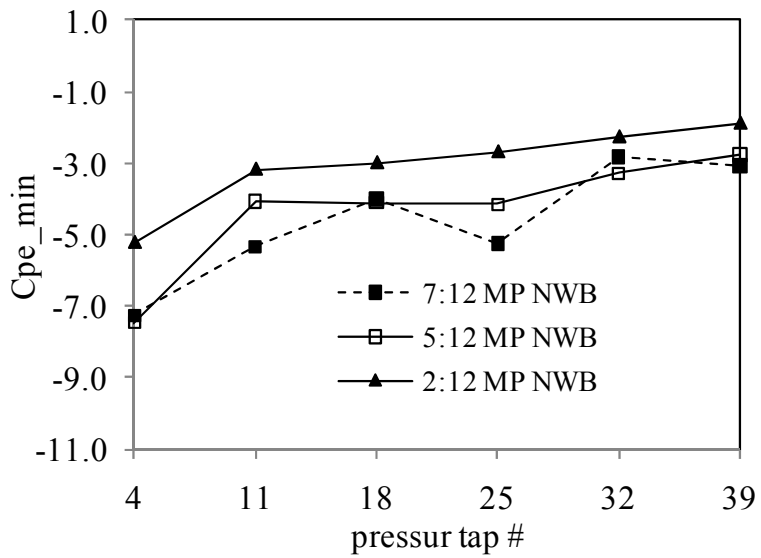

(c) $30^{\circ}$ AoA $N W B$ barrel ridge tile

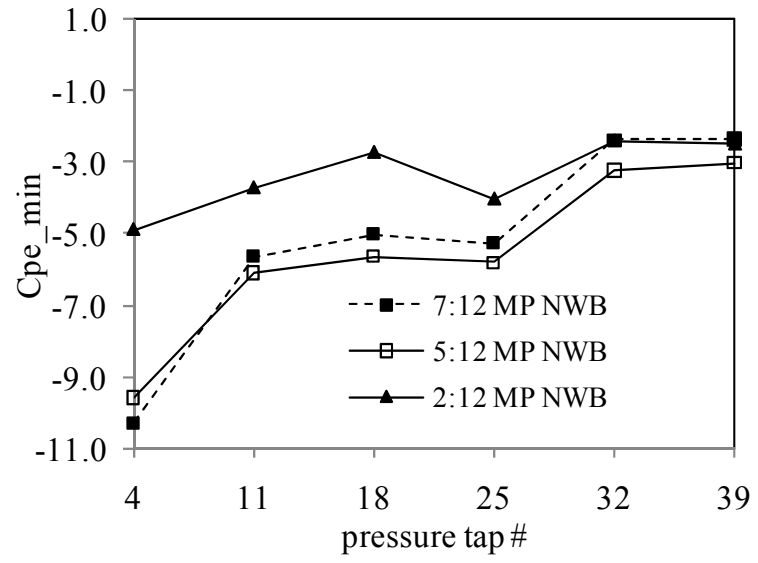

(e) $45^{\circ}$ AoA $N W B$ barrel ridge tile

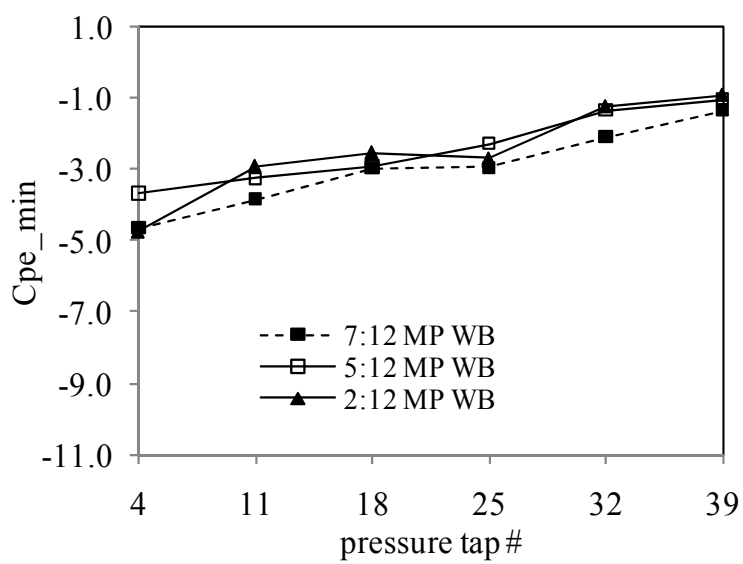

(b) $0^{\circ}$ AoA $W B$ barrel ridge tile

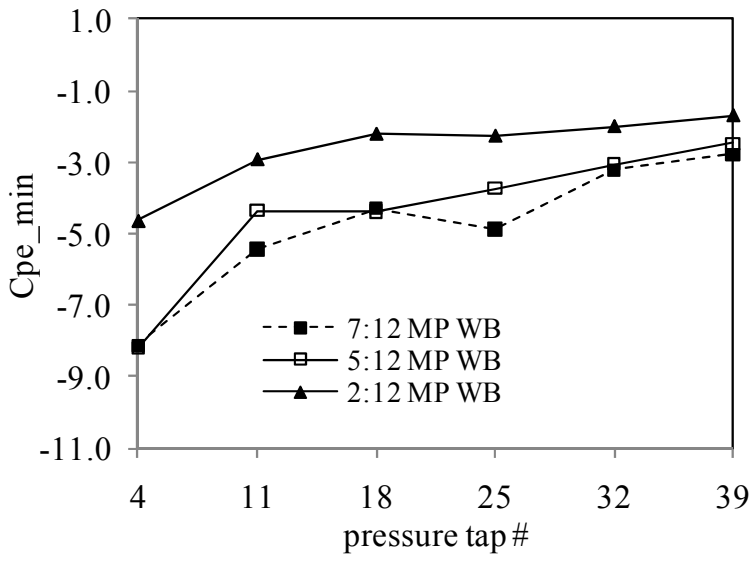

(d) $30^{\circ} \mathrm{AoA} W B$ barrel ridge tile

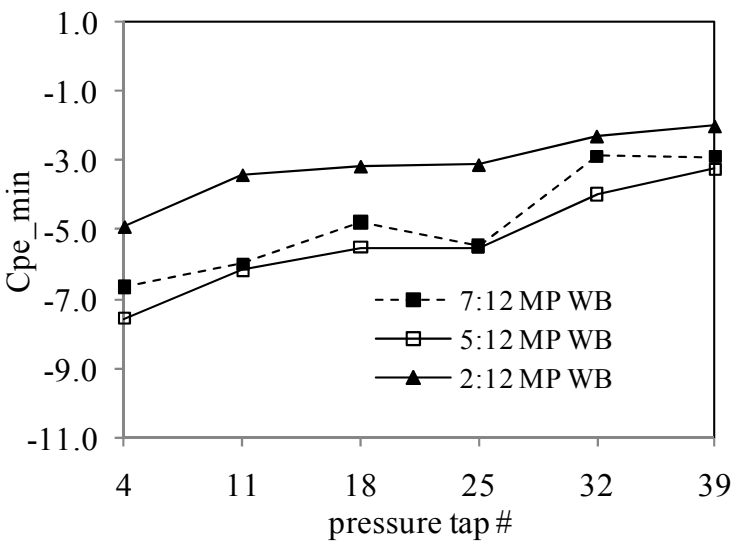

(f) $45^{\circ} A o A W B$ barrel ridge tile

Figure 6.7: Pressure distribution along the crest of the ridge tiles 
It was observed that the roof slope 2:12 experienced comparatively a very mild suction pressure at the gable-end ridge tile and the 7:12 slope experienced the highest suction in most of the cases observed in the present study (as shown in Figure 6.7e). The difference on the suction pressure among the three roof slopes disappeared while moving from the gable-end to the middle of the ridge line (as shown in all Figures 6.7a-f).

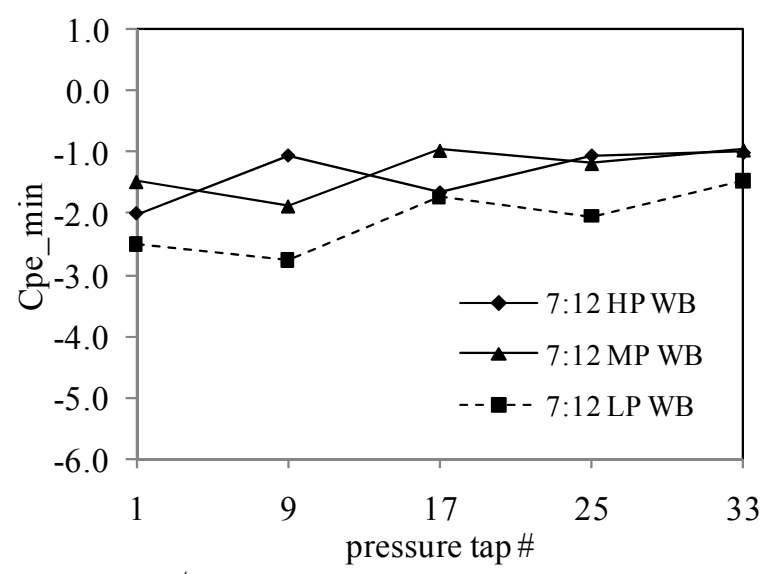

a) $1^{\text {st }}$ row field tile near the eave $\left(45^{\circ} \mathrm{AoA}\right)$

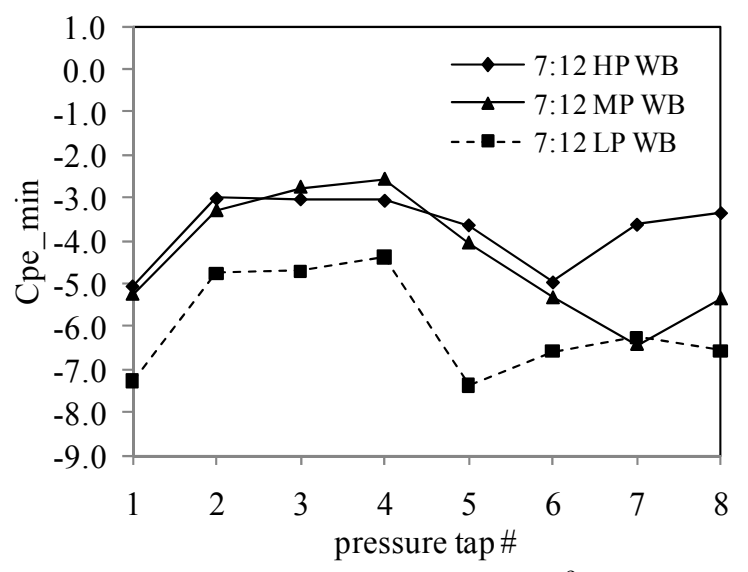

c) Field tiles near gable end at $30^{\circ} \mathrm{AoA}$

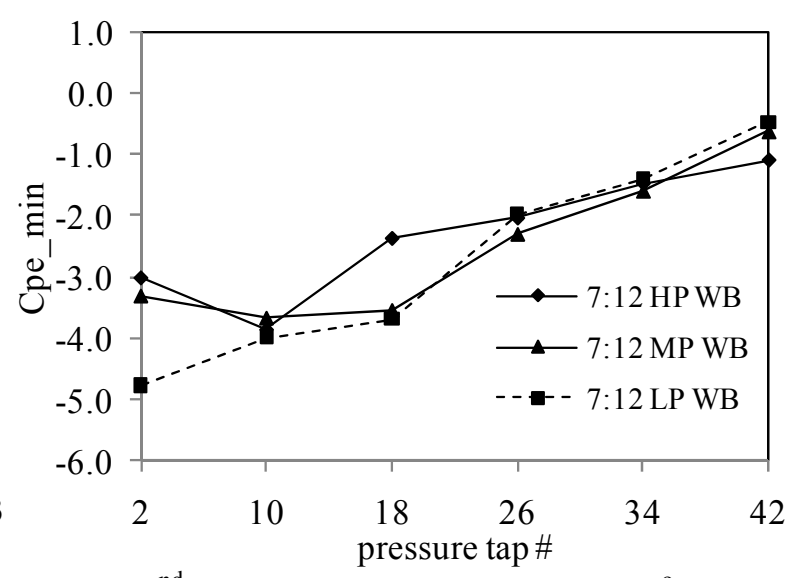

b) $2^{\text {nd }}$ row field tile near the eave $\left(45^{\circ} \mathrm{AoA}\right)$

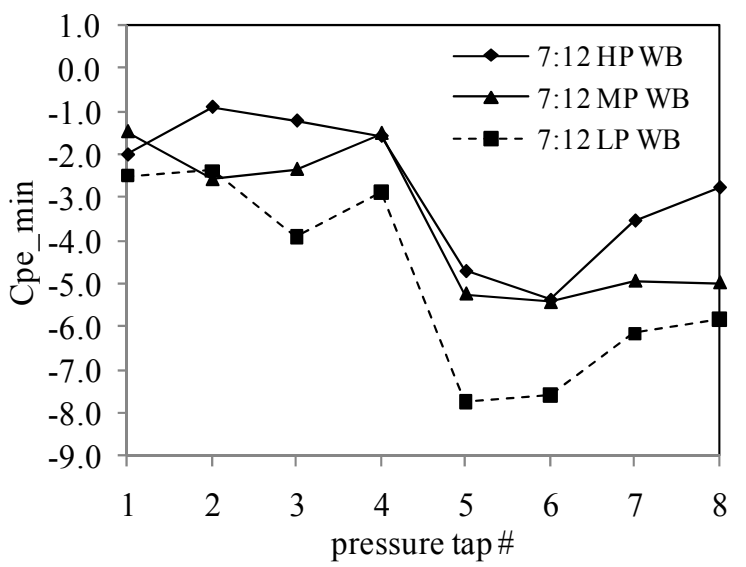

d) Field tiles near gable end at $45^{\circ} \mathrm{AoA}$

Figure 6.8: Field tile profile effect on wind pressure coefficients. 


\subsubsection{Roof profile effect on field tiles}

The different types of roof tile profiles were investigated to examine their effect on the pressure distribution that develops on the roof surface. The $1^{\text {st }}$ and $2^{\text {nd }}$ rows (i.e. parallel to the eave) of pressure taps on the field tiles of the 7:12 slope were taken for comparison as shown in Figures $6.8 \mathrm{a} \& \mathrm{~b}$ It was observed that the $L P$ roofs experience higher suction pressure compared to that of $H P$ and $M P$ on windward direction. A Similar pattern was observed on the pressure distribution along the length (i.e. parallel to the gable-end) of the roof as shown in Figures $6.8 \mathrm{c} \& d$. Compared to other slopes, the suction pressure on the leeward side for the steepest slope (i.e. 7:12) was generally high and particularly $L P$ roof tiles experienced comparatively higher suction pressure (as shown in Figure 6.8d taps \#5, 6, 7 and 8). In both cases (i.e., both at the edge and on the field surface), it was noticed that the field tile profile has played a significant role. The $L P$ roof tile being continuously sharp at the edges and monolithically flat on the surface of the roof, has resulted in an increased flow separation leading to higher suction pressure. On the other hand, the curved edges and rugged surfaces of $H P$ and $M P$ roof tiles have played a role in dampening the flow separation, thus, resulting in a reduced pressure compared to that of the $L P$. The wind load reductions on tall buildings due to balconies or chamfering at the corners can be considered analogous to the effect of the tile profile in the present study.

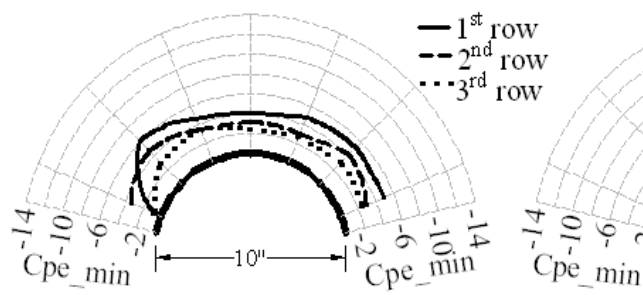

a) $H P 0^{\circ} \mathrm{AoA}$

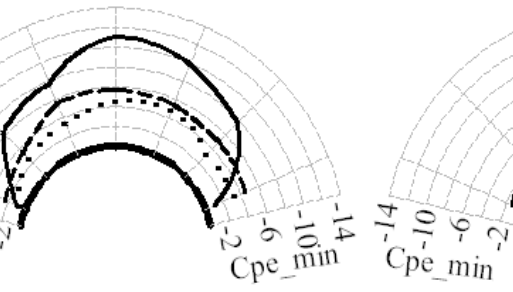

b) $H P 30^{\circ} \mathrm{AoA}$

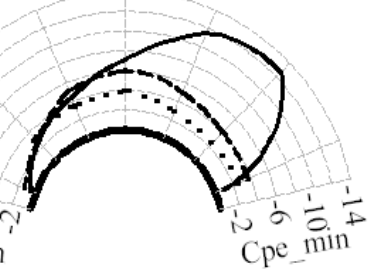

c) $H P 45^{\circ} \mathrm{AoA}$ 


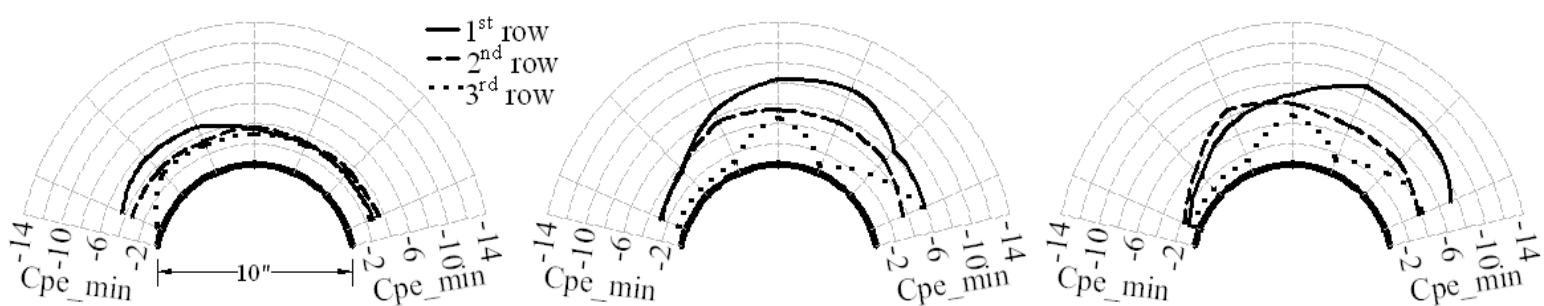

d) $M P 0^{\circ} \mathrm{AoA}$

e) $M P 30^{\circ} \mathrm{AoA}$

f) $M P 45^{\circ} \mathrm{AoA}$

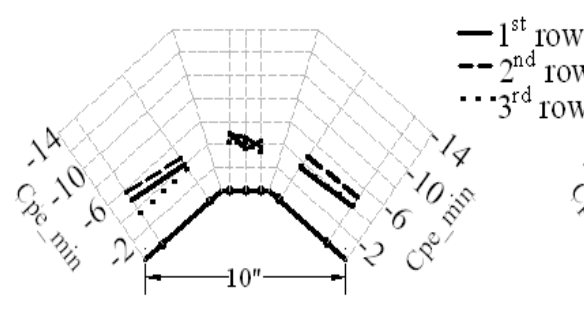

g) $L P 0^{\circ} \mathrm{AoA}$

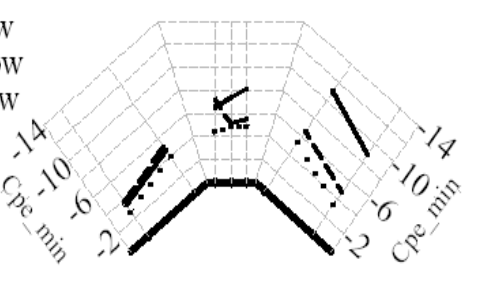

h) $L P 30^{\circ} \mathrm{AoA}$

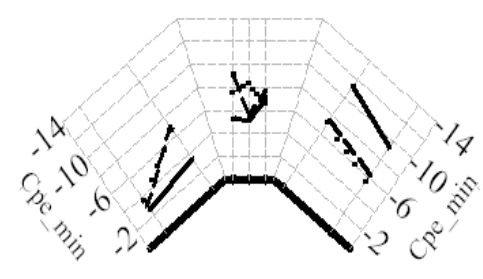

i) $L P 45^{\circ}$

Figure 6.9: WB Profile effect on ridge tile pressure distribution with roof slope of 7:12.

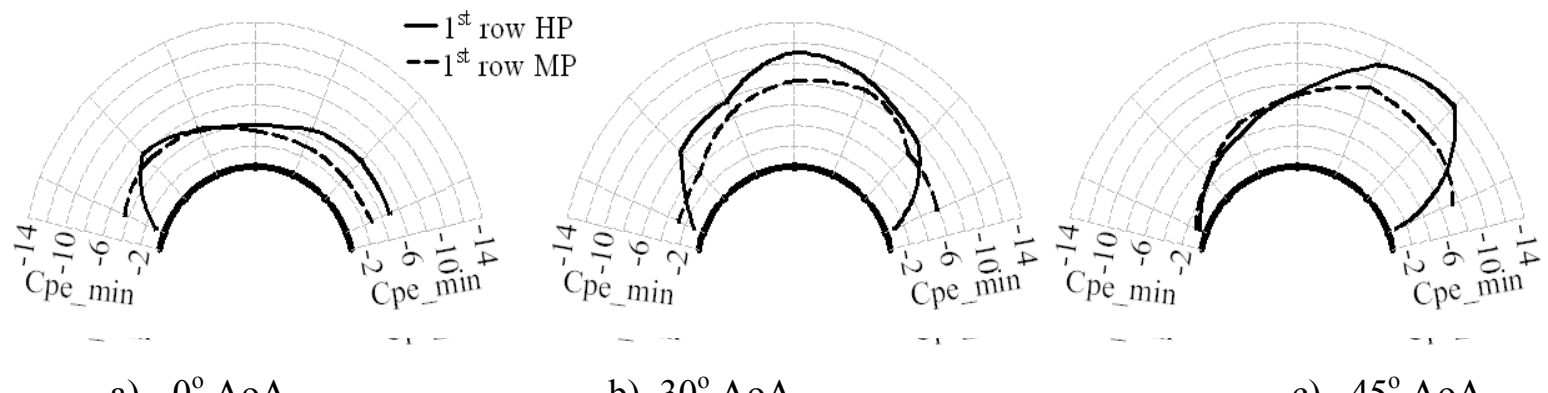
a) $0^{\circ} \mathrm{AoA}$
b) $30^{\circ} \mathrm{AoA}$
c) $45^{\circ} \mathrm{AoA}$

Figure 6.10: Profile effect on 7:12 slope barrel ridge tile.

\subsubsection{Field tile profile effect on ridge tiles}

The effect of field tile profile (i.e., $H P, M P$ or $L P$ ) on the pressure distribution over the surface of ridge tile was investigated. Three rows of pressure taps (i.e., $1^{\text {st }}, 2^{\text {nd }}$ and $3^{\text {rd }}$ rows) from the edge ridge tile (described in Figure 6.6a) were investigated for this case. These rows were observed to be the most critical causing the formation of maximum suction due to the flow separation. As illustrated in Figure 6.9 , the $30^{\circ}$ and $45^{\circ}$ wind $A o A$ 
resulted in higher suction pressure compared to the other wind $A o A$. The coefficients of pressure measured on the $1^{\text {st }}$ row taps (i.e. the outer row closest to the gable end) were higher than that of the inside $2^{\text {nd }}$ and $3^{\text {rd }}$ rows (Figures $6.9 \& 6.10$ ). For the $30^{\circ} A o A$, the $H P$ ridge tile experiences high suction pressure as compared to that of the $M P$ (Figures $6.9 \mathrm{~b} \& 6.9 \mathrm{e})$. For the $45^{\circ} A o A$, both $H P$ and $M P$ ridge tiles experienced comparable suction pressure on the windward side of the building. However, on the leeward side, the $H P$ ridge tile experienced extremely high suction pressure (Figure 6.9c). Even if the ridge tile for the $L P$ roof profile was three-sided and cannot be directly compared with that of barrel ridge tiles, it can be observed that the suction pressure is considerably high. Close observation of each ridge tile with respect to the field tile profile provided an insight on the level of flow separation that develops on the ridge. For example, the elevation of the crest of the barrel ridge tile from the valley of the $H P$ field tile was considerably higher than that of the same barrel ridge tile placed on $M P$ field tile because of its higher valley depth. Aerodynamically, the elevated surface of the ridge tile contributes to the formation of higher positive pressure on the windward side of the ridge and higher separation flow on the leeward side (Figures 6.9a-f). In the case of the three-sided ridge tile mounted on the $L P$ profile field tile, the higher suction was attributed to the sharp edges of the three sided ridge tile on the crest along with its higher elevation from the roof surface (as can be seen in Figure 6.5c). Thus, the effect of the field tile profile on the ridge tiles demonstrated that the higher elevation of ridge tiles due to the overall roof surface profile at a critical wind $A o A$ produced higher wind loading on the ridge tiles. 


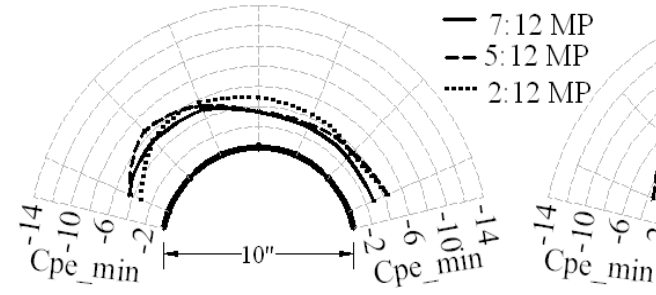

a) $0^{\circ} \mathrm{AoA}$

b) $30^{\circ} \mathrm{AoA}$

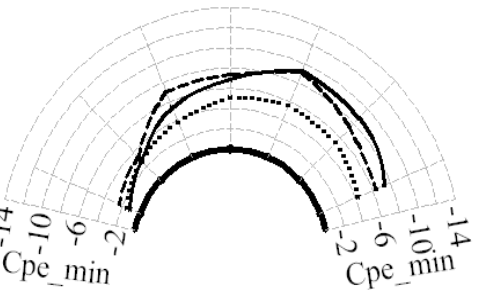

c) $45^{\circ} \mathrm{AoA}$

Figure 6.11: Slope effect on ridge tiles for the case with weather block and medium profile field tile.

\subsubsection{Slope effect on ridge tiles}

The effect of the slope on the ridge tile pressure distribution was assessed by considering the critically loaded edge ridge tile. As shown in Figure 6.9, the first 3 rows of edge tile pressure taps were analyzed for $0^{\circ}, 30^{\circ}$ and $45^{\circ}$ wind $A o A$. The measurement showed that the suction pressure was highest closer to the edge i.e. on the $1^{\text {st }}$ row pressure taps followed by the $2^{\text {nd }}$ and $3^{\text {rd }}$ rows. By considering only the critical row (i.e., $1^{\text {st }}$ row), slope effect comparison was assessed among the three $M P$ roof slopes (Figure 6.11). The pressure coefficients for the $0^{\circ} A o A$ were within close range of similarity. For the $30^{\circ}$ $A o A$, the 5:12 and 7:12 roof slopes experienced relatively higher suction pressure compared to the 2:12 slope. However the 7:12 and 5:12 roof slopes were relatively comparable to each other. For the $30^{\circ} A o A$ case, the wind-ward pressure coefficient of the 5:12 slope goes marginally higher than that of 7:12. For the $45^{\circ} A o A$ case, however, the leeward pressure coefficient of the 7:12 slope went marginally higher than that of the $5: 12$ 


\subsubsection{Comparison of edge field tiles vs edge ridge tiles}

Previous researches have revealed that the suction pressure at the eaves, corners and edges of a roof to be critical. But only few studies have showed high resolution tests that differentiates ridge tiles from field tiles. In the present study, critical pressure coefficient comparison between field tiles and ridge tiles was performed for 7:12, 5:12 and 2:12 roof slopes with $W B$ and $N W B$ conditions. Corner field tile tap \#1 (at the eave corner) and edge ridge tile tap \#4 (at the crest ridge of gable end) were selected as representative of worst locations for the onset of separation flow and conical vortices.

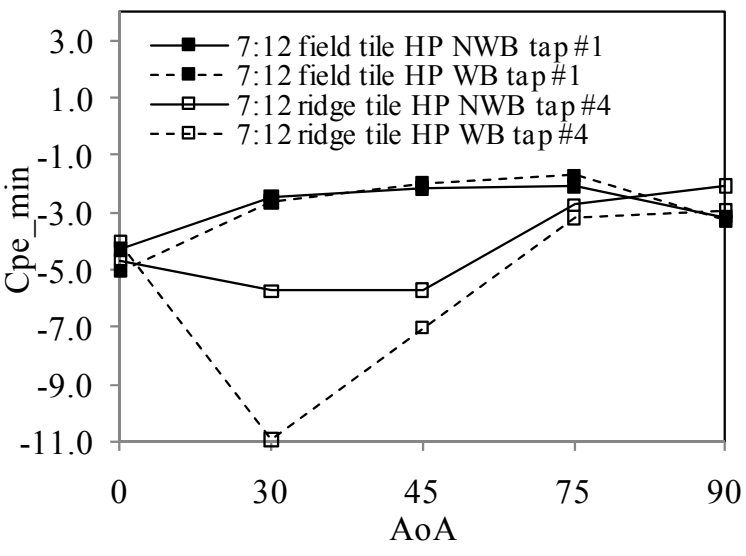

(a) 7:12 HP (field edge vs ridge edge)

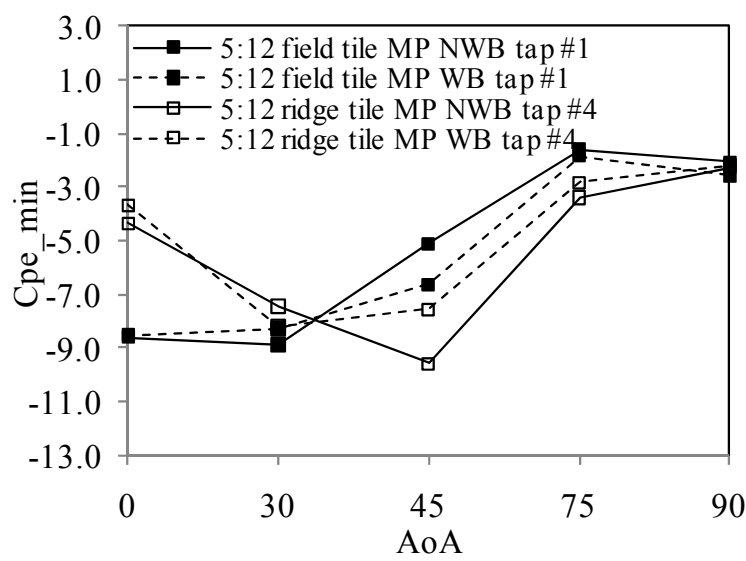

(c) 5:12 MP

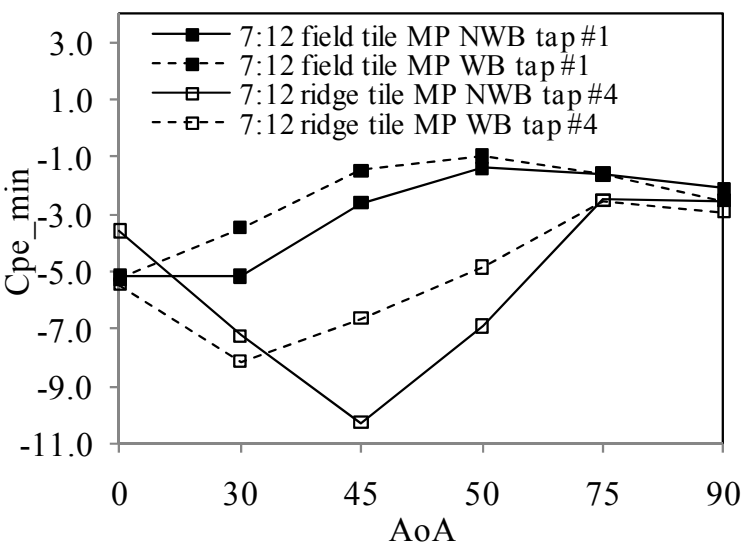

(b) 7:12 MP field edge

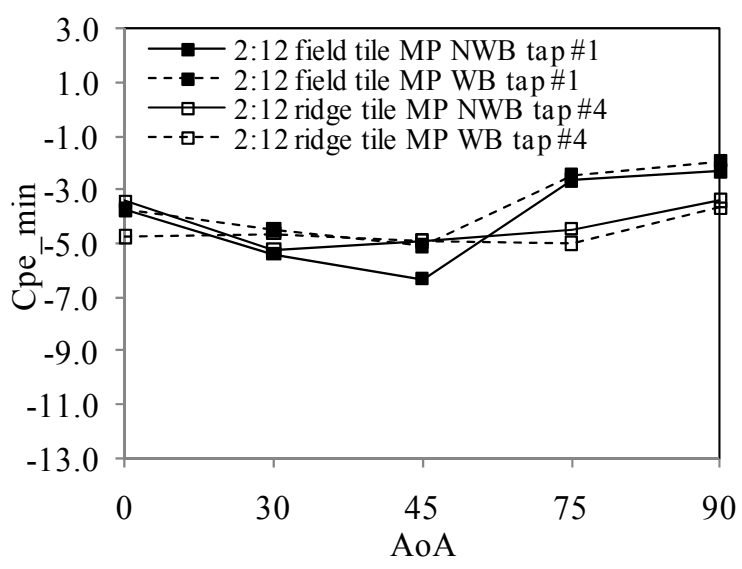

(d) 2:12 MP

Figure 6.12: Edge ridge crest (tap\#4) versus corner edge field tile (tap\#1) pressure coefficient comparison. 
As illustrated in Figures $6.12 \mathrm{a} \& 6.12 \mathrm{~b}$, it was obtained that the edge ridge tile gets exposed to higher suction pressure compared to that of corner edge field tile. The peak suction pressure coefficient on the ridge tile was extremely high for wind angle of attack between $30^{\circ}$ and $45^{\circ}$. The $C_{p \min }$ for the edge ridge was $180 \%$ to $390 \%$ higher compared to that of its corresponding corner field tile. The main difference observed between the corner field and ridge tile was the trend of pressure coefficients that both the field and ridge tile experienced with respect to the wind direction. Particularly for oblique wind directions (i.e., $30^{\circ}$ and $45^{\circ}$ wind $A o A$ ) the ridge tile exhibited significantly higher suction compared to the corner field tile both for $W B$ and $N W B$ cases (Figures 6.12a-d).

In another observation, the high resolution data has helped to assess and compare the pressure distribution on the field tile near the ridge with that on the ridge. As shown in Figures $6.8 \mathrm{c} \& 6.8 \mathrm{~d}$, the critical suction pressure coefficient on field tile tap \#4 (close to the edge ridge line) was obtained to be -4.4 . This field tile pressure, however, was much smaller than the nearby ridge surface pressure as shown in Figures $6.9 \mathrm{c}, \mathrm{d} \& \mathrm{f}$. The ridge tile pressure was observed to be more or less twice that of the field tile close to the ridge tile.

These differences would not have been captured while testing at small scale such as those carried in a typical wind tunnel. Small scale models do not replicate tile profiles aerodynamically.

\subsection{6 "Internal pressure" underneath field tiles}

The discontinuous roof tile system covering the roof deck usually leaves open spaces that allow infiltration/exfiltration of air in between the roof deck and the tiles. Although 
the openings at the tile overlap are generally helpful for convective ventilation purposes in order to cool the underlayment (or secondary water barrier), it may also act as a pathway for water intrusion. From the perspective of the present study, however, during extreme wind flows the opening spaces particularly those at the eave and gable end perimeter (here forth called "edge opening") and field tile overlap (here forth called "overlap opening") influences the wind aerodynamics on the roof surface.

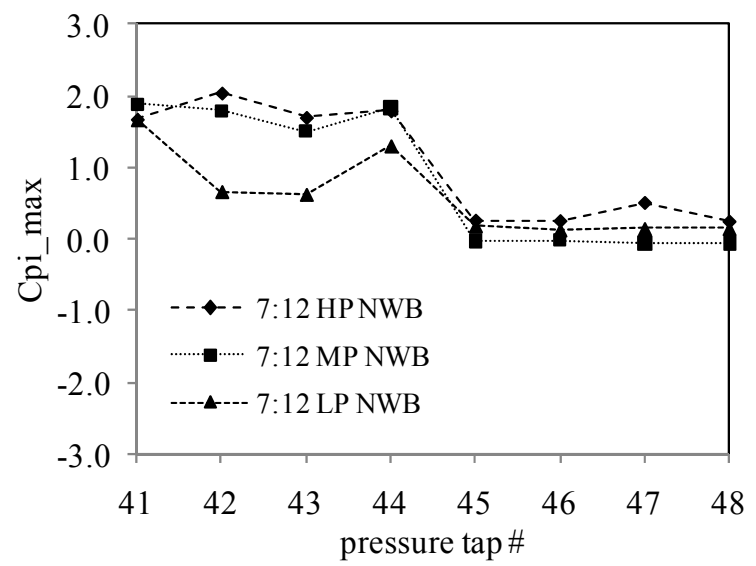

(a)

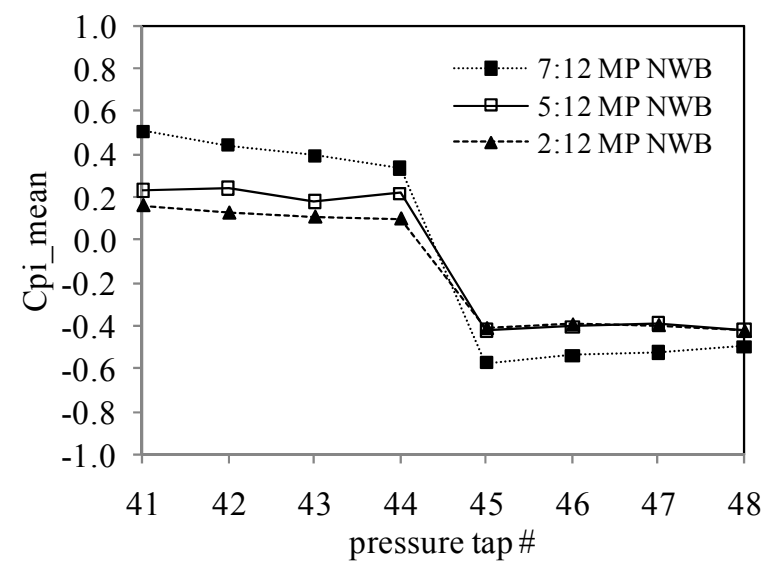

(c)

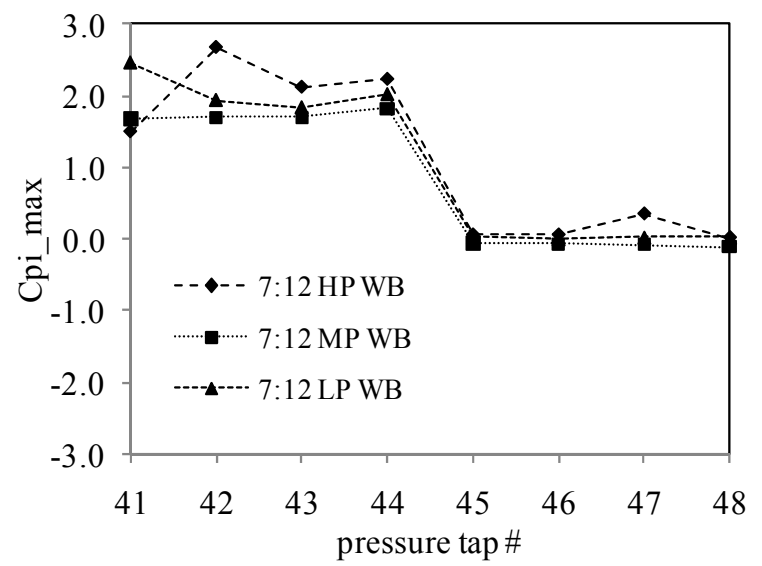

(b)

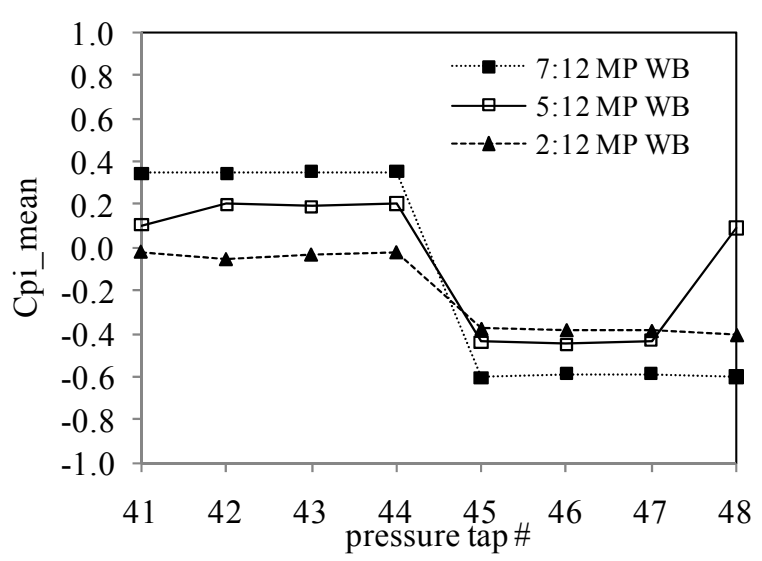

(d)

Figure 6.13: $C_{p i}$ underneath field tile: a) $90^{\circ} \mathrm{AoA} N W B \_$max; b) $90^{\circ} \mathrm{AoA} \mathrm{WB \_ max}$; c) $90^{\circ} \mathrm{AoA}$ NWB_mean; d) $90^{\circ}$ AoA WB_mean. 
Pressure transducers installed at the roof center line (Figure 6.5a) along the length of the roof perpendicular to the eave (i.e., tap \#41-48 running parallel to the gable end) were used to measure the "internal pressure" underneath field tiles. As shown in Figures6.13a \& $\mathrm{b}$, the $\max C_{p i}$ for the windward edge internal pressure underneath tile (i.e., tap \#41-44) was observed to be significant for the 7:12 HP tile profiles. Comparatively, the positive pressure underneath the tiles for $M P$ and $L P$ roof types was moderate. In the $M P$ and $L P$ type of tile profiles, the edge opening between the tile and the roof deck was minimal compared to that of $H P$ roofs wherein which large openings exist. The effect of roof slope on the underneath pressure was studied by comparing the mean $C_{p i}$ for $M P$ of $7: 12,5: 12$ and 2:12. It was observed that the 7:12 roof type, irrespective of the weather blocking, experience higher positive pressure coefficients (Figures $6.13 \mathrm{c} \& \mathrm{~d}$ ). The steeper the roof slope, the higher the positive pressure underneath the field tiles. Analyzing the peak positive internal pressure coefficient underneath field tiles with respect to the wind $A o A$, irrespective of the slope of the roof, it was observed that $90^{\circ} \mathrm{AoA}$ instigated the maximum $C_{p i}$. The lowest was recorded at $0^{\circ}$ AoA. Representative data is given in Figure 6.14 illustrating the distribution of the max internal pressure coefficient with respect to the wind angle of attack. This variation can be explained as follows; at $0^{\circ} A O A$ (flow parallel to eave or ridge), the wind flow direction doesn't see both the edge and overlap openings except those at the gable end. As the angle of rotation increases, however, the infiltration of the wind through the tile opening also increases. The flow begins to see both the edge opening as well as the overlap opening. At $90^{\circ} \mathrm{AoA}$, for instance, the wind flow and the openings are face-toface causing the infiltration of air through the edge opening as well as the overlap 
openings of the windward side of the roof. This leads to the development of positive internal pressure underneath the tile along the windward side of the roof as shown in Figure 6.14 .

The opposite direction of the mean external and internal underneath pressures causes reduction in the net pressure that develops on surfaces of the roof tile. The mean underneath pressure on the windward side was observed to be positive for the three roof slopes tested.
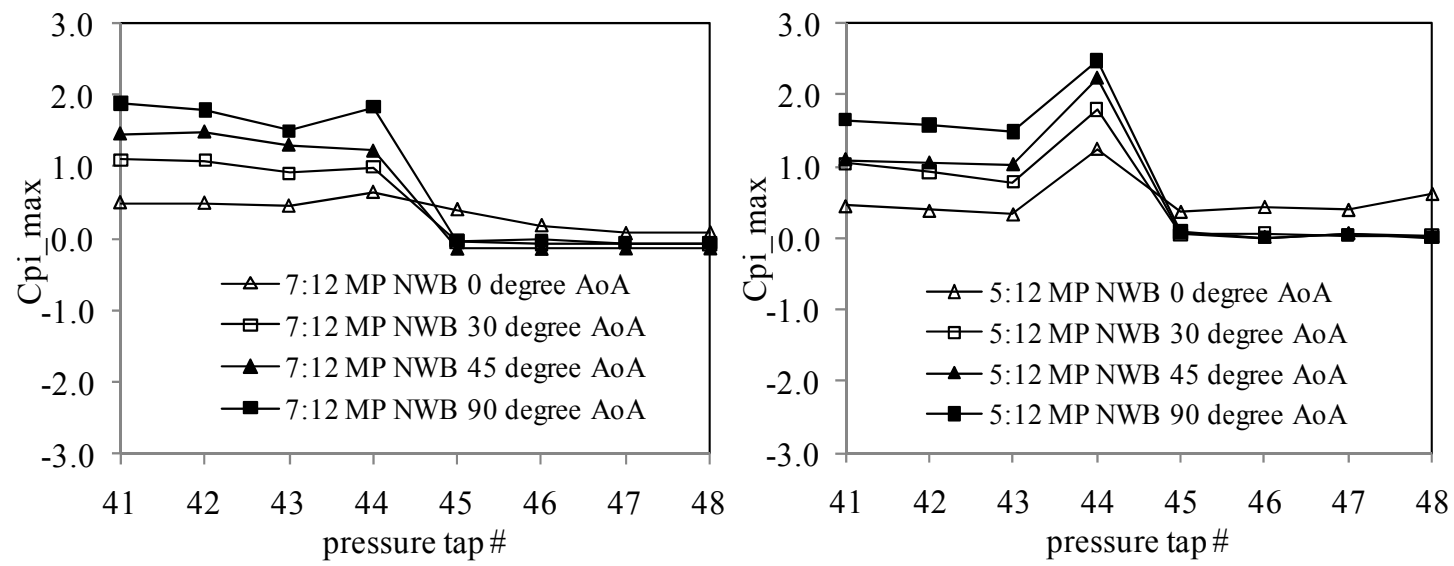

Figure 6.14: $\operatorname{Max} C_{p i}$ versus wind angle of attack.
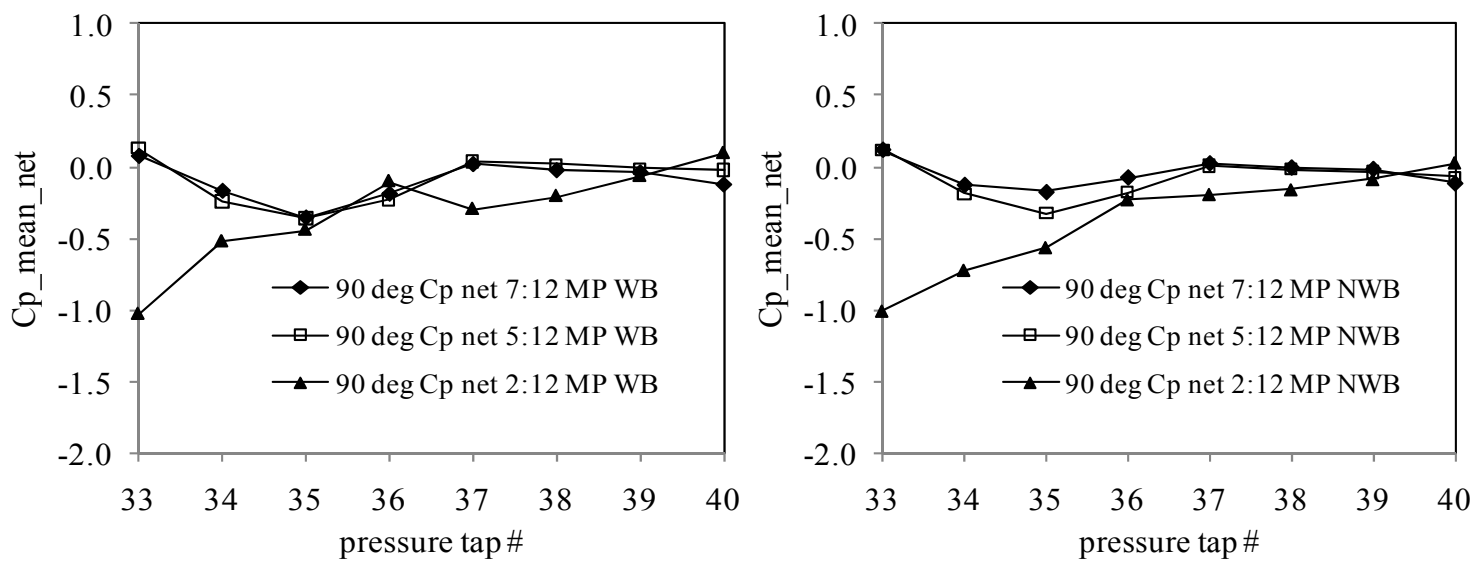

Figure 6.15: Comparison net mean roof pressure between weather blocked and non-weather blocked roof tiles. 


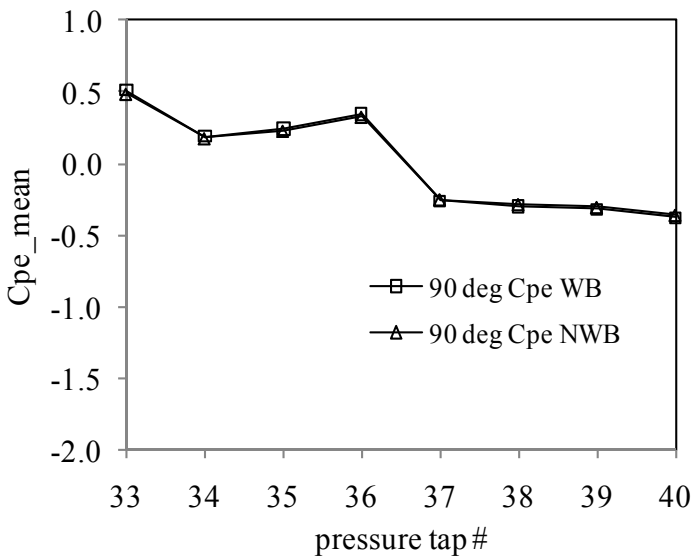

(a). 7:12 HP

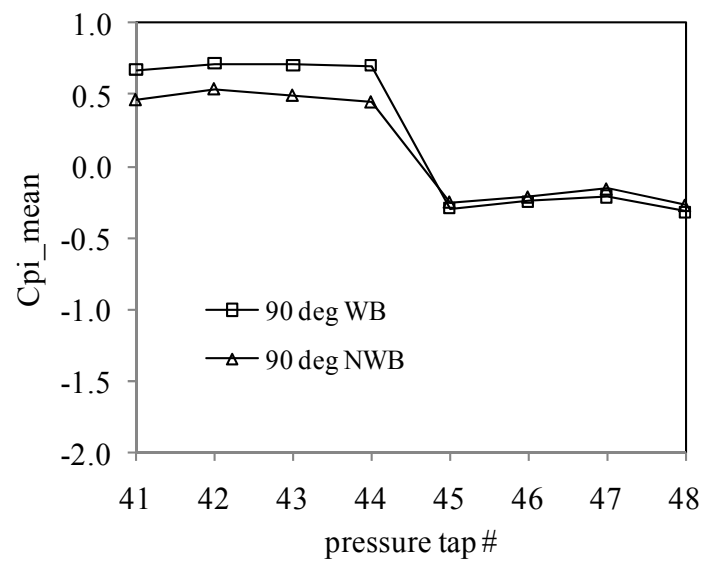

(c). 7:12 HP

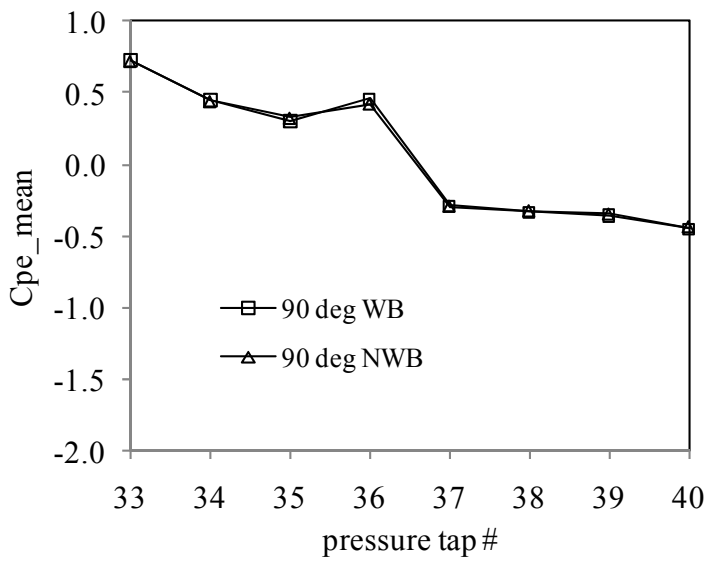

(b) . 7:12 MP

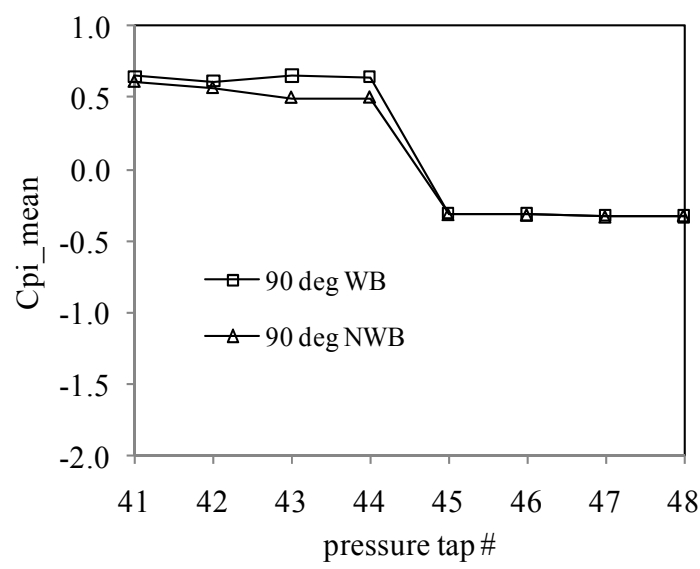

(d). 7:12 MP

Figure 6.16: Comparison between weather blocked and non-weather blocked roof tiles: mean $C_{p e}$ (a \&b); mean $C_{p i}(\mathrm{c} \& \mathrm{~d})$.

The mean external pressures for both the 7:12 and 5:12 roof was also positive. However, it was observed that the $2: 12$ roof slope experienced a mean suction windward external pressure making the external and underneath pressures in the same direction. As shown in Figure 6.15, the combined effect of the windward external and underneath pressure has a reduction effect on the 7:12 and 5:12 roof tiles. However, for the 2:12 roof slope, the 
combined effect caused an increased suction pressure on the roof tile since both were in the same direction. It was also observed that both the external and underneath pressures on the leeward side were negative for all the tests performed. This has caused a more or less insignificant pressure coefficient on the leeward side of the roof.

The impact of weather blocking on internal pressure underneath tile was also investigated. Even though weather blocking of the roof perimeter using mortar or foam was effective in preventing wind driven rain, it didnt play a significant role in minimizing the stress on the roof tiles as a result of the internal pressure underneath tile. As shown in Figure 6.16, a comparison between weather blocked and non-weather blocked roof tiles of all types was done. It was observed that the external pressure difference between the two ( $W B$ vs $N W B$ ) was dominantly insignificant. However, the positive internal pressure

underneath the tile with weather blocking was higher than that when it is non-weather blocked but not that significant to cause drastic change on the net roof pressure. One should be aware that the weather blocking was used only on the edges of the roof field tile as well as at the intersection of the field and ridge tile. However, the openings which were the sources of internal pressure were all over the roof deck where the field tiles are laid (i.e., overlap opening) and the edges (i.e., edge opening). Thus, even though the edges get sealed with weather blocking material, a significant part of the roof was left open causing the intrusion of air underneath the tile.

\subsection{Proposed mitigation}

From observation of the experimental analysis, it was shown that the probable failure initiation on a low-rise gable building was found to be the ridge edge at the gable 
end. A very high suction pressure coefficient was measured in both the barrel type and three-sided ridge tile for the different roof slopes tested. These critical suction pressures could be the causes for the onset of roof tile failure. To address the above stated problems, the following two structural mitigations were suggested: metal angle anchor and FRP fixed to the gable end starting at the ridge tile (Figure 6.17). Initial investigation showed that the metal angle mitigation method increased the uplift resistance of the ridge tile by $146 \%$. The methods also keep the aesthetic value of the ridge on the roof.

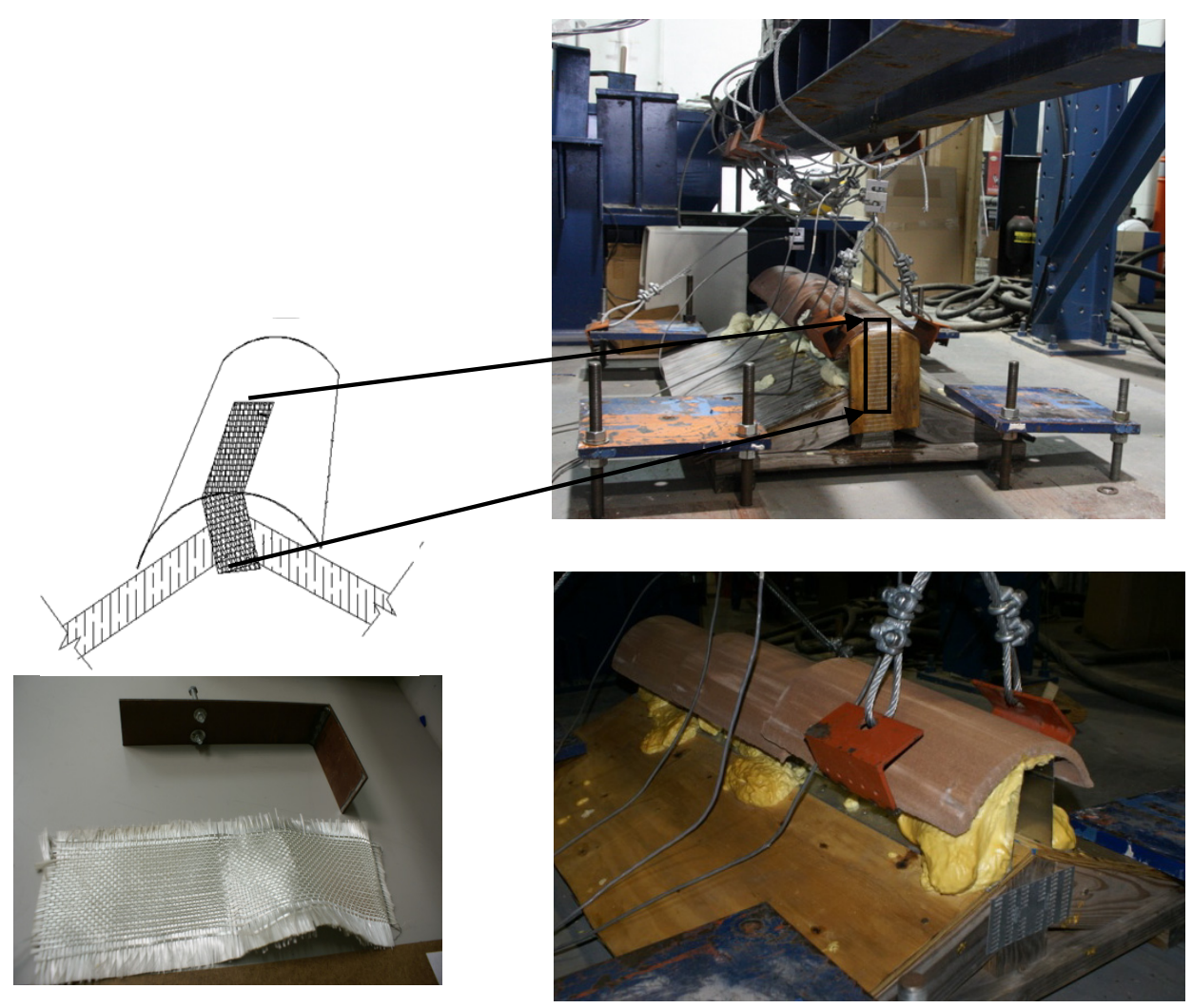

Figure 6.17: Metal angle and FRP mitigation techniques. 


\subsection{Conclusion}

A full scale aerodynamic assessment of field and ridge tiles with variable profiles and slopes was carried out. The external pressures on the roof surface as well as the "internal pressure" underneath the tiles were analyzed in detail to better understand the tile aerodynamics both with weather block and no-weather block conditions. The coefficient of pressure on field and ridge tiles were evaluated for five wind angles of attack (i.e., $0^{\circ}, 30^{\circ}, 45^{\circ}, 75^{\circ}, 90^{\circ}$ ). It was observed that the $30^{\circ}$ and $45^{\circ}$ wind $A o A$ on the edge ridge tile and $0^{\circ}$ wind $A o A$ on the corner field tile produced the highest suction pressure for the three roof slopes examined both with weather block and no-weather block conditions. Generally, the coefficients of pressure at the corner and gable end ridges of the roof were significantly high. Relatively, the gable end ridge pressure was

obtained to be considerably higher than the corner field tile explaining why failures initiate at these locations as observed in recent post damage assessments. The contribution of internal pressure underneath the roof deck was observed to be significant wherein which it dampens the net suction pressure along the windward side but magnifies that on the leeward side. Aerodynamically, the high profile roof tile performs well over the field, but because of its deep valley, it causes the formation of considerable suction pressure on the ridge tile. The surface geometry of the individual tile was observed to have a significant impact on both the external pressure on the roof surface as well as the internal pressure underneath the roof deck.

\section{Acknowledgments}

The financial support from Florida Department of Emergency Management $(F D E M)$ to carry out this project is gratefully acknowledged. The help received from the 
roofing industry representatives namely Bob Ferrante (Polyfoam Products Inc.), Mike Fulton (O'Hagin Vents), Tim Gabroski (Tim Gabroski Roofing Inc.), Manuel Oyola (Eagle roofing products Florida LLC), Tom Castellanos (East Coast Metals), and Riku Ylipelkonen (Polyfoam Products Inc.) throughout the project execution both in terms of sharing their experience, installing the tiles on the roofs and donating raw-materials is greatly appreciated. We acknowledge the help received from FIU graduate students Edward Ledesma, Francis Bain, Asmerom Hagos, and undergraduate research assistants Hugo Altimari. Last but not least we acknowledge the help received from our WoW lab manager Walter Conklin and WoW Research Scientists Roy Liu, James Erwin, and Aly Mousaad Aly.

\subsection{References}

Series "Factory Mutual Research Corporation (FM)1985. Factory Mutual Property Loss Prevention Data Sheet 1-49 - Perimeter Flashing."

Banks, D. and Meroney, R.N. (2001). "A model of roof-top surface pressures produced by conical vortices: Model development." journal of Wind Engineering and Industrial Aerodynamics 4-3: 227-246.

Bitsuamlak, G.T., Dagnew, A. and Chowdhury, A. (2009). "Computational assessment of blockage and wind simulator proximity effects for a new full-scale testing facility." Wind and structures. In press.

Cochran, L.S. and Cermark, J.E. (1992). "Full-and model-scale cladding pressures on the Texas Tech Experimental Building." journal of Wind Engineering and Industrial Aerodynamics 43: 1589-1600.

Cochran, L.S., Levitan, M.L., Cermark, J.E. and Yeatts, B.B. (1993). Geometric Similitude Applied to Model and Full-Scale Pressure Tap sizes. 3rd Asia-Pacific Symp on Wind Eng. 917 922, HK.

Cutter, S.L., Johnson, L.A., Finch, C. and Berry, M. (2007). "The US Hurricane Coasts: Increasingly Vulnerable?" Environment 47(7). 
Gerhardt, H.J. and Kramer, C. (1992). "Effects of building geometry on roof wind loading." journal of Wind Engineering and Industrial Aerodynamics 43: 1765-1773.

Huang, P., Mirmiran, A., Chowdhury, A.G., Abishdid, C. and Wang, T. (2009). "Performance of Roof Tiles under Simulated Hurricane Impact." Journal of Architectural Engineering, ASCE 15(1): 26-34.

Kawai, H. and Nishimura, G. (1996). "Characteristics of fluctuating suction and conical vortices on a flat roof in oblique flow." Journal of Wind Engineering and Industrial Aerodynamics 60: 211-225.

Kramer, C. and Gerhardt, H.J. (1989). Wind pressures on roofs of very low and very large industrial buildings. Proc. 8th Colloq. on Industrial Aerodyn. Part 2. Aachem, Germany.

Lin, J.X. and Surry, D. (1998). "The Variation of Peak Loads with Tributary Area near Corners on Flat Low Building Roofs." Journal of Wind Engineering and Industrial Aerodynamics 77-78: 185-196.

Lin, J.X., Surry, D. and Tieleman, H.W. (1995). "The distribution of pressure near roof corners of flat roof low buildings." Journal of Wind Engineering and Industrial Aerodynamics 56: 235-265.

Lott, N. and Ross, T. (2006). "Tracking and Evaluating U.S. Billion Dollar Weather Disasters, 1980-2005. Forum on Environmental Risk and Impacts on Society: Successes and Challenges." American Meteorological Society.

Mehta, K.C. and Levitan, M.L. (1992). "Roof corner pressures measured in the field on a low building." journal of Wind Engineering and Industrial Aerodynamics 41: 181-192.

Mirmiran, A. (2006). "Hurricane Loss Reduction for Housing in Florida: Section 5Performance of Tile Roofs under Hurricane Impact - Phase I." Retrieved June 10, 2010, from http://www.ihrc.fiu.edu/lwer/docs/ Year6_Section5_TileTest_RCMPY6.pdf.

Mirmiran, A., Wang, T., Abishdid, C., Huang, P., Jiménez, D.L. and Younes, C. (2007). "Hurricane Loss Reduction for Housing in Florida: Performance of Tile Roofs under Hurricane Impact- Phase II." Retrieved June 11, 2010, from http://www.ihrc.fiu.edu/lwer/docs/Year7_Section5_Tiles_RCMPY7.pdf.

Rappaport, E.N. (2000). "Loss of Life in the United States Associated with Recent Tropical Cyclones." Bulletin of the American Meteorological Society 81(9): 2065-2074.

Robertson, A.P., Hoxey, R.P., Rideout, N.M. and Freathy, P. (2007). "Full-scale study of wind loads on roof tiles and felt underlay and comparisons with design data." wind and structures 10(6): 495-510. 
Saathoff, P.J. and Melboume, W.H. (1989). "The generation of Peak Pressures in Separated/Reattaching Flows." Journal of Wind Engineering and Industrial Aerodynamics 32: 121-134.

Sparks, P.R., Schiff, S.D. and Reinhold, T.A. (1994). "Wind damage to envelopes of houses and resulting insurance losses." 53: 145-155.

Stathopoulos , T. (1987). Wind pressures on flat roof edges and corners. Proc. 7th Int. Conf. on Wind Eng. Aachen, Germany.

Stathopoulos, T., Baskaran, A. and Goh, P.A. (1990). "Full-scale measurmeents of wind pressures on flat roof corners." Journal of Wind Engineering and Industrial Aerodynamics 36: 1063-1072.

Tieleman, H.W., Surry, D. and Lin, J.X. (1994). "Characteristics of mean and fluctuating pressure coefficients under corner (delta wing) vortices." Journal of Wind Engineering and Industrial Aerodynamics 42: 263-275.

FM 4470: Approval Standard for Class 1 Roof Covers (1986)

Institute of Business and Home Safety (IBHS) (1999[1]):, "Metal Edge Flashing", Natural Hazard Mitigation Insights. No.10, June 1999, USA

Institute of Business and Home Safety (IBHS) (1999[2]):, "Performance of Metal Buildings in High Winds", Natural Hazard Mitigation Insights. No.9, January 1999, USA

Institute of Business and Home Safety (IBHS) (2009):, "Hurricane IKE:Nature's Force Vs Structural Strength”, Natural Hazard Mitigation Insights. No.9, January 1999, USA

UL 1897: Standard for Uplift Tests for Roof Covering Systems (2004) 


\title{
7. COMPUTATIONAL EVALUATION AND VALIDATION OF INTERNAL AND EXTERNAL PRESSURE FOR LOW-RISE BUILDING
}

\author{
Amanuel S. Tecle ${ }^{a}$, Teshome E. Jiru', Girma T. Bitsuamlak ${ }^{\mathrm{c}}$ \\ Presented at Fifth International Symposium on Computational Wind Engineering \\ (CWE2010) Chapel Hill, North Carolina, USA May 23-27, 2010
}

\begin{abstract}
Renormalization Group $k-\varepsilon$ turbulence model predictions of internal $\left(C p_{i}\right)$ and external $\left(C p_{e}\right)$ pressure coefficients are presented for a low-rise model building $(2.74 \mathrm{~m} \mathrm{~W}$ x $2.13 \mathrm{~m} L \times 2.13 \mathrm{~m} H$ ) with gable roof (slope 1:3), for wind angles of attack of $45^{\circ}$ and $90^{\circ}$. A parallel experimental study of full-scale low-rise buildings with dominant openings (specifically case studies of windward door (case 1) and window(case 2) openings with $7.5 \%$ and $3.75 \%$ porosity respectively) and a ceiling compartment with a hatch opening, which separates the attic from the living room was performed in FIU's Wall of Wind. Comparisons between the numerical and experimental results show that internal pressure coefficients obtained through $C F D$ modeling are comparable to those obtained experimentally. The agreement was less satisfactory for the external pressure coefficients. In addition to wind load applications, the results from the present study can be useful for natural ventilation applications.
\end{abstract}

Keywords: Internal pressure, dominant opening, $C F D$, low-rise building

\subsection{Introduction}

Low rise-buildings are immersed within the atmospheric boundary layer where turbulence intensities are high (Holmes, 2001). In addition to the fluctuations of the oncoming wind, the complex interaction of wind with the buildings themselves lead to 
further fluctuations in the form of vorticity in the separated flow regions near sharp corners, roof eaves and ridges, causing unsteady pressure both internally and externally. Design wind load on roofs, windows, doors, and walls are a combination of external and internal pressures. Internal pressure can contribute to a significant portion of the total design wind load (Simiu and Scanlan 1996, Irwin and Sifton 1998, Holmes 1979; Stathopoulos et al 1979; Sharma and Richards 2003 \& 2005) depending on the opening size and location, shape of the building and other aerodynamic factors. Understanding the basic characteristics of internal pressure and how it is affected by different aerodynamic factors is thus essential to the proper design of the main wind force resisting systems, cladding and components (Davenport and Surry, 1984).

Wind-induced loads are influenced by several factors such as building geometry, surrounding buildings, upstream terrain, and dominant openings. Internal pressure measurements are more difficult than those of external pressure (Liu 1990). The internal pressure is affected by additional factors such as background leakage, size and location of openings such as doors and windows, partitioning and ventilation openings (such as soffit, gable end, ridge, roof vents), and the structure's flexibility (Holmes 1979; Stathopoulos et al. 1979; Liu \& Saathoff 1982 and 1983; Vickery 1986; Vickery and Bloxham 1992; Sharma et al. 2003, Oh et al. 2007). Studies by Guha et al. (2009) and Meroney (2009) employed experimental and computational approaches to study internal and external pressure on buildings. Guha et al. (2009) studied characterization of flow through openings on the Texas Tech University building. Computational simulation results obtained for the internal pressure responses of this test showed that the Helmholtz frequency matches the analytical solution. Meroney (2009) also applied turbulence 
models using whole-domain and domain decomposition approaches to study natural ventilation and verified the results using Karava's (2008) wind tunnel data. Considerably more work has been performed on external pressure employing boundary layer wind tunnels $(B L W T)$ and $C F D$ modeling.

Most studies have been conducted at small scale, where matching of opening sizes and internal volume scaling can be a challenge. This paper presents $C F D$ simulation results and its comparison with experimental pressure coefficient data obtained from large-scale testing at FIU's $W O W$ test facility for a low rise building with gable roof in the presence of dominant openings and volume compartmentalization (ceiling) in high Reynolds number flows.

\subsection{Methodology}

\subsubsection{Wall of Wind (WoW) experiment}

The $W o W$ experimental apparatus is composed of six fans which can generate a $24 \mathrm{ft}$ wide and $16 \mathrm{ft}$ high wind-field engulfing a small size full-scale low-rise building (Figure 7. 1). The description of the $W o W$, velocity profile and turbulence generation methods and previous work carried out at the Wall of Wind can be found at (Huang et al. 2009, Gan Chowdhury et al. 2009, Bitusamlak et al. 2009, Bituamlak et al. 2010, Yu et al. 2008). The present study was carried out at mean wind speed of $\sim 21 \mathrm{~m} / \mathrm{s}$ at eave level ( $2.13 \mathrm{~m}$ from the ground) and turbulence intensity of $\sim 25 \%$. The $W o W$ test building has been constructed following the existing Florida construction guidelines (Figure 7.2) and the background leakage of the building is $2.76 \times 10^{-4}$ as measured by Door Blower Test (Figure $7.2 \mathrm{c}$ ). The building has two dominant openings: a door with size $1.07 \mathrm{~m}$ by $0.46 \mathrm{~m}$ 
( $7.5 \%$ porosity) and a window with size $0.52 \mathrm{~m}$ by $0.43 \mathrm{~m}$ ( $3.75 \%$ porosity). The internal volume of the building was divided into two compartments (attic and living room) at the ceiling level by a wood panel. A square hatch opening $(0.46 \mathrm{~m} \times 0.46 \mathrm{~m})$ connected the attic with the living room. The main objective of the experimental study was to evaluate the internal and external pressure coefficients on the building envelope for various openings. In this paper only door opening (case 1) and window opening (case 2) both with a hatch opening at ceiling partition are considered. The pressure was measured with pressure taps placed at aerodynamically important locations on the building envelope (Figure 7.3a). The measurements of internal pressure inside the gable building model were carried out by using ten transducers uniformly distributed inside the interior of the building. A total of 5 test cases were performed. All of the five cases were tested for angles of attack of $0^{\circ}, 15^{\circ}, 45^{\circ}, 75^{\circ}$, and $90^{\circ}$.

\subsection{Numerical modeling and simulation}

The commercial software FLUENT 6.3 was utilized for the numerical simulation. The governing equations were the Reynolds Averaged Navier-Stokes (RANS) equations, together with the Renormalization Group $(R N G) \mathrm{k}-\varepsilon$ turbulence model.
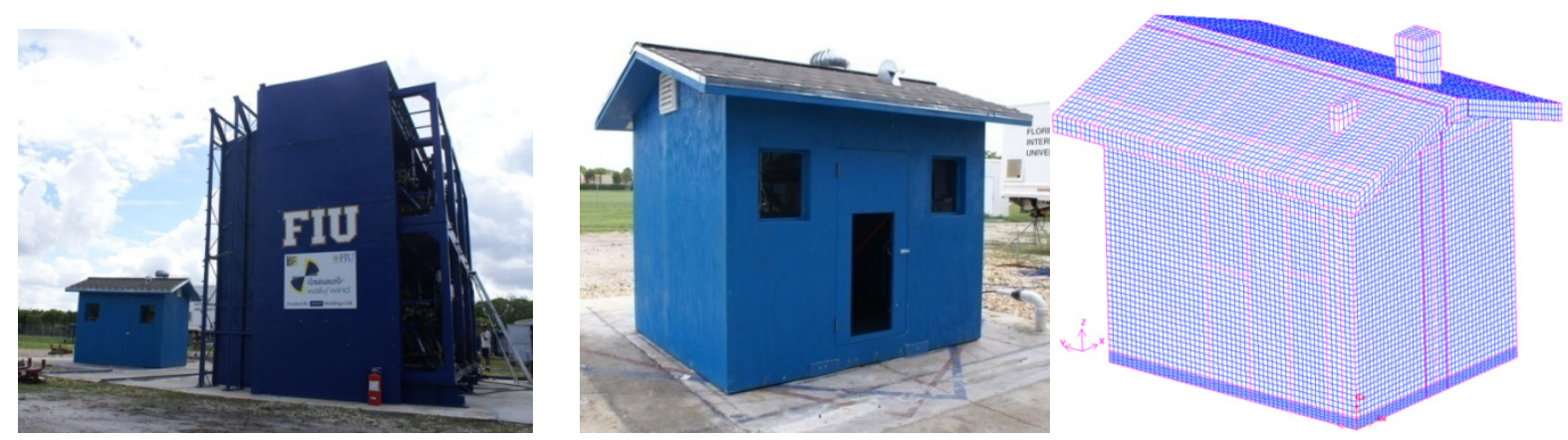

Figure 7.1: Low-rise building with gable roof in testing position, and CFD model. 

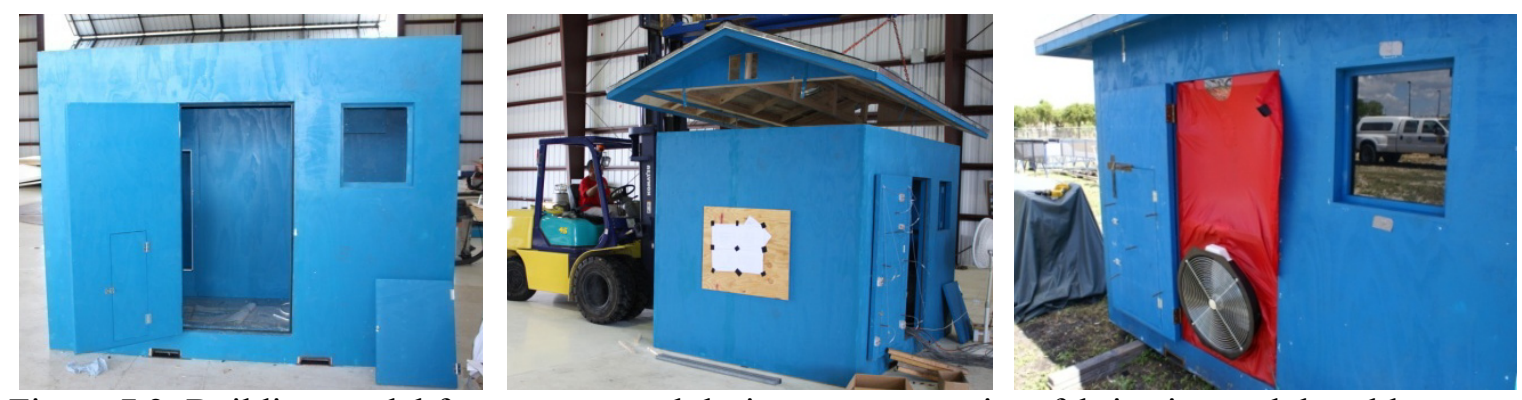

Figure 7.2: Building model from conceptual design to construction, fabrication and door blower test for porosity.
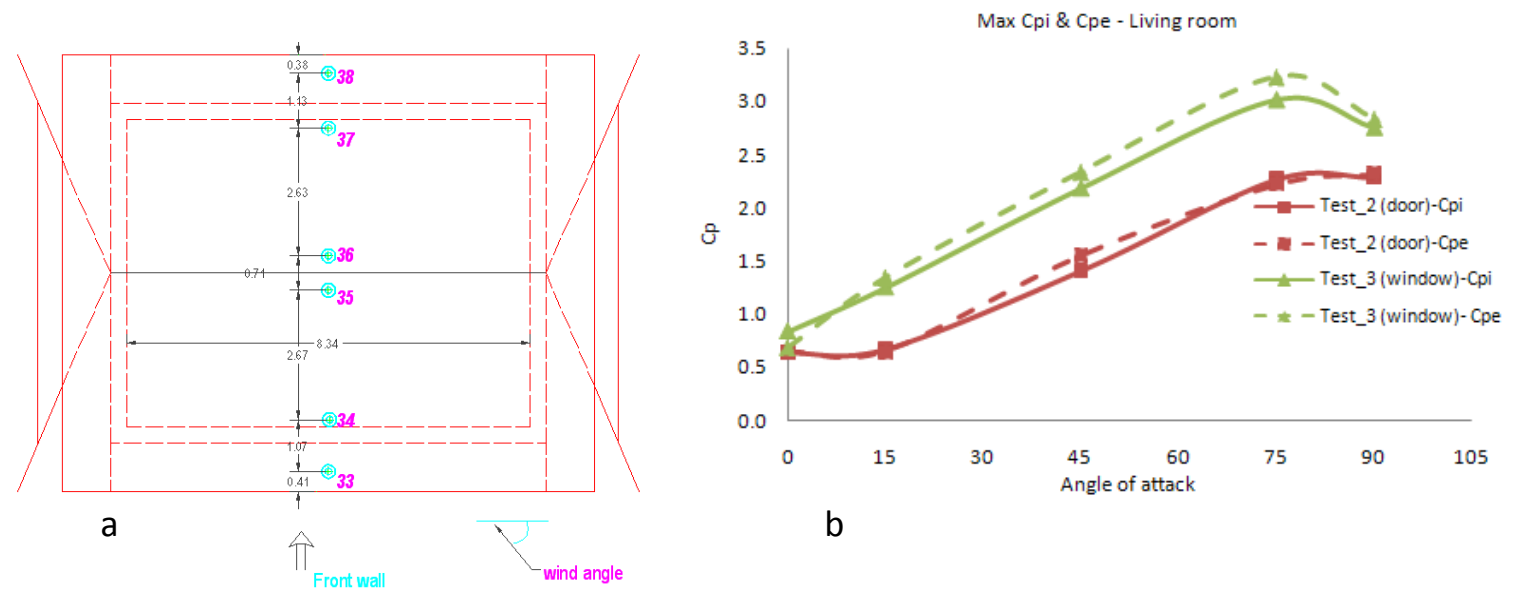

b

Figure 7.3: a) Roof external pressure tap location, b) maximum internal and external $\mathrm{Cp}$ correlation

The computational domain $(C D)$ was delineated using the Height $(H)$ of the model building as a reference. The $C D$ was extended vertically $5 \mathrm{H}$ above the roof of the model building, and laterally $5 H$ from the walls. In the flow direction, the $C D$ was extended $5 H$ from front wall to the inflow boundary and $15 H$ from the back wall to the outflow boundary. The latter allows the flow re-development behind the wake region. The $C D$ consisted of 1.8 million hexagonal and tetrahedral shaped cells. For wall bounded flow, Fluent 6.3 provided two different approaches for modeling flows in the inner viscous layer, i.e. use of wall functions or near-wall modeling based on non- 
dimensional wall units. The first grid point was placed at $0.038 \mathrm{~m}$ from the surface of the test specimen and unstructured grids were used for the $C F D$ simulation (Figure 7.1). Due to the computational cost in resolving the inner layer, standard wall functions were employed in all present simulations by maintaining the non-dimensional wall unit denoted by $\mathrm{y}^{+}$between 30 and 500 . In addition, the measured inlet velocity profile, turbulence intensity $T I=25 \%$ and a $15 \mathrm{~m}$ integral length scale were applied to the whole upstream face of the computational domain. A segregated pressure-velocity solver was used in all the discretization schemes. Pressure interpolation was standard and second order upwind schemes were used. The convergence criterion was limited to $10^{-6} . C_{p i}$ and $C_{p e}$ values extracted from the $C F D$ simulation were compared with data from full-scale Wo $W$ experimental results.

\subsection{Results and discussion}

\subsection{Experimental study of internal and external pressure using WOW}

In this section only the results for wind angle of attack of $45^{\circ}$ and $90^{\circ}$ are presented and compared with those of the $C F D$ modeling. The location of roof external pressure taps used for comparison of experiment and $C F D$ modeling are shown in Figure 7.3a. The results (Figure 7.3b) show that the coefficient of internal pressure $\left(C_{p i}\right)$ reached peak values when the wider face of the building was at $75^{\circ}$ to the direction of the wind flow.

As shown in Figure 7.3b, the instantaneous response of the internal pressure to the area averaged external pressure over the dominant openings (door and window) are closely correlated consistent with previous works done by Kopp et al. (2008). WoW data was compared as shown in Figure 7.4. 

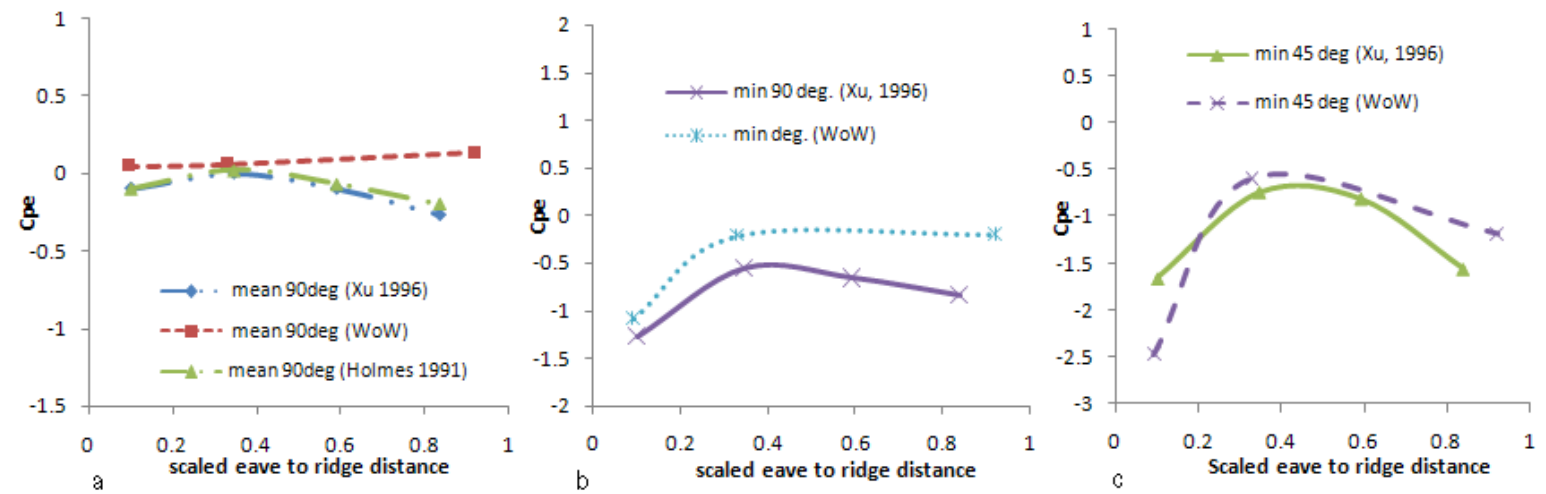

Figure 7.4: WoW vs literature data comparison of roof external pressure coefficient: a) mean $90^{\circ}$, b) $\min .90^{\circ}$ and c) $\min 45^{\circ}$.

The rms, mean, maximum and minimum internal and external pressure coefficients are shown in Figures 7.5-7.6, respectively, for both $45^{\circ}$ and $90^{\circ}$ angles of attack.

\subsection{CFD simulation and validation}

Figures 7.7 and 7.8 show the flow fields in a vertical mid-plane and a horizontal plane at $1 \mathrm{~m}$ above the ground for $90^{\circ}$ and $45^{\circ}$ angles of attack. The $R N G k$ - $\varepsilon$ turbulence model captured the flow separation at the back and recirculation region around the building. The flow field and the formation of vortices in the wake region were symmetrical for the $90^{\circ}$ angle of attack in the horizontal plane. The flow field was asymmetrical for the $45^{\circ}$ angle of attack especially in the wake region, which was divided into a small and large recirculating vortex. Figure 7.9 shows the distribution of the external pressure coefficient $\left(C_{p e}\right)$ on the surface of the building for $90^{\circ}$ and $45^{\circ}$ angles of attack. As expected, the $C_{p e}$ was positive on the wind ward surfaces (front wall for $90^{\circ}$ angle of attack and front and right walls for $45^{\circ}$ angle of attack). The local effects from the goose neck and turbine vents were also captured by the $C F D$ simulation. The comparisons of the $C F D$ predicted pressure coefficients for external $\left(C_{p e}\right)$ and internal $\left(C_{p i}\right)$ are depicted in Figure 7.10. 

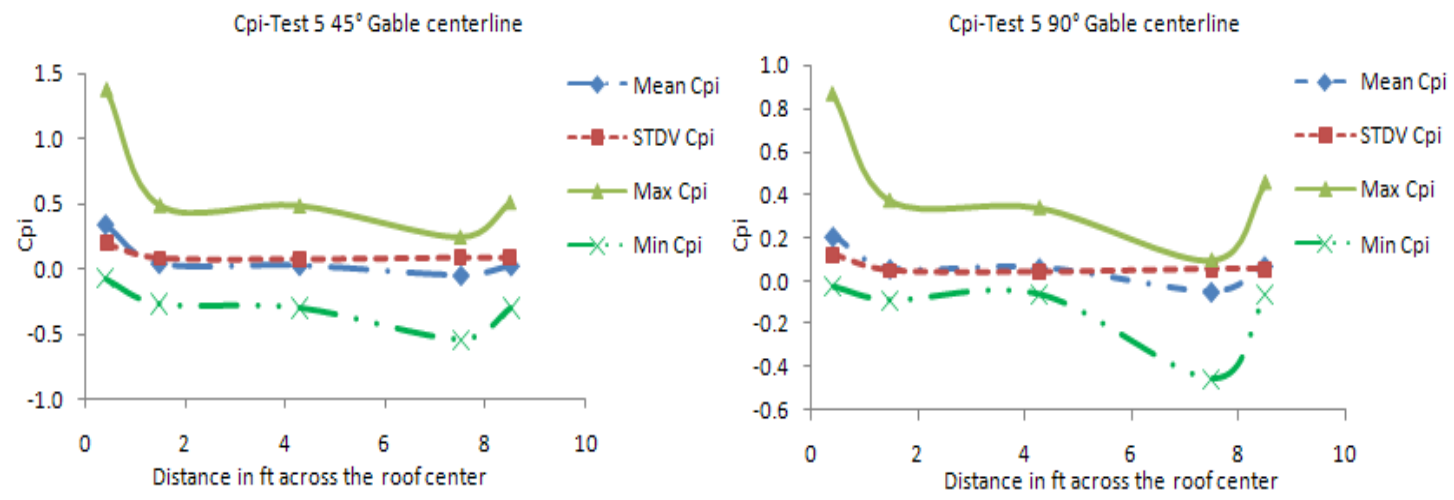

Figure 7.5: Experimental roof internal pressure coefficient at $45^{\circ}$ and $90^{\circ}$ angles of attack.
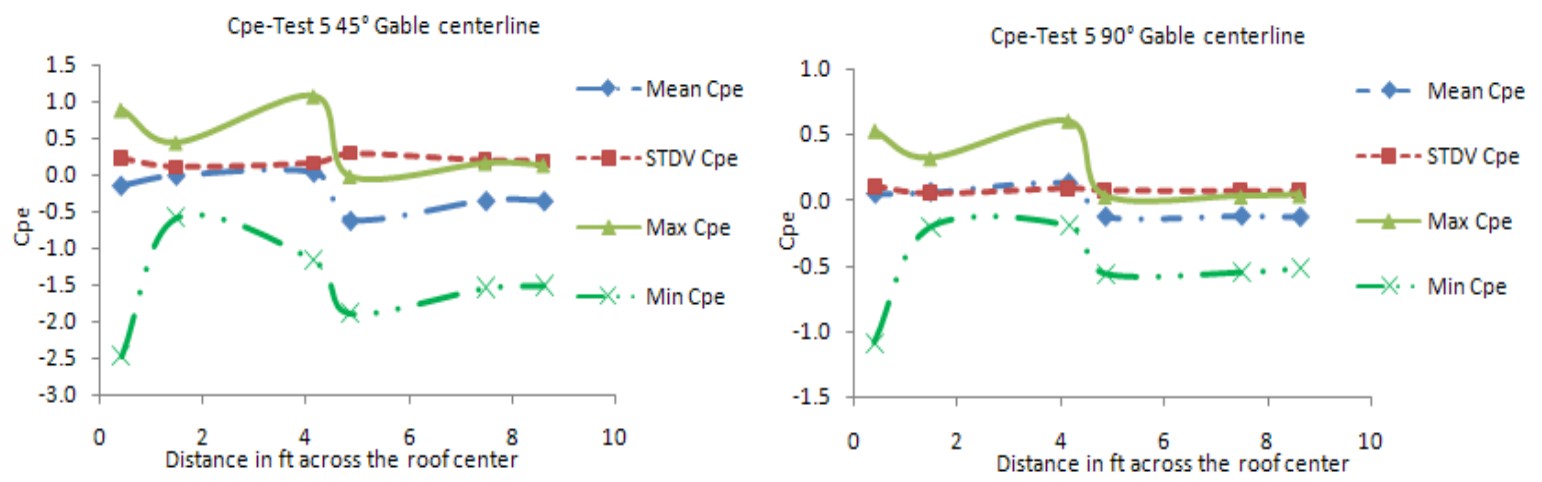

Figure 7.6: Experimental roof external pressure coefficient at $45^{\circ}$ and $90^{\circ}$ angles of attack.

Generally, there was better agreement between $C F D$ predicted and measured $C_{p i}$ values than for $C_{p e}$ values. This was attributed to the complex flow conditions externally, which affect the performance of the $R N G k-\varepsilon$ models. 

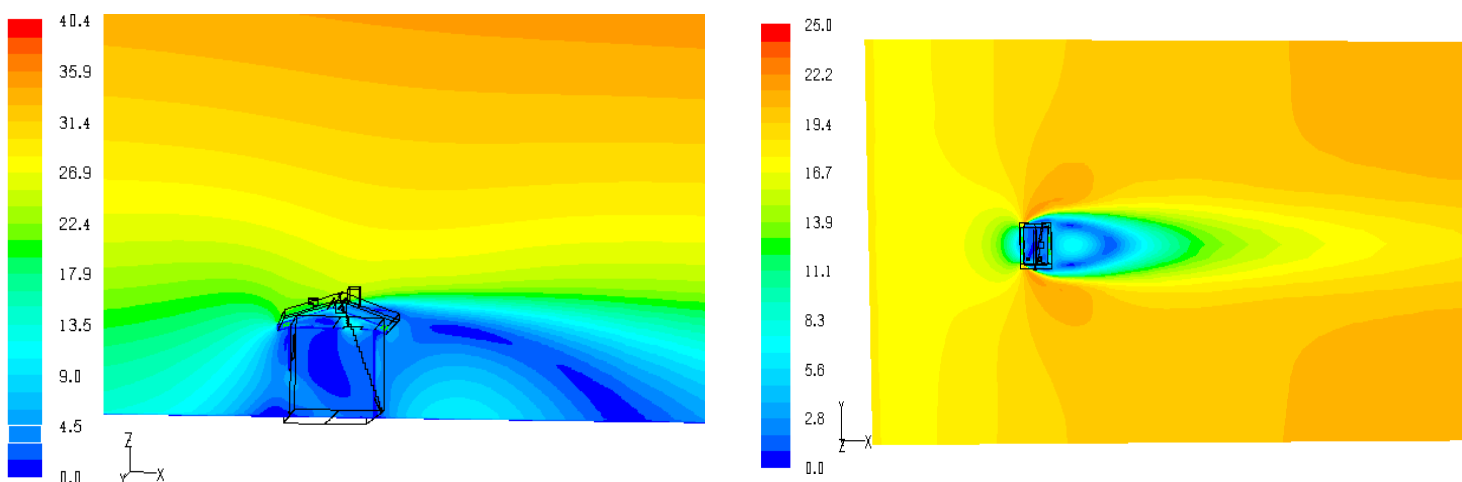

Figure 7.7: Velocity flow field vertical plane at mid-section and horizontal plane at $1 \mathrm{~m}$ high for $90^{\circ}$ angle of attack.
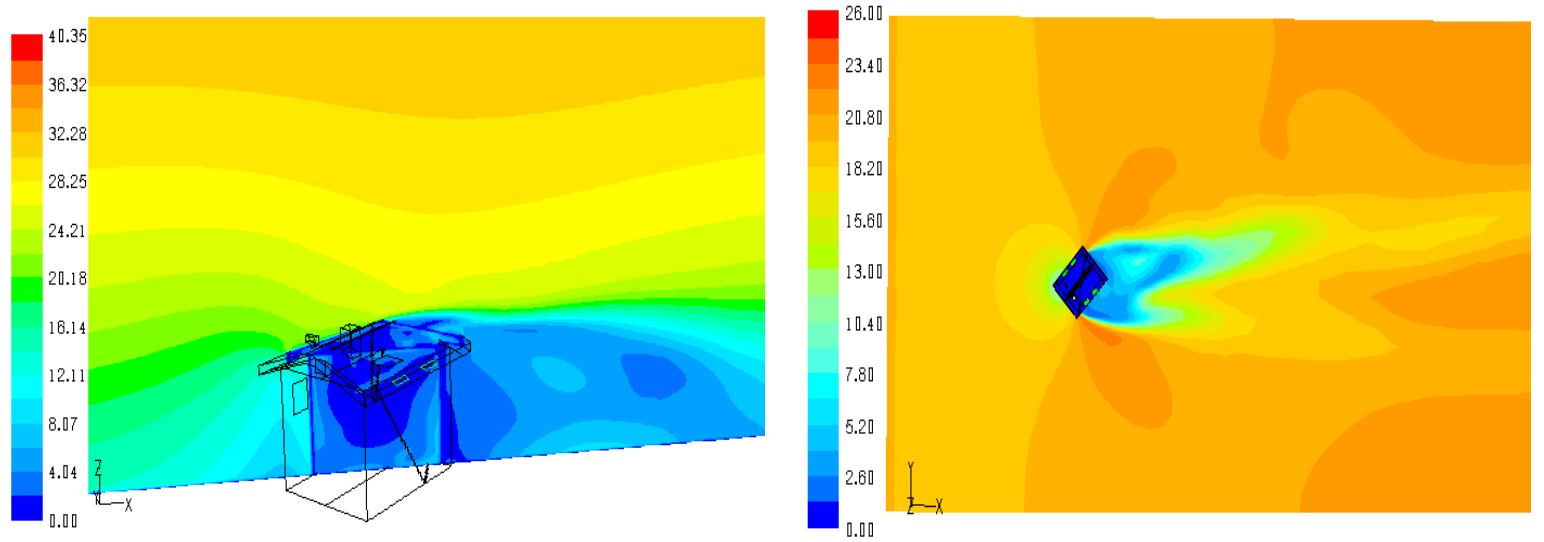

Figure 7.8: Velocity flow field vertical plane at mid-section and horizontal plane at $1 \mathrm{~m}$ height for $45^{\circ}$ angle of attack.
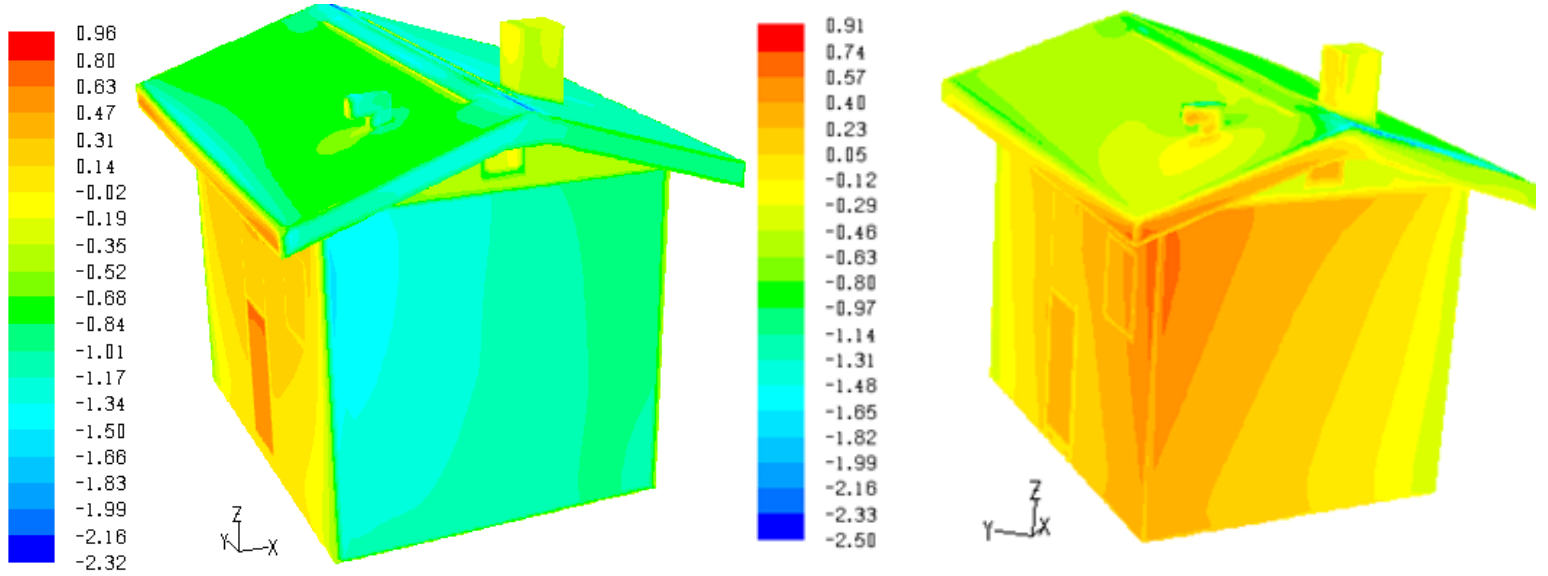

Figure 7.9: Mean roof external pressure coefficient for $90^{\circ}$ and $45^{\circ}$ angle of attack. 

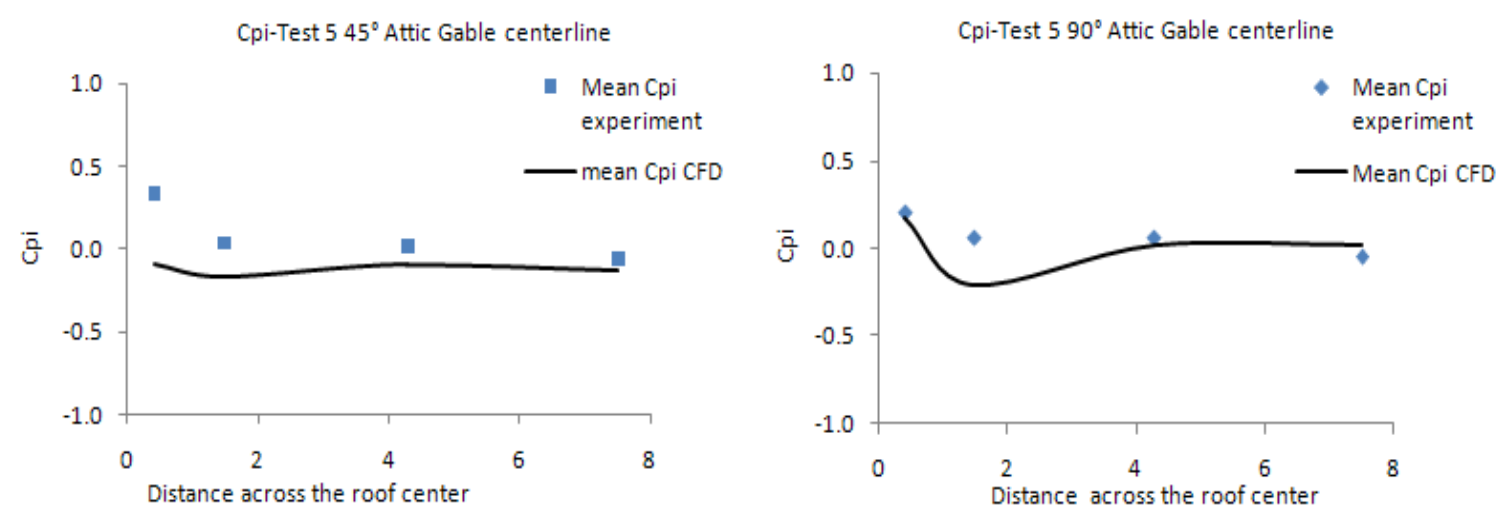

Figure 7.10: Experimental versus CFD roof centerline internal pressure comparison.
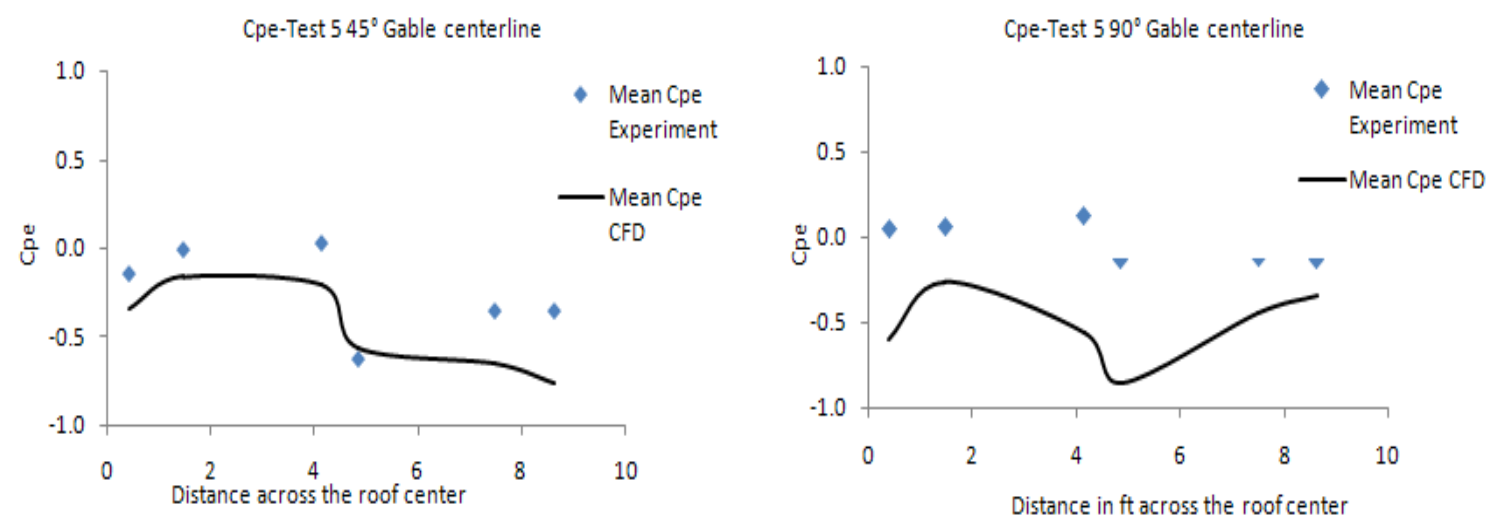

Figure 7.11: Experimental versus $C F D$ roof centerline external pressure coefficients comparison.

\subsection{Conclusions}

This is paper has demonstrated a comparison of experimental and CFD computed external and internal pressure coefficients for large scale low rise building model in the presence of a dominant opening in the windward direction. The building model has also a ceiling (with open hatch) that separates the living room from attic and ventilation systems (soffit, ridge vent, turbine and gooseneck at roof level) were installed on the gable roof. $R N G k$ - $\varepsilon$ turbulence model predicted $C_{p i}$ values were in better agreement compared to the $C_{p e}$ values. 


\section{Acknowledgements}

This material is based in part upon work supported by the National Science Foundation CAREER project under Grant Number 0846811, the Florida Department of Emergency Management and the Florida Center Excellence grants. Any opinions, findings, and conclusions or recommendations expressed in this material are those of the author(s) and do not necessarily reflect the views of the National Science Foundation or the Florida Department of Emergency Management.

\subsection{References}

Bitsuamlak, G., Gan Chowdhury, A., Sambare, D. (2009). "Application of a Full-Scale Testing Facility for Assessing Wind-Driven-Rain Intrusion.” Building and Environment, 44 (12), pp. 2430-2441.

Bitsuamlak, G.T., Dagnew, A., Gan Chowdhury, A. (2009). "Computational blockage and wind sources proximity assessment for a new full-scale testing facility." Wind and Structures, 13(1), 21-36.

Blessing, C., Gan Chowdhury, A., Lin, J., Huang, P (2009). "Full-Scale Validation of Vortex Suppression Techniques for Mitigation of Roof Uplift." Engineering Structures, 31 (12), pp. 2936-2946.

Davenport, A.G., Surry, D. (1984). "The estimation of internal pressures due to wind with application to cladding pressures and infiltration," Proc., Wind pressure workshop, Brussels, Belgium.

Gan Chowdhury, A., Huang, P., Erwin, J. (2009). "Aerodynamic Testing Application of a Full-Scale Facility for Mitigating Hurricane-Induced Coastal Disasters.” Far East Journal of Ocean Research, 2 (1), pp. 1-27.

Gan Chowdhury, Bitsuamlak, G., Emil Simiu, (2010). "Aerodynamic, hydroaerodynamic, and destructive testing." Journal of the Institution of Civil Engineers, in press.

Guha, T.K., Sharma, R.N., Richards, P.J. (2009). “Analytical and CFD modeling of transient internal pressure response following a sudden opening in building/cylindrical 
cavities." In: Proceedings of $11^{\text {th }}$ Americas Conference on Wind Engineering-San Juan, Puerto Rico.

Holmes, J.D. (1979). "Mean and fluctuating internal pressure characteristics of low-rise buildings due to wind action," in: Proceedings of the 5th Int. Conf. on Wind Engineering, 1, 435-550 Colorado, USA.

Holmes, J.D. (2001). Wind loading of structures, Spon Press, New York.

Huang, P., Gan Chowdhury, A., Bitsuamlak, G., Liu, R. (2009). "Development of Devices and Methods for Simulation of Hurricane Winds in a Full-Scale Testing Facility", Wind and Structures, 12 (2), pp. 151-177.

Irwin, P.A., Sifton, V.L. (1998). "Risk Considerations for internal pressures." Journal of Wind Engineering and Industrial Aerodynamics, 77 \& 78, $715-723$.

Karava, P. (2008). "Airflow prediction in buildings for natural ventilation design: Wind tunnel measurements and simulations." Ph.D. Thesis, Dept. of Building, Civil and Environmental Engineering, Concordia University, Montreal Quebec, Canada.

Kopp, G. A., Oh, J.H., Inculet, D.R. (2008). "Wind-induced internal pressures in houses." Journal of Structural Engineering, 134, 1129-1138

Liu, H. (1990). Wind Engineering: A handbook for structural engineers. Prentice Hall, Upper Saddle River, New Jersey, USA.

Liu, H., Saathoff, P.J. (1982). "Internal pressure and building safety" J. Structural Division, ASCE, 108(10), 2223-2234

Liu, H., Saathoff, P.J. (1983). "Internal pressure of multi-room buildings.” ASCE Journal of Engineering Mechanics Division, 109, EM3, 908-919.

Meroney, R.N. (2009). "CFD prediction of airflow in buildings for natural ventilation." In: Proceedings of $11^{\text {th }}$ Americas Conference on Wind Engineering-San Juan, Puerto Rico.

Oh, J. H., Kopp, G.A., and Inculet, D.R. (2007). "The UWO contribution to the NIST aerodynamic database for wind loads on low buildings. 3: Internal pressures." Journal of Wind Engineering and Industrial Aerodynamics, 95(8), 755-779

Sharma, R.N., Richards, P.J. (2003). "The influence of Helmholtz resonance on internal pressures in a low-rise building." Journal of Wind Engineering and Industrial Aerodynamics. 91, 807-828. 
Sharma, R.N., Richards, P.J. (2005). "Net pressure on the roof of a low-rise building with wall openings." Journal of Wind Engineering and Industrial Aerodynamics 93, 267-291.

Simiu, E., Scanlan, R.H. (1996). Wind effects on structures (3 ed.). John Wiley \& Sons Inc, New York (US).

Stathopoulos ,T., Surry, D., Davenport, A.G. (1979). Internal pressure characteristics of low-rise buildings due to wind action, in: Proceedings of the $5^{\text {th }}$ International Conference on Wind Engineering, Fort Collins, Colorado, Pergamon Press, New York, 451-463

Vickery, B.J. (1986). “Gust factors for internal pressures in a low rise buildings.” Journal of Wind Engineering and Industrial Aerodynamics, 23, 259-271.

Vickery, B.J., Bloxham, C. (1992). "Internal pressure dynamics with a dominant opening." Journal of Wind Engineering and Industrial Aerodynamics. 41, 193-204.

Yu, B., Gan Chowdhury, A., Masters, F.J. (2008). "Hurricane Power Spectra, CoSpectra, and Integral Length Scales”. Boundary Layer Meteorology, 129, pp. 411-430. 


\section{SUMMARY AND CONCLUSIONS}

The present study carried out a systematic multi-scale experimental parametric evaluation of wind-induced internal pressure $(I P)$ through experimentation at full scale in the $W o W$ and at small-scale in the $B L W T$. The study investigated peak IP loading in low rise buildings with different roof shapes for variable location and size of dominant openings, vents and background leakage, assessed effects of sudden breach of dominant openings on $I P$ in comparison with steady state conditions; performed a comparative assessment of the significance of correct internal volume scaling on the statistical characteristics of $I P$ in a $B L W T$ model through studies with and without volume correction; analyzed realistic compartmentalization effects on $I P$ for both wind-resistant design of low rise buildings and wind driven cross-ventilation applications; investigated the aerodynamic performance of three types of roof tiles (both ridge and field tiles) focusing on $I P$ beneath (i.e., underneath pressure) the tiles; and performed computational evaluation of $I P$ for low-rise buildings using $C F D$ simulations and compared the results with experimental data to assess their suitability for such applications.

The major findings/contributions of this work in the characterization of $I P$ for wind resistant design of low-rise buildings are summarized below for the case of a building envelope with existing openings:

- The location of dominant openings with respect to the upstream wind direction influences the characteristics of the IP considerably. An opening located off-center exhibits a higher peak positive and suction pressure coefficient than its equivalent dominant opening located at the center wall. A window with $3.75 \%$ porosity located 
at the right windward wall corner exhibited $30-40 \%$ peak positive and suction $I P$ compared to that of a centrally located door with $5 \%$ porosity. For critical loading, the location of the dominant opening with respect to upstream wind direction is highly significant compared to the porosity size. The present study also reaffirmed the common observations in literature that wind-induced internal pressure is highly correlated to the external pressure variation at the dominant openings.

- Compartmentalization (i.e., ceiling partition and multi-room partitioning) plays a significant role in internal pressure dynamics. For instance, the opening of a hatch having $0.4 \%$ of the attic floor area at the ceiling level, coupled with a door opening of $7.5 \%$ porosity, increased the internal pressure coefficient $\left(C_{p i}\right)$ underneath the roof sheathing by $90 \%$ in both the full scale and BLWT studies. This reinforces the need to keep not only doors and windows closed during extreme winds, but also interior openings attic access such as "hatch" needs to be secured during strong storms.

- The contribution of $I P$ underneath the roof deck was observed to be significant wherein which it dampens the net suction pressure unless the underneath openings were exposed to different pressure compared to the main external pressure on the tiles. For example on eave tiles, in which case, underneath pressure was in similar direction with the external pressure producing higher net pressure. Aerodynamically, the high profile roof tiles perform well over the field, but because of their deep valley, the shape causes the formation of considerable suction pressures on the ridge tiles. In general, the surface geometry of an individual tile was observed to have a significant 
impact on both the external pressure on the roof surface as well as the internal pressure underneath the tiles.

- The geometry of the roof significantly affected internal pressure. For example, the peak attic internal pressure for the gable roof building was higher (by more than $190 \%$ ) than the hip roof for the study cases carried out and the worst net pressure coefficient near the eave of the gable roof was found to be higher than the hip roof by more than $45 \%$.

- The comparison between the full-scale and BLWT IP responses showed good agreement in both peak and mean values. The $C F D$ model also produced mean internal pressure that was in good agreement with experimental. The ASCE 7-10 standard underestimated the peak positive internal pressure in all configurations with dominant openings and building types considered in the study.

The major findings/contributions of this work in the characterization of $I P$ for wind resistant design of low-rise buildings are summarized below for the case of a building envelope with sudden breach:

- Correct internal volume scaling was found to be necessary, as the building with incorrect volume scaling experienced a response four times faster and 30-40\% lower with respect to peak and mean $C_{p i}$ for the specific building type and porosity size of dominant openings examined.

- The transient overshooting response was lower than the subsequent steady state peak $C_{p i}$ for all wind directions and opening porosity sizes examined. 
- Comparatively, openings located near the corner of a windward wall exhibited considerable response in transient and steady state internal pressure during sudden opening breaches. For the $75^{\circ}$ wind AoA, the window opening located closest to the upstream wall corner produced peak steady state internal pressure, $45 \%$ greater than the door located at the center of the wall.

The major findings/contributions of this work in the characterization of internal pressure for wind-driven natural ventilation in a low-rise building are as follows:

- For one-sided and short distance opposite wall opening ventilation studies on residential low-rise buildings the volume correction could be relaxed while it is important to consider volume correction for adjacent side openings.

- Wind-induced cross ventilation was fairly sensitive to the porosity size of the dominant openings. It was found that the higher the ratio of area of the inlet to outlet opening or windward porosity, the higher would be the internal pressure. It was also obtained that the internal pressure due to cross ventilation was 1.5-2.5 times higher when the ratio $A_{\text {inlet }} / A_{\text {outlet }}>1$.

- The lower the porosity ratio or inlet to outlet ratio, the higher would be the pressure drop inside the building. Moreover, the cross-ventilation with opposite side openings generated higher pressure drop as compared to that of adjacent side opening of equivalent porosity ratio.

- The mean external pressure coefficients at the periphery of the dominant openings and the ensuing mean internal pressure of the building with adjacent side openings was $50-75 \%$ lower than that with opposite side openings. This could be mainly due to 
the short air flow path developed for the building with the dominant openings on adjacent walls. This reduces the mixing of air inside the building and hence the ventilation effectiveness.

- For a single dominant opening, the internal pressure distribution was uniform and equal for both buildings with and without multi-room partitioning. However, for cross-ventilation of the building with multi-room partitioning having opposite side openings, the internal pressure ceased its uniformity and the mean value at the inlet was 2-3 times higher compared with the outlet.

- The inlet pressure coefficient for the multi-room partitioning was twice that of the noroom partitioning (i.e., single room). This clearly showed that the high gradient (pressure drop) and hence the cross ventilation inside the building was considerably influenced by the multi-room partitioning, which eventually played a role in increasing the flow rate and air exchange. Thus, the realistic assessment of windinduced cross-ventilation should include the proper room partitioning specific to the building under study.

- The total discharge coefficient $C_{d_{-} \text {total }}$ and the ventilation rate $Q /\left(V_{r} A\right)$ could not be taken as a constant values for all types of openings but was rather highly dependent on the porosity ratio. The higher the porosity ratio, the higher the $C_{d_{-} \text {total }}$ and $Q /\left(V_{r} A\right)$. The discharge coefficient obtained for the building with $10 \%$ porosity ratio was, for instance, $40-45 \%$ higher than that of the building with $6 \%$ porosity having the same inlet to outlet opening ratio. 
- For the various adjacent and opposite side dominant openings examined, the total discharge coefficient obtained ranged between $0.5-0.74$ while the inlet/outlet discharge coefficients ranged between 0.65-1.08.

- The use of mesh screens on dominant openings had a considerable effect on crossventilation particularly when openings were aligned directly with the oncoming wind. The mean $C_{p i}$ for the no screen case was 2-4 times higher than with a screen. The use of mesh screens reduces the wind speed at the inlet and outlet and thus the effectiveness of the wind-induced cross-ventilation. Further study is needed to investigate the different types of mesh screens and their effect on wind speed reduction.

The major future studies that are suggested to be carried out as a continuation of the present work include:

- Modern building codes have shown tremendous progress geared towards addressing the major wind related problems in the design of buildings. Newly constructed buildings, as a result, became, relatively resilient to hurricane impacts to a certain degree. However, most buildings constructed before the adoption of the enhanced codes could adopt retrofitting and mitigation processes that encompass a comprehensive assessment including $I P$ studies due to sudden breaching. Retrofitting techniques such as secondary water barrier, hurricane straps and clips should be tested to withstand $I P$ loads.

- Numerical simulation of transient overshooting with variable porosity of dominant openings both in full scale and model scale need to be performed to effectively 
explore the phenomenon of transient response of internal pressure for smaller time response than considered in the present study i.e. for less than one tenth of a second.

- A parametric evaluation of ventilation openings (such as single vent versus multiple vents) needs to be carried out to investigate its implication on the internal pressure underneath roof sheathing.

- Cooling of a building by natural ventilation provides efficiency in energy consumption but it requires access openings to the outside environment. On the other hand, protection of the building from wind driven rain require the blockage of these openings. A solution should be sought after in order optimize the provision of energy efficiency and protection from wind driven rain impact. This can possibly be achieved by introducing mechanical system that can control the flow of air and water as needed through ventilation openings.

- Improving building codes and standards based on detailed internal pressure studies. The realistic assessment of internal pressure for different types of low rise buildings (such as complex roof shapes that are seen in most residential buildings), at different terrain conditions and variable dominant opening porosities should be performed. 
9. INDEX I 


\title{
TESTING OF RESIDENTIAL HOMES UNDER WIND LOADS
}

\author{
Emil Simiu ${ }^{1}$, Girma Bitsuamlak ${ }^{2}$, Arindam Gan Chowdhury ${ }^{3}$, Ruilong $\mathrm{Li}^{4}$, Amanuel \\ Tecle, ${ }^{4}$ DongHun $\mathrm{Yeo}^{5}$
}

Published at ASCE Natural Hazard review, (2010)

\begin{abstract}
Aerodynamic testing of low-rise structures is fraught with difficulties that can be the cause of large measurement errors resulting in the underestimation of aerodynamic pressures by a factor of as much as two. The errors are due in large part to the inadequate knowledge and simulation of wind flows affecting low-rise buildings, especially residential homes in suburban environments. A type of aerodynamic testing of sufficiently small low-rise structures is explored that does not entail the simulation of the turbulence intensity and integral turbulence scales. That type of testing would offer several advantages: eliminating a major cause of discrepancies among measurements conducted in different laboratories, allowing the use of larger model scales, and allowing testing in both typical commercial wind tunnels and in open jet facilities of the Wall of Wind (WoW) type. Preliminary tests based on data obtained at the University of Western Ontario (UWO) wind tunnel and the Florida International University (FIU) large-scale six-fan Wall of Wind facility suggest that the proposed type of testing yields systematically conservative results for the specialized type of measurements considered herein. In most but not all cases the degree of conservatism is modest. The results appear to be of sufficient interest to warrant additional research.
\end{abstract}


CE Database subject headings: Aerodynamics; low-rise structures; residential buildings; Wall of Wind; wind engineering; wind tunnels.

\section{INTRODUCTION}

An international round-robin set of wind tunnel tests of a low-rise structure conducted at six reputable laboratories produced the result that wind-induced internal forces in structural frames, and pressures at individual taps, can differ from laboratory to laboratory by factors larger than two (Fritz et al., 2008). Owing in part to such differences aerodynamic pressures on low-rise structures specified in the ASCE 7 Standard can be smaller by as much as $50 \%$ than pressures measured in the wind tunnel (Surry, 2003; St. Pierre et al, 2005; Ho et al., 2005; Coffman et al., 2009).

Among the reasons for the non-repeatability of wind tunnel tests across laboratories (i.e., for the dependence of wind tunnel test results on the laboratory in which they are conducted) are two facts. First, the low-frequency fluctuations of the oncoming flow turbulence in the atmospheric surface layer are difficult to simulate, and second, the techniques for their production in the wind tunnel are not standardized. Since those fluctuations contain the bulk of the turbulent energy, they contribute overwhelmingly to the turbulence intensity and the integral turbulence scale. This paper is concerned with the question of whether improvements in repeatability of wind-induced pressures on small structures can be achieved by subjecting models to flows that do not attempt to reproduce atmospheric turbulence intensity and integral turbulence scales. 
The paper is organized as follows. Within the framework of a general discussion on the aerodynamic testing of civil engineering structures we show why it is reasonable to hypothesize that results obtained in flows that do not contain low-frequency fluctuations are typically conservative and may be acceptable when testing sufficiently small buildings. We then show that this hypothesis appears to be supported by preliminary wind tunnel and Wall of Wind (WoW) test results. We conclude with suggestions on future research.

\section{BOUNDARY LAYER FLOWS AND THEIR LABORATORY SIMULATION}

In the 1970s it was believed that faithful laboratory simulations of atmospheric boundary layer flows could be achieved by allowing a boundary layer to grow naturally by friction at the wind tunnel floor over a sufficiently long development distance $(30 \mathrm{~m}$, say). Depths of the boundary layers so achieved turned out, however, to be insufficient for the testing of tall buildings. Even if longer development lengths were allowed for, the simulations could not reproduce atmospheric boundary layer flows faithfully for two reasons. First, high-frequency turbulent fluctuations, corresponding to the prototype inertial subrange, are not correctly reproduced in the wind tunnel owing to energy dissipation by internal friction within small eddies at small model scales. This limitation can be significant insofar as high-frequency turbulent fluctuations promote transport of free-stream particles with high momentum across separation bubbles, a phenomenon that affects flow reattachment and, therefore, the magnitude of negative pressures in separation zones. Second, the mechanisms of boundary layer formation are different in the wind tunnel and in the atmosphere. For example, in large-scale extratropical storms 
the depth of the atmospheric boundary layer, rather than being independent of flow velocity, as is implicit in the power law description of the wind profile, is inversely proportional to the Coriolis acceleration and proportional to the wind speed. It follows from this relation that the range of validity of the logarithmic law, rather than being about $50 \mathrm{~m}$, regardless of flow velocity (Davenport, 1965), as was commonly believed before the development of atmospheric boundary layer similarity theory, is also proportional to the wind speed (Csanady, 1967; Simiu and Miyata, 2006), and can be as high as $400 \mathrm{~m}$ for strong winds (Powell, Vickery, and Reinhold, 2003).

For these reasons long development distances have no longer been considered necessary for the simulation of atmospheric flows. To make up for insufficient boundary layer depth it has been proposed that spires be placed upwind of the test section. The spires, in conjunction with roughness elements placed on the wind tunnel floor, create turbulent shear flows deemed to be adequate if the development lengths over which elements may be placed are about $15 \mathrm{~m}$, say. This technique is now being widely used in commercial wind tunnel testing.

For the testing of tall building models, the justification for the requirement that the atmospheric turbulence intensity and the integral turbulence scale be simulated in the wind tunnel is that the spatial coherence of the turbulent fluctuations in the incoming flow is imperfect. This means that if the peak velocity of the oncoming flow at a point $A$ in space occurs at a time $t_{\mathrm{A}}$, at any other point $B$ of a vertical plane normal to the mean speed the peak velocity will occur at a time $t_{\mathrm{B}} \neq t_{\mathrm{A}}$. The along-wind force on a large structure will therefore be smaller than if the flow were perfectly coherent spatially (i.e., 
if it were true that $t_{\mathrm{A}}=t_{\mathrm{B}}$ ). The justification for that requirement is far less compelling if the building being tested is small in relation to the integral turbulence scale. Indeed, the coherence of the oncoming flows over lengths comparable to the building dimensions is in this case relatively large. It may therefore be hypothesized that peak aerodynamic effects experienced by a small building subjected to a flow whose velocities have significant low-frequency fluctuations are not substantially different from those induced by flows with mean velocity equal to the peak value of those velocities and no or small low-frequency content. Note, however, that for this hypothesis to be warranted the mean flow must in both cases simulate reasonably well the atmosphere's mean shear flow. This can be achieved by a variety of techniques that can be independent of wind tunnel configuration and are therefore capable of being standardized, a task that has not been achieved so far in the U.S. and Canada for wind tunnels using spires and roughness elements. One such technique, used in FIU's six-fan WoW, is described by Huang et al. (2009), and is adaptable for wind tunnel use.

A second argument may be invoked in favor of resorting to flows with little or no low-frequency content. The ASCE 7 Standard (ASCE, 2005) requires that the ratio between integral length scales and building dimensions be the same in the wind tunnel and in the prototype. The fact that integral length scales typically achievable in wind tunnels are relatively small imposes for typical commercial wind tunnels geometric model scales of the order of 1:100. At such scales model dimensions for a residential home are of the order of $0.1 \mathrm{~m}$, i.e., not much larger than those of a match box. This renders measurements difficult and prone to significant errors. Freeing the geometric 
scale from constraints associated with the integral turbulence scale offers the significant advantage of allowing the use of considerably larger geometric scales than are now possible, without violating standard blockage requirements.

\section{WIND TUNNEL TEST RESULTS}

We consider the pressures induced on the windward face of a relatively small building by a flow with mean speed described by a power law and normal to that face. We consider two cases: (1) The low-frequency turbulence is approximately similar to its counterpart in the atmosphere, and (2) the low-frequency content of the flow is negligible, while the mean speed at the eave is equal to the peak wind speed at the eave for case (1). We test the hypothesis that the peak pressures on the windward face do not differ significantly in the two cases, provided that the horizontal distance between the outermost taps being considered is not too large.

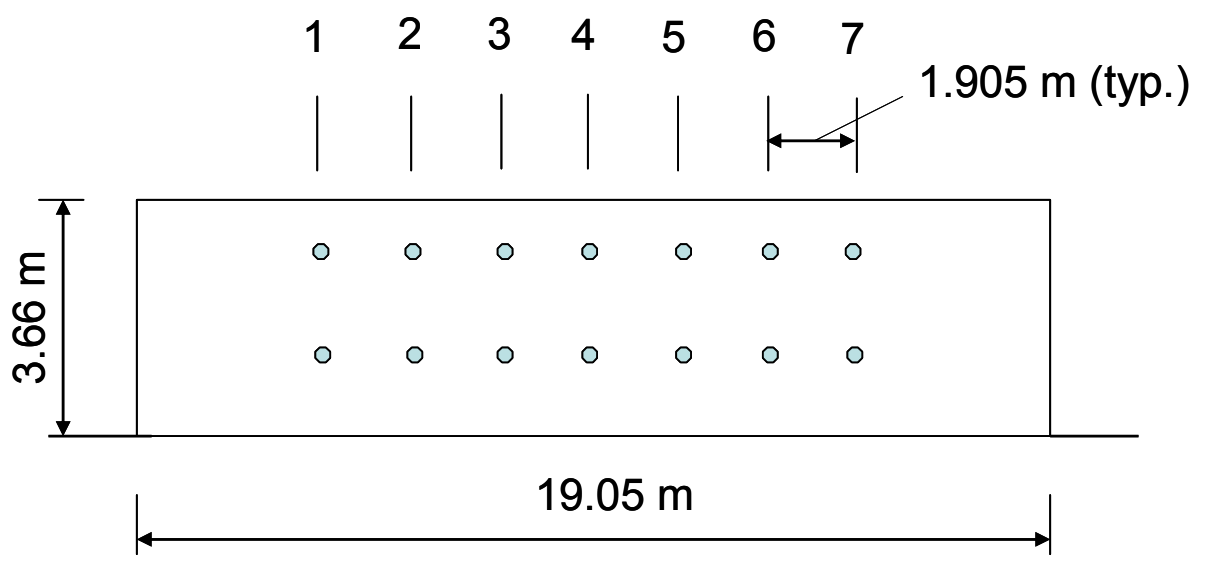

Figure 1. An Elevation of the 19.05 M X 3.66 M Building Face and the Taps of Interest We chose for this purpose a 1:100 model of a building with a 1:12 slope gable roof and with dimensions $3.66 \mathrm{~m}$ eave height and $12.20 \mathrm{~m} \mathrm{x} 19.05 \mathrm{~m}$ in plan, for which 
measurements performed in the wind tunnel of the University of Western Ontario were incorporated in the NIST aerodynamic database (www.nist.gov/wind, II, Aerodynamic Database for Rigid Buildings, NIST Aerodynamic Database, Database from Contributing Laboratories). Pressure taps on the $3.66 \mathrm{~m}$ x $19.05 \mathrm{~m}$ wall were located on two rows: one row at $0.6 \mathrm{~m}$ below the eave, and one row at $1.52 \mathrm{~m}$ above ground level. Figure 1 shows an elevation of the $19.05 \mathrm{~m} \times 3.66 \mathrm{~m}$ building face and the taps of interest in this study. We considered the following sets of taps: (1) the pair of taps located on line 4 of Fig. 1 (i.e., at the center line of the face of the building); (2) the two pairs of taps located on lines 4 and 5 ; (3) the three pairs of taps located on lines 3, 4, and 5; (4) the four pairs of taps located on lines $3,4,5$, and 6 , and (5) the five pairs of taps located on lines $2,3,4,5$, and 6. The horizontal distances tributary to the sets of taps (1), (2), (3), (4), and (5) are $1.905 \mathrm{~m}, 3.81 \mathrm{~m}, 5.715 \mathrm{~m}, 7.62 \mathrm{~m}$, and $9.525 \mathrm{~m}$, respectively.

For the case of mean flow normal to the windward wall represented in Fig. 1 the total load associated with set (1) is equal to the sum of the loads associated with the upper tap and the lower tap. The total load associated with set (2) can be calculated in the following alternative ways. First, by adding to the load associated with set (1) the load, obtained in a similar manner, associated with the taps located on line 5. This type of calculation accounts for the imperfect coherence between the pressures acting at on lines 4 and 5 . Second, by multiplying by two the load associated with the taps located on line 4 . The latter type of calculation assumes perfect coherence between pressures on line 4 and their counterparts on line 5. Because the pressures are in fact not perfectly coherent the second calculation would be conservative. Similar considerations apply to the sets (3), (4), and 
(5), in which the second type of calculation would entail the factors three, four, and five, instead of the factor two, as for the load associated with set (2). It is clear that the approximation inherent in the assumption that the pressures are perfectly coherent is closer as the horizontal distance between the outermost taps is smaller. Table 1 shows the ratios between the total loads obtained by calculations of the second type and of the first type. The ratios are a direct measure of the degree to which the assumption of perfect coherence overestimates the total load.

Note that the imperfect spatial coherence of the pressures depends on the quality of the wind tunnel simulation of the flow, and may be different from the spatial coherence in actual atmospheric flows. Indeed, it is not uncommon that in the wind tunnel the integral turbulence scale is smaller than its scaled prototype counterpart. If this was the case the prototype counterparts of the ratios $L_{1} / L_{2}$ would be closer to unity than those of Table 1 . Note that the ratios of Table 1 only provide information on loads induced on the windward building face, far enough from the corners, by wind with mean speed normal to that face. From Table 1 it may be concluded that for buildings or portions thereof with dimensions on the order of $10 \mathrm{~m}$ the errors inherent in the use of flows with little or no low-frequency turbulence content are relatively modest. 
Table 1. Ratio $L_{1} / L_{2}$ of the total load $L_{2}$ for sets (1), (2), (3), (4), and (5) calculated by assuming perfect spatial coherence, to the corresponding total load $L_{1}$ calculated by accounting for imperfect spatial coherence

\begin{tabular}{|c|c|c|c|c|c|}
\hline Set of pressure taps & $(1)$ & $(2)$ & $(3)$ & (4) & (5) \\
\hline Tributary horizontal distance & 1.91 & 3.81 & 5.72 & 7.62 & 9.53 \\
\hline$L_{1} / L_{2}$ & 1.0 & 1.03 & 1.05 & 1.12 & 1.21 \\
\hline
\end{tabular}

\section{WALL OF WIND TEST RESULTS}

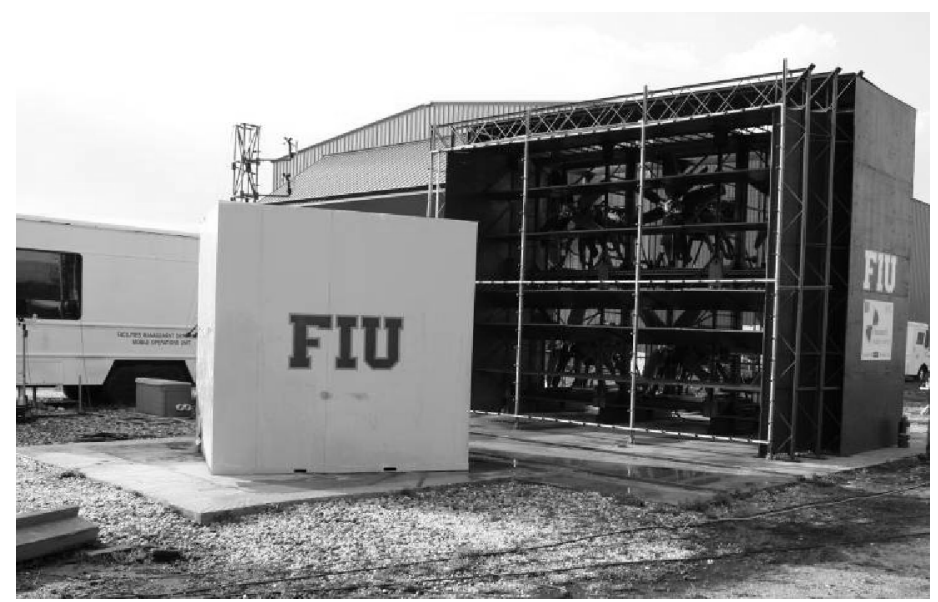

Figure 2. 6-fan Wall of Wind and $2.9 \mathrm{~m}$ Testing Cube

A new full- and large-scale testing apparatus generically named the Wall of Wind (WoW) has been built at the International Hurricane Research Center (IHRC), Florida International University (FIU). The 6-fan WoW (Fig. 2) is capable of testing large-scale building models and full-scale portions of buildings. To develop flow management devices efficiently for replicating tropical cyclone (TC) wind characteristics (based on 
Florida Coastal Monitoring Program (FCMP) data analysis by Yu et al. (2009)) in the WoW facility, a small-scale $(1: 8)$ WoW model was built, and a series of tests were carried out. Application of passive devices such as an outer frame, contraction, and inclined horizontal planks, as well as active control in the form of quasi-periodic sums of sinusoidal signals designed on the basis of TC wind data analyses, simulated the mean and turbulence characteristics of the flow, including Atmospheric Boundary Layer-like profiles, turbulence intensities, power spectral densities and gust factors (Huang et al., 2009). Two fluctuating waveforms were created and used in the small-scale WoW. The waveforms W1 and W2 were created by only using one sinusoidal signal and by combining three sinusoidal signals, respectively (Huang et al., 2009).

The knowledge gained from the small-scale WoW was successfully used to enhance the full-scale WoW wind field parameters. Five plates $\left(-0.5^{\circ}, 17^{\circ}, 17^{\circ}, 0^{\circ}\right.$ and $0^{\circ}$ inclination $)$ were placed inside the contraction of the revised full-scale WoW configuration to generate reasonable mean wind speed profiles (ABL-like profiles). Just as in the smallscale WoW, the results in full-scale WoW showed that the application of fluctuating waveforms could greatly influence the turbulence characteristics. 
Table 2. Comparison of 6-fan WoW Flow Characteristics for Flat and Quasi-periodic Waveforms

\begin{tabular}{|c|c|c|c|c|}
\hline $\begin{array}{c}\text { Case } \\
\text { (Waveform; mean } \\
\text { rpm) }\end{array}$ & $\begin{array}{l}\text { Wind speed } \\
\qquad(\mathrm{m} / \mathrm{s})\end{array}$ & $\begin{array}{l}\mathrm{TI}_{\mathrm{u}} \\
(\%)\end{array}$ & $\mathrm{GF}(\mathrm{T}, \mathrm{t})$ & $\begin{array}{l}\mathrm{L}_{\mathrm{u}}^{\mathrm{x}} \\
(\mathrm{m})\end{array}$ \\
\hline $\begin{array}{c}\text { Revised WoW } \\
\text { (Flat waveform; } \\
\quad 4,000 \text { ) }\end{array}$ & $\begin{array}{c}37 \\
\text { (1-min mean } \\
\text { speed) } \\
38 \\
\text { (3-sec peak gust) }\end{array}$ & 5 & $\begin{array}{l}G F(6 \mathrm{~min}, 3 \mathrm{sec})=1.06 \\
G F(1 \mathrm{~min}, 3 \mathrm{sec})=1.04\end{array}$ & 37 \\
\hline $\begin{array}{l}\text { Revised WoW } \\
\text { (W4 quasi-periodic } \\
\text { waveform; 2,855) }\end{array}$ & $\begin{array}{c}29 \\
(1-\text { min mean } \\
\text { speed) } \\
38 \\
\text { (3-sec peak gust) }\end{array}$ & 24 & $\begin{array}{l}G F(6 \mathrm{~min}, 3 \mathrm{sec})=1.42 \\
G F(1 \mathrm{~min}, 3 \mathrm{sec})=1.33\end{array}$ & 90 \\
\hline
\end{tabular}

Two new waveforms W3 (sinusoidal signal) and W4 (quasi-periodic signal) for full-scale WoW were created using scaling parameters. Application of quasi-periodic sums of sinusoidal signals, designed on the basis of TC wind characteristics, succeeded in adding low-frequency quasi-periodic components to the WoW flow and influencing the longitudinal power spectral densities, turbulence intensities, integral length scales, and gust factors. The results for flat waveform (with no low frequency content) and W4 (with low frequency content) are shown in Table 2. 


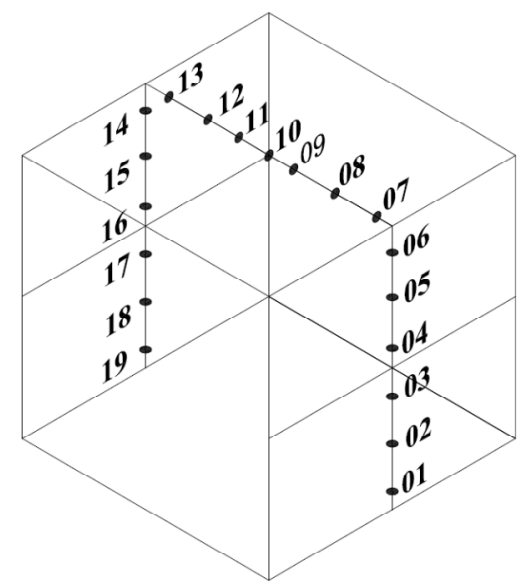

Figure 3. 2.9 m Cube Tap Layout

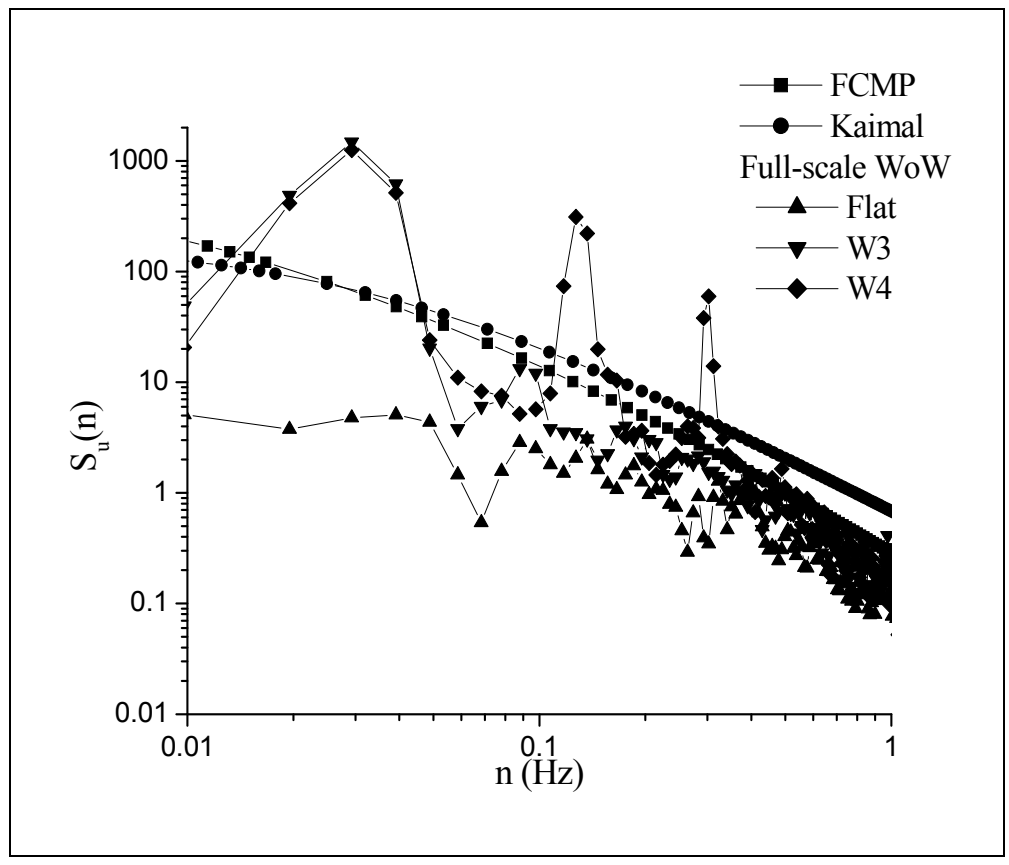

Figure 4. Longitudinal Power Spectral Density Plots for WoW Flow 


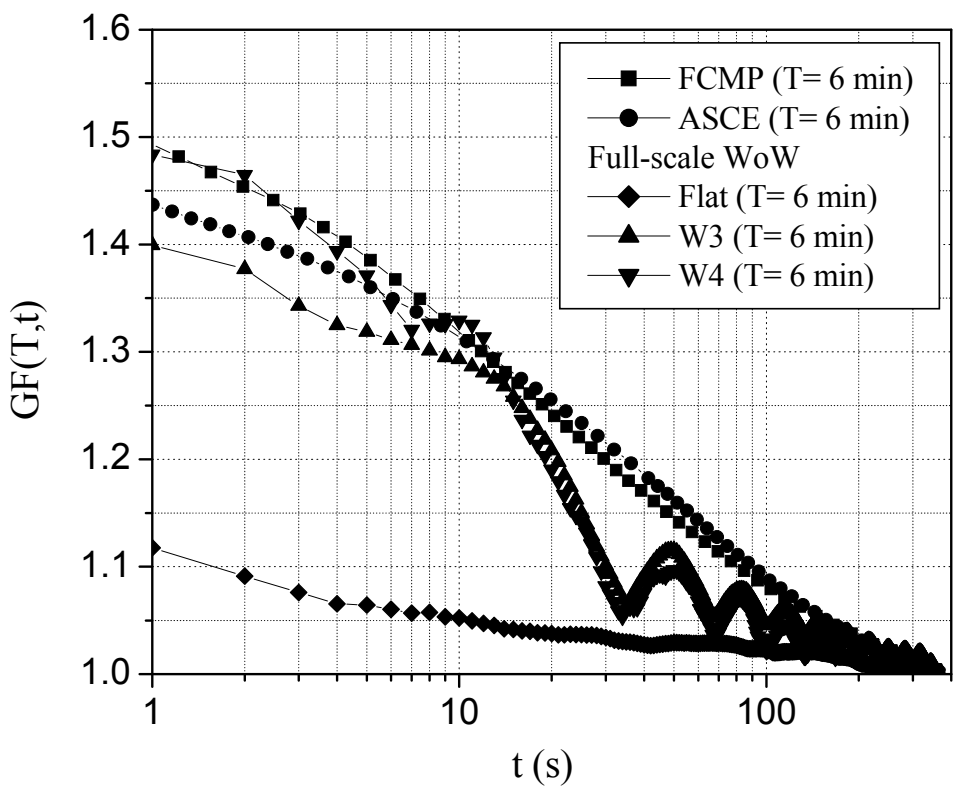

Figure 5. Gust Factors for WoW Flow

For the current testing the revised full-scale 6-fan WoW was used for the testing reported in this paper. Time histories of pressures on a cube with dimensions 2.9 x $2.9 \times$ $2.9 \mathrm{~m}$ were measured in the 6-fan WoW facility in flows simulating winds over terrain with suburban exposure. Pressure taps were placed at the intersection between the cube's exterior surface and a vertical plane passing through the center of the roof and normal to a face, as shown in Fig. 3. To reduce the cost of running the tests the test duration was 3 min. Two types of flow were used in each test. The first type of flow (flow 1, referred to as "flow with no low frequency content") was generated using the flat waveform. For the second type of flow (flow 2, referred to as "flow with low frequency content"), the lowfrequency velocity fluctuations were obtained by imparting to the fans quasiperiodic rotational speeds (generated by W4 waveform) consistent with the low-frequency content 
of the spectral density of the atmospheric longitudinal velocity fluctuations at eave height (Fig. 4). The gust factors comparison is shown in Fig. 5. With the application of W4 waveform, the estimated turbulence intensity value at $3.0 \mathrm{~m}$ height (the average roof eave height for typical low-rise residential buildings) was approximately $24 \%$ as compared to $5 \%$ for the flat waveform which was much smaller than for atmospheric flows. The 3-s peak wind speed for the flow with low-frequency content (generated by quasiperiodic W4 waveform) was $38 \mathrm{~m} / \mathrm{s}$ which was comparable to the 3 -s peak and mean wind speed of 38 $\mathrm{m} / \mathrm{s}$ and $37 \mathrm{~m} / \mathrm{s}$, respectively, for the flow with no low frequency content (generated by the flat waveform).

Thus, the nominal peak velocities in both flows were approximately the same. The mean speed profile was approximately the same for both flows. Conceptually, both types of flow may be viewed as having the same mean wind speed. However, while for the flow with low-frequency content a velocity fluctuation is added onto the mean wind speed via quasiperiodic rotations of the fans, in the flow with no low-frequency content that velocity fluctuation is replaced by a uniform increment of the mean wind speed equal to the peak of the low-frequency velocity fluctuation. Alternatively, the increment of the mean speed in the flow with no low-frequency fluctuations may be viewed as a fluctuation with zero frequency, meaning that this flow is one in which the entire significant frequency content of the flow has been concentrated at zero frequency.

Pressures were measured for the case of the mean flow speed normal to the face containing taps 1 through 6 and at a $45^{\circ}$ angle to that face. The distance between the 
outermost plane of the WoW and the windward face of the cube was $2.74 \mathrm{~m}$. The time history of the pressures over the 3-min duration was recorded at each tap.

Table 3. Ratios $\mathrm{R}=\mathrm{a} / \mathrm{b}$, where $\mathrm{a}$ and $\mathrm{b}$ are 95 percentile peak pressures in flows with no low frequency content and with low-frequency content, respectively. Mean speed at $90^{\circ}$ and at $45^{\circ}$ to windward face. Nominal flow duration: $60 \mathrm{~min}$.

\begin{tabular}{|c|c|c|c|c|c|c|c|c|c|c|}
\hline Tap & 1 & 2 & 3 & 4 & 5 & 6 & 7 & 8 & 9 & 10 \\
\hline $\begin{array}{l}R \\
\left(90^{\circ}\right)\end{array}$ & 1.07 & 1.38 & 1.21 & 1.06 & 0.9 & 1.03 & 1.26 & 1.08 & 1.51 & 1.39 \\
\hline $\begin{array}{l}R \\
\left(45^{\circ}\right)\end{array}$ & 1.18 & 1.25 & 1.25 & 1.12 & 1.15 & 1.41 & 1.06 & 1.33 & 0.99 & 0.80 \\
\hline Tap & 11 & 12 & 13 & 14 & 15 & 16 & 17 & 18 & 19 & \\
\hline $\begin{array}{l}R \\
\left(90^{\circ}\right)\end{array}$ & 1.46 & 1.77 & 1.42 & 1.40 & 1.01 & 0.97 & 1.13 & 1.36 & 1.41 & \\
\hline $\begin{array}{l}R \\
\left(45^{\circ}\right)\end{array}$ & 0.86 & 1.14 & 1.33 & 1.04 & 0.98 & 1.09 & 1.08 & 1.13 & 1.21 & \\
\hline
\end{tabular}

To achieve meaningful comparisons the $95^{\text {th }}$ percentile values of the peak pressures for a 60-min record were estimated from the 3-min time histories by using the method developed by Sadek and Simiu (2003). Software for the implementation of this method is available on www.nist.gov/wind, III.B.

Table 3 lists the ratios $R$ between the maximum of the absolute values of the peak 60min pressures obtained for the two flows $(R=$ result for flow $1 /$ result for flow 2$)$. As expected, the results corresponding to the 60-min nominal flow with no low frequency content (flow 1) tend to be conservative. However, the conservative bias is not insignificant in some instances. Note that for tap 12 the ratio is very large $(R=1.77)$; in this case, for flow with low-frequency content the peak pressures at tap 12 are small 
(about $20 \%$ of the peak windward pressure at tap 4), so the difference between the peak pressure in the two types of flow, while significant, is unlikely to influence the design. A judgment is required on whether the bias is acceptable in relation to errors, in many instances on the unconservative side, between results obtained in different wind tunnels or even in the same wind tunnel (Fritz et al., 2008; Surry et al., 2003), and between windtunnel based pressure estimates and pressures specified in the ASCE 7 Standard (St. Pierre et al., 2005; Ho et al., 2005; Coffman et al., 2009). Note that comparisons between conical vortices on a flat roof reported by Kawai (1997) showed that results for the smooth flow case were conservative in relation to those obtained in turbulent flows. The results of Table 3 suggest that testing in flow with no low-frequency fluctuations has the potential of yielding pressures that could be used for design purposes in lieu of pressures obtained in flow simulating atmospheric low-frequency velocity fluctuations. However, before a definitive assertion can be made to this effect, it will be necessary to subject the results reported herein to careful scrutiny via additional testing to be performed in the future.

\section{CONCLUSIONS}

The question arises whether it is desirable to use for the testing of residential homes and other low-rise buildings or portions thereof flows that attempt to simulate lowfrequency fluctuations. The drawbacks of tests in such flows are the following. First, they induce errors in the estimation of the pressures. These errors tend to be significantly larger than the overall conservative bias inherent in the use of flows with no lowfrequency fluctuations. Second, flows that attempt to simulate low-frequency fluctuations 
affect adversely the repeatability of the tests. To achieve repeatability across laboratories a standard flow simulation protocol for low-rise buildings would have to be used. Largely because it would require uniformity not only in the roughness of the wind tunnel floor and the configuration of the spires, but also in the type and size of the wind tunnel facility, no such protocol has been established so far in the U.S. or Canada. On the other hand, standardization may be achievable for passive devices controlling the creation of mean wind speed profiles (e.g., devices such as those described in Huang et al., 2009). Third, the simulation of low-frequency turbulent fluctuations imposes severe constraints on the geometric model scale, which unavoidably entail additional errors in the estimation of aerodynamic effects. These constraints are eliminated for flows with no low-frequency fluctuations. Fourth, most residential homes are located in suburban environments, and the flows affecting a particular building are not text-book atmospheric boundary layer flows, but rather flows powerfully affected by the presence of other buildings and/or, e.g., trees and parked cars. Research on wind effects on low-rise buildings within such environments remains to be performed, and should be accounted for when making decisions on aerodynamic simulations of wind effects on low-rise structures. The nature of flows in such complex environments can be studied far more effectively at the larger scales allowed by simulations with no low-frequency flow fluctuations.

A debate on the issue of testing buildings with small dimensions for wind loads is warranted. This work is intended to be an exploratory contribution to such a debate. The tests results reported in this paper suggest that the proposed type of testing wherein the 
flow has weak or no low-frequency content is conservative; the differences with pressures obtained in testing with conventional flows appear to be, typically, modest but can in some instances be high, particularly for relatively small absolute values of the pressures. Such differences may be acceptable, but to reach definitive conclusions more thorough testing than was conducted in this exploratory project will be necessary. Additional research will concentrate on the appropriate ratios between mean speeds in the flows with and without low frequency content. In the authors' opinion further research into the issue raised by this paper is warranted because current large differences between aerodynamic coefficients specified in standards on the one hand and those measured in the laboratory on the other can affect significantly the safety of residential homes as well as the estimation of wind-induced losses in strong winds.

\section{NOTATION}

The following symbols are used in this paper:

$t_{\mathrm{A}}$ or $t_{\mathrm{B}} \quad=\quad$ time at point $\mathrm{A}$ or $\mathrm{B}$

$L_{1}$ or $L_{2}=$ total load;

$R \quad=\quad$ ratios between the maximum of the absolute values of the peak 60min pressures obtained for the two flows (without or with low frequency content) 


\section{REFERENCES}

American Society of Civil Engineers (2006), ASCE Standard 7-05, Reston, VA

Csanady, G.T. (1967). "On the Resistance Law of a Turbulent Ekman Layer," $J$. Atmospheric Science, 24 467-471.

Coffman, B.F., Main, J.A., Duthinh, D., and Simiu, E (2009). "Wind effects on low-rise buildings: Database-assisted design vs. ASCE 7-05 Standard estimates." J. Struct. Eng. (in press) www.nist.gov/wind.2009

Davenport, A.G. (1965). "The Relationship of Wind Structure to Wind Loading," Proc., Symp. Wind Effects BuildingsStruct., Vol. 1, Natl. Physical Lab., Teddington, U.K., H.M. Stationery Off., London.

Fritz, W.P., Bienkiewicz, B., Cui, B., Flamand, O., Ho, T. C. E., Kikitsu, H., Letchford, C.W., and Simiu, E. (2008). "International Comparison of Wind Tunnel Estimates of Wind Effects on Low-Rise Buildings: Test-Related Uncertainties," J. Struct. Eng., 134 1887-1890,.

Ho, T.C.E., Surry, D., Morrish, D., and Kopp, G.A. (2005). "The UWO contribution to the NIST aerodynamic database for wind loads on low buildings: Part I. Archiving format and basic aerodynamic data," J. Wind Eng. Ind. Aerodyn. 93 1-30.

Huang, P., Chowdhury Gan, A., Bitsuamlak, G., and Liu, R. (2009). "Development of Devices and Methods for simulation of hurricane winds in a full-scale testing facility," Wind and Structures 12,.

Kawai, H. (1997). "Structure of conical vortices related with suction fluctuation on a flat roof in oblique smooth and turbulent flows," J. Wind Eng. Ind. Aerodyn. 69-71 579-588.

Powell, M.D., Vickery, P.J., and Reinhold, T.A. (2003). "Reduced drag coefficient for high wind speeds in tropical cyclones," Nature 422 279-283.

Simiu, E., and Miyata, T. (2006). Design of Buildings and Bridges for Wind, Hoboken: Wiley.

St. Pierre, L.M., Kopp, G.A., Surry, D., and Ho, T.C.E. (2005). "The UWO contribution to the NIST aerodynamic database for wind loads on low buildings: Part II. Comparison of data with wind load provisions," J. Wind Eng. Ind. Aerodyn. 93 31-59.

Surry, D., Ho, T.C.E., and Kopp, G.A. (2003). "Measuring Pressures is Easy, Isn't It?" Proceedings, International Conf. on Wind Engineering, Texas Tech University, Lubbock, TX, 2 2618-2623.

Sadek, F., and Simiu, E. (2002). "Peak non-Gaussian wind effects for database-assisted low-rise building design." J. Eng. Mech., 128(5), 530-539. 
Yu, B., Gan Chowdhury, A. and Masters, F.J. (2008), "Hurricane power spectra, cospectra, and integral length scales.” Bound.-Lay. Meteorol, 129 411-430. 
VITA

AMANUEL SEBHATU TECLE

Jan. 04, 1978

1996-2002

1998-2006

2005-2006

2006-2008

2008-2011
Born, Assela, Ethiopia

B.Sc. Civil Engineering University of Asmara,

Asmara, Eritrea

Project Engineer

Wk and Sons Construction LLC

Asmara, Eritrea

Lecturer

Mereb Corporation

M.Sc. Environmental Engineering and Sustainable Infrastructure, Stockholm, Sweden

Research/Teaching Assistant Florida International University Miami, Florida, US 